\title{
Charakterisierung der bradyzoitspezifisch exprimierten P-Typ Plasmamembran ATPase TgPMA1 in
} Toxoplasma gondii

\author{
Dissertation \\ zur Erlangung des Doktorgrades \\ der Mathematisch-Naturwissenschaftlichen Fakultäten \\ der Georg-August-Universität zu Göttingen
}

vorgelegt von

Mathias Holpert

aus

Alzenau

Göttingen, den 26.05.2003 
D 7

Referent:

Prof. Dr. G. Braus

Korreferent:

Prof. Dr. H.-J. Fritz

Tag der mündlichen Prüfung:

02. Juli 2003 
Dummheit ist ansteckend.

Verstand wächst sich kaum zur Epidemie aus.

T. Pratchett 


\section{Danksagung}

Mein erster Dank geht an Prof. Dr. Uwe Groß für seine Unterstützung während der Erstellung dieser Arbeit und die Ermöglichung dieser Dissertation. Außerdem hätte ich ohne inn wohl nie Göttingen kennengelernt.

Ferner danke ich Herrn Prof. Dr. G. Braus für die Übernahme des Erst- und Herrn Prof. Dr. H.-J. Fritz für die Übernahme des Zweitgutachtens.

Besonderer Dank geht an Herrn Dr. Wolfgang Bohne für die Bereitstellung des interessanten Themas, die gute Betreuung während meiner Arbeit und die konstruktive Kritik an meinen Versuchen, diese Dissertation in Worte zu fassen.

Vielen Dank an Anne Wirsing für die hervorragende technische Assistenz während meiner Zeit in Würzburg. Du hast mir sehr dabei geholfen, meine Zellkultur frei von Kontaminationen zu halten. Vielen Dank auch an Sandra Pusch für die technische Assistenz nach dem Umzug nach Göttingen.

Für die orale Infektion der Mäuse möchte ich Dr. Schmidt-Ott danken, der den Mäusen und mir damit einen großen Dienst erwiesen hat.

Danke auch an alle Kollegen, die während der späteren Zeit meiner Doktorarbeit für ein tolles Arbeitsklima gesorgt haben, insbesondere Özden, Stefan, Christine, Michaela und Tobias.

Ebenfalls vielen Dank an Herbert Mecke für all die lustigen Gespräche auf dem Gang und die stetige große Hilfsbereitschaft bei all meinen Sonderwünschen.

Natürlich geht auch ein herzlicher Dank an meine Eltern, die mit mir das Studium und meine ganze Doktorarbeit durchlebt haben.

Zuletzt ein besonders herzlicher Dank an Simone, die mich während der ganzen Zeit unterstützt hat und wegen mir ihren Job in Würzburg an den Nagel gehängt hat, um auch weiterhin mit mir durch dick und dünn zu gehen. 


\section{$\underline{\text { Inhaltsverzeichnis }}$}

1 EINLEITUNG ........................................................................................... 1

1.1 Entdeckung und Lebenszyklus von Toxoplasma gondii............................................... 1

1.2 Medizinische Bedeutung von Toxoplasma gondii ..............................................................3

1.3 Aufbau von Tachyzoiten und Bradyzoiten ............................................................................... 4

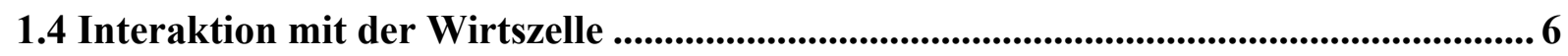

1.5 Genetische Manipulation von T. gondii ...............................................................9

1.6 Stadienkonversion von Tachyzoiten zu Bradyzoiten in vitro .......................................... 11

1.7 Molekulare Unterschiede zwischen Tachyzoiten und Bradyzoiten ............................. 13

1.7.1 Differentielle Expression von Oberflächenproteinen............................................... 14

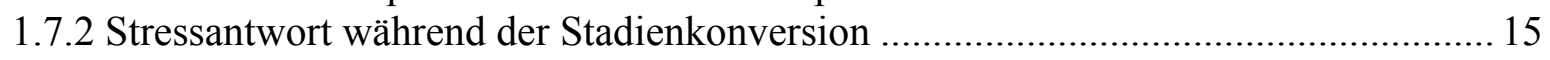

1.7.3 Unterschiedlicher Metabolismus von Tachyzoiten und Bradyzoiten........................ 16

1.8 Strategien zur Identifizierung von stadienspezifisch regulierten Genen .................... 19

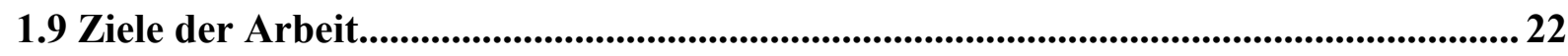

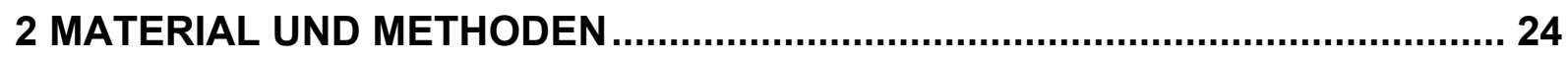

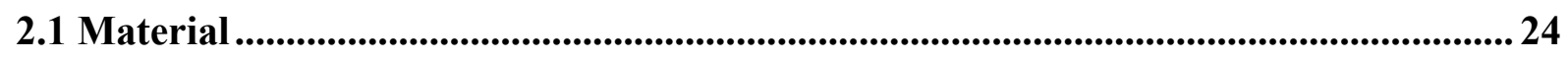

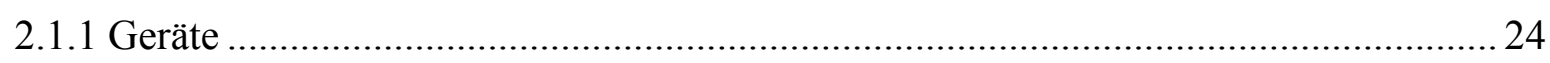

2.1.2 Medien und Verbrauchsmaterialien für die Zellkultur.......................................... 25

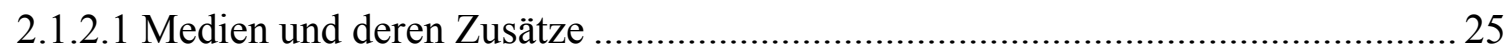

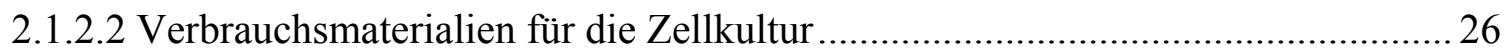

2.1.2.3 Zelllinien (Wirtszellen, T. gondii Stämme, E. coli Linien) ................................. 26

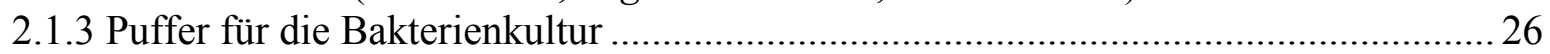

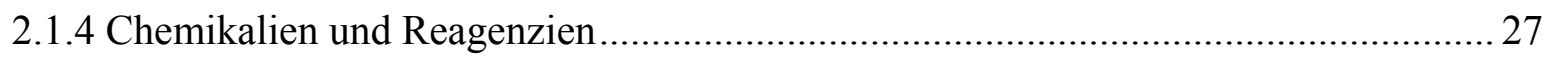

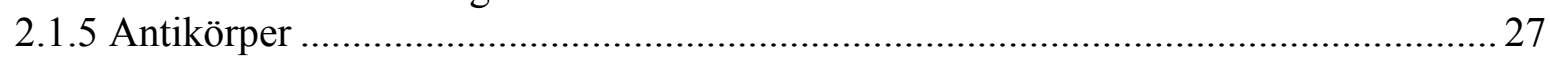

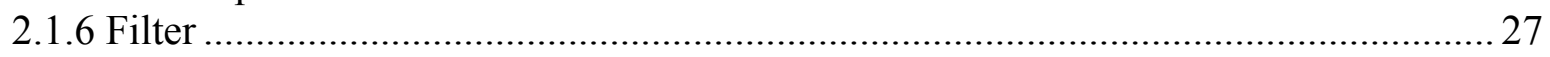

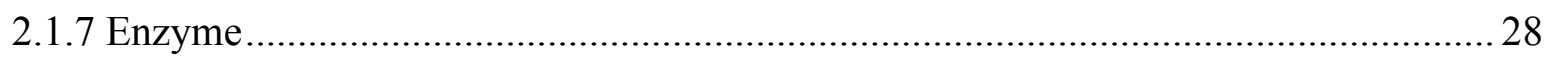

2.1.8 Reaktionssets (“Kits") und Reagenzien zur Isolierung und Bearbeitung von

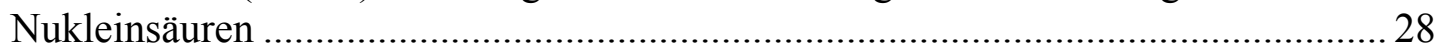

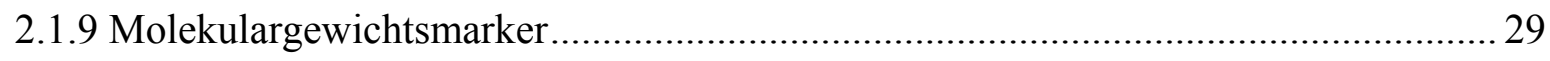

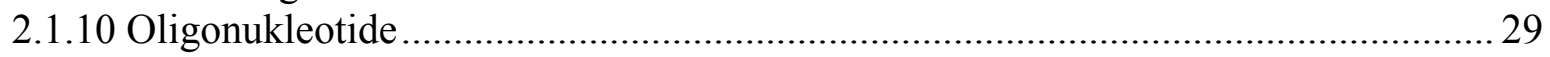

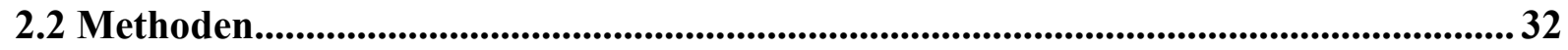

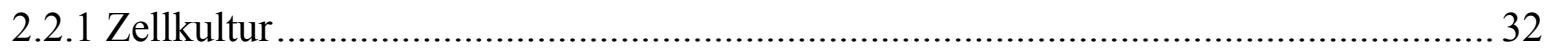

2.2.1.1 Kultur und Passagierung der humanen Vorhaut Fibroblasten (HFFs) ................. 32

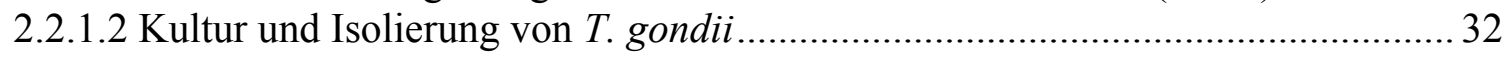

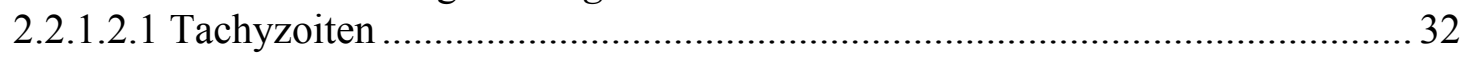

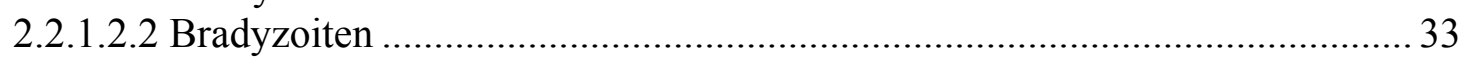




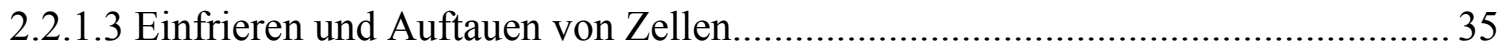

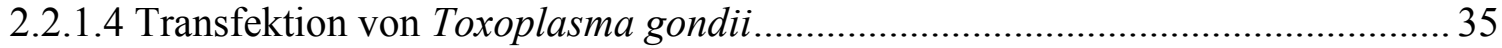

2.2.1.4.1 Optimierung der Transfektionsbedingungen für Prugniaud/ $\mathrm{HX}^{-}$; $\beta$ -

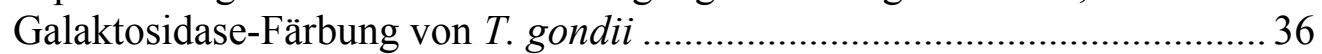

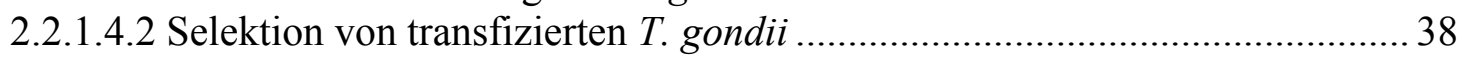

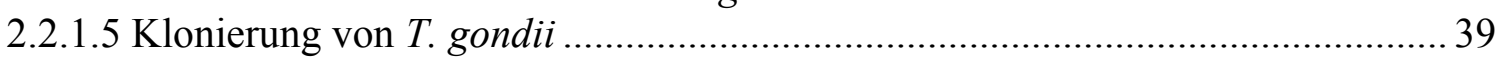

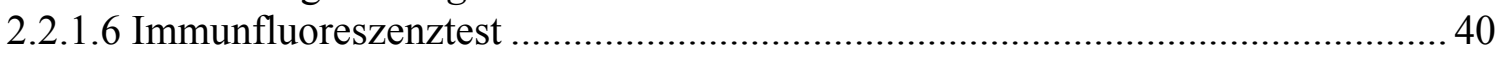

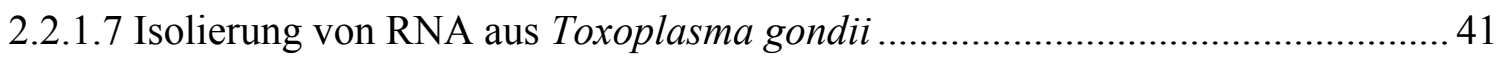

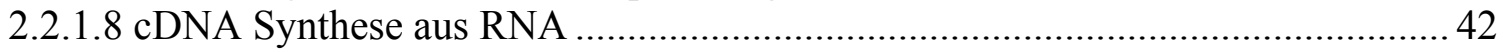

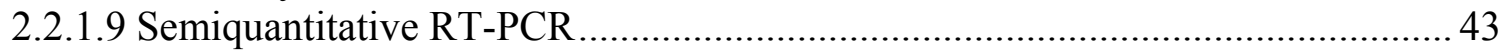

2.2.1.10 Isolierung von genomischer DNA (gDNA) aus $T$. gondii ............................... 43

2.2.1.10.1 Isolierung genomischer DNA durch Aceton-Fällung ............................... 44

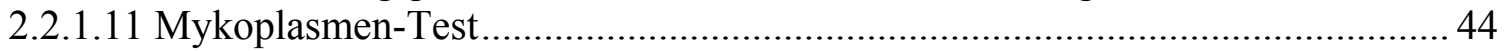

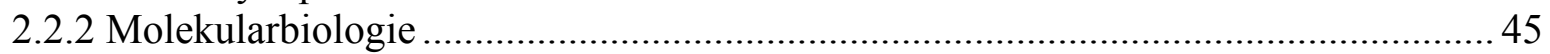

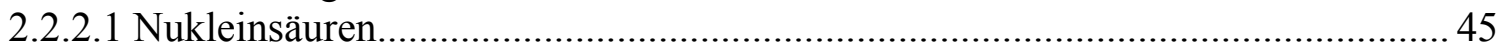

2.2.2.1.1 Isolierung von Plasmid-DNA aus Escherichia coli ................................... 45

2.2.2.1.2 Alkoholische Fällung von DNA.......................................................... 45

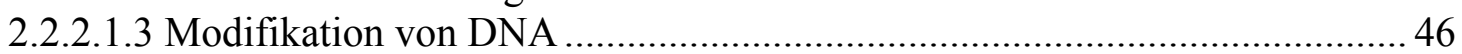

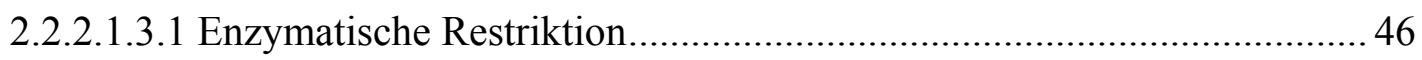

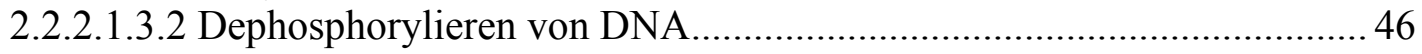

2.2.2.1.3.3 Ligation von DNA durch T4 DNA Ligase ............................................ 46

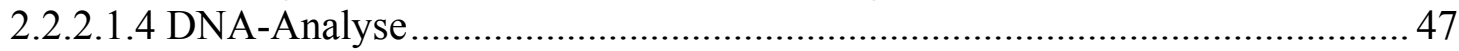

2.2.2.1.4.1 Photometrische Konzentrationsbestimmung ....................................... 47

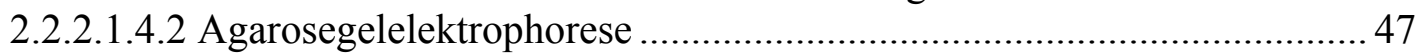

2.2.2.1.4.3 Extraktion von DNA aus einem präparativen Agarosegel .................... 48

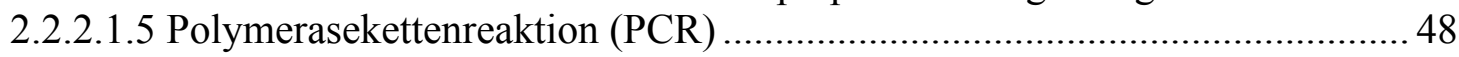

2.2.2.1.6 Real-Time PCR am Lightcycler ............................................................ 51

2.2.2.1.7 Subklonierung von PCR-Produkten in pCR2.1 TOPO ............................. 53

2.2.2.1.8 Klonierung durch inverse PCR ................................................................ 54

2.2.2.1.9 Transformation von Plasmid-DNA in chemisch kompetente E. coli............55

2.2.2.1.9.1 Präparation kompetenter Zellen, $\mathrm{CaCl}_{2}$-Methode ............................... 54

2.2.2.1.9.2 Transformation in $\mathrm{CaCl}_{2}$-kompetente $E$. coli ...................................... 55

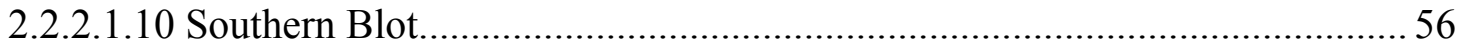

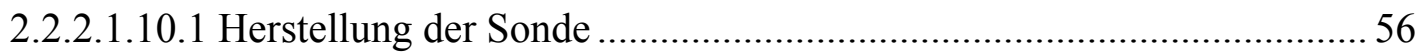

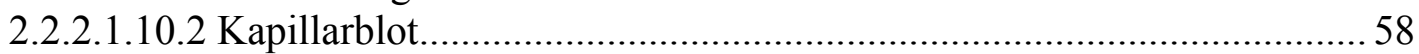

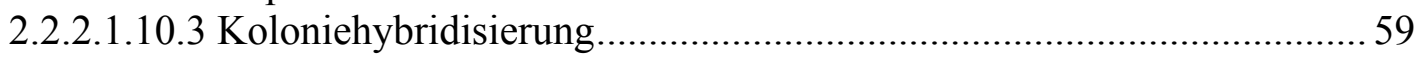

2.2.2.1.10.4 Hybridisierung der Membranen ........................................................... 60

2.2.2.1.10.5 Detektion Digoxigenin-markierter Sonden, alkalische Phosphatase

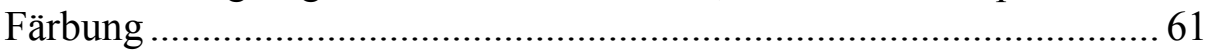

2.2.2.1.10.6 Detektion Digoxigenin-markierter Sonden, CSPD Färbung................ 62

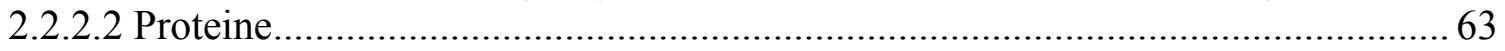

2.2.2.2.1 Herstellung und Aufreinigung rekombinanter His-Tag Fusionsproteine...... 63

2.2.2.2.1.1 Prinzip des QiaExpress Systems .......................................................... 63

2.2.2.2.1.2 Expression der rekombinanten Loop und C-Terminus Proteine............ 64

2.2.2.2.1.3 Optimierung der Protein-Aufreinigungsbedingungen........................... 64

2.2.2.2.1.3.1 Native Proteinaufreinigung, Optimierung ...................................... 64

2.2.2.2.1.3.2 Denaturierende Proteinaufreinigung, Optimierung.........................6 65

2.2.2.2.1.4 Denaturierende Proteinaufreinigung, präparativ ............................... 66

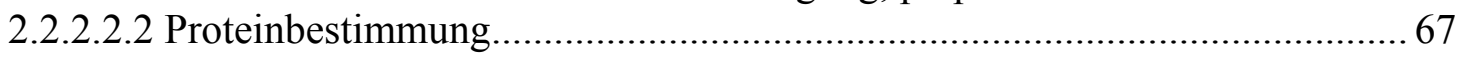

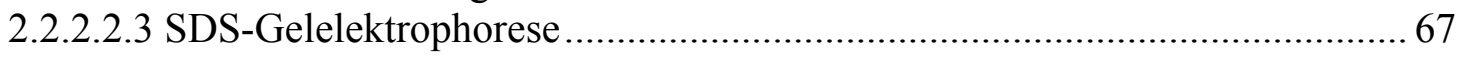

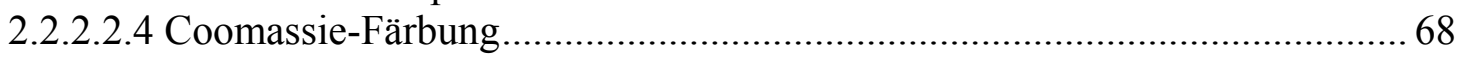




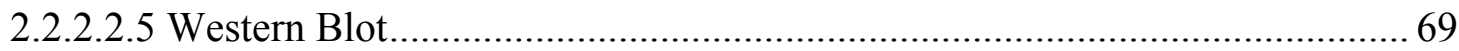

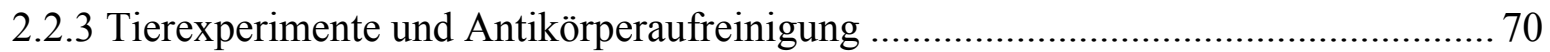

2.2.3.1 Immunisierung von Mäusen zur Antikörpergewinnung ................................... 70

2.2.3.2 Affinitätschromatographie über CNBr-aktivierte Sepharose B .......................... 71

2.2.3.3 Affinitätschromatographie mit dem HydraS Activated Affinity Resin Kit ......... 72

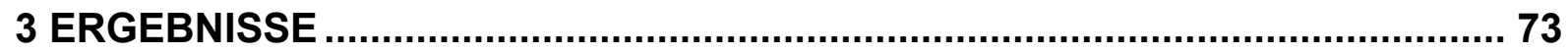

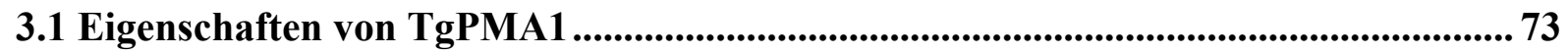

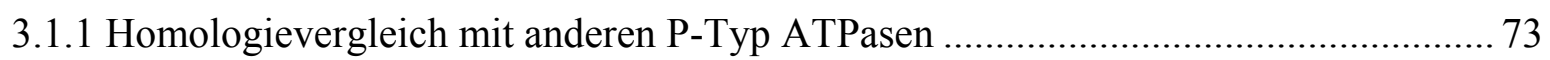

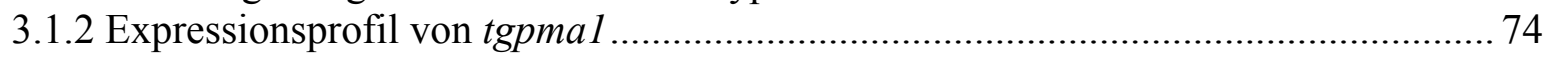

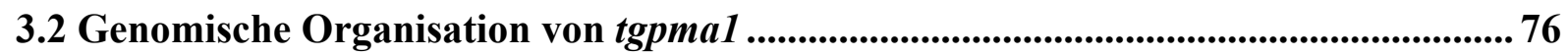

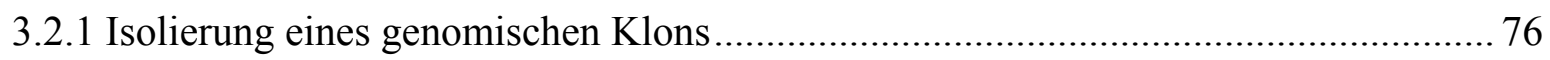

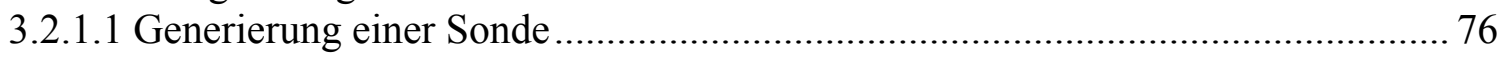

3.2.1.2 Screening einer genomischen T. gondii Cosmid Bibliothek ............................... 77

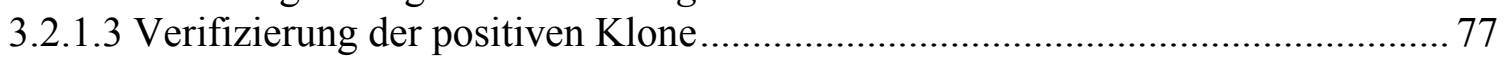

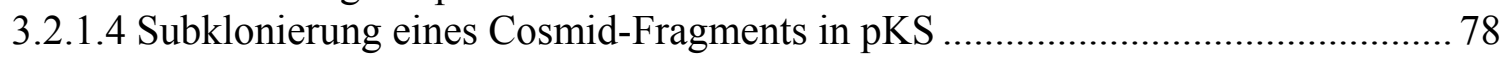

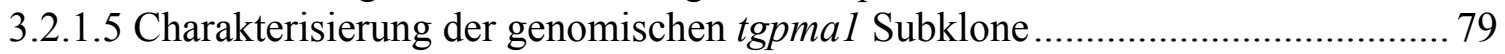

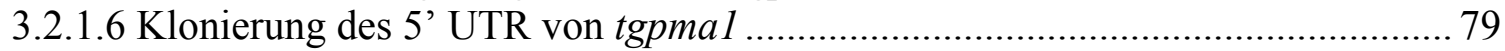

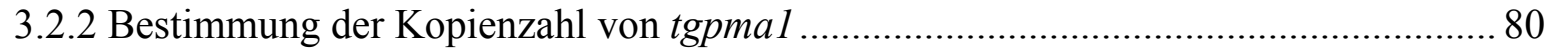

3.3 Lokalisation von TgPMA1 in Bradyzoiten ............................................................................ 81

3.3.1 Expression rekombinanter TgPMA1-Fragmente in E. coli......................................... 81

3.3.1.1 Klonierung des rekombinanten Loop und C-Terminus Fragments...................... 82

3.3.1.2 Expression der rekombinanten Loop und C-Terminus Proteine........................... 82

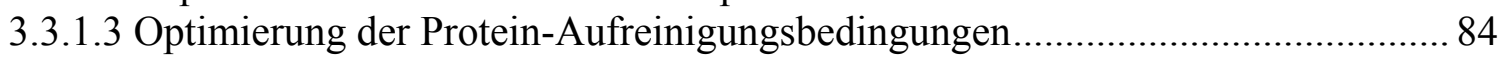

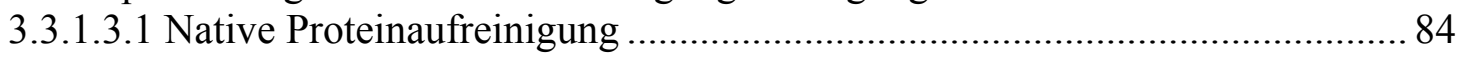

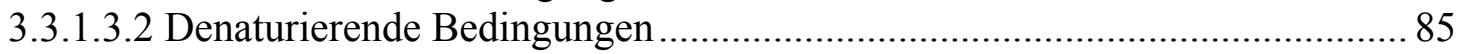

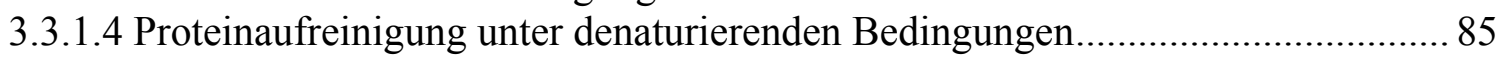

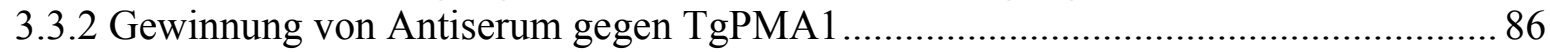

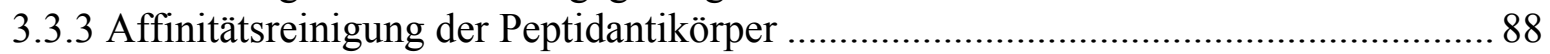

3.3.4 Lokalisation von TgPMA1 auf der Oberfläche von Toxoplasma Bradyzoiten........... 89

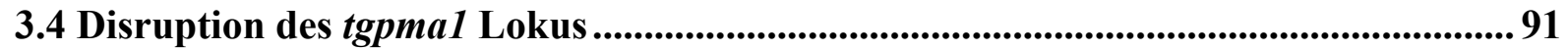

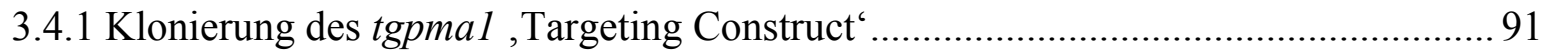

3.4.2 Transfektion des Targeting Constructs und Selektion einer TgPMA1

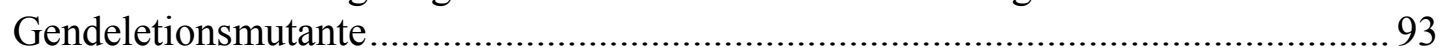

3.4.3 Nachweis der homologen Integration in der TgPMA1 Gendeletionsmutante ............ 95

3.4.3.1 Southern Blot mit genomischer DNA ............................................................. 95

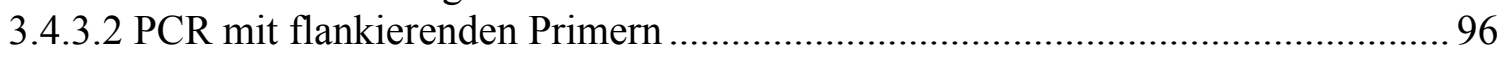

3.4.3.3 Doppelimmunfluoreszenzfärbung an Bradyzoiten........................................... 98

3.5 Charakterisierung der tgpma1 Gendeletionsmutante in vitro ....................................98

3.5.1 Wachstumsgeschwindigkeit von Tachyzoiten ......................................................... 98

3.5.2 Wachstumsgeschwindigkeit während Stadienkonversion von Tachyzoiten zu

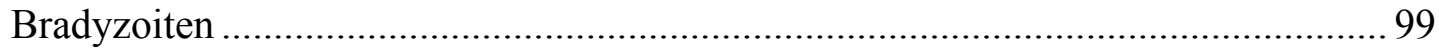

3.5.3 Wachstumsgeschwindigkeit während Stadienkonversion von Bradyzoiten zu

Tachyzoiten. 


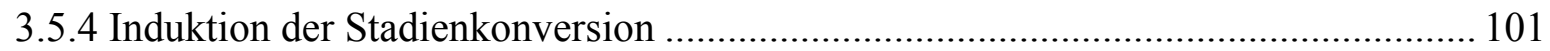

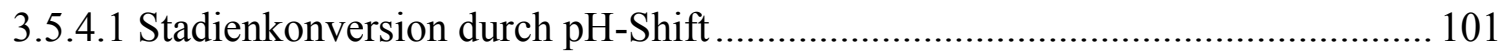

3.5.4.2 Stadienkonversion durch andere Shift-Methoden ......................................... 103

3.5.4.2.1 Stadienkonversion durch extrazelluläre Inkubation ..................................... 104

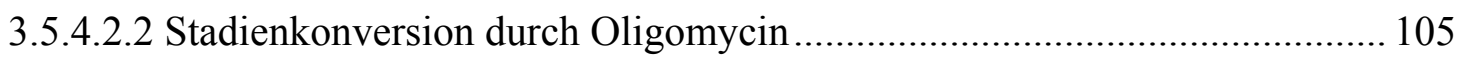

3.5.4.2.3 Stadienkonversion durch eine externe NO-Quelle..................................... 106

3.5.5 Semiquantitative RT-PCR an in vitro differenzierten Bradyzoiten ......................... 107

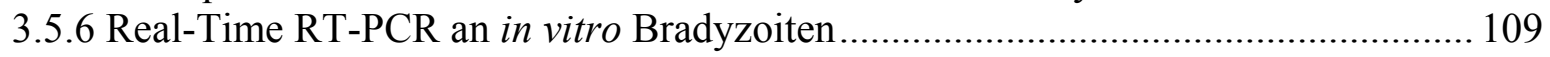

3.6 Charakterisierung der tgpmal Gendeletionsmutante in vivo...................................... 111

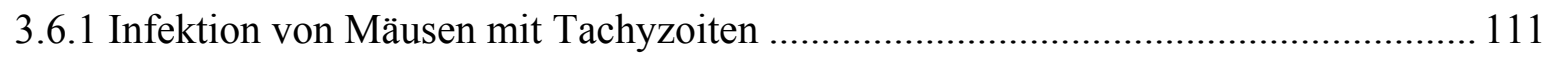

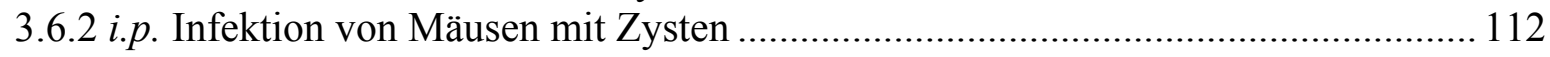

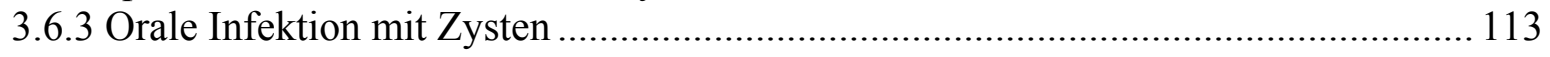

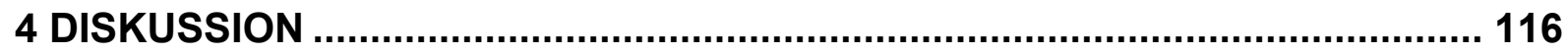

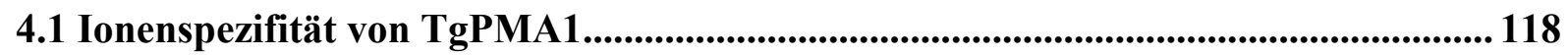

4.2 Analyse der genetischen Organisation von tgpma1 ........................................................ 118

4.3 Aufgaben von P-Typ Protonen ATPasen ........................................................................ 121

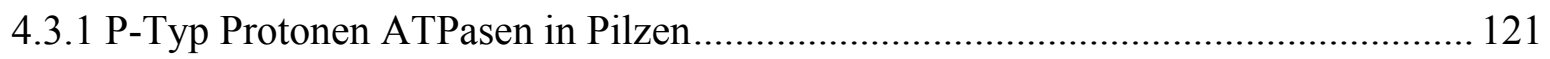

4.3.2 Pflanzen: viele Isoformen an P-Typ Protonen ATPasen.......................................... 122

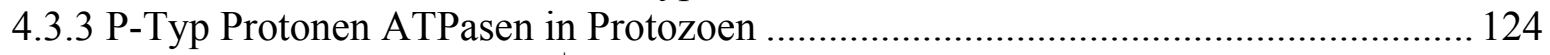

4.3.3.1 Funktion von P-Typ $\mathrm{H}^{+}$-ATPasen in Flagellaten ............................................ 124

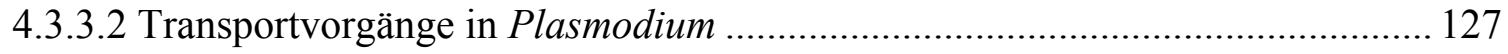

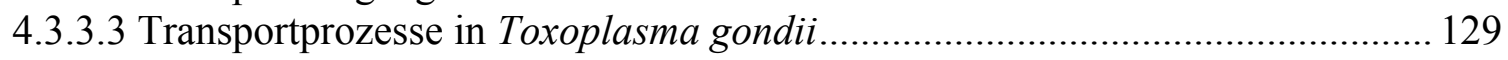

4.4 Charakterisierung der tgpma1 Gendeletionsmutante................................................... 131

4.5 Transportprozesse in Bradyzoiten und mögliche Funktion von TgPMA1 ............... 135

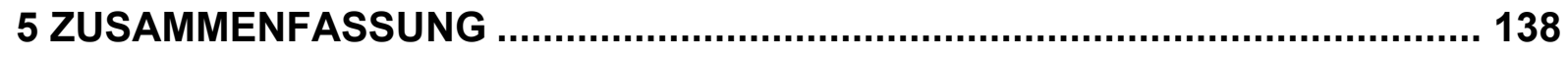

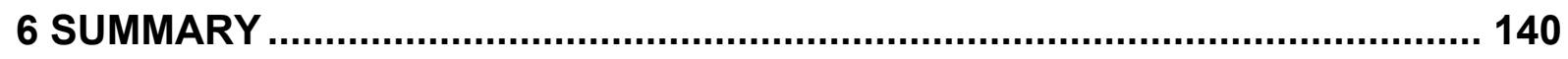

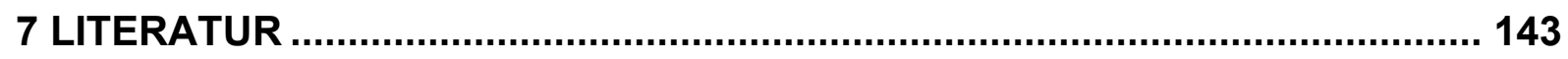

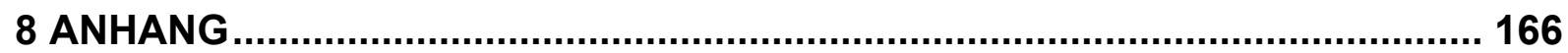




\section{Abkürzungsverzeichnis}

Abb. Abbildung

APS Ammoniumpersulfat

ATP Adenosintriphosphat

bidest. doppelt destilliert

bp Basenpaar

BSA Rinderserumalbumin

cDNA zur RNA komplementäre DNA

$\mathrm{Ci} \quad$ Curie

$\mathrm{cp} \quad$ crossing point

Cy2 Carbocyanin

Cy3 Indocarbocyanin

dATP Desoxyadenosin-5'-triphosphat

dCTP Desoxycytidin-5'-triphosphat

dGTP Desoxyguanosin-5'-triphosphat

DMEM Dulbecco's MEM

DMSO Dimethylsulfoxid

DNA Desoxyribonukleinsäure

dNTP Desoxynuleosid-5'-triphosphat

DTAF Diaminotriazinylaminofluorescein

DTT Dithiothreitol

dTTP Desoxythymidin-5'-triphosphat

EDTA Ethylendiamintetraessigsäure

EST Expressed Sequence Tag, ansequenzierte cDNA

FCS fötales Kälberserum

gDNA genomische DNA

GRA Proteine aus den dichten Granula

h Stunde

HEPES 4-(2-Hydroxyethyl)-1-Piperazin-Ethansulfonsäure

HFFs humane Vorhautfibroblasten

HSP Hitzeschockprotein

IFN- $\gamma \quad$ Interferon- $\gamma$ 
Ig Immunglobulin

IPTG Isopropyl-beta-D-Thiogalactopyranosid

kDa kilo-Dalton

I Liter

LB Luria Broth

M molar

$\min \quad$ Minuten

NBT 4-Nitroblau Tetrazoliumchlorid

nt Nukleotid

NTP Nukleosid-5'-triphosphat

OD optische Dichte

PAGE Polyacrylamidgelelektrophorese

PBS Phosphat-gepufferte Kochsalzlösung

PEG Polyethylenglycol

Pen-Strep Penicillin / Streptomycin, $10.000 \mathrm{U} / 10.000 \mu \mathrm{g} / \mathrm{ml}$

PMA Plasmamembran ATPase

PPase Pyrophosphatase

RNA Ribonukleinsäure

ROP Proteine aus den Rhoptrien

rpm Umdrehungen pro Minute

S Sekunde

SAG Familie von Oberflächenantigenen in T.gondii

SDS Natriumdodecylsulfat

SNP Natriumnitroprussiat

TEMED N,N,N',N'-Tetramethylendiamin

Tris Tris(Hydroxymethyl)-Aminomethan

var. variabel

X-Gal 5-Bromo-4-Chloro-3-Indolyl-beta-D-Galaktopyranosid

X-Phosphat 5-Bromo-4-Chloro-3-Indoylphosphat

ZNS Zentralnervensystem 


\section{Einleitung}

\subsection{Entdeckung und Lebenszyklus von Toxoplasma gondii}

Anfang des 20ten Jahrhunderts wurden die ersten asexuellen Stadien von Toxoplasma gondii in Vögeln und Säugetieren dokumentiert. Die erste genauere Beschreibung des Parasiten erfolgte im Jahre 1908 von Nicolle und Manceaux, die ihm später auch den Namen Toxoplasma gondii gaben, um an seine gebogene Form (griechisch: toxon = Bogen; plasma $=$ Form) und das Tier zu erinnern, in dem sie inn entdeckt hatten: dem Gondi, einem nordafrikanischen Nagetier (Ctenodactylus gundi; Nicolle \& Manceaux, 1909). In den folgenden Jahren bis heute wurde Toxoplasma gondii in etlichen tierischen und klinischen Isolaten überall auf der Welt beschrieben. Der obligat intrazelluläre Parasit besitzt ein extrem breites Wirtsspektrum und kann alle warmblütigen Vertebraten infizieren, wodurch Toxoplasma zu einem der am weitesten verbreiteten Parasiten der Welt wurde. Toxoplasma gondii gehört innerhalb der Protozoen zu dem Unterstamm Apicomplexa, dem auch andere wichtige Pathogene wie Plasmodium, Eimeria, Cyclospora, Babesia und Cryptosporidium zugeordnet werden. Apicomplexa sind obligat intrazelluläre Parasiten, die komplexe Lebenszyklen aufweisen und sich durch das Vorhandensein eines Apikalkomplexes auszeichnen, einem Komplex aus sekretorischen Organellen am apikalen Pol des Parasiten, der aus Mikronemen und Rhoptrien besteht. Der vollständige Lebenszyklus konnte erst 1970 aufgeklärt werden, mit der Entdeckung der Katze als Endwirt des Parasiten (Frenkel et al., 1970).

Toxoplasma gondii kann während seines Lebenszyklus in drei verschiedenen Stadien vorkommen: als Tachyzoiten oder Bradyzoiten im Zwischenwirt (allen warmblütigen Vertebraten einschließlich des Menschen) und als Sporozoiten in ihrem Endwirt, der Hauskatze oder anderer Angehöriger der Familie Felidae (Lindsay et al., 1991; Dubey et al., 1998).

Tachyzoiten treten während der akuten Phase der Infektion auf und sind durch eine hohe Replikationsrate mit einem durchschnittlichen Reproduktionszyklus von fünf bis neun Stunden gekennzeichnet. Sie vermehren sich ungeschlechtlich in einer parasitophoren Vakuole innerhalb einer Mutterzelle durch Längsteilung (Endodyogenie). Nach sieben bis acht Teilungen platzt die Wirtszelle auf und die freigesetzten Parasiten können neue Zellen infizieren. Während dieser Phase der Infektion kommt es 
zu einer Ausbreitung des Parasiten in viele Organsysteme, hauptsächlich Leber, Lymphknoten und Lunge (Frenkel, 1988). Durch das Einsetzen der spezifischen Immunantwort des Wirtes wird die akute Infektion in der Regel überwunden. Der Parasit kann sich dem Immunsystem allerdings durch Differenzierung in das Bradyzoitenstadium entziehen, wobei die parasitophore Vakuole zu einer Zystenhülle ausgebaut wird (Ferguson \& Hutchison, 1987, Dubey et al., 1998). Bradyzoiten vermehren sich ebenfalls durch Endodyogenie, allerdings weisen sie eine stark reduzierte Replikationsrate und einen verlangsamten Metabolismus auf. Sie stellen ein Ruhestadium dar, das für die gesamte Lebensdauer ihres Wirtes innerhalb von Zysten persistieren kann, ohne im immunkompetenten Wirt klinische Symptome hervorzurufen (Bohne et al., 1999). Zysten finden sich, abhängig vom Zwischenwirt, vor allem im zentralen Nervensystem, aber auch im Muskelgewebe, der Retina und zu einem geringen Teil in anderen Geweben (Dubey \& Peattie, 1988; Dubey et al., 1998).

Werden Zysten mit der Nahrung durch infiziertes und nicht gut durchgekochtes Fleisch aufgenommen, löst sich die Zystenhülle im Magen auf und die säure- und pepsinresistenten Bradyzoiten infizieren im Dünndarm Epithelzellen, in denen sie sich wieder zu Tachyzoiten differenzieren (Jacobs et al., 1957; Pettersen, 1979). Diese lösen erneut einen Zyklus von akuter Infektion mit anschließender chronischer Infektion und Zystenbildung aus.

Wird ein mit Zysten infizierter Zwischenwirt von einer Katze, dem Endwirt des Parasiten, gefressen, verläuft die Infektion anfänglich wie in einem Zwischenwirt: die Zystenwand wird im Magen der Katze aufgelöst, die freiwerdenden Bradyzoiten invadieren Zellen des Dünndarmepithels. Ab diesem Punkt unterscheidet sich der Vermehrungszyklus stark von dem des Zwischenwirtes. Im Dünndarmepithel der Katze initiieren die Bradyzoiten mehrere Generationen sexueller Vermehrung, wobei sie zu männlichen und weiblichen Gametozyten differenzieren, die nach Fusionierung eine Zygote bilden (Freyre et al., 1989). Nach der Befruchtung bildet sich eine dichte Oozystenwand um die Zygote aus. Infizierte Epithelzellen platzen auf und entlassen die Oozysten in das Lumen des Darms, von wo sie mit den Faeces ausgeschieden werden. Die Sporulation erfolgt im Freien innerhalb von einem bis fünf Tagen, wobei acht Sporozoiten gebildet werden. Werden diese durch kontaminierte Nahrung, Wasser oder Erde von einem warmblütigen Vertebraten aufgenommen, 
differenzieren sie im Dünndarmepithel wieder zu Tachyzoiten und der Infektionszyklus schließt sich.

\subsection{Medizinische Bedeutung von Toxoplasma gondii}

Toxoplasma gondii ist als Erreger der Toxoplasmose im Menschen einer der häufigsten humanpathogenen Parasiten weltweit. Schätzungen gehen davon aus, dass bis zu einem Drittel der Weltbevölkerung infiziert ist, wobei es allerdings starke lokale Unterschiede gibt (Tenter et al., 2000). Die Durchseuchungsrate korreliert in Deutschland mit dem Lebensalter: etwa 20\% aller 20-jährigen und etwa 30\% aller 30-jährigen sind seropositiv (Groß, 1994). Eine Infektion immunkompetenter Individuen verläuft in der Regel asymptomatisch. Da nur 1-5\% der Infizierten Symptome wie Lymphadenitis, Ermüdungserscheinungen ohne Fieber und Kopfschmerzen aufweisen, verläuft eine Erstinfektion mit anschließender chronischer Infektion normalerweise unerkannt.

Komplikationen können in immunsupprimierten Patienten und während einer Schwangerschaft auftreten. Bei einer Erstinfektion während einer Schwangerschaft kommt es in ca. 50\% aller Fälle zu einer in utero Übertragung des Parasiten, was letztendlich zu konnataler Toxoplasmose des Fötus führt. Häufig treten Hydrocephalus oder intracraniale Kalzifikationen auf, allerdings sind die Symptome sehr unterschiedlich und reichen bis zu Multiorganinfektionen, die zum Abort führen können (Remington \& Desmonts, 1990).

Eine Infektion von Toxoplasma gondii wird vor allem durch die zelluläre Immunabwehr des Wirtes kontrolliert, wobei Interferon- $\gamma$ (IFN- $\gamma$ ) eine zentrale Rolle spielt (Subauste \& Remington, 1991). Wenn eine entsprechende Immunantwort nicht stattfinden kann, wie etwa bei fortgeschrittener HIV-Infektion oder induzierter Immunsuppression nach Organtransplantation, kann aus einer chronischen Infektion durch Reaktivierung wieder eine akute Infektion werden. Die in den Zysten enthaltenen Bradyzoiten können sich nach Aufplatzen der Zyste wieder zu Tachyzoiten differenzieren, die sich bei fehlender Immunantwort ungehindert replizieren, dabei schwere Hirnläsionen verursachen und zu einer toxoplasmatischen Enzephalitis führen (Luft \& Remington, 1992; Ambroise-Thomas \& Pelloux, 1993; Luft et al., 1993). 
Es sind einige Medikamente vorhanden, um akute oder reaktivierte Toxoplasmose effizient zu behandeln. Allerdings gibt es bis heute keine Behandlung, die Zysten aus Infizierten effektiv eliminiert, so dass die Gefahr einer reaktivierten Toxoplasmose ständig bestehen bleibt. Der reversiblen Differenzierung von Tachyzoiten zu Bradyzoiten kommt hierbei eine zentrale Rolle zu, bei der noch viele wichtige Fragen ungeklärt sind.

\subsection{Aufbau von Tachyzoiten und Bradyzoiten}

Da Toxoplasma gondii jede kernhaltige Wirtszelle infizieren und sich darin replizieren kann, ist eine einfache Aufzucht in der Zellkultur in einer Reihe von Wirtszellen möglich. Dadurch konnte T. gondii als Modellorganismus für intrazelluläre Parasiten etabliert werden (Joiner \& Dubremetz, 1991; Mc Leod et al., 1991). Es existieren mittlerweile eine große Anzahl an tierischen und klinischen Isolaten, die sich einer Reihe verschiedener Toxoplasma Stämme zuordnen lassen. Diese weisen untereinander sehr starke genetische und phänotypische Ähnlichkeiten auf und lassen sich in drei klonale Linien (Typ I, II, III) unterteilen, die jeweils global verstreut in Tieren und Menschen gefunden wurden (Dardé et al., 1992; Howe \& Sibley, 1995). Durch Sequenzanalysen konnte ermittelt werden, dass sich die verschiedenen Stämme nur in etwa 1\% ihrer DNA unterscheiden. Eine wichtige Beobachtung war, dass die unterschiedliche Virulenz der verschiedenen Toxoplasma Stämme in der Maus mit der Zugehörigkeit zu einer der drei klonalen Linien korreliert, also genetisch bedingt ist (Grigg et al., 2001; Sibley \& Boothroyd, 1992). Parasiten vom Typ I zeigen durch ihre hohe Virulenz bei Infektion in Mäusen eine $L D_{100}$ von weniger als 10 Organismen auf. Sie bilden nur selten Zysten und sind besonders häufig assoziiert mit konnataler Toxoplasmose. Typ II Parasiten sind die Hauptursache von chronischer Toxoplasmose in Menschen. Sie sind weniger stark virulent und bilden eine große Anzahl Zysten im Mausmodell. Die ebenfalls gering virulenten Angehörigen des Typs III werden nur selten in klinischen Isolaten gefunden und treten besonders häufig in Tieren auf (Sibley \& Howe, 1996).

Das nukleäre Genom von Toxoplasma umfasst ca. $87 \mathrm{Mb}$, verteilt auf 11 Chromosomen. Neben diesem besitzt T. gondii noch in zwei DNA-haltigen Organellen ein 6 kb mitochondriales Genom und ein episomales 35 kb plastidenähnliches Genom in 
einem Organell, das in vielen Vertretern der Apicomplexa gefunden wurde: dem Apicoplasten (Kohler et al., 1997; Ajioka et al., 2001). Eine erfolgreiche Replikation des Apicoplasten-Genoms ist essentiell für den Parasiten. Es ist homolog zu dem aus Plastiden photosynthetischer Organismen und wahrscheinlich der Ort der Synthese von aromatischen Aminosäuren und Fettsäuren (Fichera \& Roos, 1997; Kohler et al., 1997; Roberts et al., 1998). Viele Proteine werden allerdings nicht im Apicoplasten selbst kodiert, sondern müssen erst aus der Zelle importiert werden (Waller et al., 1998; Gleeson, 2000). Ultrastrukturelle Untersuchungen ergaben, dass dieses Organell durch vier Membranen vom Zytoplasma des Parasiten abgetrennt ist. Zusammen mit phylogenetischen Untersuchungen des Plastidengenoms verschiedener Angehöriger der Apicomplexa deutet dies auf einen wahrscheinlichen Ursprung dieses Organells durch sekundäre Endosymbiose einer Grün- oder Rotalge hin (Kohler et al., 1997).

Strukturell unterscheiden sich Tachyzoiten und Bradyzoiten nur geringfügig (s. Abb. 1). Die Parasiten sind etwa $2 \times 6 \mu \mathrm{m}$ groß und haben eine leicht gebogene Form, wobei Bradyzoiten etwas, schlanker' sind. Umschlossen wird der Organismus von einem Pellikel, der aus drei Membranen besteht: der Plasmamembran und zwei dicht beieinander liegenden Membranen, die den inneren Membrankomplex bilden. Am apikalen Pol befinden sich, wie auch bei anderen Apicomplexa, das Konoid und zwei sekretorische Organelle, Mikronemen und Rhoptrien. Das Konoid ist eine Struktur aus spiralförmig aufgewundenen Tubulinpolymeren, die in extrazellulären Parasiten ausgefahren werden und rotieren kann (Hu et al., 2002). Die Rhoptrien sind keulenförmige Strukturen, die bei Bradyzoiten häufig eine Schleife ausbilden und sich dadurch von solchen aus Tachyzoiten unterscheiden. Innerhalb der Zelle verteilt befinden sich die übrigen Organellen, wie Mitochondrien, Golgi Apparat, Endoplasmatisches Reticulum, und die dichten Granula, ein weiteres sekretorisches Organell. Bei Tachyzoiten befindet sich der Zellkern in der Mitte der Zelle, während er in Bradyzoiten am posterioren Pol lokalisiert ist. Einen Hauptunterschied zwischen den beiden Lebensstadien stellt das Vorhandensein vieler Amylopektin-haltiger Granula in Bradyzoiten dar, die in Tachyzoiten nicht, oder nur in sehr geringer Anzahl vorkommen (Dubey et al., 1998).

Im Gegensatz zu Tachyzoiten gelten Bradyzoiten als säure- und magensaftresistent, weshalb sie eine Magenpassage unbeschadet überstehen können (Jacobs et al., 1960). Zunächst nahm man an, dass dies auf eine Resistenz gegenüber Pepsin und 
anderen proteolytischen Enzymen des Magens zurückzuführen sei, doch konnte gezeigt werden, dass dies auch auf einer Resistenz gegenüber saurem Milieu allgemein beruht (Pettersen, 1979). Gleiche Inkubationsbedingungen führten bei Tachyzoiten innerhalb kurzer Zeit zum vollständigen Verlust der Infektiosität.

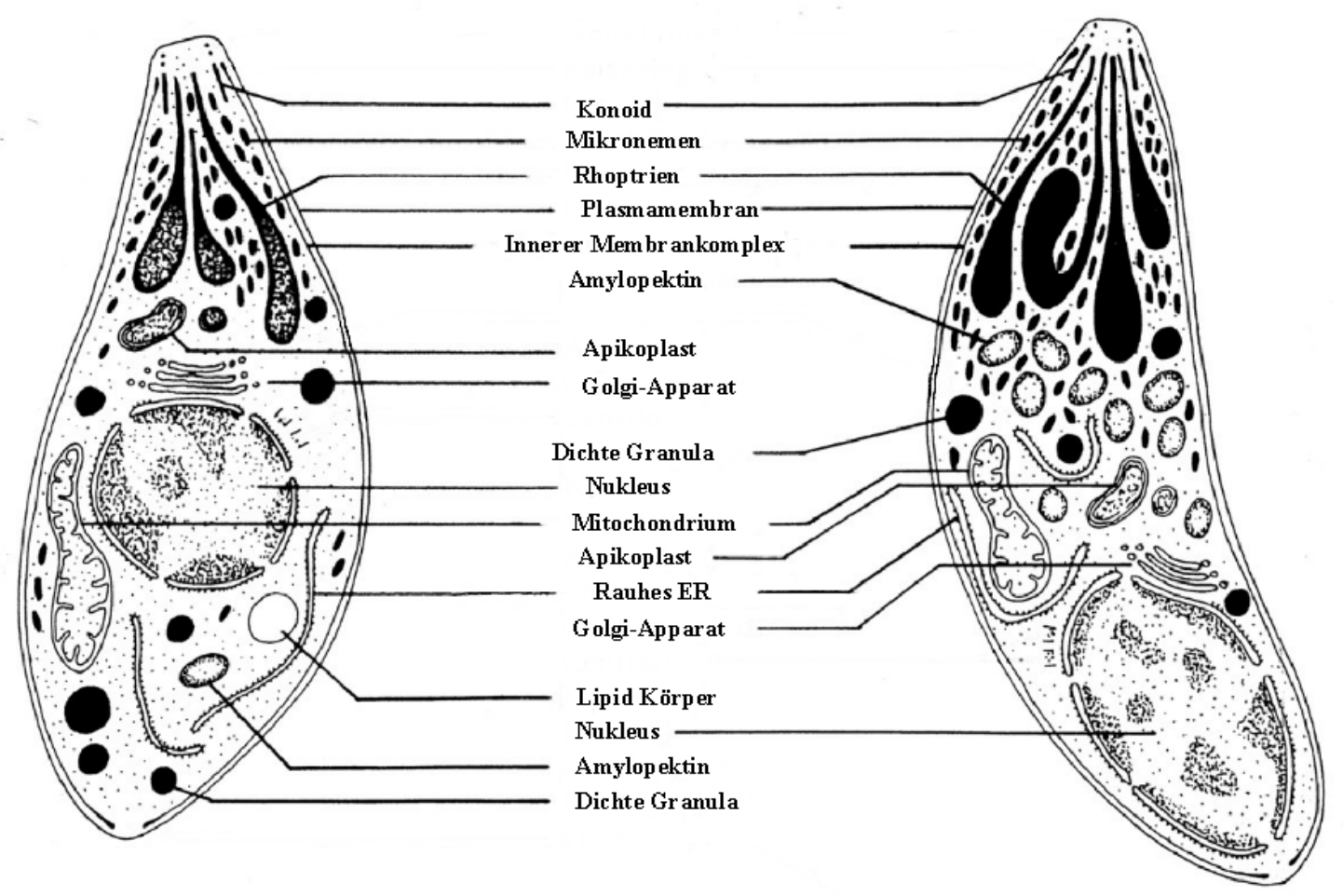

Abb. 1. Ultrastruktureller Vergleich von Tachyzoiten und Bradyzoiten. Die Unterschiede in der Form der Rhoptrien, Anzahl der Amylopektin-haltigen Vesikel und Lage des Nukleus sind deutlich erkennbar. Abbildung modifiziert aus Dubey et al., 1998.

\subsection{Interaktion mit der Wirtszelle}

Die Organellen des Apikalkomplexes, Mikronemen, Rhoptrien und dichte Granula, werden mit Zelladhärenz und Invasion der Wirtszelle in Verbindung gebracht. Die Invasion ist ein aktiver, vom Parasiten gesteuerter Prozess und wird nicht durch Phagozytose der Wirtszelle vermittelt (Dobrowolski \& Sibley, 1996; Dubremetz et al., 1998).

Zu Beginn des Invasionsprozesses muss der Parasit einen ersten Kontakt zu seiner Wirtszelle aufnehmen. Der Rezeptor hierfür ist bisher noch nicht bekannt, da 
Toxoplasma aber anscheinend jede kernhaltige Zelle infizieren kann, müssen die vom Parasiten erkannten Strukturen ubiquitär auf allen Zellen vorhanden sein. Für den Kontakt scheinen sowohl Komponenten der Wirtszelle, als auch des Parasiten verantwortlich zu sein. Hierfür wurden sowohl Oberflächenproteine wie SAG1, als auch Proteine aus den Mikronemen verantwortlich gemacht, wobei die Bindung an einen glykosylierten Wirtszellrezeptor erfolgt (Mineo et al., 1993; Fourmaux et al., 1996; Ortega-Barria \& Boothroyd, 1999). Dies wird durch einen neueren Fund bestätigt, in dem für ein Protein aus den Mikronemen (MIC1) eine Eigenschaft als Lactosebindendes Lektin gezeigt werden konnte (Lourenco et al., 2001).

Nach Anheftung an die Wirtszelle reorientiert sich der Parasit, so dass der Apikalkomplex der Wirtszellmembran gegenüber liegt. Bei diesem Prozess scheint ein weiteres Oberflächenmolekül des Parasiten eine Rolle zu spielen: SAG2. Maskierung von SAG2 mit Hilfe von monoklonalen Antikörpern immobilisiert den Parasiten auf der Oberfläche der Wirtszelle, so dass keine Reorientierung mehr stattfinden kann (Smith, 1995; Grimwood \& Smith, 1996). Eine lokal begrenzte Kontaktausbildung zwischen der Membran des Parasiten und der Wirtszelle, eine sogenannte ,Tight Junction' (Michel et al., 1980) wird ausgebildet, die im Verlauf der Internalisierung des Parasiten zum hinteren Pol wandert, wobei Membran und assoziierte Oberflächenmoleküle abgeworfen werden. Am Ende des nur ca. $10 \mathrm{~s}$ dauernden Invasionsprozesses befindet sich der Parasit in einer intrazellulären parasitophoren Vakuole, die ursprünglich aus der Plasmamembran der Wirtszelle entstammt und selektiv von fast allen Oberflächenmolekülen befreit wurde (Suss-Toby et al., 1996; Mordue et al., 1999). Noch während der Invasion entleeren die Rhoptrien ihren Inhalt in die entstehende parasitophore Vakuole, wobei für einige Proteine wie ROP1 und ROP2 eine spätere Lokalisierung auf der Membran der parasitophoren Vakuole nachgewiesen werden konnte (Saffer et al., 1992). ROP Proteinen wird eine generelle strukturelle Funktion beim Aufbau der parasitophoren Vakuole zugeschrieben. Im Falle von ROP2 konnte gezeigt werden, dass es für die auffällig dichte Anlagerung von Endoplasmatischem Reticulum und Mitochondrien der Wirtszelle an die Außenseite der parasitophoren Vakuole verantwortlich ist (Sinai et al., 1997; Sinai \& Joiner, 2001).

Eine interessante Eigenschaft der parasitophoren Vakuole ist neben dem Fehlen von Wirtszellproteinen ihre Unfähigkeit, mit Vesikeln der Wirtszelle zu fusionieren. Dadurch wird eine Ansäuerung der Vakuole verhindert, die durch Verschmelzung mit 
Lysosomen ansonsten zum Tod des Parasiten führen würde (Sibley et al., 1985; Joiner et al., 1990).

Innerhalb von 10 Minuten nach Invasion in die Zelle werden auch die dichten Granula in die Vakuole ausgeschüttet. Es konnte gezeigt werden, dass dieser Prozess, ebenso wie die Sekretion von Mikronemen und Rhoptrien, $\mathrm{Ca}^{2+}$ abhängig ist (Carruthers \& Sibley, 1999; Saffer \& Schwartzman, 1991). Proteine aus den dichten Granula (GRA Proteine) werden zu den Excreted-Secreted Antigens (ESAs) gezählt; sie werden während der gesamten intrazellulären Entwicklung von Tachyzoiten und Bradyzoiten sekretiert. Die GRA Proteine sind an der Ausbildung eines intravakuolären Netzwerkes tubulärer Membranen und an der Modifizierung der Vakuolenmembran beteiligt (Achbarou et al., 1991; Cesbron-Delauw, 1994; Mercier et al., 2002). Bei Bradyzoiten zeigen die GRA Proteine eine andere Verteilung auf. Während einige ähnlich der parasitophoren Vakuole in der Zystenmatrix verteilt sind, zeigen andere eine Verbindung zur Zystenwand auf, so dass sie mit deren Aufbau während der Differenzierung in Verbindung gebracht werden (Torpier et al., 1993; Ferguson et al., 1999). Neben GRA1-6 konnte ein weiteres Protein in den dichten Granula lokalisiert werden, dessen Funktion aufgeklärt wurde. Es handelt sich hierbei um eine NTPase, die ATP in die jeweiligen Di- und Monophosphat-Formen degradiert (Bermudes et al., 1994; Asai et al., 1995) und der eine Funktion bei der Aufnahme von Purinen aus der Wirtszelle zugeschrieben wird. T. gondii kann Pyrimidine de novo synthetisieren, ist aber auxotroph für Purine und dadurch auf einen ständigen Nachschub seitens der Wirtszelle angewiesen (Schwartzman \& Pfefferkorn, 1982). Da sich die parasitophore Vakuole wie ein Molekularsieb verhält und frei durchlässig für kleine Substanzen bis zu einem Molekulargewicht von 1,3 kDa ist, kann hier ein Austausch von Nährstoffen mit der Wirtszelle, wie Aminosäuren, Zucker und ATP stattfinden (Schwab et al., 1998).

Die Replikation des Parasiten findet innerhalb der parasitophoren Vakuole durch Endodyogenie statt. Die ersten drei bis vier Zellteilungen verlaufen hierbei synchron und es kommt zu der für $T$. gondii typischen Rosettenbildung. Nach sieben bis acht Zellteilungen platzt die Wirtszelle und die freiwerdenden Parasiten infizieren benachbarte Zellen.

Bradyzoiten sind ebenfalls in der Lage, Zellen aktiv zu infizieren und müssen sich hierzu nicht zuerst zu Tachyzoiten umwandeln. Ähnlich wie Tachyzoiten reorientieren sie sich ebenfalls mit dem Apikalkomplex zur Wirtszelle, nachdem ein erster Kontakt 
stattgefunden hat. Der Inhalt der Rhoptrien wird entleert, aber im Gegensatz zur Invasion bei Tachyzoiten kann weder die Bildung einer, Tight Junction', noch das Abwerfen von Membranmaterial beobachtet werden. Ferner wurden fingerähnliche Auswüchse der Wirtszelle, ähnlich Pseudopodien, entlang der Oberfläche des invadierenden Parasiten beobachtet (Speer et al., 1995; Sasono \& Smith, 1998).

Bei oraler Infektion einer Maus mit Bradyzoiten (Zysten), penetrieren diese Enterozyten des Dünndarmepithels innerhalb von zwei Stunden und haben sich innerhalb von 18 Stunden nach Infektion bereits zu Tachyzoiten umgewandelt. Eine Parasitämie lässt sich innerhalb von 24 Stunden und eine Invasion von Lungen, Gehirn und anderen Organen nach vier Tagen nachweisen (Dubey, 1997). Eine erste Zystenbildung kann ca. sechs Tage nach Infektion beobachtet werden (Weiss \& Kim, 2000). Die Zystenhülle, innerhalb derer sich Bradyzoiten teilen, ist mit ca. 0,5 $\mu \mathrm{m}$ relativ dünn. Zysten variieren stark in ihrer Größe und der Anzahl der enthaltenen Parasiten. Während sowohl 5 um große Zysten beschrieben wurden, die nur zwei Parasiten enthielten, lassen sich im Gehirn infizierter Mäuse auch bis zu $70 \mu \mathrm{m}$ große Zysten mit Hunderten bis Tausenden Bradyzoiten finden. Der Umfang der Zyste wächst mit zunehmendem Alter, während sich die Bradyzoiten in ihr langsam teilen. Vor allem in älteren Zysten können manche Parasiten auch degenerieren (Pavesio et al., 1992). Aus nicht genauer bekannten Gründen scheinen Zysten im Gehirn chronisch Infizierter von Zeit zu Zeit zu platzen, wodurch Bradyzoiten freigesetzt werden (Frenkel \& Escajadillo, 1987; Ferguson et al., 1989). Ob Bradyzoiten auch aus intakten Zysten austreten können, ist nicht bekannt. Es wird angenommen, dass sich freigesetzte Bradyzoiten wieder zu Tachyzoiten umwandeln, die bei Immunsuppression eine reaktivierte Toxoplasmose hervorrufen können. Der Mechanismus, durch den neue Generationen von Zysten in chronisch infizierten Mäusen gebildet werden, ist unbekannt (Dubey et al., 1998). Auch über einen sicherlich stattfindenden Stofftransport in und aus der Zyste und damit eine Kommunikation mit der Wirtszelle ist nichts bekannt.

\subsection{Genetische Manipulation von T. gondii}

Die Entwicklung zahlreicher Methoden zur genetischen Manipulation von Toxoplasma gondii hat das Verständnis über diesen Parasiten in den letzten Jahren 
stark vorangetrieben. Im Gegensatz zu vielen anderen Protozoen ist die genetische Struktur von Toxoplasma sehr ähnlich der von Säugetieren, in Hinsicht auf Codonund Nukleotidhäufigkeit (Roos et al., 1994).

Transiente Expression von Chloramphenicoltransferase (CAT) als Reportergen wurde nach Elektroporation von Tachyzoiten mit Plasmiden erreicht, die CAT unter Kontrolle verschiedener Promotoren trugen. (Soldati \& Boothroyd, 1993; Donald \& Roos, 1993). Die Stärke der transienten Expression war dabei abhängig vom verwendeten Promotor, wobei TUB1, der Promotor des a-tubulin Gens eine besonders starke Expression vermittelte (Nagel \& Boothroyd, 1988). Mit der Entwicklung von Selektionsmarkern konnte bald auch auf eine stabile Transfektion selektiert werden. Neben einer Resistenz gegen Pyrimethamin durch Transfektion einer Fusion aus Dihydrofolat Reduktase und Thymidylat Synthase (DHFR-TS, Donald \& Roos, 1993), wurden hier auch Resistenzen gegen Chloramphenicol (Kim et al., 1993), Phleomycin (Messina et al., 1995; Soldati et al., 1995), oder eine Selektion auf Komplementation der natürlich vorkommenden Tryptophan Auxotrophie von T. gondii (Sibley et al., 1994) erfolgreich induziert. Mittlerweile sind Selektionsmarker verfügbar, die eine positiv/negativ Selektion erlauben, wie Hypoxanthin-Xanthin-GuaninPhosphoribosyltransferase (HXGPRT; Donald et al., 1996), oder eine Fusion aus Dihydrofolat Reduktase- Cytosin Deaminase- Thymidylat Synthase (Fox et al., 1999). Neben stabiler Transfektion durch nicht-homologe Integration eines Fragmentes Fremd-DNA an eine zufällige Stelle des Genoms, kann auch gezielt eine homologe Integration erreicht werden. Dies ist lediglich abhängig von der Größe der flankierenden homologen DNA, so dass die gezielte Disruption einzelner Gene möglich ist (Kim et al., 1993; Donald \& Roos, 1994). Durch Generierung gezielter Gendeletionsmutanten konnte bereits die Funktion einiger Gene aufgeklärt werden.

Die Etablierung zusätzlicher Methoden, wie der Entwicklung eines stabilen episomalen Vektors (Black \& Boothroyd, 1998) und der Expression von antisense-RNA (Nakaar et al., 1999; Nakaar et al., 2000), oder der Rekombinase Cre (Brecht et al., 1999) erlaubt eine genauere Untersuchung der Funktion eventuell essentieller Gene. Auch Markerproteine für die Lokalisation von Transgenen in $T$. gondii durch Zellfärbungen sind mittlerweile etabliert. So lassen sich $\beta$-Galaktosidase exprimierende Parasiten sowohl in Zellkultur, als auch im Gehirn chronisch infizierter Mäuse leicht nachweisen (Seeber \& Boothroyd, 1996; Dao et al., 2002). Der endogene Proteintransport des Parasiten konnte durch Fusion des grün fluoreszierenden Proteins 
GFP mit unterschiedlichen $T$. gondii Proteinen gezielt zu verschiedenen Organellen verfolgt werden (Striepen et al., 1998).

Eine Optimierung der Transfektionsmethoden erlaubte ausgefeiltere Methoden der genetischen Manipulation von $T$. gondii, wobei die zufällige nicht-homologe Rekombination dazu ausgenutzt werden kann, das komplette Genom des Parasiten in einer einzigen Transfektion zu markieren (Donald \& Roos, 1995; Roos et al., 1997). Durch geschickten Einsatz positiv/negativ selektierbarer Marker wurde eine sogenannte ,Hit and Run' Mutagenese etabliert, die es erlaubt, eine Gendisruption an Genloki einzufügen, für die kein Selektionsschema vorhanden ist (Donald \& Roos, 1998). Dies wiederum kann auch dazu verwendet werden, Genmutationen in Toxoplasma durch Transfektion eines kompletten Genoms zu komplementieren und anschließend die komplementierende Sequenz zu analysieren (Striepen et al., 2002).

\subsection{Stadienkonversion von Tachyzoiten zu Bradyzoiten in vitro}

Durch die Zugänglichkeit von $T$. gondii gegenüber molekulargenetischen Untersuchungsmethoden und der Etablierung eines Systems zur Induktion der Stadienkonversion in vitro, kann nun auch dieser für die Pathogenität des Parasiten so wichtige Teil seines Lebenszyklus genauer untersucht werden.

Vor der Entwicklung molekularer Marker durch stadienspezifische Antikörper wurden Tachyzoiten und Bradyzoiten allein durch ihre Unterschiede in Ultrastruktur, Säureresistenz und der Fähigkeit, Oozystenbildung in Katzen zu induzieren, definiert (Dubey et al., 1998). Erst 1983 wurde durch Lunde \& Jacobs bewiesen, dass auch Unterschiede in der Antigenizität zwischen Tachyzoiten und Bradyzoiten existieren, und dass diese durch polyklonale Antiseren erkannt werden können. Aber erst durch die Entwicklung eines Zellkulturmodells zur Induktion der Stadienkonversion in vitro wurden die Untersuchungen über die Unterschiede zwischen Tachyzoiten und Bradyzoiten weiter vorangetrieben.

In einer Tachyzoitenpopulation exprimiert immer ein geringer Prozentsatz, abhängig vom untersuchten Toxoplasma Stamm, spontan bradyzoitspezifische Proteine, so dass ein geringer Anteil spontaner Stadienkonversion stattzufinden scheint (Lindsay et al., 1991; Soete et al., 1993). Um den Anteil der Bradyzoiten in einer Tachyzoitenkultur zu erhöhen, können verschiedene Arten von Stress appliziert werden. Durch 
eine Aktivierung von Mausmakrophagen mit IFN- $\gamma$ kann die Expression bradyzoitspezifischer Proteine induziert werden (Bohne et al., 1993). Dies konnte auf eine Freisetzung von NO aus aktivierten Makrophagen zurückgeführt werden, welches mit Eisen-Schwefel Zentren in Proteinen interagiert und dadurch Proteine der mitochondrialen Atmungskette inhibiert. Eine externe Quelle von NO in Form von Natriumnitroprussiat (SNP) zeigt den gleichen Effekt auf die Stadienkonversion wie eine Aktivierung der Makrophagen durch IFN- $\gamma$, wobei ein Zusammenhang zwischen reduzierter Wachstumsrate und Bradyzoiteninduktion besteht (Bohne et al., 1994). In Fibroblasten führt IFN- $\gamma$ auch zu einer Reduzierung des Wachstums, allerdings zu keiner Induktion der Stadienkonversion (Pfefferkorn \& Guyre, 1984; Gross \& Bohne, 1994). Dies ist auf einen anderen Wirkungsmechanismus des IFN- $\gamma$ in Makrophagen und Fibroblasten zurückzuführen: während Makrophagen zur NO-Freisetzung stimuliert werden, bewirkt IFN- $\gamma$ in Fibroblasten eine Reduktion der Konzentration des intrazellulären Tryptophans, das Toxoplasma zum Überleben innerhalb der Zelle benötigt (Pfefferkorn et al., 1986). Durch SNP kann deshalb auch in Fibroblasten eine Stadienkonversion induziert werden. Eine Bestätigung für die Wirkung von NO auf die Mitochondrien des Parasiten liefern mitochondriale Inhibitoren, wie Oligomycin oder Antimycin A, die ebenfalls eine Stadienkonversion induzieren können (Gross \& Bohne, 1994; Bohne et al., 1994; Tomavo \& Boothroyd, 1995).

Andere Stressfaktoren, wie eine Erhöhung oder Erniedrigung des $\mathrm{pH}-$ Wertes $(\mathrm{pH} 8$ oder pH 6.8) des Zellkulturmediums, Hitzeschock durch Erhöhung der Inkubationstemperatur auf $43{ }^{\circ} \mathrm{C}$, oder Zugabe von Interleukin-6 führen alle zu einer Induktion der Differenzierung zum Bradyzoiten (Soete et al., 1994; Weiss et al., 1995). Ebenso Chemikalien wie Pyrimethamin, ein Inhibitor der Dihydrofolat Reduktase, oder Natriumarsenit (Gross et al., 1996; Soete et al., 1994).

Die Fähigkeit, Stadienkonversion als Antwort auf eine große Anzahl verschiedener äußerer Faktoren zu induzieren deutet darauf hin, dass $T$. gondii hierfür mehrere unabhängige Wege zur Verfügung stehen. Alle Methoden, in vitro Differenzierung auszulösen (s. Abb. 2), zeigen auch eine gewisse Toxizität der Wirtszelle gegenüber, so dass die Dauer solcher Versuche auf einige Tage limitiert ist. Außerdem scheinen sich in vitro induzierte Bradyzoiten zu einem gewissen Teil von aus der Maus isolierten Bradyzoiten zu unterscheiden, da Bradyzoitenmarker wie P21 (Tomavo et al., 1991) in vitro nur sehr spät auftreten und in manchen Untersuchungen gar nicht 
gefunden wurden. Aus diesem Grund ist die Verfügbarkeit in vitro induzierter Bradyzoiten zwar eine Große Hilfe beim Studium der Stadienkonversion, doch müssen die auf diese Weise erhaltenen Ergebnisse nicht unbedingt auch für in vivo auftretende Parasiten zutreffen. Die Schlüsselgene für die Entwicklung von Bradyzoiten wurden bisher noch nicht entdeckt, ein Hinweis könnte allerdings aus dem möglichen Zusammenhang zwischen einer Reduzierung der Replikationsrate und der Induktion der Bradyzoitenentwicklung hervorgehen, der von einigen Autoren beschrieben wurde.

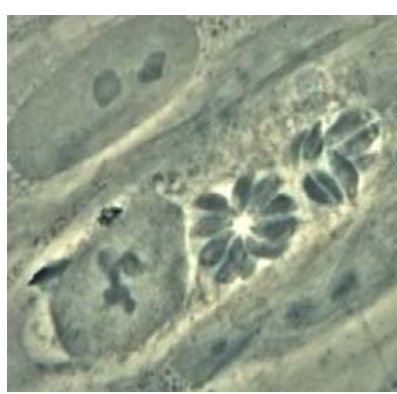

Tachyzoiten

\section{chronische Infektion}

Inhibierung der Mitochondrien extrazelluläre Inkubation hoher/ niedriger $\mathrm{pH}$ Hitzeschock NO

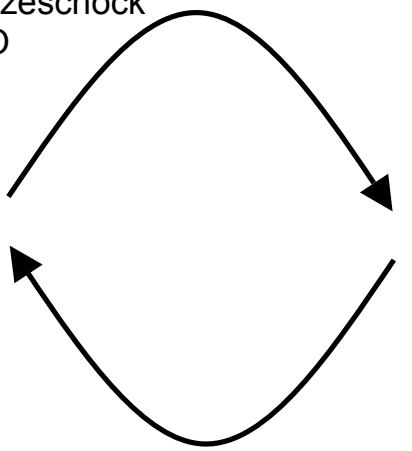

Reaktivierung

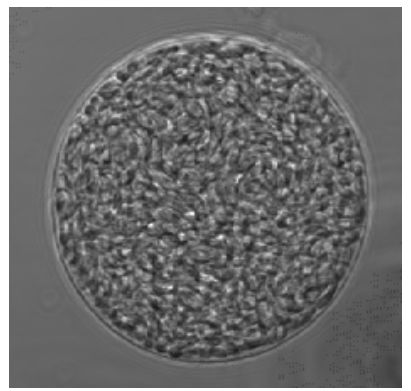

Bradyzoiten/ Zyste

Abb. 2. Die Stadienkonversion von Tachyzoiten zu Bradyzoiten ist ein reversibler Prozess, der als Antwort des Parasiten auf diverse Arten an Stress ausgelöst werden kann. Durch die einhergehende Zystenbildung wird eine chronische Infektion hervorgerufen. Eine Reaktivierung mit Stadienkonversion in umgekehrter Richtung läuft spontan bei Fehlen solch eines Stresses ab, wie bei einer Immunsuppression.

Links: Tachyzoiten mit typischer Rosettenbildung nach der Teilung in ihrer Wirtszelle. Rechts: Zyste aus dem Gehirn einer chronisch infizierten Maus mit Hunderten von Bradyzoiten in ihrem Inneren. Die begrenzende Zystenwand ist deutlich zu erkennen.

\subsection{Molekulare Unterschiede zwischen Tachyzoiten und Brady- zoiten}

Während der Stadienkonversion differentiell exprimierte Proteine lassen sich in drei Klassen unterteilen: Oberflächenstrukturen, Stressantwort und Metabolismus. 


\subsubsection{Differentielle Expression von Oberflächenproteinen}

Die Oberfläche des Parasiten ist bedeckt von einer Familie GPI-verankerter Oberflächenmoleküle, die gemeinsame strukturelle Merkmale und wahrscheinlich ähnliche Sekundär- und Tertiärstrukturen aufweisen. Die ersten Oberflächenmoleküle (SAG14) wurden durch Immunoscreening von cDNA Expressionsbibliotheken kloniert (Boothroyd et al., 1998). SAG1 ist das Hauptoberflächenantigen von Tachyzoiten, ein immundominantes Molekül, das eine starke humorale Immunantwort auslöst (Burg et al., 1988). SRS1 (SAG-related sequence 1), ein Gen mit Homologie zu SAG1 konnte in der genomischen Region direkt 5' des SAG1 Gens gefunden werden (Hehl et al., 1997b). Eine Analyse der Expressed Sequence Tag (EST) Datenbank (s. unten) führte zur Identifizierung vier weiterer SRS Gene (Manger et al., 1998a). Ein weiteres Oberflächenantigen von Bradyzoiten, das bereits zuvor mit Hilfe eines monoklonalen Antikörpers beschrieben worden war, wurde dabei mit BSR4 (= P36) identifiziert (Tomavo et al., 1991; Knoll \& Boothroyd, 1998a). Weitere Homologe zu SAG1 wurden mit den drei im Genom in tandem angeordneten Genen SAG5A-C entdeckt (Spano et al., 2002). Des weiteren existieren auch mehrere Homologe zu SAG2, wie der Fund von SAG2B-D beweist (Lekutis et al., 2000).

Von den Genen her zu schließen, deren Expression bisher auf Stadienspezifität überprüft wurde, scheint die Oberfläche des Parasiten während der Stadienkonversion eine drastische Modifizierung zu durchlaufen. Die Hauptoberflächenproteine SAG1, SAG2 und SAG2B verschwinden während der Differenzierung zum Bradyzoiten von der Oberfläche des Parasiten, während einige neue zu SAG1 und SAG2 homologe Gene, einschließlich SAG4, BSR4, SAG2C und SAG2D induziert werden (Bohne et al., 1999; Lekutis et al., 2000). Die Induktion von SAG1 während der Konversion vom Bradyzoiten zum Tachyzoiten findet schnell statt und beginnt innerhalb von 12- 24 Stunden nach Invasion der Bradyzoiten in ihre Wirtszellen (Bohne et al., 1993; Soete et al., 1993). Die biologische Funktion einer Änderung in der Zusammensetzung der Oberflächenmoleküle ist noch unklar. Eine Hypothese ist, dass Tachyzoiten eine starke Immunantwort als eine Art selbstlimitierenden Schritt für die Replikation auslösen, um ein Ableben des Wirtes während der akuten Infektion zu vermeiden, bevor Zystenbildung stattfindet (Knoll \& Boothroyd, 1998b). Die sich entwickelnden Bradyzoiten vermeiden dann einen Angriff durch das Immun- 
system, indem sie ihre Oberfläche verändern. Allerdings wird das Bild etwas komplizierter, da manche Oberflächenmoleküle wie SAG3 in beiden Stadien exprimiert werden.

\subsubsection{Stressantwort während der Stadienkonversion}

Differentielle Expression von Hitzeschockproteinen, insbesondere kleinen Hitzeschockproteinen (sHSPs) während Entwicklungsprozessen wurde in einer Vielzahl an Organismen beobachtet (Lindquist \& Craig, 1988). BAG1 ist ein kleines Hitzeschockprotein aus $T$. gondii, das größte Ähnlichkeiten mit sHSPs aus Pflanzen aufweist und wird deshalb auch als HSP-30 bezeichnet (Bohne et al., 1995; Parmley et al., 1995). Das Protein wird stadienspezifisch im Zytosol von Bradyzoiten exprimiert. BAG1 wird auf mRNA Ebene reguliert und stellt eines der am stärksten exprimierten Gene in Bradyzoiten dar. Trotzdem konnte durch eine BAG1 Gendeletionsmutante gezeigt werden, dass das Protein weder für die Stadienkonversion vom Tachyzoiten zum Bradyzoiten, noch für die Etablierung einer neuen Infektion nach oraler Aufnahme von Zysten notwendig ist (Bohne et al., 1998). Allerdings weist diese Mutante eine reduzierte Fähigkeit zur Zystenbildung im Gehirn von Mäusen auf (Zhang et al., 1999).

Ein T. gondii Homologes zu HSP-70 wird während der Stadienkonversion in vitro induziert (Weiss et al., 1998). Dieses Protein kann nur während einer kurzen Zeit im Verlauf der Differenzierung nachgewiesen werden, wogegen voll ausdifferenzierte Tachyzoiten und Bradyzoiten keine, oder nur sehr schwache Expression von HSP70 zeigen (Silva et al., 1998). Diese Ergebnisse lassen vermuten, dass HSP-70 Expression in $T$. gondii primär während der Konversion des Parasiten induziert wird. Hitzeschockprotein HSP-60, welches in anderen Eukaryonten eine Funktion als Chaperone für die Faltung mitochondrieller Proteine innehat, wird in T. gondii Bradyzoiten hochreguliert, obwohl Transkripte auch in Tachyzoiten nachgewiesen werden können. Durch differentielles Spleißen entstehen zwei Transkripte, die beide sowohl in Tachyzoiten, als auch in Bradyzoiten vorhanden sind, ebenso wie die entsprechenden Proteine. Allerdings ist inre Lokalisation innerhalb des Parasiten verschieden: während HSP-60 in Tachyzoiten innerhalb des Mitochondriums nachgewiesen werden konnte, scheint es in Bradyzoiten außerhalb des Mitochondriums in nicht näher bestimmten Vesikeln lokalisiert zu sein (Toursel et al., 2000). 
Ein DNA-Reparaturenzym (TgDRE) wird in Tachyzoiten exprimiert. Die mRNA dieses Gens lässt sich zwar auch in Bradyzoiten finden, nicht aber das Protein. Durch heterologe Expression dieses Enzyms in E. coli Mutanten wurden diese resistenter gegen DNA-Schäden wie UV-Licht und Mitomycin C (Dendouga et al., 2002). Das Auftreten stadienspezifischer DNA-Reparaturenzyme könnte eine Erklärung für die verlangsamte Replikationsrate von Bradyzoiten sein. Die zelluläre Stressantwort, die mit der Stadienkonversion verbunden ist, könnte ein Indikator von DNA Schäden im Bradyzoitenstadium sein, ähnlich wie in anderen eukaryontischen Zellen (Nasmyth, 1996). Verstärktes Auftreten von DNA Schäden und deren Reparatur kann daraufhin die Replikation und das Eintreten in die Mitose stark verzögern (Yahiaoui et al., 1999).

Ein weiterer Fund der zeigt, dass Stadienkonversion als Folge einer Stressantwort auftreten kann, ist eine Verbindung zu zyklischen Nukleotiden. Signaltransduktion durch zyklische Nukleotide (cAMP) ist in anderen Organismen, wie Saccharomyces cerevisiae und Plasmodium falciparum an Differenzierungsvorgängen beteiligt, die im Falle der Hefe mit Stress in Verbindung gebracht werden. Es konnte gezeigt werden, dass eine Erhöhung der cAMP und möglicherweise der cGMP Konzentration in Tachyzoiten Stadienkonversion auslösen kann, und dass wahrscheinlich auch eine Erhöhung der cAMP und cGMP Konzentrationen der Wirtszelle Stadienkonversion des Parasiten auslösen kann (Kirkman et al., 2001).

\subsubsection{Unterschiedlicher Metabolismus von Tachyzoiten und Bradyzoiten}

Mehrere Hinweise deuten darauf hin, dass Glykolyse, und nicht oxidative Phosphorylierung den hauptsächlichen Weg der Energiegewinnung in Bradyzoiten darstellt: Ein Vergleich der Aktivitäten verschiedener glykolytischer Enzyme verriet, dass die Aktivitäten von Pyruvat Kinase und Lactat Dehydrogenase in Bradyzoiten höher sind als in Tachyzoiten (Denton et al., 1996). Dies deutet darauf hin, dass Glykolyse, die zur Produktion von Lactat führt, der hauptsächliche Weg der Energiegewinnung von Bradyzoiten ist. Dagegen wurden Aktivitäten von Succinat Dehydrogenase und Isocitrat Dehydrogenase, zwei mitochondrialen Enzymen aus dem Tricarbonsäure Zyklus, in Tachyzoiten detektiert, aber nicht in Bradyzoiten. Zusammen mit der Lokalisation von HSP-60 außerhalb der Mitochondrien in Bradyzoiten (Toursel et al., 2000) deutet dies darauf hin, dass die Mitochondrien in Bradyzoiten nicht funktionell sind. 
Ein direkter Hinweis, dass Tachyzoiten und Bradyzoiten sich im Gebrauch der Glykolyse unterscheiden, kommt von der Klonierung einiger Gene, die für stadienspezifische Isoformen glykolytischer Enzyme kodieren. Toxoplasma besitzt zwei Isoenzyme der Lactat Dehydrogenase, LDH1 und LDH2, die in 71\% inrer Aminosäuren identisch sind (Yang \& Parmley, 1997). LDH2 war eines der ersten bradyzoitspezifischen Gene, die identifiziert und durch Immunoscreening einer cDNA Bank aus Zysten mRNA isoliert wurden (Yang \& Parmley, 1995). Eine zweite Isoform, LDH1, wurde später aus einer Tachyzoiten cDNA Bibliothek kloniert (Yang \& Parmley, 1997). Während LDH2 mRNA nur in Bradyzoiten nachgewiesen wurde, ist LDH1 mRNA in beiden Stadien vorhanden. Das LDH1 Protein wird allerdings nur in Tachyzoiten exprimiert, wie durch 2D Gelelektrophorese gezeigt wurde, durch die die beiden Isoformen unterschieden werden konnten (Tomavo, 2001). In ihrer Enzymkinetik unterscheiden sich beide Isoformen allerdings kaum (Dando et al., 2001).

Neben Lactatdehydrogenase werden auch $\beta$-Enolase, das Enzym, das die Konvertierung von 2-Phosphoglycerat zu Phosphoenolpyruvat katalysiert, und Glucose-6Phosphat Isomerase, das Enzym für die Umwandlung von Fructose-6-Phosphat zu Glucose-6-Phosphat, in Form von stadienspezifischen Isoformen exprimiert. Zwei Isoformen von $\beta$-Enolase wurden in der EST Datenbank aus Tachyzoiten und Zysten mRNA identifiziert (Manger et al., 1998b). Aus einer substraktiven cDNA Bibliothek, in der cDNAs aus Bradyzoiten angereichert waren, wurde jeweils ein cDNA Fragment isoliert, das Homologien zu Enolasen, bzw. Glucose-6-Phosphat Isomerasen aufwies (Yahiaoui et al., 1999). Die kompletten cDNA Klone wurden über 5' und 3' RACE per PCR kloniert. Beide Enzyme weisen starke Ähnlichkeiten zu ihren Homologen aus $P$. falciparum und höheren Pflanzen auf. Über RT-PCR und Western Blot konnte gezeigt werden, dass die $\beta$-Enolase (ENO1) ausschließlich im Bradyzoitenstadium exprimiert wird (Dzierszinski et al., 1999). Glucose-6-Phosphat Isomerase (G6-PI) mRNA konnte in beiden Lebensstadien nachgewiesen werden, allerdings ist das Transkript im Zystenstadium ca. zehnfach hochreguliert. Das korrespondierende Protein konnte nur im Bradyzoitenstadium nachgewiesen werden, so dass eine translationelle Kontrolle der Genexpression vermutet wird (Dzierszinski et al., 1999). Ein cDNA-Klon einer tachyzoitspezifisch exprimierten Isoform der $\beta$ Enolase, ENO2, konnte später durch Sequenzinformation aus der EST-Datenbank (Manger et al., 1998b) über PCR und anschließende 5' und 3' RACE gewonnen werden. Auf Aminosäureebene zeigen die beiden Isoformen ENO1 und ENO2 74\% 
Identität (Dzierszinski et al., 2001). Beide Enzyme zeigen verschiedene enzymatische Aktivitäten: tachyzoitspezifische ENO2 hat eine dreifach erhöhte spezifische Aktivität bei $V_{\max }$, dafür ist ENO1 wesentlich thermostabiler. Dies ist in guter Übereinstimmung mit den metabolischen und physiologischen Adaptionen, die während der Differenzierung und Zystenbildung von $T$. gondii erforderlich sind. Während der Stadienkonversion in vivo wird der Wechsel in der Expression der Isoenzyme LDH1/ LDH2 und ENO1/ ENO2 bereits sehr früh induziert, zu einem Zeitpunkt, zu dem Bradyzoiten noch aktiv replizieren, so dass die differentielle Expression dieser Enzyme wahrscheinlich nicht nur aufgrund einer geringeren Anforderung des Metabolismus erfolgt. Während der frühen Entwicklungsstadien sind ENO1 und ENO2 vor allem im Nukleus von Bradyzoiten und Tachyzoiten lokalisiert, wogegen in ausdifferenzierten Bradyzoiten zusätzlich zur Lokalisierung im Nukleus auch eine zytoplasmatische Verteilung von ENO1 gefunden werden kann. LDH1 und LDH2 sind dagegen ausschließlich im Zytoplasma lokalisiert. Dies deutet darauf hin, dass die Enolasen zusätzlich zu ihrer Funktion als glykolytische Enzyme noch andere Aufgaben während der Entwicklung der Parasiten übernehmen (Ferguson et al., 2002). In anderen Organismen konnten homologen Enzymen bereits Funktionen als Hitzschockprotein, Plasminogenrezeptor, oder Komponenten des Zentrosoms nachgewiesen werden.

Ein weiteres Enzym, das in Form von stadienspezifischen Isoformen exprimiert wird, ist Phosphatidylinositol Synthase, welches für die Synthese eines essentiellen Phospholipids verantwortlich ist. Dieses spielt eine wichtige Rolle als Signalmolekül, in der Zellmembran und der Verankerung von Proteinen über einen GPI Anker (Tomavo, 2001). Zwei Gene konnten analog ENO1 und ENO2 identifiziert und kloniert werden (Yahioui et al., 1999; Séron et al., 2000). Die Expression der beiden Gene TgPIS1 und TgPIS2 wird auf mRNA Ebene reguliert. Eine Funktion der tachyzoitspezifischen Isoform TgPIS2 als Phosphatidylinositol Synthase konnte durch Komplementation einer entsprechenden Hefemutante nachgewiesen werden.

Das Auftreten stadienspezifischer Isoformen von Enzymen des Metabolismus lässt vermuten, dass Bradyzoiten sich in ihrem Metabolismus relativ stark von Tachyzoiten unterscheiden. Sie sind nicht auf funktionelle Mitochondrien angewiesen und eine selektive Hemmung der Mitochondrien des Parasiten führt zur Stadienkonversion (Bohne et al., 1994; Tomavo \& Boothroyd, 1995). Bradyzoiten scheinen verstärkt auf Glykolyse zur Energiegewinnung angewiesen zu sein, wodurch sich saure Metabolite 
wie Lactat im Zytosol anreichern. Über Transportprozesse in und aus dem Zystenstadium ist so gut wie nichts bekannt, obwohl sie sicherlich stattfinden. Die meisten Untersuchungen diesbezüglich sind bisher mit Tachyzoiten durchgeführt worden, da diese sich wesentlich einfacher in Zellkultur halten lassen. Eine Untersuchung von Bradyzoiten ist immer erschwert durch das gleichzeitige Auftreten von wesentlich schneller wachsenden Tachyzoiten in den Kulturen und die relativ rasche spontane Umwandlung von Bradyzoiten in der Zellkultur.

\subsection{Strategien zur Identifizierung von stadienspezifisch regulierten Genen}

Um das Verständnis des für den Parasiten essentiellen Mechanismus der Stadienkonversion voranzutreiben und neue Angriffspunkte für Medikamente gegen das Zystenstadium entwickeln zu können, wurden einige erfolgversprechende Strategien entwickelt, bradyzoitspezifisch exprimierte Gene zu identifizieren.

Erste Versuche machten sich die schon mehrfach beobachteten Unterschiede in der Antigenizität von Tachyzoiten und Bradyzoiten zu Nutze (Lunde \& Jacobs, 1983).

Mit monoklonalen Antikörpern wurde schon recht früh die stadienspezifische Expression von SAG1 (P30) und SAG2 (P22) auf der Oberfläche von Tachyzoiten bewiesen (Kasper et al., 1984; 1989). Ferner konnte mit Hilfe poly- und monoklonaler Antikörper aus Maus und Ratte eine Reihe zytoplasmatischer und Oberflächenantigene des Bradyzoitenstadiums identifiziert werden, einschließlich einiger Moleküle aus der Zyste. Eine anschließende molekulare Charakterisierung der Antigene gelang mit Hilfe mehrerer Strategien.

Das Oberflächenprotein SAG4 wurde durch einen spezifischen monoklonalen Antikörper durch Affinitätschromatographie isoliert, ansequenziert und mittels degenerierter Primer aus genomischer DNA amplifiziert (Ödberg-Ferragut et al., 1996).

Durch Screening von cDNA Expressionsbanken mit mono- und polyklonalen Antiseren konnten die bradyzoitspezifischen Gene MAG1 (Parmley et al., 1994), LDH2 (Yang \& Parmley, 1995) und BAG1 (Bohne et al., 1995; Parmley et al., 1995) kloniert werden. MAG1 ist ein $65 \mathrm{kDa}$ Zystenantigen, welches in der extrazellulären Matrix und zu einem geringeren Teil in der Wand von Zysten lokalisiert ist, wobei später eine Expression von sowohl mRNA, als auch des Proteins in der parasitophoren 
Vakuole von Tachyzoiten nachgewiesen werden konnte (Ferguson, 2002). Dadurch kann MAG1 nicht als bradyzoitspezifisch exprimiertes Gen angesehen werden, obgleich es anscheinend stadienspezifisch prozessiert wird, da in Western Blots verschiedene Bandengrößen im Tachyzoiten- und Bradyzoitenstadium festgestellt wurden.

Bohne et al. umgingen bei der Erstellung ihrer cDNA Expressionsbank aus in vitro induzierten Bradyzoiten die bei dieser Methode immer auftretende Tachyzoitenkontamination durch Anreicherung der Bradyzoiten. Hierbei wurden Bradyzoiten durch den bradyzoitspezifischen monoklonalen Antikörper 4F8 gebunden und anschließend durch magnetische Zellsortierung von Tachyzoiten getrennt.

Der Selektionsmarker HXGPRT, der für eine selektierte Inhibierung von entweder Tachyzoiten oder Bradyzoiten geeignet ist (Bohne \& Roos, 1997), wurde in einem ,Promoter Trap' Experiment dazu verwendet, den bradyzoitspezifischen Oberflächenmarker P36 (BSR4) zu isolieren. Dazu wurden Tachyzoiten mit einem DNAFragment transfiziert, das HXGPRT ohne Promoter trug. Anschließend wurden die Parasiten negativ selektioniert, um das Wachstum von HXGPRT-exprimierenden Tachyzoiten zu inhibieren. Anschließend wurde Stadienkonversion induziert und positiv für Bradyzoiten selektiert, die HXGPRT unter Kontrolle eines bradyzoitspezifischen Promoters im Genom integriert hatten. Mit Hilfe eines monoklonalen Antikörpers wurde ein Klon isoliert, der den bradyzoitspezifischen Oberflächenmarker P36 nicht exprimierte. Eine Analyse dieser Mutante zeigte, dass BSR4 für P36 kodiert (Knoll \& Boothroyd, 1998a).

Die Erstellung und Sequenzierung einer substraktiven cDNA Bank, die für bradyzoitspezifische Gene angereichert war, erlaubte die Klonierung einer ganzen Reihe an stadienspezifischen Genen (Yahiaoui et al., 1999). Auf diese Weise wurden cDNA Fragmente isoliert, deren dazugehörige Gene und stadienspezifische Expression später näher charakterisiert werden konnten. Unter anderem wurden so die bereits oben beschriebenen bradyzoitspezifisch exprimierten Gene für ENO1, G6-PI, Phosphatidylinositol Synthase und HSP-60 kloniert (Toursel et al., 2000; Tomavo, 2001).

In zwei Studien wurden bisher Differenzierungsmutanten auf genomischer Ebene mit Hilfe von Microarrays analysiert (Singh et al., 2002; Matrajt et al., 2002). In beiden Fällen wurden mit einem selektierbaren Marker transgene Parasiten, die einen selektionierbaren Marker (GFP oder HXGPRT) unter Stadienkonversion indu- 
zierenden Bedingungen exprimierten als Ausgangsstamm für eine Mutagenese (chemische oder Insertionsmutagenese) verwendet. Die so entstandenen klonierten Differenzierungsmutanten wurden anschließend mit dem Ausgangsstamm verglichen. Das Ergebnis der Microarrayuntersuchungen war jeweils, dass eine ganze Reihe bradyzoitspezifischer Gene in den Differenzierungsmutanten nicht mehr so stark induziert wurden, wogegen andere, ebenfalls bradyzoitspezifische Gene nicht betroffen waren. Ein Nachteil beider Studien war, dass zufällig mutagenisierte Parasiten verwendet wurden, bei denen die beobachtete Reduzierung der Stadienkonversion auf keinen bestimmten Gendefekt zurückgeführt werden konnte.

Die Identifizierung der in diesen und anderen Studien beobachteten stadienspezifischen Gene wurde erst durch ein großangelegtes EST-Datenbankprojekt ermöglicht (Wan et al., 1996; Ajioka et al., 1998; Manger et al., 1998b). Hierfür wurde cDNA aus Tachyzoiten und Bradyzoiten (in vitro differenziert und aus Mäusen isoliert) ansequenziert und zu überlappenden Clustern zusammengefasst. Auf diese Weise wurden 16067 ESTs generiert, die zu 6384 Clustern zusammengefasst werden konnten. Diese sind getrennt nach ihrer Herkunft aus Tachyzoiten, oder in vitro, bzw. in vivo gewonnenen Bradyzoiten in einer Datenbank aufgelistet, die unter folgender Internetadresse durchsucht werden kann:

http://paradb.cis.upenn.edu/toxo1/index.html. Die Anzahl der enthaltenen ESTs eines Clusters gibt erste Informationen über die Expressionsstärke des jeweiligen Gens in Tachyzoiten und Bradyzoiten. Auf diese Weise können leicht potentiell stadienspezifisch exprimierte Gene identifiziert werden, wobei allerdings das Expressionsmuster anschließend noch verifiziert werden muss.

Mittels dieser Datenbank konnte unter anderem die Existenz von zwei Isoformen der Enolasen vorhergesagt werden, die später durch Klonierung der Gene bestätigt wurde (Manger et al., 1998b). Eine Suche nach ESTs mit Homologie zu SAG1 lieferte die Sequenzen von drei weiteren SRS Genen (SRS2, SRS3, SRS4). Nach Klonierung der ersten beiden dieser Gene konnte ihre Lokalisierung auf der Oberfläche von Tachyzoiten bestätigt werden (Hehl et al., 1997a; Manger et al., 1998b). Auch MIC2, ein Protein aus den Mikronemen wurde zuerst in der EST-Datenbank identifiziert und anschließend kloniert und näher charakterisiert (Wan et al., 1997).

Die EST-Datenbank stellt also eine schnelle und effiziente Methode dar, erste Informationen über die Expression etlicher Gene in den verschiedenen Lebensstadien von T. gondii zu gewinnen. Bei einer Suche nach bisher unbekannten bradyzoit- 
spezifisch exprimierten Genen in der EST-Datenbank konnten die zwei ESTs Ctoxqual2_361 und EST \#607688 (mittlerweile umbenannt in EST Ctoxoqual4_5284 und EST \#1435326) identifiziert werden, die starke Ähnlichkeit zu P-Typ Plasmamembran Protonen ATPasen aufwiesen. Über P-Typ Protonen ATPasen in Protozoen war zu diesem Zeitpunkt noch nichts bekannt und Transportprozesse in Bradyzoiten waren noch völlig unerforscht. Dies machte dieses Gen zu einem geeigneten Ziel näherer Untersuchungen.

\subsection{Ziele der Arbeit}

Eine reaktivierte Toxoplasmose stellt die häufigste opportunistische Infektion des Zentralnervensystems in AIDS Patienten dar. Die chronische Infektion ist verbunden mit einer Differenzierung des Parasiten in das Bradyzoitenstadium und einer Zystenbildung, wodurch $T$. gondii bis zum Ableben seines Wirtes überdauern kann. Bisher ist keine Behandlung in der Lage, das Zystenstadium erfolgreich zu eliminieren, so dass die Gefahr einer Reaktivierung ständig bestehen bleibt.

Die Identifizierung eines Gens mit Homologie zu P-Typ Protonen ATPasen und möglicher stadienspezifischer Expression in Bradyzoiten eröffnete neue Möglichkeiten, das Verständnis dieses Lebensstadiums des Parasiten zu vergrößern und Angriffspunkte für neue Medikamente zu erschließen.

P-Typ Protonen ATPasen wurden zu Beginn dieser Arbeit nur in Pflanzen und Pilzen beschrieben und kommen in tierischen Zellen nicht vor. Sie gehören zu einer extensiv untersuchten Klasse von Transportproteinen, deren Hauptaufgabe darin besteht, einen Protonengradienten über der Plasmamembran aufrecht zu erhalten. Dieser dient als treibende Kraft für sekundäre Transportprozesse und ist essentiell für die Nährstoffaufnahme der Zelle, konnte aber auch mit der Aufrechterhaltung des intrazellulären $\mathrm{pH}$ Wertes bei der Anpassung an niedrigen äußeren $\mathrm{pH}$ in Verbindung gebracht werden.

Ziel dieser Arbeit war es, die Funktion der P-Typ Protonen ATPase TgPMA1 für die Stadienkonversion von $T$. gondii zu charakterisieren. Hierzu sollten zunächst die Lokalisierung und Kinetik der Expression untersucht werden. 
Durch Disruption des Gens sollte eine Gendeletionsmutante generiert werden, mit deren Hilfe die mögliche Funktion von TgPMA1 bei der Stadienkonversion des Parasiten durch in vitro und in vivo Studien analysiert werden sollte. 


\section{Material und Methoden}

\subsection{Material}

\subsubsection{Geräte}

Brutschränke

Electro Cell Manipulator

Fluoreszenzmikroskop

Geldokumentationsanlage

Gelelektrophoresekammern für

Agarosegele

Gelelektrophoresekammern für PAGE Gradi-Frac für Proteinaufreinigung Hybridisierungsofen

Konfokales Laserscan -

mikroskop

Lightcycler

Magnetrührer

Mikrotiterschüttelplatte

PCR-Thermocycler

$\mathrm{pH}-$ Meter

Pipetten

Pipettierhilfe

Phosphoimager

Photometer

Reagenzglasschüttler

Schüttelinkubator

Semi-Dry Blotter

Spannungsgeräte
Heraeus, Hanau

Typ 600, BTX, Holliston, MA, USA

Modell DM R, Leica, Heidelberg

BioDoc II, Biometra, Göttingen

von Keutz Labortechnik, Reiskirchen

Modell Mini Protean II, BioRad, München

Pharmacia, Peapack, NJ, USA

Modell OV5, Biometra, Göttingen

Modell TCS SP2, Leica, Heidelberg

Roche, Basel, Schweiz

RCT basic, IKA Labortechnik, Staufen

Modell MTS 4, IKA Labortechnik, Staufen

Modell T3, Biometra, Göttingen

Modell 766 Calimatic, Knick, Berlin

Modell Research, Eppendorf, Hamburg

Modell Reference, Eppendorf, Hamburg

Hirschmann Laborgeräte, Eberstadt

Molecular Imager FX, Bio-Rad, Hercules,

CA, USA

Ultraspec 1000, Pharmacia Biotech,

Freiburg

Reax Top, Heidolph, Kelheim

SM-30 Control, Johanna Otto $\mathrm{GmbH}$, Hechingen

Sartorius, Göttingen

EPS 600, Pharmacia Biotech, Freiburg 
Standard Power Pack P25, Biometra, Göttingen

Sterilbank

BDK-S 1800, BDK Luft- und Reinraum-

Technik, Sonnenbühl

Thermocycler

Modell T3, Biometra, Göttingen

Thermomixer

Modell Compact, Eppendorf, Hamburg

Überkopfschüttler

Renner GmbH, Dannstadt

UV-Tisch

TFX-20M, Gibco BRL, Eggenstein

UV-Crosslinker

UVC-500, Hoefer, San Francisco, CA, USA

Vortexer

Reax Top, Heidolph, Kelheim

Waagen

BP 221 S, Sartorius, Göttingen

Wasserbad

LP 6200 S, Sartorius, Göttingen

Zellkulturmikroskop

GFL, Burgwedel

Zentrifugen

Modell DM IL, Leica, Heidelberg

Megafuge 2.0 RS, Heraeus, Hanau

Megafuge 2.0, Heraeus, Hanau

Modell 5417 R, Eppendorf, Hamburg

Modell 5417 C, Eppendorf, Hamburg

RC-26 Plus, Sorvall-Kendro, Hanau

\subsubsection{Medien und Verbrauchsmaterialien für die Zellkultur}

\subsubsection{Medien und deren Zusätze}

Roswell Park Memorial Institute (RPMI) 1640 Medium mit 300 mg/ I L-Glutamin und $2 \mathrm{~g} / \mathrm{I} \mathrm{NaHCO} 3$

Dulbecco's MEM (DMEM) Medium mit $580 \mathrm{mg} / \mathrm{I} \mathrm{L-Glutamin} \mathrm{und} \mathrm{3,7} \mathrm{g/} \mathrm{I} \mathrm{NaHCO}_{3}$

DMEM Medium (10x) mit 4,5 g/ I D-Glucose, 8 mg/ I Phenol Rot, ohne $\mathrm{NaHCO}_{3}$, NaPyruvat, L-Glutamin

Penicillin / Streptomycin (Pen-Strep), $10.000 \mathrm{U} / 10.000 \mu \mathrm{g} / \mathrm{ml}$

Fötales Kälberserum (FCS); inaktiviert durch 45 min Inkubation bei $56{ }^{\circ} \mathrm{C}$

EDTA (Versen) $1 \%$ in PBS ohne $\mathrm{Ca}^{2+}, \mathrm{Mg}^{2+}$

Trypsin (1:250) $0,25 \%$ in PBS ohne $\mathrm{Ca}^{2+}, \mathrm{Mg}^{2+}$

HEPES, $1 \mathrm{M}$ 
L-Glutamin, $200 \mathrm{mM}$

$\mathrm{NaHCO}_{3} 7,5 \%$ in PBS

PBS (phosphate buffered saline)

Alle Medien und Zusätze wurden von Biochrom, Berlin bezogen.

\subsubsection{Verbrauchsmaterialien für die Zellkultur}

Verbrauchsmaterialien für die Zellkultur wurden von folgenden Firmen bezogen: Nunc, Roskilde, Dänemark; Falcon, Becton-Dickinson, Heidelberg; Corning / Costar, Bodenheim; Greiner, Frickenhausen; Braun, Braun-Melsungen, Melsungen.

\subsubsection{Zelllinien (Wirtszellen, T. gondii Stämme, E. coli Linien)}

Humane Vorhaut-Fibroblasten (Human foreskin fibroblasts, HFF)

T. gondii Stämme:

Prugniaud/ $\mathrm{HX}^{-}$(D. Soldati)

Me49

$\mathrm{RH} / \mathrm{HX}^{-}$(Pfefferkorn \& Borotz, 1994)

E. coli Stämme:

$\mathrm{DH} 5 \alpha$

TOP10 (Stratagene, La Jolla, CA, USA)

M15[pREP4] (Qiagen, Hilden)

\subsubsection{Puffer für die Bakterienkultur}

$$
\begin{gathered}
\text { Luria Broth (LB) } \\
1 \% \text { Bacto-Trypton } \\
0,5 \% \text { Bacto-Hefeextrakt } \\
0,5 \% \mathrm{NaCl}
\end{gathered}
$$

\author{
LB-Platten (ca. $15 \mathrm{ml}$ pro Schale) \\ 0,5\% Bacto-Hefeextrakt \\ 0,1\% Bacto-Trypton \\ $1 \% \mathrm{NaCl}$ \\ 1,5\% Agar (Difco, Detroit, USA) \\ Ampicillin $(100 \mu \mathrm{g} / \mathrm{ml})$ oder \\ Tetracyclin $(20 \mu \mathrm{g} / \mathrm{ml})$
}




\subsubsection{Chemikalien und Reagenzien}

Die verwendeten Chemikalien und Lösungsmittel wurden, soweit im Text nicht anders erwähnt, von den Firmen Boehringer (Mannheim), Merck (Darmstadt), Roth (Karlsruhe), Calbiochem (Bad Soden), oder Sigma-Aldrich (Deisenhofen) bezogen. Lösungen wurden generell mit doppelt destilliertem Wasser angesetzt.

\subsubsection{Antikörper}

Kaninchen-anti-Toxoplasma, Serum ( $p$ )

Maus-anti-His-Tag IgG (m); Qiagen, Hilden

Cy2-konjugiertes Esel-anti-Ratte IgG, $\mathrm{F}\left(\mathrm{ab} \mathrm{b}_{2}\right)_{2}$-Fragment; Dianova, Hamburg Cy2-konjugiertes Esel-anti-Maus IgG, $\mathrm{F}\left(\mathrm{ab}{ }^{\prime}\right)_{2}$-Fragment; Dianova, Hamburg DTAF-konjugiertes Esel-anti-Maus IgG, $F\left(a b^{\prime}\right)_{2}$-Fragment; Dianova, Hamburg DTAF-konjugiertes Esel-anti-Kaninchen IgG, $F\left(a b^{\prime}\right)_{2}$-Fragment; Dianova, Hamburg Cy3-konjugiertes Esel-anti-Kaninchen IgG, $\mathrm{F}\left(\mathrm{ab}{ }^{\prime}\right)_{2}$-Fragment; Dianova, Hamburg Cy3-konjugiertes Esel-anti-Maus IgG, $\mathrm{F}\left(\mathrm{ab}^{\prime}\right)_{2}$-Fragment ; Dianova, Hamburg AP-konjugiertes Schaf-anti-Digoxigenin IgG, $\mathrm{F}\left(\mathrm{ab}^{\prime}\right)_{2}$-Fragment ; Roche, Mannheim AP-konjugiertes Ziege-anti-Maus IgG; Dianova, Hamburg

POX-konjugiertes Ziege-anti-Kaninchen IgG; Dianova, Hamburg

(p): polyklonal

(m): monoklonal

AP: Alkalische Phosphatase

Cy2: Carbocyanin

Cy3: Indocarbocyanin

DTAF: Diaminotriazinylaminofluorescein

POX: Meerrettich Peroxidase

\subsubsection{Filter}

Falcon Cell Strainer, $70 \mu \mathrm{m}$ Nylon

Corning Bottle Top Filter, 0,22 $\mu \mathrm{m}$ CA (Cellulose Acetate)

Corning $26 \mathrm{~mm}$ Syringe Filter, 0,20 $\mu \mathrm{m}$ Micron Membran, 0,45 $\mu \mathrm{m}$ Micron Membran 


\subsubsection{Enzyme}

T4 DNA Ligase

Quick Ligase

Proteinase $\mathrm{K}$

Pfu DNA-Polymerase

Taq DNA-Polymerase

Restriktionsendonukleasen

Shrimp Alkalische Posphatase

RNase A

Pepsin
New England Biolabs, Schwalbach

New England Biolabs, Schwalbach

Roth, Karlsruhe

Promega, Mannheim

Roche, Mannheim

New England Biolabs, Schwalbach

Boehringer Mannheim

Sigma-Aldrich, Deisenhofen

Sigma-Aldrich, Deisenhofen

\subsubsection{Reaktionssets (“Kits”) und Reagenzien zur Isolierung und Bearbeitung von Nukleinsäuren}

\section{RNA Isolation}

Qiashredder

RNeasy Mini Kit

RNase freie DNase

RNase free DNase Set

\section{Reverse Transkription}

Omniscript reverse transcriptase

RNase Inhibitor

\section{Plasmid-DNA Isolation}

QIAprep Spin Miniprep Kit

QIAGEN Plasmid Kits

\section{DNA Isolation aus Agarose Gelen}

QIAEX II Gel Extraction Kit

\section{DNA Fällung}

QIAquick PCR Purification Kit

gDNA Isolation

QiaAmp DNA Mini Kit

Protein-His Tag Expression+ Aufreinigung

QIAexpress
Qiagen, Hilden

Qiagen, Hilden

Promega, Mannheim

Qiagen, Hilden

Qiagen, Hilden

Promega, Mannheim

Qiagen, Hilden

Qiagen, Hilden

Qiagen, Hilden

Qiagen, Hilden

Qiagen, Hilden

Qiagen, Hilden 


\section{Proteinkonzentrationsbestimmung}

Pierce BCA Protein Assay Kit

Pierce, Rockford, IL, USA

\subsubsection{Molekulargewichtsmarker}

\section{DNA Standard}

100 bp-DNA Ladder

MBI Fermentas, St. Leon-Rot

$1 \mathrm{~kb}$ Ladder

MBI Fermentas, St. Leon-Rot

\section{Proteinstandard}

Prestained Protein Marker

New England Biolabs, Schwalbach

\subsubsection{Oligonukleotide}

\begin{tabular}{|l|l|}
\hline \multicolumn{1}{|c|}{ Name des Primers } & Sequenz 5'-3' \\
\hline 9-2/+ & 5'-TACTTATCGCTGTTCGACCCT-3' \\
\hline P-7/+ & 5'-CAGAGACGGTAACCGTAAACT-3' \\
\hline 9-P10/- & 5'-CTTGTAGAAGCCGATCTTGGT-3' \\
\hline P-11/- & 5'-CTCCATCACCTGTCATTGCTA-3' \\
\hline 9-P12/- & 5'-GAACAACGTCTCCTGGCACGA-3' \\
\hline 9-P15/+ & 5'-CAGAGTGTTCGAACACGAAGC-3' \\
\hline 9-20/- & 5'-ATCAAGGTAGAATCGCGGCTC-3' \\
\hline 9-21/- & 5'-GCGTCAGCAACACTTCGGATC-3' \\
\hline Intr/+ & 5'-TACACATGAACCACACCGCG-3' \\
\hline ATPase-3-Kpn/- & 5'-CGGGGTACCTCAACGCGTGATCGAAGGAACCGC-3' \\
\hline PM1-1785-Kpn/- & 5'-CGGGGTACCTCAATCGTTCACTCCATCACCTGT-3' \\
\hline PM1-1008-Bam/+ & 5'-CGCGGATCCAAGACGGGGACTTTGACGAAA-3' \\
\hline PM1-2608-Bam/+ & 5'-CGCGGATCCGCGTGGCCAGTGATAACACGA-3' \\
\hline PMAI5'Apa/+ & 5'-AAAGGGCCCATCTTCCATACCTACCAGTTC-3' \\
\hline PMAI5'Cla/- & 5'-AAAATCGATATGGTCGTCCCTTTGGTCAC-3' \\
\hline PMAI3'/+ & 5'-AAATCTAGATGCAGCTGTTTCTCGATTGTC-3' \\
\hline PMAI3'/- & 5'-AAAGAGCTCTACCGCATTGTGCCTTGTGAAAC-3' \\
\hline PM1-5'-2 & 5'-TCGGCTTCGTTGTTGATAAGGG-3' \\
\hline PMA1seq/+ & 5'-TTTTTTTTTTTTTTT-3' \\
\hline Oligo-dT & '-ACATGCCTTTTCATCTTCT-3' \\
\hline
\end{tabular}

Tabelle 1. Zur Klonierung und zum Nachweis von tgpma1 verwendete Primer. 


\begin{tabular}{|c|c|c|}
\hline $\begin{array}{l}\text { Name des } \\
\text { Primers }\end{array}$ & $\begin{array}{c}\text { nachgewiesenes } \\
\text { Gen }\end{array}$ & Sequenz \\
\hline TUB2/+ & $\beta$-tubulin & 5'-AGTCCAGCGTCTGTGACATCC-3' \\
\hline TUB2/- & $\beta$-tubulin & 5'-GCACCCATCTCGCCCTCTTCC-3' \\
\hline 7E5-2 & bag1 & 5'-GCACCCATCTCGCCCTCTTCC-3' \\
\hline 7E5-7 & bag1 & 5'-GCAAGTCAGCCAAAATAATCA-3' \\
\hline PM2-20/+ & tgpma2 & 5'-GACGGGACCGACTTTGGCATTTG-3' \\
\hline PM2-6/- & tgpma2 & 5'-GCTGTGGGCTTCGAGGTCTTC-3' \\
\hline 9-P13/+ & tgpma1 & 5'-CGTGATCATGCCAGCTGACGG-3' \\
\hline $9-3 /-$ & tgpma1 & 5'-CGTTCAGCTGCTCACGCAGTT-3' \\
\hline ENO2/+ & ENO1 & 5'-TTGGCGACCTGGGAGTGTTTTG-3' \\
\hline ENO2/- & ENO1 & 5'-TTCAGGTTTCCCATAGATCC-3' \\
\hline LDH2/+ & $L D H 2$ & 5'-TTCCACGGGACCCATTGTCAC-3' \\
\hline LDH2/- & $L D H 2$ & 5'-AGGCGGGCAGCACAGAAGGAGC-3' \\
\hline SRS9/+ & SRS9 & 5'ATGCGACGTAAATATGAAAATG-3' \\
\hline SRS9/- & SRS9 & 5'ATAACGAGGAATCAGCACCCTC-3' \\
\hline MAG1/+ & Mag1 & 5'-TTCTGTGTGCTAGACGTACTC-3' \\
\hline MAG1/- & Mag1 & 5'-GTGACTGCAACTTCCCGTGCC-3' \\
\hline Tgpis2-32S2/+ & $\begin{array}{l}\text { Phosphatidylinositol } \\
\text { Synthase } 1\end{array}$ & 5'-GGCGCTGCCGCACGCCGTCGTGGCCAAG-3' \\
\hline Tgpis1-3pisas4/- & $\begin{array}{l}\text { Phosphatidylinositol } \\
\text { Synthase } 1\end{array}$ & 5'-CGCTTCTGAGCATCATCGCG-3' \\
\hline Sag1/+ & Sag1 & 5'-CAGCCGCGGTCATTCTCACAC-3' \\
\hline Sag1/- & Sag1 & 5'-CCTGCCACGGGTTCTCACTTA-3' \\
\hline Sag2/+ & Sag2D & 5'-ACCATCAGTCCCAGTGGCGAAGGTGA-3' \\
\hline Sag2/- & Sag2D & 5'-ATTATTACGACCAGCGGGAGCAC-3' \\
\hline Sag4/+ & Sag4 & 5'-ATGTGATGCGGTTCGCTTGAAG-3' \\
\hline Sag4-b/- & Sag4 & 5'-TCTCTATCGAAACACTATCGC-3' \\
\hline met-pep/+ & MetAp2 & 5'-ATCCCGGAGACAATCGAGTGC-3' \\
\hline met-pep/- & MetAp2 & 5'-TTGCGGATGGACTTTATCGGC-3' \\
\hline TgVP1/+ & $\operatorname{TgVP1}$ & 5'-TAGCGCGATGACCATGAAGAG-3' \\
\hline TgVP1/- & $T g V P 1$ & 5'-TGTGTGCCTGAGAGCCCTTCC-3' \\
\hline Ctoxo1284/+ & ctoxoqual_1284 & 5'ATCCTGAGGAGCGCCTTTCTC-3' \\
\hline Ctoxo1284/- & ctoxoqual_1284 & 5'-TACCGTTCCTCCTGTAGCTTCC-3' \\
\hline Ctoxo2388/+ & ctoxoqual_2388 & 5'ATGAGTGACGCCGAGGATGTC-3' \\
\hline Ctoxo2388/- & ctoxoqual_2388 & 5'AATGCAACAACCGTTTCCGAC-3' \\
\hline Ctoxo3175/+ & MyoC & 5'ACGTCTCGTACTTGATTGGC-3' \\
\hline Ctoxo3175/- & MyoC & 5'-TTGTGATAAATCGTACACCTCC-3' \\
\hline
\end{tabular}




\begin{tabular}{|l|l|l|}
\hline $14-3-3 c /+$ & ctoxoqual_3690 & 5'-AAGAATCTGCGCGATGAATAC-3' \\
\hline 14-3-3c/- & ctoxoqual_3690 & 5'-ACAGAGTAGTTCAAGGCAAGG-3' \\
\hline Ctoxo3969/+ & ctoxoqual_3969 & 5'-ACTGTGAAATGAACGAGTGG-3' \\
\hline Ctoxo3969/- & ctoxoqual_3969 & 5'-ATGCACATGAAACCGAAAAGGGC-3' \\
\hline Ctoxo4101/+ & ctoxoqual_4101 & 5'-ATGGGGAACTGCTTTTTCACG-3' \\
\hline Ctoxo4101/- & ctoxoqual_4101 & 5'-AATGCAACGTGGACCACTCC-3' \\
\hline VEEb/+ & ctoxoqual_4131 & 5'-TAGCATAAAACTGGTGGCGAG-3' \\
\hline VEEb/- & ctoxoqual_4131 & 5'-AATGAAACTTGCACACGTAGC-3' \\
\hline DRPA/+ & ctoxoqual_4436 & 5'-TGCTGTGTTTGGTAGACACGG-3' \\
\hline DRPA/- & ctoxoqual_4436 & 5'-ATCGAATGCCTCATAGATTGG-3' \\
\hline
\end{tabular}

Tabelle 2. In der RT-PCR verwendete Primer zur Bestimmung der Expressionsstärke von Genen aus T. gondii

Alle Oligonukleotide wurden von Sigma ARK, Darmstadt bezogen. 


\subsection{Methoden}

\subsubsection{Zellkultur}

\subsubsection{Kultur und Passagierung der humanen Vorhaut Fibroblasten (HFFs)}

Als Wirtszelllinie zur Kultivierung der Parasiten wurden ausschließlich humane Vorhaut-Fibroblasten (human foreskin fibroblasts, HFF) verwendet. Diese wurden in $175 \mathrm{~cm}^{2}$ oder $25 \mathrm{~cm}^{2}$ Zellkulturflaschen in DMEM mit 10\% FCS, und $1 \% 100 \mathrm{U} / \mathrm{ml}$ Penicillin und $100 \mu \mathrm{g} / \mathrm{ml}$ Streptomycin (Pen-Strep) kultiviert. Nach spätestens 5 Wochen wurden sie zur Passagierung mit $5 \mathrm{ml}$ 1\% EDTA in PBS gespült und dann mit $5 \mathrm{ml} \mathrm{0,25 \%} \mathrm{Trypsin} \mathrm{in} \mathrm{PBS} \mathrm{inkubiert,} \mathrm{bis} \mathrm{sie} \mathrm{vollständig} \mathrm{vom} \mathrm{Untergrund} \mathrm{abgelöst}$ waren. Anschließend wurden sie in DMEM Medium mit 10\% FCS und 1\% Pen-Strep aufgenommen, auf neue Zellkulturflaschen verteilt und bei $37^{\circ} \mathrm{C}$ unter $5 \% \mathrm{CO}_{2^{-}}$ Zufuhr inkubiert.

\subsubsection{Kultur und Isolierung von T. gondii}

\subsection{Tachyzoiten}

T. gondii Tachyzoiten der maus-avirulenten Stämme Prugniaud/HX- (D. Soldati), ME49 und des maus-virulenten Stammes RH/HX' (Pfefferkorn \& Borotz, 1994) wurden in humanen Vorhaut Fibroblasten (human foreskin fibroblasts, HFF) als Wirtszellen vermehrt. Parasiten wurden auf $25 \mathrm{~cm}^{2}$ Zellkulturflaschen gegeben, die bereits konfluent mit HFFs bewachsen waren und in DMEM, supplementiert mit $1 \%$ hitzeinaktiviertem fötalem Kälberserum (FCS) und 1\% Pen-Strep, bei $37{ }^{\circ} \mathrm{C}$ und $5 \%$ $\mathrm{CO}_{2}$ inkubiert. Kurz vor der vollständigen Lyse der Wirtszellen wurden die Parasiten vom Stamm $\mathrm{RH} / \mathrm{HX}^{-}$auf frische Wirtszellen umgesetzt. Parasiten der avirulenten Stämme lysieren ihre Wirtszellen schlechter und mussten daher durch Abschaben des Zellrasens mit Zellschabern und mehrfacher Passage durch Kanülen $(\varnothing=0,9$ $\mathrm{mm}$ und $0,45 \mathrm{~mm}$ ) erst aus diesen befreit werden. 


\subsection{Bradyzoiten}

Für Versuche, in denen $T$. gondii Bradyzoiten benötigt wurden, konnten diese entweder aus chronisch infizierten Mäusen isoliert, oder in vitro aus Tachyzoiten differenziert werden. Ein Nachteil der in vitro gewonnenen Bradyzoiten ist, dass immer nur ein Teil der Parasiten sich zu Bradyzoiten differenzieren, während einige noch im Tachyzoitenstadium verweilen.

\section{in vivo}

Um eine reine Bradyzoitenpopulation zu erhalten, mussten diese in Form von Zysten aus den Gehirnen chronisch infizierter Mäuse isoliert werden. Mäuse des Stammes NMRI oder CBA/Ca waren hierzu etwa vier Wochen zuvor mit 10 bis 20 Zysten pro Maus i. p. infiziert worden. Die Mäuse wurden mittels zervikaler Dislokation getötet, die Gehirne steril in PBS aufgenommen und zwei mal mit PBS gewaschen. Anschließend wurde RPMI zugegeben, die Gehirne durch kräftiges Schütteln in Anwesenheit von Glaskügelchen ( $\varnothing=5 \mathrm{~mm}$ ) homogenisiert und die Suspension zehn mal durch Kanülen ( $\varnothing=0,9 \mathrm{~mm}$ und $0,6 \mathrm{~mm}$ ) gepresst.

Zysten haben eine höhere spezifische Dichte als Gehirngewebe und können mit Hilfe eines Dichtegradienten von diesem getrennt werden (Cornelissen et al., 1981). Dazu wurde Percoll mit 9 prozentigem $\mathrm{NaCl}$ im Verhältnis 9:1 gemischt und in einem $50 \mathrm{ml}$ Falconröhrchen ein Gradient bestehend aus vier Schichten Percoll/ $\mathrm{NaCl}$ zu RPMI in folgendem Verhältnis geschichtet: (i) 30:70; (ii) 25:75; (iii) 20:80; (iv) 15:85. Das homogenisierte Hirnmaterial wurde vorsichtig auf die oberste Schicht des Gradienten gegeben. Die Zentrifugation erfolgte ohne Rotorbremse für 25 min bei $2400 \mathrm{rpm}$. Unter diesen Bedingungen pelletieren die Zysten, wohingegen sich der größte Teil des Hirnhomogenats weiter oben auf dem Gradienten befindet. Nach vorsichtigem Absaugen des Gradienten bis auf etwa $1 \mathrm{ml}$ Restvolumen wurden die Zysten in dem verbleibenden Volumen resuspendiert und ein Aliquot zur Bestimmung der Ausbeute ausgezählt. Um das restliche Percoll zu entfernen, wurde die Zystensuspension mit $10 \mathrm{ml}$ RPMI bei $1360 \mathrm{rpm}$ für 5 min gewaschen.

Für Immunfluoreszenztests (IFT) oder Infektionsversuche mussten die Bradyzoiten zunächst von ihrer Zystenhülle befreit werden. Diese läßt sich leicht mit Pepsin oder Trypsin entfernen, wobei die freigesetzten Bradyzoiten eine Exposition diesen Enzymen gegenüber auch über relativ lange Zeiträume überstehen können (Jacobs 
et al., 1957). Hierzu wurde das Zystenpellet in $900 \mu \mathrm{l} 0,9 \% \mathrm{NaCl}, \mathrm{pH} 1,5$ aufgenommen und $100 \mu \mathrm{l}$ frisch angesetzte Pepsinlösung $(1 \mathrm{mg} / \mathrm{ml}$ in $0,9 \% \mathrm{NaCl}$, pH 1,5) hinzugegeben. Nach 2 min wurden 20 ml RPMI/ 10\% FCS hinzugefügt um das Pepsin zu inaktivieren, und die Bradyzoiten für $10 \mathrm{~min}$ bei $2000 \mathrm{rpm}$ pelletiert. Danach wurde das Pellet in DMEM aufgenommen und die Bradyzoitenzahl in der Neubauer-Zählkammer bestimmt.

\section{in vitro}

Zur Untersuchung der ersten Schritte der Stadienkonversion wurden Tachyzoiten in vitro zu Bradyzoiten differenziert. Die Stadienkonversion von Tachyzoiten läßt sich durch verschiedene Stressfaktoren induzieren, wie zum Beispiel durch Änderung des umgebenden $\mathrm{pH}$-Wertes, der Temperatur, der Zugabe von IFN- $\gamma$ bzw. NO, oder mitochondrialen Inhibitoren (Bohne et al., 1993/ 1994, Soête et al., 1994, Tomavo \& Boothroyd, 1995). Als verlässlichste Methode hat sich eine Alkalisierung des pHWertes erwiesen ( $\mathrm{pH}$-Shift), der standardmäßig zur Gewinnung von Bradyzoiten aus Zellkultur verwendet wurde.

Hierzu wurden konfluent wachsende humane Fibroblasten in 24-Napf Zellkulturschalen auf sterilen Glasplättchen (für eine spätere Untersuchung durch Immunfluoreszenz) oder $25 \mathrm{~cm}^{2}$ Zellkulturflaschen (zur Isolierung von RNA) mit Tachyzoiten in DMEM/ 1\% FCS/ $1 \%$ Pen-Strep infiziert und $3 \mathrm{~h}$ bei $37{ }^{\circ} \mathrm{C}$ in einem Zellkulturinkubator unter $\mathrm{CO}_{2}$-Begasung inkubiert. Hiernach waren die Parasiten in die Wirtszellen eingedrungen, der Überstand wurde abgesaugt und gegen vorgewärmtes pH-Shift Medium ersetzt. Die Kulturen wurden in einen Zellkulturinkubator ohne zusätzliche $\mathrm{CO}_{2}$-Begasung transferiert. Alle zwei Tage wurde das Medium abgesaugt, zwei mal mit pH-Shift Medium gewaschen um extrazelluläre Parasiten zu entfernen, und frisches Medium hinzugegeben. Nach der gewünschten Zeit (zwei, vier oder sechs Tage) konnten die Zellen entweder für Immunfluoreszenzfärbungen fixiert, oder für RNA-Gewinnung weiterbehandelt werden. 


\author{
pH-Shift Medium \\ $5 \mathrm{ml}$ DMEM ohne $\mathrm{NaHCO}_{3}, \mathrm{Na}-\mathrm{Pyruvat}$, L-Glutamin (Biochrom) \\ $5 \mathrm{ml} \mathrm{NaHCO} 3(7,5 \%)$ \\ $10 \mathrm{ml}$ Tricin $\left(1 \mathrm{M}, \mathrm{pH} 8,2\right.$ bei $\left.37^{\circ} \mathrm{C}\right)$ \\ $5 \mathrm{ml}$ Pen-Strep \\ $5 \%$ FCS \\ $5 \mathrm{ml}$ L-Glutamin (200 mM, Biochrom) \\ auf $\mathrm{pH} 8,2\left(37^{\circ} \mathrm{C}\right)$ mit $\mathrm{KOH}$
}

\title{
2.2.1.3 Einfrieren und Auftauen von Zellen
}

Zur längeren Lagerung von Zellen wurden diese in flüssigem Stickstoff eingefroren. Dazu wurden Zellsuspensionen des entsprechenden Zellkulturmediums mit demselben Volumen 2x Einfriermedium gemischt und in Kryoröhrchen aliquotiert. Die Zellen wurden einige Tage in einem Styroporblock auf $-80{ }^{\circ} \mathrm{C}$ heruntergekühlt und später in flüssigen Stickstoff überführt.

Zum Auftauen wurden die Zellen aus dem flüssigen Stickstoff in einem $37{ }^{\circ} \mathrm{C}$ warmen Wasserbad angetaut, zügig in warmes Zellkulturmedium gegeben, gleichmäßig verteilt und bei $37^{\circ} \mathrm{C}$ und $5 \% \mathrm{CO}_{2}$ inkubiert. Am folgenden Tag wurde ein Medienwechsel durchgeführt, da das restliche DMSO des Einfriermediums das Wachstum der Zellen beeinflusste.

\author{
2x Einfriermedium \\ $40 \%$ DMEM \\ $40 \%$ FCS \\ 20\% Dimethylsulfoxid (DMSO)
}

\subsubsection{Transfektion von Toxoplasma gondii}

Um Plasmid DNA in T. gondii einzuführen, wurde diese in Cytomix gelöst und durch Elektroporation in Tachyzoiten transfiziert.

Plasmid-DNA wurde in T. gondii durch einen BTX-ElectroCell Manipulator eingeführt. Hierzu wurden frisch geschlüpfte Tachyzoiten mit ihren Wirtszellen abgeschabt, durch mehrfache Passage durch Kanülen von diesen befreit und 10 min bei 2000 
rpm pelletiert. Nach Resuspendieren in $10 \mathrm{ml}$ Cytomix wurden die Parasiten in einer Neubauer Zählkammer ausgezählt, erneut abzentrifugiert und in Cytomix/ GSH/ ATP mit einer Konzentration von $1 * 10^{7} / 350 \mu$ laufgenommen. Pro Transfektion wurden $350 \mu \mathrm{l}$ Parasiten und $50 \mu \mathrm{g}$ Plasmid-DNA in Cytomix in einer $2 \mathrm{~mm}$ Küvette möglichst luftblasenfrei vermischt. Bei Verwendung von linearisiertem Plasmid wurden zusätzlich noch $50 \mathrm{U}$ des Restriktionsenzyms, welches zur Linearisierung verwendet worden war, pro Ansatz hinzugegeben, um die Effizienz der Transfektion zu erhöhen (Restriction Enzyme Mediated Integration, Black et al., 1995). Die Parasiten wurden anschließend bei 2,5 kV (maximum voltage range), $72 \Omega$ (resistance timing) mit 1,25 kV angelegter Spannung (s. Kapitel 2.2.1.4.1.) elektroporiert und der Inhalt der Küvette sofort nach Transfektion auf HFFs in DMEM/ 1\% FCS/ 1\% Pen-Strep gegeben und bei $37^{\circ} \mathrm{C}$ inkubiert.

$$
\begin{gathered}
\text { Cytomix } \\
120 \mathrm{mM} \mathrm{KCl} \\
0,15 \mathrm{mM} \mathrm{CaCl}_{2} \\
10 \mathrm{mM} \mathrm{K}_{2} \mathrm{HPO}_{4} / \mathrm{KH}_{2} \mathrm{PO}_{4}, \mathrm{pH} 7,6 \\
25 \mathrm{mM} \mathrm{HEPES} \\
2 \mathrm{mM} \mathrm{EDTA} \\
5 \mathrm{mM} \mathrm{MgCl} \\
\text { auf pH } 7,6 \text { mit } \mathrm{KOH}
\end{gathered}
$$

\section{Cytomix/ GSH/ ATP}

$$
30 \mathrm{mg} \text { ATP }
$$

$38 \mathrm{mg}$ Glutathion

in $25 \mathrm{ml}$ Cytomix

\subsection{Optimierung der Transfektionsbedingungen für Prugniaud/HX; ß- Galaktosidase-Färbung von $T$. gondii}

Da die Transfektionsbedingungen, und hierbei vor allem die angelegte Spannung bei der Transfektionseffizienz eine starke Rolle spielen und diese in Abhängigkeit vom transfizierten $T$. gondii Stamm stark variieren können, mussten die optimalen Transfektionsbedingungen für diesen Stamm erst ausgetestet werden.

Hierzu wurden je $50 \mu \mathrm{g}$ des Plasmids pKS-ROP-ß-Gal, welches das Gen für ßGalaktosidase unter Kontrolle des ROP1-Promotors trägt, mit 2,5 kV (maximum voltage range), $72 \Omega$ (resistance timing) und 1, 1,25, 1,5, 1,75 und $2 \mathrm{kV}$ angelegter Spannung in Prugniaud/HX Tachyzoiten wie oben beschrieben transfiziert. Als Kontrolle für die Transfektion und die nachfolgende Färbung wurden Tachyzoiten des 
Stammes $\mathrm{RH} / \mathrm{HX}^{-}$mit demselben Plasmid, aber $24 \Omega$ (resistance timing) und 1,5 kV angelegter Spannung (im Labor etablierte Bedingungen für diesen Stamm) transfiziert.

Die transfizierten Parasiten wurden nach der Transfektion auf je zwei $25 \mathrm{~cm}^{2}$ Zellkulturfläschchen verteilt, die mit einem konfluenten Zellrasen HFFs beschichtet waren. $36 \mathrm{~h}$ nach Inkubation bei $37^{\circ} \mathrm{C}$ und $\mathrm{CO}_{2}$ Begasung im Zellkulturinkubator wurde das Medium abgesaugt, die Zellen kurz mit PBS gewaschen und anschließend mit Fixierlösung 10 min fixiert. Nach 2x Waschen mit PBS wurden die Zellen mit X-Gal Färbelösung versetzt und ca. $3 \mathrm{~h}$ im Zellkulturinkubator inkubiert. Hiernach wurde nochmals kurz mit PBS gewaschen und am Zellkulturmikroskop ausgewertet.

Eine Expression von ß-Galaktosidase in transient transfizierten Parasiten konnte mittels X-Gal Färbung durch eine starke Blaufärbung der Vakuolen sichtbar gemacht werden (Seeber \& Boothroyd, 1996). Durch Auszählen des Prozentsatzes der angefärbten Vakuolen ergab sich ein Maß für die Transfektionseffizienz. Es zeigte sich, dass diese bei Prugniaud/HX' bei 1,0 und 1,25 mit jeweils $16,6 \%$ und $17,9 \%$ annähernd gleich war, während bei stärkeren angelegten Spannungen nicht genügend Parasiten die Transfektion überlebten, um prozentuale Angaben machen zu können. Für nachfolgende Experimente wurden folglich immer Spannungen von $1,25 \mathrm{kV}$ angelegt.

Bei der Kontrolltransfektion mit $\mathrm{RH} / \mathrm{HX}^{-}$ergab sich eine Transfektionseffizienz von ca. 40\%. Dass dieser Wert deutlich höher lag, als bei Prugniaud/HX' war in Einklang mit den Erwartungen, da sich Gruppe I Parasiten leichter transfizieren lassen, als Angehörige der Gruppen II oder III.

Fixierlösung

2\% Formaldehyd

$0,2 \%$ Glutaraldehyd

$2 \mathrm{mM} \mathrm{MgCl}_{2}$

$0,02 \%$ Triton X-100

0,04\% Desoxycholat

\section{X-Gal Färbelösung}

$100 \mathrm{mM} \mathrm{Na}_{3} \mathrm{PO}_{4}, \mathrm{pH} 7,3$

$1,3 \mathrm{mM} \mathrm{MgCl} 2$

$0,1 \% \mathrm{X}$-Gal

$3 \mathrm{mM} \mathrm{K}_{4} \mathrm{Fe}(\mathrm{CN})_{6}$

$3 \mathrm{mM} \mathrm{K}_{3} \mathrm{Fe}(\mathrm{CN})_{6}$

$0,02 \%$ Triton X-100

$0,04 \%$ Desoxycholat 


\subsection{Selektion von transfizierten $T$. gondii}

Eine Selektion von transfizierten Parasiten ist essentiell für die Generierung stabil transfizierter Zelllinien. Es stehen mittlerweile einige Selektionsmarker zur positiven, wie auch negativen Selektion transfizierter $T$. gondii zur Verfügung, wobei allerdings die meisten einen bestimmten genetischen Hintergrund bei der Wahl des Ausgangsstammes voraussetzen. Neben Vermittlung einer Resistenz gegen Chloramphenicol, Pyrimethamin, Phleomycin, oder 5-Fluorocytosin kann auch eine Komplementation der natürlichen Tryptophan Auxotrophie des Parasiten zur Selektion verwendet werden. (Kim et al., 1993, Donald \& Roos, 1993, Messina et al., 1995, Sibley et al., 1994, Fox et al., 1999). Unter Verwendung von HypoxanthinXanthin-Guanin-Phosphoribosyltransferase (HXGPRT) Gendeletionsmutanten kann auf Komplementation des HXGPRT Gens selektiert werden. (Donald et al., 1996).

Als besonders geeignet zur Selektion haben sich die Verwendung von Chloramphenicol zur Selektion von Chloramphenicoltransacetylase (CAT) exprimierenden Parasiten und Mycophenolsäure zur Selektion auf HXGPRT Komplementation erwiesen.

a) Chloramphenicol

Chloramphenicol ist ein Antibiotikum, das sowohl gram-positive, als auch gramnegative Bakterien inhibiert, indem es die Peptidsynthese durch Bindung an die Peptidyltransferase von 50S Ribosomen verhindert. Eine Resistenz gegen dieses Antibiotikum kann durch Expression von Chloramphenicoltransacetylase (CAT) erreicht werden. Dieses Enzym acetyliert Chloramphenicol, welches dadurch schlechter an 50S Ribosomen binden kann.

Die Wirkung von Chloramphenicol auf Toxoplasma gondii ist etwas verzögert, wodurch die Parasiten etwa 20 bis 25 Teilungen durchlaufen müssen, also etwa drei mal den Wirtszellrasen lysiert haben, bevor die Selektion überhaupt einsetzt (Kim et al., 1993).

Die Zugabe von Chloramphenicol in das Zellkulturmedium zur Selektion erfolgt direkt nach der Transformation mit einem Plasmid, welches CAT (samt Promotor und 3'-flankierendem Bereich) als Selektionsmarker enthält, wobei die Konzentration mit $5 \mu \mathrm{M}$ für schwache und $10 \mu \mathrm{M}$ für starke Promotoren aus einer $50 \mathrm{mM}$ 
Stammlösung (in Wasser) variiert werden kann. CAT wurde als Selektionsmarker für die Generierung der tgpma1 Gendeletionsmutante verwendet.

b) Hypoxanthin-Xanthin-Guanin-Phosphoribosyltransferase (HXGPRT)

Das Enzym HXGPRT spielt eine wichtige Rolle im Purin-Metabolismus des Parasiten. GMP kann in Toxoplasma gondii auf zwei alternativen Wegen synthetisiert werden: durch IMP Dehydrogenase oder HXGPRT. Mycophenolsäure inhibiert IMP Dehydrogenase, wodurch der Parasit auf die Expression von HXGPRT angewiesen ist. Vorraussetzung für eine effiziente Selektion HXGPRTpositiver Parasiten ist die Verwendung eines HXGPRT' Stammes bei dem auf Komplementierung von HXGPRT selektiert wird (Donald et al., 1996). Die Selektion setzt sofort nach Zugabe von $25 \mu \mathrm{g} / \mathrm{ml}$ Mycophenolsäure aus einer $25 \mathrm{mg} /$ $\mathrm{ml}$ Stammlösung (in Ethanol) und $50 \mu \mathrm{g} / \mathrm{ml}$ Xanthin aus einer $50 \mathrm{mg} / \mathrm{ml}$ Stammlösung (in 0,5 M KOH) ein. Um eine effiziente Expression des Selektionsmarkers zu gewährleisten, wurde das Selektionsmedium erst 24 Stunden nach Transfektion zu den Zellen gegeben.

\subsubsection{Klonierung von $T$. gondii}

Um aus einer polyklonalen Population an transfizierten Parasiten nach Selektion Klone mit definiertem Genotyp zu gewinnen, ist es nötig, diese zu klonieren. Im Falle von Toxoplasma gondii erreicht man dies durch Verdünnungsreihen auf einer mit Wirtszellen beschichteten Mikrotiterplatte, indem man mit einer definierten Anzahl an Parasiten startet und diese so weit herunterverdünnt, bis nur noch ein Klon in einem Napf der Mikrotiterplatte vorhanden ist.

Hierzu wurden zuerst Mikrotiterplatten mit HFFs beschichtet. HFFs wurden gesplittet und in DMEM/ 10\% FCS/ 1\% Pen-Strep aufgenommen. Mit einer Mehrkanalpipette wurden in jeden Napf einer Mikrotiterplatte $200 \mu$ der Zellsuspension gegeben und diese im Brutschrank bei $37{ }^{\circ} \mathrm{C}$ unter $\mathrm{CO}_{2}$-Begasung inkubiert, bis die Zellen konfluent waren.

Das Medium wurde abgesaugt und gegen $100 \mu$ DMEM/ 1\% FCS/ 1\% Pen-Strep mit $20 \mu \mathrm{M}$ Chloramphenicol pro Napf ersetzt. Die zu klonierenden Parasiten wurden mit dem Zellrasen abgeschabt und durch Kanülen gepresst, um die Wirtszellen zu 
zerstören und die Toxoplasmen aus diesen zu befreien. Die Anzahl der Parasiten wurde in einer Neubauer Zählkammer bestimmt und die Konzentration der Parasiten auf $1 / \mu \mathrm{l}$ mit dem für die Passage der Parasiten verwendeten Medium eingestellt. Mit einer Mehrkanalpipette wurden je $100 \mu \mathrm{l}$ dieser Parasitensuspension aufgenommen und in die erste Reihe Näpfe der Mikrotiterplatte pipettiert. Der Inhalt der Pipette wurde vorsichtig mit dem Medium in der Mikrotiterplatte vermischt und daraus $100 \mu \mathrm{l}$ in die nächste Reihe pipettiert. Auf diese Weise wurden pro 96-Napf Platte 16 Verdünnungsreihen erstellt mit einem Verdünnungsfaktor von zwei pro Reihe. Die letzten $100 \mu$ l jeder Verdünnungsreihe wurden verworfen. Nach sechs Reihen enthält ein Napf theoretisch 3,125 Parasiten- also immer noch mehr als einen Klon. Da allerdings nicht jeder ausgezählte Parasit eine Wirtszelle infiziert, reicht dieser Wert in den meisten Fällen aus, um die Parasiten effektiv zu klonieren.

Die so behandelten Mikrotiterplatten wurden im Brutschrank bei $37{ }^{\circ} \mathrm{C}$ und $\mathrm{CO}_{2}$ Begasung für sechs Tage (RH-Stamm) oder 10 Tage (zystenbildende Stämme wie ME49, Prugniaud/HX') inkubiert, ohne die Platten während dieser Zeit zu bewegen. Die Parasiten vermehren sich in den Zellen und lysieren diese. Die freigewordenen Parasiten infizieren umliegende Zellen und vermehren sich in diesen, so dass nach einiger Zeit ein Plaque im Zellrasen an den Stellen entsteht, an denen ursprünglich ein Parasit eine Zelle infiziert hatte. Plaques wurden im Lichtmikroskop gesucht und der Inhalt von Näpfen mit nur einem Plaque weiterpassagiert.

\subsubsection{Immunfluoreszenztest}

Um Proteine auf Einzelzellebene nachweisen zu können, wurden Immunfluoreszenztests (IFT) durchgeführt. Durch Auszählen der für das jeweils nachgewiesene Protein positiven parasitophoren Vakuolen konnte so der Prozentsatz der für die Expression des jeweiligen Proteins positiven Vakuolen unter verschiedenen Bedingungen untersucht werden.

Dazu wurden HFFs in 24-Napfplatten ausgesät, in die runde Deckgläschen (Durchmesser $13 \mathrm{~mm}$ ) gelegt worden waren. Nach Adhärenz und konfluentem Wachstum der Zellen erfolgte die Infektion mit Toxoplasma gondii unter verschiedenen Bedingungen. 
Für den IFT wurden die Zellen nach Beendigung des Versuches zwei mal mit PBS gewaschen, um Reste des Mediums und extrazelluläre Parasiten wegzuspülen. Anschließend wurde mit 4\% Paraformaldehyd (Pfa) in PBS für 10 min bei Raumtemperatur fixiert und danach die Zellen mit 0,25\% Triton X100 in PBS für 15 min bei Raumtemperatur permeabilisiert. In Abhängigkeit von dem später verwendeten primären Antikörper musste in manchen Fällen statt 4\% Pfa mit kaltem $\left(-20^{\circ} \mathrm{C}\right)$ Methanol für 5 min bei Raumtemperatur fixiert werden, ohne anschließende Permeabilisierung. Die fixierten Zellen wurden mit Blockierlösung (1\% BSA, 0,02\% Natriumazid in PBS) für eine Stunde bei Raumtemperatur oder über Nacht bei $4{ }^{\circ} \mathrm{C}$ blockiert. Der primäre Antikörper wurde in PBS verdünnt und eine Stunde bei Raumtemperatur mit den Zellen inkubiert. Nach dreimaligem Waschen mit PBS für jeweils 10 min wurden die Zellen mit einem mit Fluoreszenzfarbstoff (Сy3, Сy2, DTAF, TRITC) gekoppelten Sekundärantikörper für eine weitere Stunde bei Raumtemperatur inkubiert. Zum Entfernen ungebundener Antikörper wurde erneut drei mal mit PBS für jeweils 10 min gewaschen. Danach wurden die Deckgläschen kurz in entmineralisiertes Wasser getaucht um eine Kristallisation des PBS zu verhindern und mit $10 \mu \mathrm{l}$ Mowiol pro Deckgläschen auf Objektträger gebracht. Nach dem Trocknen über Nacht bei $4{ }^{\circ} \mathrm{C}$ konnten die fertigen Präparate unter dem Fluoreszenzmikroskop ausgewertet werden.

Blockierlösung

$$
1 \% \mathrm{BSA}
$$

$0,02 \% \mathrm{NaN}_{3}$

in PBS
Mowiol

2,4 g Mowiol 4-88

$6,0 \mathrm{~g}$ Glycerol

$6 \mathrm{ml} \mathrm{H}_{2} \mathrm{O}$ bidest.

$12 \mathrm{ml} \mathrm{0,2} \mathrm{M} \mathrm{Tris/} \mathrm{HCl,} \mathrm{pH} \mathrm{8,5}$

bei $4^{\circ} \mathrm{C}$ rühren, bis klare Lösung entsteht

Inkubation bei $50^{\circ} \mathrm{C}, 10 \mathrm{~min}$

Zentrifugation für $15 \mathrm{~min}, 5000 \mathrm{~g}$

Überstand bei $-20^{\circ} \mathrm{C}$ aufbewahren

\subsubsection{Isolierung von RNA aus Toxoplasma gondii}

Für RT-PCR Untersuchungen musste zunächst RNA aus den Parasiten gewonnen werden. Da eine menschliche Zelle ein etwa 30 mal größeres Genom und dadurch 
auch mehr mRNA besitzt als Toxoplasma gondii, erhält man eine starke Verunreinigung mit Wirtszell-mRNA, wenn man Gesamt-RNA aus Parasiten isoliert, die in Zellkultur gehalten wurden. Deshalb ist es nötig, diese vorher von den Wirtszellen durch Filtration zu trennen.

Hierzu wurden die Parasiten mit dem Zellrasen abgeschabt, durch mehrere Passagen durch Kanülen $(\varnothing=0,9 \mathrm{~mm}$ und $0,45 \mathrm{~mm})$ getrennt und durch einen Filter der Porengröße $3 \mu \mathrm{m}$ gesaugt. Nach dem Filtrieren wurden die Parasiten durch Zentrifugation (2500 rpm, $10 \mathrm{~min}$ ) einmal mit PBS gewaschen, pelletiert und RNA durch den RNeasy Kit (Qiagen) nach den Angaben des Herstellers gewonnen.

Die Parasiten wurden in Puffer RLT aufgenommen und durch eine QIAshredderSäule durch Zentrifugation homogenisiert. Das Homogenat wurde mit 70\% Ethanol versetzt und auf eine RNeasy-Säule zentrifugiert, wodurch die RNA an die Säulenmatrix bindet. Kontaminierende genomische DNA, die in anschließenden RTPCR Reaktionen stören würde, wurde durch einen DNase-Verdau direkt auf der Säule mittels des RNase-freien DNase Sets (Qiagen) eliminiert. Nach einigen Waschschritten wurde die RNA mit RNase-freiem destilliertem Wasser von der Säule eluiert und für anschließende Versuche wie cDNA Synthese verwendet werden. Eventuell noch immer vorhandene Kontamination durch gDNA konnte durch nachträgliche Behandlung mit RNase-freier DNase (Promega, Mannheim) eliminiert werden.

Anmerkung: eine Konzentrationsbestimmung, um die Ausbeute an RNA zu bestimmen war in diesem Fall nicht möglich, da hierbei nicht zwischen RNA der Parasiten und Wirtszell-RNA unterschieden werden kann. Eine Angleichung der Konzentrationen konnte also immer erst in der RT-PCR durchgeführt werden.

\subsubsection{8 cDNA Synthese aus RNA}

Zur cDNA-Synthese nutzt man den bei eukaryotischen mRNAs den am 3'-Ende vorhandenen Poly-A Schwanz aus, an den ein Oligo-dT Oligonukleotid binden kann, um die Reaktion zu initiieren.

In dieser Arbeit wurde der Omniscript RT-PCR Kit (Qiagen, Hilden) nach den Angaben des Herstellers verwendet. Dabei wird die RNA mit RT-Puffer, dNTPs, Oligo-dT Primer, RNase Inhibitor und Omniscript Reverser Transkriptase versetzt 
und ca. drei Stunden bei $37^{\circ} \mathrm{C}$ in einzelsträngige cDNA umgeschrieben. Diese ist wesentlich stabiler als RNA und läßt sich über längere Zeit bei $-20^{\circ} \mathrm{C}$ lagern.

\subsubsection{Semiquantitative RT-PCR}

Unter RT-PCR versteht man die Kombination aus Reverser Transkriptase mit nachgeschalteter PCR-Reaktion, um cDNA spezifisch zu amplifizieren. Semiquantitativ wird diese RT-PCR, wenn verschiedene cDNA-Pools untereinander durch Angleichung der Expression eines konstitutiv exprimierten Gens miteinander abgeglichen werden, also bei Einsatz bestimmter Mengen cDNA in der PCRReaktion ein gleich starkes Signal ergeben. Die so eingestellten cDNA-Pools können bei Verwendung der gleichen Mengen cDNA, die für das konstitutiv exprimierte Gen verwendet wurde, hinsichtlich der Expression beliebiger Gene miteinander verglichen werden.

In dieser Arbeit wurde das $\beta$-tubulin Gen aus Toxoplasma gondii zur Angleichung der cDNA Proben verwendet, wobei die Primer (Tub2/+, Tub2/-) so gewählt waren, dass sie ein Intron flankieren, also im Falle einer Kontamination mit genomischer DNA ein zweites, größeres PCR-Produkt auftritt.

Um sicher zu stellen, dass die jeweilige PCR-Reaktion (s. Kapitel 2.2.2.1.5) sich noch in der linearen Phase befand, wurden für jeden Ansatz in der PCR drei Verdünnungen der cDNA eingesetzt (1,1/3 und 1/10), die auch dementsprechend abgestufte Signalintensitäten ergeben sollten. War dies nicht der Fall, wurde das jeweilige PCR-Programm durch Änderung der Zyklenzahl abgeändert.

\subsubsection{Isolierung von genomischer DNA (gDNA) aus T. gondii}

Für die Gewinnung von gDNA aus Toxoplasma gondii wurden zwei Methoden angewendet:

a) eine auf Aceton-Fällung basierende Methode für die Analyse genomischer DNA aus einer großen Anzahl verschiedener Klone, von denen nur wenig Ausgangsmaterial zur Verfügung stand

b) der DNEasy Tissue Kit (Qiagen) für die Gewinnung von genomischer DNA aus größeren Mengen an Parasiten nach den Angaben des Herstellers. 
Der Vorteil der zweiten Methode lag darin, dass die gewonnene DNA einen höheren Reinheitsgrad aufwies, wodurch bei Analyse durch PCR größere PCR-Produkte ermöglicht wurden.

\title{
2.2.1.10.1 Isolierung genomischer DNA durch Aceton-Fällung
}

Zur Gewinnung von gDNA aus geringen Mengen an Parasiten wurden diese durch Zentrifugation pelletiert und mit $40 \mu$ l Proteinase K Lösung versetzt und $2 \mathrm{~h}$ bei $56^{\circ} \mathrm{C}$ inkubiert. Die Proteinase $\mathrm{K}$ wurde anschließend für $10 \mathrm{~min}$ bei $96^{\circ} \mathrm{C}$ inaktiviert, die Proben kurz anzentrifugiert und $200 \mu$ l Präzipitationslösung dazugegeben. Die DNA wurde bei 15 min, 14000 rpm pelletiert und anschließend zwei mal mit 70\% Ethanol gewaschen. Nach dem Trocknen wurde sie in $25 \mu \mathrm{H} \mathrm{H}_{2} \mathrm{O}$ bidest. aufgenommen und zur Charakterisierung in einer PCR-Reaktion eingesetzt.

\author{
Proteinase K Lösung \\ $10 \mathrm{mM}$ Tris, $\mathrm{pH} 7,6$ \\ $100 \mathrm{mM}$ EDTA \\ $0,6 \%$ SDS \\ $250 \mu \mathrm{g} / \mathrm{ml}$ Proteinase K
}

\author{
Präzipitationslösung \\ $70 \%$ Aceton \\ $5 \%$ Dimethylformamid
}

\subsubsection{Mykoplasmen-Test}

Um sicherzustellen, dass die Zellen nicht mit Mykoplasmen kontaminiert waren, wurde in regelmäßigen Abständen ein Mykoplasmentest durch Hoechst-Färbung durchgeführt. Hierzu wurden konfluent auf Glasplättchen wachsende HFFs in 24Napf Platten mit den zu untersuchenden Toxoplasmen infiziert und über Nacht bei 37 ${ }^{\circ} \mathrm{C}$ in DMEM/ 1\% FCS/ 1\% Pen-Strep im Zellkulturinkubator inkubiert. Am nächsten Tag wurden die Zellen zwei mal mit PBS gewaschen und anschließend mit $4 \%$ Pfa/ PBS für $10 \mathrm{~min}$ fixiert und 15 min mit 0,25\% Triton X100/ PBS permeabilisiert. Anschließend wurden sie 60 min mit 50 ng/ ml Hoechst 33258 in PBS inkubiert, drei mal 10 min mit PBS gewaschen und wie in der Immunfluoreszenzfärbung mit Mowiol eingedeckelt. Der Hoechst 33258 Farbstoff färbt DNA intensiv an und kann durch blaue Fluoreszenz an einem Fluoreszenzmikroskop sichtbar gemacht werden. Da 
sowohl die DNA der Wirtszellen, als auch der Parasiten und möglicher Mykoplasmen angefärbt wurde, konnten mit Mykoplasmen infizierte Zelllinien ausgesondert werden. Diese wurden sofort vernichtet und neue Chargen an Zellen aufgetaut.

\subsubsection{Molekularbiologie}

\subsubsection{Nukleinsäuren}

\subsection{Isolierung von Plasmid-DNA aus Escherichia coli}

Die Präparation und Reinigung von Plasmid-DNA aus E. coli wurde mit den Qiagen Plasmid Kits für Mini, Midi und Maxi Präparationen nach den Angaben des Herstellers durchgeführt. Hierbei wurden die Bakterien in Gegenwart von RNase nach dem Prinzip der alkalischen Lyse lysiert und die Lysate durch Zentrifugation von Proteinen und genomischer DNA befreit. Die klaren Lysate wurden daraufhin auf Säulen gegeben, und die Plasmid-DNA an die Silika-Membran der Säulen gebunden. Weitere Verunreinigungen wurden durch Waschschritte entfernt und die reine Plasmid-DNA in einem kleinen Volumen Wasser aufgenommen.

\subsection{Alkoholische Fällung von DNA}

DNA wurde zur Abtrennung von Proteinen und/ oder niedermolekularen Substanzen aus wässrigen Lösungen in Alkohol gefällt. Die DNA wurde dazu mit 2,5 Volumen absolutem Ethanol und 0,1 Vol. $3 \mathrm{M}$ Natriumacetat $(\mathrm{pH} \mathrm{5,2)}$ versetzt und 60 min bei 4 ${ }^{\circ} \mathrm{C}$ und $14000 \mathrm{rpm}$ in einer Eppendorfzentrifuge gefällt. Bei geringen DNAKonzentrationen wurde die DNA vor der Zentrifugation $30 \mathrm{~min}$ bei $-20^{\circ} \mathrm{C}$ gefällt und erst im Anschluss pelletiert. Das Pellet wurde 2 mal mit eiskaltem 70\%igem Ethanol gewaschen, um mitgefällte Salze zu lösen, und der restliche Alkohol abgesaugt. Nachdem das Pellet für etwa 10 min an der Luft getrocknet war, konnte es in dem gewünschten Volumen $\mathrm{H}_{2} \mathrm{O}$ bidest oder Cytomix (zur anschließenden Transfektion in Toxoplasma gondii) aufgenommen werden. 


\subsection{Modifikation von DNA}

\subsection{Enzymatische Restriktion}

Alle Restriktionsenzyme wurden nach den Angaben des Herstellers eingesetzt. Zur Analyse von DNA Minipräparationen wurde $1 / 8$ einer Minipräparation mit $1 \mathrm{U}$ Restriktionsenzym versetzt und zusammen mit dem jeweiligen Puffer in $20 \mu$ für ca. 3 Stunden bei $37^{\circ} \mathrm{C}$ (falls für das jeweilige Enzym keine andere Temperatur erforderlich war) inkubiert. Die geschnittene DNA konnte anschließend durch Agarosegelelektrophorese analysiert werden.

\subsection{Dephosphorylieren von DNA}

Wenn ein Insert in einen Vektor kloniert werden sollte, der mit nur einem Restriktionsenzym geschnitten wurde, musste dieser zunächst dephosphoryliert werden, um eine Selbstligation des Vektors zu vermeiden.

Hierzu wurde die Shrimp Alkalische Phosphatase (SAP, Boehringer Mannheim) verwendet.

Reaktionsansatz:

Vektor-DNA (linearisiert, $100 \mathrm{ng} / \mu \mathrm{l}$ )

$$
\begin{array}{r}
0,5 \mu \mathrm{l} \\
1 \mu \mathrm{l} \\
1 \mu \mathrm{l} \\
7,5 \mu \mathrm{l} \\
10 \mu \mathrm{l}
\end{array}
$$

SAP Puffer $10 x$

SAP $(1 \mathrm{U} / \mu \mathrm{l})$

$\mathrm{H}_{2} \mathrm{O}$ bidest.

Endvolumen

Der Ansatz wurde 30 min bei $37{ }^{\circ} \mathrm{C}$ inkubiert und die Phosphatase für 10 min bei 65 ${ }^{\circ} \mathrm{C}$ deaktiviert. Der dephosphorylierte Vektor konnte ohne weitere Aufreinigung für eine Ligation verwendet werden.

\subsection{Ligation von DNA durch T4 DNA Ligase}

Zur Klonierung von DNA-Fragmenten wurden Vektor- und Insert DNA mit passenden Restriktionsenzymen verdaut und über ein Agarosegel aufgetrennt. Die 
entsprechenden Banden wurden auf einem UV-Transilluminator aus dem Gel ausgeschnitten, aufgereinigt und in Wasser aufgenommen. Eine Konzentrationsbestimmung erfolgte durch Abschätzung eines erneut auf ein Agarosegel aufgetragenen Aliquots der aufgereinigten DNA. Pro Ligationsansatz wurden etwa $50 \mathrm{ng}$ Vektor- und die dreifache Menge an Insert-DNA zusammen mit 2 $\mu \mathrm{l}$ 10x Ligase-Puffer und $1 \mu \mathrm{l}$ T4 DNA Ligase (400 U/ $\mu$ l) in einem Endvolumen von $20 \mu \mathrm{l}$ vermischt. Die Reaktion wurde über Nacht bei $16{ }^{\circ} \mathrm{C}$ inkubiert und am nächsten Tag für eine Transformation in chemisch kompetente $E$. coli verwendet.

\subsection{DNA-Analyse}

\subsection{Photometrische Konzentrationsbestimmung}

Gemäß dem Lambert-Beer'schen Gesetz ist die Konzentration einer Lösung direkt proportional zu ihrer Extinktion bzw. Absorption. Diese Relation macht man sich bei der spektralphotometrischen Quantifizierung von Nukleinsäuren zu Nutze.

Von einer Verdünnung der gereinigten Nukleinsäure wurde im Spektralphotometer die Absorption bei $260 \mathrm{~nm}$ (Absorptionsmaximum der Nukleinsäuren) und bei $280 \mathrm{~nm}$ (Absorptionsspektrum von Proteinen) bestimmt. Die Messung erfolgte in $500 \mu \mathrm{l}$ Quarz- Küvetten. Es gilt folgende Relation zwischen gemessener Absorption und Konzentration der Nukleinsäure:

$$
\begin{array}{ll}
\text { dsDNA } & 1 \mathrm{OD}_{260}=50 \mu \mathrm{g} / \mathrm{ml} \\
\text { ssDNA } & 1 \mathrm{OD}_{260}=33 \mu \mathrm{g} / \mathrm{ml} \\
\text { RNA } & 1 \mathrm{OD}_{260}=40 \mu \mathrm{g} / \mathrm{ml}
\end{array}
$$

Um ein Maß für die Reinheit der Nukleinsäurelösung zu erhalten, kann der Quotient aus $\mathrm{OD}_{260} / \mathrm{OD}_{280}$ gebildet werden. Bei einer proteinfreien Nukleinsäurelösung sollte dieser im Bereich von 1,7-1,9 liegen.

\subsection{Agarosegelelektrophorese}

Um DNA-Fragmente nach ihrer Größe aufzutrennen, wurde diese auf einem 1\%igem Agarosegel elektrophoretisch aufgetrennt (Sambrook et al., 1989). Agarose wurde in 
TAE-Puffer in einer Mikrowelle aufgekocht und nach dem Abkühlen auf etwa $60{ }^{\circ} \mathrm{C}$ wurde $0,1 \mu \mathrm{g} / \mathrm{ml}$ Ethidiumbromid zugegeben und das Gel zum Abkühlen in eine mit einem Kamm bestückte Flachgelapparatur gegossen. Nach Erstarren der Lösung wurde das $\mathrm{Gel}$ in einer Gelkammer mit TAE-Puffer überschichtet und der Kamm entfernt. Die DNA-Proben wurden mit 10x Auftragspuffer versetzt und zusammen mit einem DNA-Molekulargewichtsstandard auf das Gel aufgetragen. Die Elektrophorese erfolgte bei $5-10 \mathrm{~V} / \mathrm{cm}$ in der Flachgelapparatur. Durch die Interkalation des Ethidiumbromids in die DNA konnte diese bei UV-Anregung auf einem Transilluminator sichtbar gemacht und fotografiert werden. Die Nachweisgrenze liegt dabei bei etwa $20 \mathrm{ng}$ pro Bande.

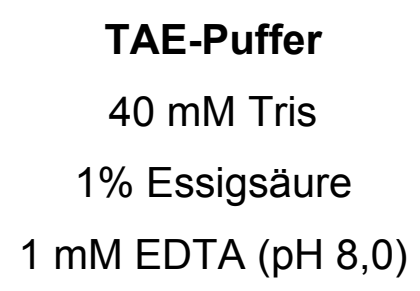

\author{
10x Auftragspuffer \\ 0,07\% Bromphenolblau \\ $33 \%$ Glycerin \\ $7 \%$ SDS \\ in TES-Puffer
}

\author{
TES-Puffer \\ $50 \mathrm{mM}$ Tris \\ 5 mM EDTA (pH 8,0) \\ $50 \mathrm{mM} \mathrm{NaCl}(\mathrm{pH} 8,0)$
}

\subsection{Extraktion von DNA aus einem präparativen Agarosegel}

DNA wurde durch Agarosegelelektrophorese aufgetrennt. Die entsprechende DNABande wurde auf einem Transilluminator unter UV-Licht $(70 \%$ der normalen Intensität, um DNA-Schäden zu vermeiden) mit einem Skalpell ausgeschnitten und mit Hilfe des QuiaExII-Kits der Firma Qiagen isoliert. Der Kit arbeitet mit einer SilikaMatrix, an die selektiv und quantitativ DNA gebunden wird, nachdem die Agarose aufgelöst ist. Dazu wurde das ausgeschnittene Agarosegelfragment in einem Puffer bei $50{ }^{\circ} \mathrm{C}$ gelöst, die gelöste Agarose und der restliche Puffer durch Waschen entfernt und die DNA aus der Silika-Matrix in $\mathrm{H}_{2} \mathrm{O}$ eluiert. Da das Endvolumen nur 20 $\mu \mathrm{l}$ betrug, musste nicht noch einmal gefällt werden und die eluierte DNA konnte direkt für weitere Reaktionen wie z.B. DNA-Ligation verwendet werden.

\subsection{Polymerasekettenreaktion (PCR)}

PCR (nach Saiki et al., 1988) wurde zur Amplifikation von DNA-Fragmenten zur Analyse oder Klonierung verwendet. Die Methode beruht im Prinzip auf zyklischen 
Wiederholungen von Denaturierung der template-DNA, Anlagerung sequenzspezifischer Oligonukleotide (Primer), und der Synthese einer komplementären DNA-Kopie durch eine thermostabile DNA-Polymerase. Durch Durchlaufen mehrerer Zyklen kommt es zu einer exponentiellen Vermehrung der durch die Primer flankierten DNA-Sequenz. Normalerweise wurde Taq DNAPolymerase zur Amplifizierung der DNA verwendet; nur wenn die DNA später zur Klonierung verwendet werden sollte, wurden aufgrund der geringeren Fehlerrate $3 \mathrm{U}$ Pfu-DNA-Polymerase (3 U/ $\mu$; Promega) eingesetzt.

Zur Amplifizierung von DNA-Fragmenten wurden folgende Bedingungen gewählt:

\begin{tabular}{c|c} 
Template-DNA & $10-100 \mathrm{ng}$ \\
\hline Desoxyribonukleotide (dNTPs, $25 \mathrm{mM})$ & je $2,5 \mathrm{mM}$ \\
\hline Primer I $(5 \mu \mathrm{M})$ & $0,5 \mu \mathrm{M}$ \\
\hline Primer II $(5 \mu \mathrm{M})$ & $0,5 \mu \mathrm{M}$ \\
\hline 10x Taq-Puffer & $5 \mu \mathrm{l}$ \\
\hline Taq DNA-Polymerase & $0,3-0,5 \mathrm{U}$ \\
\hline gesamt & ad $50 \mu \mathrm{l}$
\end{tabular}

Da der Thermocycler einen beheizbaren Deckel besaß, musste nicht mit Mineralöl überschichtet werden. Nach Zugabe aller Reagenzien wurden die Reaktionsgefäße kurz anzentrifugiert und in den bereits auf $95{ }^{\circ} \mathrm{C}$ vorgeheizten Block der PCRMaschine gestellt.

\section{Standard-PCR Protokoll:}

$$
\begin{gathered}
96{ }^{\circ} \mathrm{C}, 2 \mathrm{~min} \\
25 \mathrm{x}\left(94^{\circ} \mathrm{C}, 30 \mathrm{~s} ; 55^{\circ} \mathrm{C}, 30 \mathrm{~s} ; 72^{\circ} \mathrm{C}, 1 \mathrm{~min}\right) \\
72{ }^{\circ} \mathrm{C}, 10 \mathrm{~min} \\
4{ }^{\circ} \mathrm{C}, \text { Pause }
\end{gathered}
$$

Das Protokoll wurde je nach Primerkombination, Größe des zu amplifizierenden DNA-Fragmentes und Art der Template-DNA (cDNA oder gDNA) in Zyklenzahl, Temperatur der Primer-Anlagerung und Länge der Polymerisierungszeit abgewandelt (s. Tabelle 3). 


\begin{tabular}{|c|c|c|c|c|c|}
\hline $\begin{array}{c}\text { Kapitel, } \\
\text { amplifiziertes } \\
\text { Gen }\end{array}$ & $\begin{array}{l}\text { verwendete } \\
\text { Primer }\end{array}$ & Zyklen & Denaturierung & Anlagerung & Verlängerung \\
\hline \multicolumn{6}{|l|}{3.1 .2} \\
\hline $\begin{array}{l}\beta \text {-tubulin } \\
\text { cDNA }\end{array}$ & $\begin{array}{l}\text { tub2/++, } \\
\text { tub2/- }\end{array}$ & 25 & $94^{\circ} \mathrm{C}, 30 \mathrm{~s}$ & $55^{\circ} \mathrm{C}, 30 \mathrm{~s}$ & $72^{\circ} \mathrm{C}, 45 \mathrm{~s}$ \\
\hline $\begin{array}{l}B A G 1 \\
c D N A\end{array}$ & $\begin{array}{l}\text { 7E5/+, } \\
7 \mathrm{E} 5 /-\end{array}$ & 25 & $94^{\circ} \mathrm{C}, 30 \mathrm{~s}$ & $55^{\circ} \mathrm{C}, 30 \mathrm{~s}$ & $72^{\circ} \mathrm{C}, 45 \mathrm{~s}$ \\
\hline tgpma1, cDNA & $\begin{array}{l}9-\mathrm{P} 15 /+ \\
9-10 /-\end{array}$ & 30 & $94^{\circ} \mathrm{C}, 30 \mathrm{~s}$ & $55^{\circ} \mathrm{C}, 30 \mathrm{~s}$ & $72^{\circ} \mathrm{C}, 45 \mathrm{~s}$ \\
\hline tgpma2, cDNA & $\begin{array}{l}\text { PM2-20/+, } \\
\text { PM2-6/- }\end{array}$ & 30 & $94^{\circ} \mathrm{C}, 30 \mathrm{~s}$ & $60^{\circ} \mathrm{C}, 30 \mathrm{~s}$ & $72^{\circ} \mathrm{C}, 45 \mathrm{~s}$ \\
\hline \multicolumn{6}{|l|}{ 3.2.1.6 } \\
\hline $\begin{array}{c}\text { tgpma1, } \\
\text { gDNA } \\
\text { verdaut und } \\
\text { ligiert }\end{array}$ & $\begin{array}{l}\text { sämtliche im } \\
\text { Text } \\
\text { angegebene } \\
\text { Kombinationen }\end{array}$ & 40 & $94^{\circ} \mathrm{C}, 45 \mathrm{~s}$ & $55^{\circ} \mathrm{C}, 45 \mathrm{~s}$ & $72^{\circ} \mathrm{C}, 8 \mathrm{~min}$ \\
\hline \multicolumn{6}{|l|}{ 3.3.1.1 } \\
\hline $\begin{array}{l}\text { tgpma1, } \\
\text { CDNA }\end{array}$ & $\begin{array}{l}\text { PM1-1008-Bam/+, } \\
\text { PM1-1785-Kpn/- }\end{array}$ & 25 & $94^{\circ} \mathrm{C}, 30 \mathrm{~s}$ & $55^{\circ} \mathrm{C}, 30 \mathrm{~s}$ & $72^{\circ} \mathrm{C}, 3 \mathrm{~min}$ \\
\hline $\begin{array}{l}\text { tgpma1, } \\
\text { CDNA }\end{array}$ & $\begin{array}{l}\text { PM1-2608-Bam/+, } \\
\text { ATPase-3-Kpn/- }\end{array}$ & 25 & $94^{\circ} \mathrm{C}, 30 \mathrm{~s}$ & $55^{\circ} \mathrm{C}, 30 \mathrm{~s}$ & $72^{\circ} \mathrm{C}, 3 \mathrm{~min}$ \\
\hline \multicolumn{6}{|l|}{3.4 .1} \\
\hline $\begin{array}{l}\text { tgpma1, } \\
\text { Plasmid }\end{array}$ & $\begin{array}{l}\text { PMAI5'Apa/+, } \\
\text { PMAI5'Cla/- }\end{array}$ & 25 & $94^{\circ} \mathrm{C}, 45 \mathrm{~s}$ & $60^{\circ} \mathrm{C}, 45 \mathrm{~s}$ & $72^{\circ} \mathrm{C}, 6 \mathrm{~min}$ \\
\hline $\begin{array}{l}\text { tgpma1, } \\
\text { Plasmid }\end{array}$ & $\begin{array}{l}\text { PMAI3'/+, } \\
\text { PMAI3'/- }\end{array}$ & 25 & $94^{\circ} \mathrm{C}, 45 \mathrm{~s}$ & $60^{\circ} \mathrm{C}, 45 \mathrm{~s}$ & $72^{\circ} \mathrm{C}, 6 \mathrm{~min}$ \\
\hline \multicolumn{6}{|l|}{3.4 .2} \\
\hline $\begin{array}{l}\text { tgpma1, } \\
\text { gDNA }\end{array}$ & $\begin{array}{l}\text { Intr/+, } \\
\text { P11/- }\end{array}$ & 35 & $94^{\circ} \mathrm{C}, 45 \mathrm{~s}$ & $62^{\circ} \mathrm{C}, 45 \mathrm{~s}$ & $72^{\circ} \mathrm{C}, 150 \mathrm{~s}$ \\
\hline $\begin{array}{l}\text { tgpma1, } \\
\text { gDNA }\end{array}$ & $\begin{array}{l}\text { Intr/+, } \\
\text { Tub/CAT4/+ }\end{array}$ & 35 & $94^{\circ} \mathrm{C}, 45 \mathrm{~s}$ & $62^{\circ} \mathrm{C}, 45 \mathrm{~s}$ & $72^{\circ} \mathrm{C}, 150 \mathrm{~s}$ \\
\hline \multicolumn{6}{|l|}{ 3.4.3.2 } \\
\hline $\begin{array}{l}\text { tgpma1, } \\
\text { gDNA }\end{array}$ & $\begin{array}{l}\text { Intr/+, } \\
9-3 /-\end{array}$ & 40 & $94^{\circ} \mathrm{C}, 45 \mathrm{~s}$ & $60^{\circ} \mathrm{C}, 45 \mathrm{~s}$ & $72^{\circ} \mathrm{C}, 5 \mathrm{~min}$ \\
\hline \multicolumn{6}{|l|}{3.5 .5} \\
\hline$\beta$-tubulin & $\begin{array}{l}\text { TUB2/+, } \\
\text { TUB2/- }\end{array}$ & 25 & $94^{\circ} \mathrm{C}, 30 \mathrm{~s}$ & $55^{\circ} \mathrm{C}, 30 \mathrm{~s}$ & $72^{\circ} \mathrm{C}, 30 \mathrm{~s}$ \\
\hline$B A G 1$ & $\begin{array}{l}\text { 7E5/+, } \\
7 \mathrm{E} 5 /-\end{array}$ & 30 & $94^{\circ} \mathrm{C}, 30 \mathrm{~s}$ & $60^{\circ} \mathrm{C}, 30 \mathrm{~s}$ & $72^{\circ} \mathrm{C}, 30 \mathrm{~s}$ \\
\hline Ctoxo4101 & $\begin{array}{l}\text { Ctoxo4101/+, } \\
\text { Ctoxo4101/- }\end{array}$ & 35 & $94^{\circ} \mathrm{C}, 30 \mathrm{~s}$ & $60^{\circ} \mathrm{C}, 30 \mathrm{~s}$ & $72^{\circ} \mathrm{C}, 30 \mathrm{~s}$ \\
\hline DRPA & $\begin{array}{l}\text { DRPA/+, } \\
\text { DRPA/- }\end{array}$ & 35 & $94^{\circ} \mathrm{C}, 30 \mathrm{~s}$ & $55^{\circ} \mathrm{C}, 30 \mathrm{~s}$ & $72^{\circ} \mathrm{C}, 40 \mathrm{~s}$ \\
\hline ENO1 & $\begin{array}{l}\text { ENO2/+, } \\
\text { ENO2/- }\end{array}$ & 30 & $94^{\circ} \mathrm{C}, 30 \mathrm{~s}$ & $60^{\circ} \mathrm{C}, 30 \mathrm{~s}$ & $72^{\circ} \mathrm{C}, 30 \mathrm{~s}$ \\
\hline$L D H 2$ & $\begin{array}{l}\mathrm{LDH} 2 /+ \\
\mathrm{LDH} 2 /-\end{array}$ & 35 & $94^{\circ} \mathrm{C}, 30 \mathrm{~s}$ & $60^{\circ} \mathrm{C}, 30 \mathrm{~s}$ & $72^{\circ} \mathrm{C}, 30 \mathrm{~s}$ \\
\hline Sag4 & $\begin{array}{l}\text { Sag4/+, } \\
\text { Sag4-b/- }\end{array}$ & 35 & $94^{\circ} \mathrm{C}, 30 \mathrm{~s}$ & $55^{\circ} \mathrm{C}, 30 \mathrm{~s}$ & $72^{\circ} \mathrm{C}, 40 \mathrm{~s}$ \\
\hline SRS9 & $\begin{array}{l}\text { SRS9/+, } \\
\text { SRS9/- }\end{array}$ & 35 & $94^{\circ} \mathrm{C}, 30 \mathrm{~s}$ & $55^{\circ} \mathrm{C}, 30 \mathrm{~s}$ & $72^{\circ} \mathrm{C}, 40 \mathrm{~s}$ \\
\hline Tgpis1 & $\begin{array}{l}\text { Tgpis2-32S2/+, } \\
\text { Tgpis1-3pisas4/- }\end{array}$ & 35 & $94^{\circ} \mathrm{C}, 30 \mathrm{~s}$ & $55^{\circ} \mathrm{C}, 30 \mathrm{~s}$ & $72^{\circ} \mathrm{C}, 1 \mathrm{~min}$ \\
\hline
\end{tabular}




\begin{tabular}{|c|c|c|c|c|c|}
\hline tgpma1 & $\begin{array}{l}\text { 9-P13/+, } \\
\text { 9-3/- }\end{array}$ & 35 & $94^{\circ} \mathrm{C}, 40 \mathrm{~s}$ & $58^{\circ} \mathrm{C}, 30 \mathrm{~s}$ & $72{ }^{\circ} \mathrm{C}, 45 \mathrm{~s}$ \\
\hline Ctoxo3969 & $\begin{array}{l}\text { Ctoxo3969/+, } \\
\text { Ctoxo3969/- }\end{array}$ & 35 & $94{ }^{\circ} \mathrm{C}, 30 \mathrm{~s}$ & $60^{\circ} \mathrm{C}, 30 \mathrm{~s}$ & $72{ }^{\circ} \mathrm{C}, 30 \mathrm{~s}$ \\
\hline Mag1 & $\begin{array}{l}\text { MAG1/+, } \\
\text { MAG1/- }\end{array}$ & 35 & $94{ }^{\circ} \mathrm{C}, 30 \mathrm{~s}$ & $55^{\circ} \mathrm{C}, 30 \mathrm{~s}$ & $72^{\circ} \mathrm{C}, 40 \mathrm{~s}$ \\
\hline MetAP2 & $\begin{array}{l}\text { met-pep/+, } \\
\text { met-pep/- }\end{array}$ & 35 & $94^{\circ} \mathrm{C}, 30 \mathrm{~s}$ & $55^{\circ} \mathrm{C}, 30 \mathrm{~s}$ & $72^{\circ} \mathrm{C}, 40 \mathrm{~s}$ \\
\hline TIF & $\begin{array}{l}\text { Ctoxo2388/+, } \\
\text { Ctoxo2388/- }\end{array}$ & 35 & $94{ }^{\circ} \mathrm{C}, 30 \mathrm{~s}$ & $55^{\circ} \mathrm{C}, 30 \mathrm{~s}$ & $72{ }^{\circ} \mathrm{C}, 40 \mathrm{~s}$ \\
\hline Oligopep & $\begin{array}{l}\text { Ctoxo1284/+, } \\
\text { Ctoxo1284/- }\end{array}$ & 30 & $94^{\circ} \mathrm{C}, 30 \mathrm{~s}$ & $60^{\circ} \mathrm{C}, 30 \mathrm{~s}$ & $72{ }^{\circ} \mathrm{C}, 30 \mathrm{~s}$ \\
\hline Sag1 & $\begin{array}{l}\text { Sag1/+, } \\
\text { Sag1/- }\end{array}$ & 25 & $94{ }^{\circ} \mathrm{C}, 30 \mathrm{~s}$ & $60^{\circ} \mathrm{C}, 30 \mathrm{~s}$ & $72{ }^{\circ} \mathrm{C}, 30 \mathrm{~s}$ \\
\hline Sag2D & $\begin{array}{l}\text { Sag2/+, } \\
\text { Sag2/- }\end{array}$ & 30 & $94^{\circ} \mathrm{C}, 30 \mathrm{~s}$ & $60^{\circ} \mathrm{C}, 30 \mathrm{~s}$ & $72{ }^{\circ} \mathrm{C}, 30 \mathrm{~s}$ \\
\hline
\end{tabular}

Tabelle 3. Verwendete PCR-Bedingungen, nach Kapitel geordnet.

\subsubsection{Real-Time PCR am Lightcycler}

Um vergleichbare quantitative Werte für die Expression einzelner Gene zu erhalten, wurden einige Proben durch Real-Time PCR am Lightcycler (Roche, Mannheim) untersucht (Higuchi et al., 1992). Hierzu wurde unter Verwendung des Fast Start DNA Master SYBR Green I Kits (Roche, Mannheim) ein Master-Mix angesetzt, der je nach verwendeter Primerkombination verschiedene $\mathrm{MgCl}_{2}$-Konzentrationen enthielt. Je $17 \mu \mathrm{l}$ des Master Mix wurden auf eine Glaskapillare pipettiert und $2 \mu \mathrm{l}$ an Template cDNA zugefügt. Die Kapillaren wurden mit einem Deckel verschlossen und die Proben $30 \mathrm{~s}$ bei $3000 \mathrm{rpm}$ in die Kapillaren zentrifugiert. Im Lightcycler wurde die Expression der untersuchten Gene mit einem in Abhängigkeit vom verwendeten Primerpaar abgeänderten Standardprotokoll untersucht. Der Crossing Point jeder Probe wurde unter voreingestellten Bedingungen (Baseline Adjustment $=$ Arithmetic) ermittelt.

Um die Expression spezifischer Gene in unterschiedlichen Proben miteinander vergleichen zu können, wurden die berechneten Expressionsstärken bezüglich der ßTubulin Expression jeder Probe abgeglichen. Da jeweils die Induktion eines Gens während der Differenzierung vom Tachyzoiten zum Bradyzoiten untersucht wurde, wurden die Induktionsfaktoren jedes untersuchten spezifischen Gens nach folgender Formel berechnet: 
$\frac{\operatorname{Exp}_{\text {Brady }}}{\operatorname{Exp}_{\text {Tachy }}}=\frac{2^{\Delta c p_{\text {spez(tachy-brady) }}}}{2^{\Delta c p_{\text {Tub(tachy-brady) }}}}$

Exp $=$ Expression

$\mathrm{cp}_{\mathrm{spez}}=$ crossing point des spezifischen Gens

$c p_{\text {Tub }}=$ crossing point des dazugehörigen $\beta$-Tubulin Wertes

\section{Gesamt-Ansatz}

$12 \mu \mathrm{H}_{2} \mathrm{O}$ bidest. $+\mathrm{MgCl}_{2}$-Lösung I-IV

$2 \mu$ Primer 1

$2 \mu$ Primer 2

$1 \mu$ l Master Mix SYBR Green

$2 \mu \mathrm{l}$ Template cDNA

\begin{tabular}{|c|c|c|c|c|}
\hline \multicolumn{5}{|c|}{ MgCl$_{2}$-Lösungen I-IV } \\
\hline & I & II & III & IV \\
\hline $\mathrm{MgCl}_{2}(1 \mathrm{mM})$ & $40 \mu \mathrm{l}$ & $80 \mu \mathrm{l}$ & $120 \mu \mathrm{l}$ & $160 \mu \mathrm{l}$ \\
\hline $\mathrm{H}_{2} \mathrm{O}$ bidest. & $560 \mu \mathrm{l}$ & $520 \mu \mathrm{l}$ & $480 \mu \mathrm{l}$ & $440 \mu \mathrm{l}$ \\
\hline
\end{tabular}

Alle PCR-Programme am Lightcycler waren ähnlich aufgebaut und bestanden aus einer anfänglichen Denaturierung mit anschließender Amplifizierung, gefolgt von der Schmelzkurve und einem Kühlungsschritt. Bei den verschiedenen verwendeten Primerpaaren wurde dabei lediglich der Amplifizierungsschritt variiert, der Rest des Programms blieb konstant. Ein typisches Programm sah dabei wie folgt aus:

\begin{tabular}{|ccccc|}
\hline $\begin{array}{c}\text { Segment \# } \\
\text { Denaturierung }\end{array}$ & $\begin{array}{c}\text { Temperature } \\
\text { Target }\left({ }^{\circ} \mathrm{C}\right)\end{array}$ & $\begin{array}{c}\text { Hold Time } \\
(\mathrm{s})\end{array}$ & $\begin{array}{c}\text { Slope } \\
\left({ }^{\circ} \mathrm{C} / \mathrm{s}\right)\end{array}$ & $\begin{array}{c}\text { Acquisition } \\
\text { Mode }\end{array}$ \\
$\begin{array}{c}\text { Amplifizierung } \\
1\end{array}$ & 95 & 600 & 20 & none \\
2 & 95 & 10 & 20 & none \\
3 & var. & 5 & 20 & none \\
Schmelzkurve & 72 & var. & 20 & single \\
\hline 1 & 95 & 0 & & none \\
2 & 65 & 15 & 20 & none \\
3 & 95 & 0 & 20 & continuous \\
Kühlung & & & 0,2 & none \\
\hline 1 & 40 & 30 & 20 & \\
\hline
\end{tabular}


Der für das jeweilige Primerpaar verwendete variierte Teil des Amplifizierungsschritts war wie folgt aufgebaut; es wurde immer $\mathrm{MgCl}_{2}$-Lösung II verwendet:

\begin{tabular}{|c|c|c|c|}
\hline $\begin{array}{c}\text { nachgewiesenes } \\
\text { Gen }\end{array}$ & Primerpaar & $\begin{array}{c}\text { Temperature Target } \\
\text { Segment \# } 2\left({ }^{\circ} \mathrm{C}\right)\end{array}$ & $\begin{array}{c}\text { Hold Time Segment } \\
\text { \# } 3 \text { (s) }\end{array}$ \\
\hline$\beta$-tubublin & $\begin{array}{l}\text { tub2/+ } \\
\text { tub2/- }\end{array}$ & 60 & 20 \\
\hline bag1 & $\begin{array}{l}7 \mathrm{E} 5 /+ \\
7 \mathrm{E} 5 /-\end{array}$ & 60 & 20 \\
\hline LDH2 & $\begin{array}{l}\mathrm{LDH} 2 /+ \\
\mathrm{LDH} 2 /-\end{array}$ & 55 & 24 \\
\hline tgpma2 & $\begin{array}{l}\text { PM2-20/+ } \\
\text { PM2-6/- }\end{array}$ & 55 & 24 \\
\hline VEE & $\begin{array}{l}\text { VEEb/+ } \\
\text { VEEb/- }\end{array}$ & 55 & 24 \\
\hline $14-3-3$ & $\begin{array}{l}14-3-3 c /+ \\
14-3-3 c /-\end{array}$ & 55 & 24 \\
\hline myoC & $\begin{array}{l}\text { Ctoxo3175/+ } \\
\text { Ctoxo3175/- }\end{array}$ & 55 & 24 \\
\hline TgVP1 & $\begin{array}{l}\text { TgVP1/+ } \\
\text { TgVP1/- }\end{array}$ & 55 & 24 \\
\hline
\end{tabular}

\subsection{Subklonierung von PCR-Produkten in pCR2.1 TOPO}

Um eine effizientere Klonierung von PCR-Produkten zu ermöglichen, wurden diese direkt nach der PCR-Reaktion auf einem Agarosegel elektrophoretisch aufgetrennt, aus diesem isoliert und in den Vektor pCR2.1 des TOPO TA Cloning Kits (Invitrogen, Karlsruhe) nach den Angaben des Herstellers subkloniert.

Der Kit basiert auf einem bereits geschnittenen Vektor, der die bei einer Amplifikation durch Taq-Polymerase entstehenden terminalen Desoxyadenosin-Überhänge ausnutzt. An den geschnittenen Vektor ist eine Topoisomerase gekoppelt, die eine Ligation bei Raumtemperatur innerhalb von fünf Minuten ermöglicht. Wenn für die PCR-Reaktion Pfu-DNA-Polymerase verwendet wurde, musste durch nachträgliche Inkubation des aufgereinigten PCR-Produktes in Gegenwart von dATP und Taq DNA-Polymerase in Taq DNA-Polymerasepuffer für $15 \mathrm{~min}$ bei $72{ }^{\circ} \mathrm{C}$ ein nachträgliches Anfügen der terminalen Desoxyadenosin-Überhänge erreicht werden. Das in den Vektor ligierte PCR-Produkt wurde anschließend in chemisch kompetente E. coli TOP10 transfiziert und auf Ampicillin-Resistenz der Zellen selektiert. 


\subsubsection{Klonierung durch inverse PCR}

Mit Hilfe inverser PCR kann ein DNA-Fragment unbekannter Sequenz kloniert werden, das direkt an DNA bekannter Sequenz angrenzt. In diesem Fall wurde die Methode verwendet, um die bekannte Sequenz aus dem 5' UTR von tgpma1 zu erweitern.

Genomische DNA des Stammes $\mathrm{RH} / \mathrm{HX}^{-}$wurde aus zwei durchlysierten 175er Zellkulturflaschen isoliert und in insgesamt $800 \mu \mathrm{l} \mathrm{H}_{2} \mathrm{O}$ bidest. gelöst. Je $50 \mu \mathrm{l}$ wurden in einem Restriktionsverdau über Nacht mit je $160 \mathrm{U}$ Sacl, Xhol, EcoRI, Dral und Nhel verdaut. Die Proben wurden anschließend aufgereinigt und in $\mathrm{H}_{2} \mathrm{O}$ bidest. gelöst. Um eine Ligation zweier Fragmente miteinander möglichst zu verhindern und eine Selbstligation einzelner Fragmente zu begünstigen, wurde das Volumen der Ligation möglichst groß gewählt. Die DNA Fragmente wurden $30 \mathrm{~min}$ bei Raumtemperatur in einem Volumen von je $180 \mu \mathrm{l}$ mit 2,5 $\mu \mathrm{l}$ QuickLigase ligiert, anschließend erneut aufgereinigt und in $100 \mu \mathrm{l} \mathrm{H}_{2} \mathrm{O}$ bidest. aufgenommen.

An den aufgereinigten Ligationsansätzen wurden jeweils zwei PCR Reaktionen mit den Primern 9-20/- und 9-21/- durchgeführt. Die Primer wurden so gewählt, dass jeweils 9-20/- oder 9-21/- in 5' Richtung aus der bekannten Sequenz heraus amplifizierten und je nach vorherigem Restriktionsverdau ein Primer, der möglichst nahe der Restriktionsschnittstelle innerhalb des tgpma1 Lokus lag, in 3' Richtung amplifizierte: Sacl: PMA1seq/+; Xhol: PM1-5‘-2; EcoRI: P-7/+; Dral: PMA1seq/+; Nhel: P-13/+. Da größere PCR-Produkte zu erwarten waren, wurde zusätzlich jede Reaktion mit und ohne Zusatz von TaqExtender durchgeführt, um die Ausbeute zu verbessern. Die PCR-Produkte wurden durch Agarosegelelektrophorese aufgetrennt, einige Banden ausgeschnitten und aus dem Gel aufgereinigt. Die Fragmente wurden in den Vektor PCR2.1 subkloniert und sequenziert.

\subsection{Transformation von Plasmid-DNA in chemisch kompetente $E$. coli}

\subsection{Präparation kompetenter Zellen, $\mathrm{CaCl}_{2}$-Methode}

Für die Aufnahme von Plasmiden müssen E. coli Zellen erst kompetent gemacht werden. In dieser Arbeit wurde ausschließlich mit chemisch kompetenten E. coli nach der $\mathrm{CaCl}_{2}$-Methode gearbeitet. 
Ausgehend von einer Einzelkolonie oder einem gefrorenen Aliquot des entsprechenden Stammes an E. coli Zellen wurde eine Übernachtkultur von $5 \mathrm{ml}$ angesetzt und unter Schütteln bei $37^{\circ} \mathrm{C}$ inkubiert. $4 \mathrm{ml}$ dieser Übernachtkultur wurden am nächsten Morgen mit $100 \mathrm{ml}$ vorgewärmtem $\left(37^{\circ} \mathrm{C}\right)$ LB-Medium versetzt, die Kultur wieder bei $37^{\circ} \mathrm{C}$ unter Schütteln inkubiert und bis zu einer $\mathrm{OD}_{550}$ von 0,4 bis 0,5 wachsen lassen. Nach Erreichen der erforderlichen Zelldichte wurden die Zellen in $50 \mathrm{ml}$ Zentrifugationsröhrchen auf Eis ca. 15 min abgekühlt und danach in einer vorgekühlten $\left(4^{\circ} \mathrm{C}\right)$ Zentrifuge bei $4500 \mathrm{rpm}$ und $4^{\circ} \mathrm{C}$ für $10 \mathrm{~min}$ sedimentiert. Das Pellet wurde in $30 \mathrm{ml}$ eiskaltem TfBI resuspendiert und 30 min auf Eis abgekühlt. Nach erneuter Zentrifugation wurde das Zellpellet in $4 \mathrm{ml}$ kaltem TfBIl aufgenommen und Aliquots von $100 \mu \mathrm{l}$ in Eppendorf-Caps bei $-70^{\circ} \mathrm{C}$ gelagert.

TfBI

$100 \mathrm{mM} \mathrm{RbCl}$

$50 \mathrm{mM} \mathrm{MnCl} 2 \times 4 \mathrm{H}_{2} \mathrm{O}$

$30 \mathrm{mM} \mathrm{KAc}$

$10 \mathrm{mM} \mathrm{CaCl}_{2}$

$\frac{15 \%(\mathrm{v} / \mathrm{v}) \text { Glycerin }}{\operatorname{ad~} 50 \mathrm{ml}}$
TfBII

$10 \mathrm{mM}$ MOPS, $\mathrm{pH} 7,0$

$10 \mathrm{mM} \mathrm{RbCl}$

$75 \mathrm{mM} \mathrm{CaCl}_{2}$

$15 \%(v / v)$ Glycerin

ad $50 \mathrm{ml}$

auf $\mathrm{pH} 7$ mit $\mathrm{HCl}$ einstellen

auf pH 5,8 mit Essigsäure einstellen

Die sterilfiltrierten Lösungen können bei $4{ }^{\circ} \mathrm{C}$ über mehrere Monate aufbewahrt werden.

\subsection{Transformation in $\mathrm{CaCl}_{2}$-kompetente $\mathrm{E}$. coli}

Für die Transformation wurden die kompetenten Zellen auf Eis für ca. 5 min aufgetaut. Die zu transfizierende DNA wurde zu den Zellen gegeben (10 $\mu$ l eines Ligationsansatzes oder 10-100 ng Plasmid-DNA). Die Zellen wurden 30 min auf Eis gestellt und nach einem Hitzeschock von $45 \mathrm{~s}$ bei $42{ }^{\circ} \mathrm{C}$ erneut für 5 min auf Eis inkubiert. Nach Zugabe von $1 \mathrm{ml}$ LB-Medium wurden die Zellen 30 min (AmpicillinResistenz) oder eine Stunde (Kanamycin-Resistenz) bei $37{ }^{\circ} \mathrm{C}$ unter Schütteln inkubiert, um eine Expression der Resistenzkassette des transformierten Plasmids zu gewährleisten. Von den Zellen wurden etwa $100 \mu$ (bei Transformation eines 
Plasmids aus einer DNA-Präparation) oder der gesamte Ansatz (nach kurzer Zentrifugation zum Einengen der Zellen bei Ligationen) auf selektiven LB-Platten ausplattiert und über Nacht bei $37^{\circ} \mathrm{C}$ inkubiert.

Falls das verwendete Plasmid eine Blau-Weiß Selektion unterstützte und dies für die jeweilige Klonierung sinnvoll war, konnten vor dem Ausplattieren noch jeweils $40 \mu \mathrm{l}$ X-Gal (40 mg/ ml) und IPTG (1 M) auf den Platten verteilt werden. Dadurch verfärbten sich alle Kolonien, die nur das Plasmid ohne Insert aufgenommen hatten, auf der Platte blau und konnten für Plasmidpräparationen von vornherein ausgeschlossen werden.

\subsection{Southern Blot}

Um DNA auf einer immobilisierten Matrix mittels einer spezifischen Sonde nachweisen zu können, musste die DNA zuerst in einem Agarosegel elektrophoretisch aufgetrennt werden, um dann aus dem Gel auf eine Nylonmembran (Amersham, Uppsala, Schweden) transferiert zu werden. Der Southern Blot wurde ausschließlich mittels des Kapillarblotverfahrens durchgeführt. Falls ein Screening direkt aus Bakterienkolonien gewünscht war, wurde eine Koloniehybridisierung durchgeführt.

\subsection{Herstellung der Sonde}

Eine für den spezifischen Nachweis von DNA verwendete Sonde wurde entweder radioaktiv mit ${ }^{32} \mathrm{P}$-markiertem dATP, oder nicht-radioaktiv mit Digoxigenin-11markiertem dUTP hergestellt. Für den Nachweis von Plasmid-DNA aus Agarosegelen oder Bakterienkolonien wurden ausschließlich nicht-radioaktiv markierte Sonden verwendet. Aufgrund der höheren Sensitivität wurde für den Nachweis von DNA-Fragmenten aus genomischer DNA auf radioaktiv-markierte Sonden zurückgegriffen.

\section{a) nicht-radioaktiv}

Nicht-radioaktiv markierte Sonden wurden durch den PCR DIG Labeling Mix (Boehringer Mannheim) hergestellt. 
Hierbei wird Digoxigenin-11-dUTP, ein Analoges von dTTP zusammen mit dNTPs in einer PCR-Reaktion eingesetzt, so dass ein Teil der Nukleotide des Amplifikats mit Digoxigenin markiert sind. Diese können später durch spezifische anti-Digoxigenin Antikörper nachgewiesen werden.

$\begin{array}{cl}\text { Reaktionsansatz } & \\ \text { DNA } & \text { var. } \\ \mathrm{H}_{2} \mathrm{O} \text { bidest. } & \text { var. } \\ \text { Taq Polymerase Puffer 10x } & 5 \mu \mathrm{l} \\ \text { PCR DIG Labeling Mix 10x } & 5 \mu \mathrm{l} \\ \text { Primer }(5 \mu \mathrm{M}) & 5 \mu \mathrm{l} \\ \text { Primer }(5 \mu \mathrm{M}) & 5 \mu \mathrm{l} \\ \text { Taq DNA Polymerase }(5 \mathrm{U} / \mu \mathrm{l}) & 0,5 \mu \mathrm{l} \\ { } } & 50 \mu \mathrm{l}\end{array}$

verwendete PCR-Programme zur Generierung der Sonden:

verwendete Primer: 9-2/+, 9-10/-

(Kapitel 3.2.1.1)

$94{ }^{\circ} \mathrm{C}, 5 \mathrm{~min}$

$30 x\left(94^{\circ} \mathrm{C}, 90 \mathrm{~s} ; 55^{\circ} \mathrm{C}, 2 \mathrm{~min}, 72^{\circ} \mathrm{C}, 2 \mathrm{~min}\right)$

$$
\begin{aligned}
& 72^{\circ} \mathrm{C}, 10 \mathrm{~min} \\
& 4{ }^{\circ} \mathrm{C} \text {, Pause }
\end{aligned}
$$

verwendete Primer: Intr/+, P-12/-

(Kapitel 3.4.3.2)

$96{ }^{\circ} \mathrm{C}, 2 \mathrm{~min}$

$30 x\left(94^{\circ} \mathrm{C}, 45 \mathrm{~s} ; 55^{\circ} \mathrm{C}, 45 \mathrm{~s}, 72^{\circ} \mathrm{C}, 1 \mathrm{~min}\right)$

$72^{\circ} \mathrm{C}, 10 \mathrm{~min}$

$4{ }^{\circ} \mathrm{C}$, Pause

Die Sonden wurden nach der PCR-Reaktion auf einem Agarosegel elektrophoretisch aufgetrennt und aus dem Gel durch den Gene Clean II Kit (Qbiogene, Heidelberg) nach den Angaben des Herstellers aufgereinigt und bis zum Gebrauch bei $-20{ }^{\circ} \mathrm{C}$ aufbewahrt.

\section{b) radioaktiv}

Eine radioaktiv-markierte Sonde wurde mit Hilfe des Prime-It II Random Primer Labeling Kit (Stratagene, La Jolla, CA, USA) mit [a- $\left.{ }^{32} \mathrm{P}\right]$ dATP (Amersham Buchler, Braunschweig) markiert.

Dazu wurden $25 \mathrm{ng}$ DNA Template mit $10 \mu \mathrm{l}$ Random Primer (Stratagene, La Jolla, CA, USA) mit $\mathrm{H}_{2} \mathrm{O}$ bidest auf $34 \mu \mathrm{l}$ aufgefüllt, 5 min aufgekocht, danach kurz abzentrifugiert und auf Raumtemperatur heruntergekühlt. Nun wurden $10 \mu \mathrm{l} 5 \mathrm{x}$ Primer buffer (Stratagene), $5 \mu \mathrm{l}\left[\alpha^{32} \mathrm{P}\right]$ dATP $(3000 \mathrm{Ci} / \mathrm{mmol}$; Amersham) und $1 \mu \mathrm{l}$ 
Exo(-) Klenow-Enzym (Stratagene) zugegeben, gut vermischt und 10 min bei $37^{\circ} \mathrm{C}$ inkubiert. Die Reaktion wurde mit $2 \mu \mathrm{l}$ Stop Mix abgestoppt, ungebundene Nukleotide über den Qiaquick Nucleotide Removal Kit (Qiagen, Hilden) entfernt und die Sonde in $200 \mu \mathrm{l}$ Puffer EB (Qiagen) eluiert. Nach Bestimmung der inkorporierten Radioaktivität wurde die Sonde mit $10^{6} \mathrm{cpm} / \mathrm{ml}$ Hybridisierungspuffer im Southern Blot eingesetzt.

\subsection{Kapillarblot}

Vor dem eigentlichen Blotten musste die auf einem Agarosegel aufgetrennte DNA zunächst zerkleinert und in ihre Einzelstränge aufgetrennt werden. Dazu wurde das Gel aus dem Laufpuffer herausgeholt und $10 \min$ in $0,25 \mathrm{M} \mathrm{HCl}$ depuriniert, danach zwei mal 15 min in $0,5 \mathrm{M} \mathrm{NaOH} / 1,5 \mathrm{M} \mathrm{NaCl}$ denaturiert und anschließend zwei mal 20 min in $1 \mathrm{M}$ Tris-HCl/ $1,5 \mathrm{M} \mathrm{NaCl}(\mathrm{pH} 7,5)$ neutralisiert.

Das so behandelte Agarosegel wurde markiert, indem die rechte untere Ecke abgeschnitten wurde und mit der Rückseite nach oben (da sich die DNA eher unten befindet) auf eine Glasplatte gelegt. Um das Gel herum wurde eine ,Maske' aus Plastikmaterial gelegt, um sicherzustellen, dass sämtliche Flüssigkeit durch das Gel hindurch fließen muss.

Anschließend wurde für den Blot ein Sandwich aufgebaut, das von unten nach oben aus folgenden Komponenten bestand: eine Glasplatte, ein langer Streifen Filterpapier in der Breite des Gels, das Gel mit Maske aus Plastikmaterial, Nylonmembran (kurz in 2x SSC eingeweicht und luftblasenfrei auf das Gel gelegt), zwei dicke und zwei dünne Stücke Filterpapiere getränkt in 2x SSC. Oben auf das Sandwich wurde ein möglichst großer Stapel saugfähiger Papiertücher gelegt, der mit Klebeband an der Unterlage fixiert und mit einem Gewicht von etwa 0,5 kg beschwert wurde. Das fertige Sandwich wurde in eine Kunststoffschale gestellt die mit 20x SSC gefüllt war, die Enden des untersten langen Filterpapiersteifens in die Flüssigkeit getaucht und der Aufbau so über Nacht stehen gelassen (s. Abb. 3). 


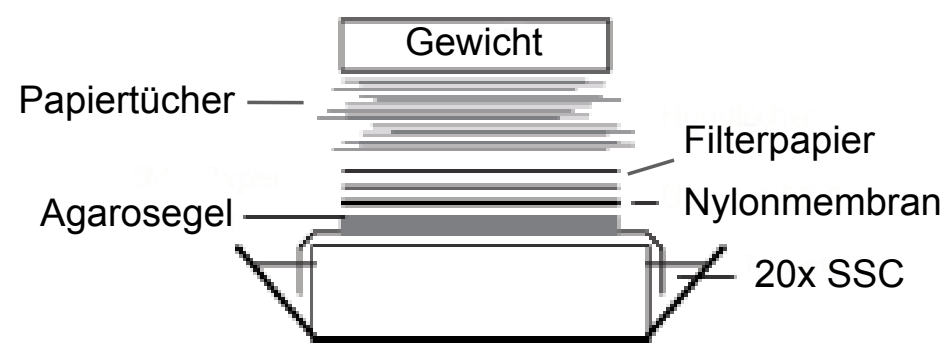

Abb. 3. Aufbau eines Kapillarblots.

Durch Kapillarkräfte zieht sich ein Flüssigkeitsstrom aus der Schüssel durch das Filterpapier, Gel, Nylonmembran und Filterpapiere bis in den Stapel Papiertücher, wodurch die DNA aus dem Gel auf die Membran geblottet wird.

Am nächsten Tag wurde das Sandwich abgebaut, die Taschen des Gels mit einem Kugelschreiber auf der Nylonmembran markiert, die Membran kurz in 2x SSC gewaschen und anschließend auf einem Papiertuch getrocknet. In einem UVCrosslinker wurde die DNA bei 1200 Joule für 1 min kovalent an die Membran gebunden.

Die Membran wurde entweder sofort für eine Hybridisierung weiterverwendet, oder getrocknet bei $-20^{\circ} \mathrm{C}$ aufgehoben.

\author{
20x SSC \\ $3 \mathrm{M} \mathrm{NaCl}$ \\ $300 \mathrm{mM}$ Natriumcitrat \\ $\mathrm{pH} 7,0$
}

\title{
2.2.2.1.10.3 Koloniehybridisierung
}

Mittels Koloniehybridisierung ist es möglich, spezifische DNA-Sequenzen in situ in Bakterienzellen nachzuweisen. Da durch die direkte Fixierung der durch Lyse der Bakterien freigesetzte DNA an eine Nylonmembran eine Isolierung aus den Zellen nicht notwendig ist, bietet die Koloniehybridisierung die Möglichkeit, eine große Kolonienzahl in kurzer Zeit auf das Vorhandensein bestimmter DNA-Sequenzen hin zu untersuchen. In dieser Arbeit wurde eine $\lambda \mathrm{DASH}$ genomische Bibliothek aus dem T. gondii Stamm $\mathrm{P}(\mathrm{LK})$ (Bohne et al., 1998) mit Hilfe der Koloniehybridisierung nach einem Klon untersucht, der eine Kopie von tgpma1 auf einem Cosmid trug. 
Hierzu wurden Bakterien der Cosmid Genbank auf LB/ Tetracyclin (10 $\mu \mathrm{g} / \mathrm{ml}$ ) Platten ausplattiert und über Nacht bei $37^{\circ} \mathrm{C}$ inkubiert.

Eine Nylonmembran der Größe einer Petrischale wurde ausgeschnitten, mit 2x SSC angefeuchtet, abgetupft und luftblasenfrei auf den Agar gelegt. Mit einer Kanüle und Tinte wurden am Rand der Membran mehrere Markierungen angebracht, um eine nachträgliche Zuordnung von Signalen auf der Membran mit bestimmten Klonen zu ermöglichen.

Die Membran wurde anschließend auf Filterpapier 5 min in $0,5 \mathrm{M} \mathrm{NaOH} / 1,5 \mathrm{M} \mathrm{NaCl}$ denaturiert. Nun wurde $5 \mathrm{~min}$ in $1 \mathrm{M}$ Tris-HCl/ 1,5 M NaCl $(\mathrm{pH} 7,5)$ neutralisiert und anschließend 5 min in 2x SSC gewaschen. Die so behandelte Membran wurde auf einem Filterpapier getrocknet und die DNA in einem UV-Crosslinker bei $1200 \mathrm{~J}$ für 1 min kovalent an die Membran gebunden. Analog zum Kapillarblot konnte die Membran sofort für eine Hybridisierung verwendet, oder für längere Zeit bei $-20{ }^{\circ} \mathrm{C}$ aufbewahrt werden.

\subsection{Hybridisierung der Membranen}

Um DNA spezifisch auf der Membran mittels einer DNA-Sonde nachweisen zu können, musste diese mit der Sonde hybridisiert werden. Hierbei wurden zwei verschiedene Protokolle angewendet, je nachdem, ob die verwendete Sonde mit Digoxigenin oder radioaktiv markiert war.

\section{a) nicht-radioaktiv}

Um zu verhindern, dass die Sonde unspezifisch an die Membran bindet, mussten zunächst freie Bindungsstellen auf der Nylonmembran blockiert werden. Dazu wurden auf die Membran in einem Hybridisierungsröhrchen etwa $20 \mathrm{ml}$ Hybridisierungslösung I luftblasenfrei zugegeben und $1 \mathrm{~h}$ bei $65^{\circ} \mathrm{C}$ in einem Hybridisierungsofen unter Drehen blockiert. In weiteren 20 ml Hybridisierungslösung I wurde die Sonde 10 min aufgekocht, damit die DNA einzelsträngig vorlag. Diese wurde nach dem Kochen sofort gegen die Hybridisierungslösung auf der Membran ausgetauscht und über Nacht im Hybridisierungsofen unter Drehen bei $65{ }^{\circ} \mathrm{C}$ inkubiert. Am nächsten Tag wurde die Membran kurz mit Waschlösung I gewaschen, mit $\mathrm{H}_{2} \mathrm{O}$ dest. gespült und anschließend im Hybridisierungsofen unter Drehen 30 min bei $65^{\circ} \mathrm{C}$ mit Waschlösung I gewaschen. 


\section{Hybridisierungslösung I}

$5 \times$ SSC

0,5\% Blocking-Reagenz (Boehringer Mannheim)

$0,1 \% \mathrm{~N}$-Lauroylsarkosin, Na-Salz

$$
0,02 \% \text { SDS }
$$

Waschlösung I

$0,5 \times$ SSC

$0,1 \%$ SDS

\section{b) radioaktiv}

Bei Verwendung einer radioaktiv markierten Sonde, wurde zunächst der Blot $1 \mathrm{~h}$ in einem Hybridisierungsröhrchen in Hybridisierungslösung II bei $60{ }^{\circ} \mathrm{C}$ wie oben beschrieben prähybridisiert. Nach Zugabe der durch 12 minütiges Kochen denaturierten DNA-Sonde wurde über Nacht bei $60^{\circ} \mathrm{C}$ hybridisiert. Anschließend wurde die Membran kurz mit Waschlösung III gespült, dann 3x $10 \mathrm{~min}$ in Waschlösung II bei $60^{\circ} \mathrm{C}$ und 2x 30 min in Waschlösung III bei $42^{\circ} \mathrm{C}$ gewaschen. Nach dem Trocknen der Membran konnte diese auf einem Röntgenfilm exponiert werden.

\section{Hybridisierungslösung II}

$10 \mathrm{ml} 5 x$ SSPE

$4 \mathrm{ml} 5 \mathrm{x}$ Denhardt's solution

$4 \mathrm{ml} 1 \%$ SDS

einzelsträngige Heringssperma-DNA

ad $40 \mathrm{ml}$ mit $\mathrm{H}_{2} \mathrm{O}$ bidest
Waschlösung II

2x SSPE

$0,1 \%$ SDS
Waschlösung III

$0,2 x$ SSPE

$0,1 \%$ SDS

\subsection{Detektion Digoxigenin-markierter Sonden, alkalische Phosphatase Färbung}

Zur Detektion einer Digoxigenin-markierten Sonde wurden Antikörper verwendet, die Digoxigenin spezifisch erkennen und an Alkalische Phosphatase gekoppelt sind; alle folgenden Schritte wurden bei Raumtemperatur durchgeführt. Hierzu wurde die Membran kurz mit Puffer I gewaschen, freie Bindungsstellen 30 min mit Puffer II unter Drehen blockiert und nochmals kurz mit Puffer I gewaschen. Das Schaf-antiDigoxigenin-alkalische Phosphatase Konjugat (Fab Fragment, Boehringer Mannheim) wurde 1:5000 in Puffer I verdünnt und 30 min unter Drehen an die Sonde gebunden. Hiernach wurde zwei mal 15 min in Puffer I gewaschen, anschließend 2 min in Puffer III äquilibriert. 
Anschließend folgte eine alkalische Phosphatase Färbung aus neun Teilen Puffer III, einem Teil NBT und 0,1 Teilen X-Phosphat. Die Lösung wurde $30 \mathrm{~min}$ bis $2 \mathrm{~h}$ im Dunkeln auf der Membran unter leichtem Schütteln verteilt, bis eine spezifische Färbung erkennbar war. Die Färbereaktion wurde durch Waschen der Membran mit $\mathrm{H}_{2} \mathrm{O}$ dest. gestoppt und die Membran anschließend auf einem Filterpapier getrocknet und aufbewahrt.

\author{
Puffer I \\ $0,1 \mathrm{M}$ Tris \\ $0,15 \mathrm{M} \mathrm{NaCl}$ \\ $\mathrm{pH} 7,5$
}

Puffer II

$5 \%$ Blocking-Reagenz

(Boehringer Mannheim) in

Puffer I

\section{Puffer III}

$0,1 \mathrm{M}$ Tris- $\mathrm{HCl}$

$0,1 \mathrm{M} \mathrm{NaCl}$

$50 \mathrm{mM} \mathrm{MgCl} 2$

$\mathrm{pH} 9,5$

NBT: $\quad 1 \mathrm{mg} / \mathrm{ml}$ 4-Nitroblau Tetrazoliumchlorid

X-Phosphat: $5 \mathrm{mg} / \mathrm{ml}$ 5-Bromo-4-Chloro-3-Indoylphosphat, Toluidin-Salz in

Dimethylformamid

\subsection{Detektion Digoxigenin-markierter Sonden, CSPD Färbung}

Für manche Versuche ist es nötig, eine möglichst hohe Sensitivität des Nachweisverfahrens zu verwenden. Wenn außerdem ein Blot für mehrere Färbungen verwendet werden soll, empfiehlt es sich, statt einer irreversiblen alkalischen Phosphatase-Färbung direkt auf der Membran ein Substrat zu verwenden, welches mittels Chemilumineszenz indirekt auf einem Röntgenfilm nachgewiesen werden kann.

Zu diesem Zweck wurde der Farbstoff CSPD (Boehringer Mannheim) verwendet. Der gewaschene Blot wurde kurz in CSPD Waschpuffer äquilibriert und anschließend 30 min in $100 \mathrm{ml} \mathrm{CSPD-Blocking} \mathrm{Buffer} \mathrm{blockiert.} \mathrm{Nun} \mathrm{wurde} \mathrm{Schaf-anti-Digoxigenin-}$ alkalische Phosphatase Konjugat in einer Verdünnung von 1/10000 dazugegeben und 30 min mit der Membran inkubiert. Überschüssige Antikörper wurden in 2x 15 min mit $100 \mathrm{ml}$ CSPD Waschpuffer entfernt und der Blot 3 min in 0,1 M Tris-HCl/ 0,1 $\mathrm{M} \mathrm{NaCl}, \mathrm{pH}$ 9,5 äquilibriert. Der Blot wurde auf einer Glasplatte mit $1 \mathrm{ml}$ CSPD Gebrauchslösung beschichtet und $5 \mathrm{~min}$ bei Raumtemperatur inkubiert. Überschüssige Flüssigkeit wurde vorsichtig entfernt, die feuchte Membran mit einer dünnen Plastikfolie luftblasenfrei verschlossen und zur Verstärkung der 
Chemilumineszenz $10 \mathrm{~min}$ im Dunkeln bei $37^{\circ} \mathrm{C}$ inkubiert. Anschließend wurde der so behandelte Blot 5 bis 20 min auf einem Röntgenfilm exponiert und entwickelt.

CSPD Waschpuffer

$0,1 \mathrm{M}$ Maleinsäure

$0,15 \mathrm{M} \mathrm{NaCl}, \mathrm{pH} 7,5$

$0,3 \%$ Tween 20

\section{CSPD-Blocking Buffer}

$0,1 \mathrm{M}$ Maleinsäure

$0,15 \mathrm{M} \mathrm{NaCl}, \mathrm{pH} 7,5$

1\% Blockierungsreagenz (Boehringer Mannheim)

\subsubsection{Proteine}

\subsubsection{Herstellung und Aufreinigung rekombinanter His-Tag Fusionsproteine}

\subsection{Prinzip des QiaExpress Systems}

QiaExpress (Qiagen) ist ein System zur Klonierung, Expression, Aufreinigung und Nachweis von rekombinanten Proteinen in dem E. coli Stamm M15(pREP4).

Die DNA-Sequenz, die das gewünschte Protein kodiert wird per PCR amplifiziert und in die Multiple Cloning Site des pQE30 Expressionsvektors kloniert. Auf dem Vektor befinden sich ein starker Phage-T5 Promotor mit zwei lac-Operon Sequenzen, ein eigenes ATG-Start Codon mit einem ,Tag' bestehend aus sechs Histidin-Resten und Stopp-Codons in allen Leserahmen. Die lac-Operons dienen der effizienten Repression des T5-Promotors. Lac-Repressor Protein, welches in relativ großen Mengen durch das pREP4-Plasmid des E. coli Wirtes M15(pREP4) konstitutiv exprimiert wird, bindet an die lac-Operons und verhindert so die Transkription am T5-Promotor. Setzt man IPTG hinzu, bindet dieses an das lacRepressor Protein, so dass eine Transkription am T5 Promoter stattfinden kann.

Die Transkripte werden daraufhin in das rekombinante Protein translatiert. Der Histidin-Tag am N-Terminus dient der Aufreinigung und des späteren Nachweises der Proteine. Sechs aufeinanderfolgende Histidin-Moleküle bilden eine Struktur aus, die spezifisch an Nickel-Nitrilotriessigsäure (Ni-NTA) bindet, was man zur Aufreinigung der Proteine nutzen kann. Ni-NTA Agarose (Ni-NTA gekoppelt an Sepharose) dient dabei als Matrix, an die spezifisch die rekombinanten His-Tag Fusionsproteine gebunden werden, wodurch sie sich aus E. coli Lysat isolieren lassen. Mittels Antikörpern, die spezifisch den His-Tag erkennen, lassen sich die so aufgereinigten Proteine in späteren Experimenten nachweisen. 
In dieser Arbeit wurden zwei rekombinante His-Tag Fusionsproteine aus dem Loop und dem C-Terminus von TgPMA1 kloniert, in E. coli exprimiert und aufgereinigt.

\subsection{Expression der rekombinanten Loop und C-Terminus Proteine}

Zum Nachweis der Induzierbarkeit und Expression der His-Tag Fusionsproteine, wurden jeweils zwei Klone für Loop- (L2, L3) und C-Terminus (C4, C5) ausgewählt und in $3 \mathrm{ml}$ LB-Medium mit $100 \mu \mathrm{g} / \mathrm{ml}$ Ampicillin und $25 \mu \mathrm{g} / \mathrm{ml}$ Kanamycin über Nacht bei $37^{\circ} \mathrm{C}$ im Schüttelinkubator inkubiert. Am nächsten Tag wurde $1 \mathrm{ml}$ der Übernachtkulturen in $25 \mathrm{ml}$ LB-Medium mit $100 \mu \mathrm{g} / \mathrm{ml}$ Ampicillin und $25 \mu \mathrm{g} / \mathrm{ml}$ Kanamycin verdünnt und bis zu einer optischen Dichte von $\mathrm{OD}_{600}=0,5-0,7$ hochgezogen. Nun wurde von jeder Kultur ein Aliquot von $1 \mathrm{ml}$ abgenommen und Proteinexpression in der übrigen Kultur durch Zugabe von IPTG (Endkonzentration 1 $\mathrm{mM}$ ) induziert. Nach weiteren $5 \mathrm{~h}$ Inkubation wurden die Kulturen zusammen mit den zuvor entnommenen nicht-induzierten Aliquots durch Zentrifugation pelletiert und in PBS aufgenommen.

Vergleichbare Mengen aller Aliquots wurden auf einem SDS-Polyacrylamidgel aufgetrennt und analysiert.

\subsection{Optimierung der Protein-Aufreinigungsbedingungen}

Aus einer Übernachtkultur der Klone L2 und C5 wurde $1 \mathrm{ml}$ auf $15 \mathrm{ml}$ LB-Medium mit $100 \mu \mathrm{g} / \mathrm{ml}$ Ampicillin und $25 \mathrm{\mu g} / \mathrm{ml}$ Kanamycin überimpft und im Schüttelinkubator bei $37^{\circ} \mathrm{C}$ bis zu einer $\mathrm{OD}_{600}$ von 0,6 inkubiert. Ein Aliquot von $1 \mathrm{ml}$ wurde aus jeder Kultur entnommen, pelletiert und zur späteren Verwendung bei $-20^{\circ} \mathrm{C}$ aufbewahrt. Der Rest wurde durch Zusatz von IPTG (Endkonzentration $1 \mathrm{mM}$ ) induziert und weitere $5 \mathrm{~h}$ im Schüttelinkubator inkubiert. Die $\mathrm{OD}_{600}$ von beiden Kulturen wurde erneut gemessen $(L 2=1,48 ; C 5=1,38)$ und von jeder jeweils zwei mal $1 \mathrm{ml}$ pelletiert und zur späteren Verwendung bei $-20^{\circ} \mathrm{C}$ aufbewahrt.

\subsection{1 Native Proteinaufreinigung, Optimierung}

Je ein Pellet der induzierten L2 und C5 Kulturen wurde auf Eis aufgetaut und in 100 $\mu \mathrm{l}$ Lysepuffer aufgenommen, ein Aliquot (A1) von $10 \mu$ entnommen und weggefroren. Lysozym wurde zu einer Endkonzentration von $1 \mathrm{mg} / \mathrm{ml}$ zugesetzt, $30 \mathrm{~min}$ auf Eis 
inkubiert und die Zellen schließlich durch Vortexen lysiert. Das Lysat wurde im Anschluss $10 \mathrm{~min}$ bei $14000 \mathrm{rpm}$ in einer Eppendorfzentrifuge zentrifugiert, der Überstand abgenommen, erneut ein Aliquot (A2) von $10 \mu \mathrm{l}$ entnommen und weggefroren. Zum restlichen Überstand wurden $20 \mu \mathrm{l} \mathrm{Ni-NTA} \mathrm{Agarose} \mathrm{zugesetzt} \mathrm{und}$ $30 \mathrm{~min}$ bei $4^{\circ} \mathrm{C}$ auf einem Überkopfschüttler bei $200 \mathrm{rpm}$ das Fusionsprotein an die Matrix gebunden. Die Ni-NTA Agarose mit gebundenem Fusionsprotein wurde im Anschluss für $10 \mathrm{~s}$ bei $14000 \mathrm{rpm}$ pelletiert, ein $10 \mu \mathrm{l}$ Aliquot (A3) vom Überstand abgenommen und der Rest verworfen. Das verbleibende Ni-NTA Agarose Pellet wurde zwei mal mit je $100 \mu \mathrm{l}$ Waschpuffer gewaschen, nach dem zweiten Waschschritt ein $10 \mu \mathrm{l}$ Aliquot (A4) des Überstandes entnommen und das gebundene Fusionsprotein danach drei mal mit jeweils $20 \mu$ Elutionspuffer von der Matrix eluiert (A5-7).

Vergleichbare Mengen aller Aliquots wurden zusammen mit je $10 \mu \mathrm{l}$ des induzierten und des nicht-induzierten E. coli Lysats durch SDS-PAGE aufgetrennt und die Proteine im Anschluss durch Coomassie-Färbung sichtbar gemacht.

$\begin{array}{ccc}\text { Lysepuffer } & \text { Waschpuffer } & \text { Elutionspuffer } \\ 50 \mathrm{mM} \mathrm{NaH}_{2} \mathrm{PO}_{4}, \mathrm{pH} 8,0 & 50 \mathrm{mM} \mathrm{NaH}_{2} \mathrm{PO}_{4}, \mathrm{pH} 8,0 & 50 \mathrm{mM} \mathrm{NaH}_{2} \mathrm{PO}_{4}, \mathrm{pH} 8,0 \\ 300 \mathrm{mM} \mathrm{NaCl} & 300 \mathrm{mM} \mathrm{NaCl} & 300 \mathrm{mM} \mathrm{NaCl} \\ 10 \mathrm{mM} \text { Imidazol } & 20 \mathrm{mM} \text { Imidazol } & 250 \mathrm{mM} \text { Imidazol }\end{array}$

\subsection{Denaturierende Proteinaufreinigung, Optimierung}

Die Pellets der induzierten L2 und C5 Kulturen wurden auf Eis aufgetaut, in $200 \mu \mathrm{l}$ Puffer B resuspendiert und $5 \mu \mathrm{l}$ für Aliquot $\mathrm{A} 1$ abgenommen. Die Zellen wurden durch Vortexen lysiert und die Zellreste durch Zentrifugation $10 \mathrm{~min}$ bei $14000 \mathrm{rpm}$ pelletiert. $5 \mu \mathrm{l}$ des Überstandes wurden für A2 abgenommen, der Rest mit $50 \mu \mathrm{l} \mathrm{Ni-}$ NTA Agarose versetzt und wie bei der nativen Proteinaufreinigung 30 min bei $4^{\circ} \mathrm{C}$ im Überkopfschüttler vermischt. Die Matrix wurde $10 \mathrm{~s}$ bei $14000 \mathrm{rpm}$ pelletiert, 1,25 $\mu \mathrm{l}$ des Überstandes für A3 abgenommen, der Rest verworfen. Das Waschen erfolgte einmal mit $250 \mu$ l Puffer $C(6,25 \mu$ für A4 abgenommen) und einmal mit $250 \mu$ Puffer D $(6,25 \mu \mathrm{l}$ Aliquot für A5). Schließlich wurde das Fusionsprotein durch dreimalige Elution mit je $25 \mu \mathrm{l}$ Puffer $E$ (je 0,6 $\mu$ l entsprechen A6, A7 und A8) wieder von der Matrix eluiert. 
Alle Aliquots wurden durch SDS-PAGE aufgetrennt und anschließend mit ComassieBlau gefärbt.

$\begin{array}{ccc}\text { Puffer B (Lysepuffer) } & \text { Puffer C (Waschpuffer) } & \text { Puffer D (Elutionspuffer) } \\ 8 \mathrm{M} \mathrm{Harnstoff} & 8 \mathrm{M} \mathrm{Harnstoff} & 8 \mathrm{M} \text { Harnstoff } \\ 0,1 \mathrm{M} \mathrm{NaH}_{2} \mathrm{PO}_{4} & 0,1 \mathrm{M} \mathrm{NaH}_{2} \mathrm{PO}_{4} & 0,1 \mathrm{M} \mathrm{NaH}_{2} \mathrm{PO}_{4} \\ 0,01 \mathrm{M} \text { Tris-Cl, pH } 8,0 & 0,01 \mathrm{M} \mathrm{Tris-Cl}, \mathrm{pH} 6,3 & 0,01 \mathrm{M} \text { Tris-Cl, pH 5,9 }\end{array}$

Puffer E (Elutionspuffer)

\author{
8 M Harnstoff \\ $0,1 \mathrm{M} \mathrm{NaH}_{2} \mathrm{PO}_{4}$ \\ 0,01 M Tris-Cl, $\mathrm{pH} 4,5$
}

\title{
2.2.2.2.1.4 Denaturierende Proteinaufreinigung, präparativ
}

Zur präparativen Aufreinigung der His-Tag Fusionsproteine wurden L2 und C5 in je 2x 0,5 I in LB-Medium mit $100 \mu \mathrm{g} / \mathrm{ml}$ Ampicillin und $25 \mu \mathrm{g} / \mathrm{ml}$ Kanamycin aus einer Übernachtkultur angeimpft, bis zu einer $\mathrm{OD}_{600}$ von 0,6 bis 0,7 im Schüttelinkubator bei $37{ }^{\circ} \mathrm{C}$ inkubiert, je $1 \mathrm{ml}$ abgenommen, pelletiert und bei $-20{ }^{\circ} \mathrm{C}$ zur späteren Verwendung aufbewahrt. Nach Induktion der Proteinexpression mit 1 mM IPTG wurde weitere $5 \mathrm{~h}$ inkubiert, anschließend die Kulturen durch Zentrifugation pelletiert und die Pellets gewogen (zwischen 1,6 und 4,4 g). Die Pellets wurden in $5 \mathrm{ml}$ Puffer B pro Gramm Nassgewicht aufgenommen, jeweils die beiden L2 und C5 Kulturen gepoolt und für 60 min auf dem Überkopfschüttler bei $4{ }^{\circ} \mathrm{C}$ lysiert. Die Zellreste wurden durch $30 \mathrm{~min}$ Zentrifugation bei $10000 \mathrm{~g}$ abgetrennt und der Überstand abgenommen. Pro $4 \mathrm{ml}$ Lysat wurde $1 \mathrm{ml}$ Ni-NTA Agarose zugegeben und für $60 \mathrm{~min}$ bei Raumtemperatur auf dem Überkopfschüttler die His-Tag Fusionsproteine an die Matrix gebunden.

Ein Gradi-Frac System (Amersham Pharmacia, Uppsala, Schweden) wurde mit Puffer B durchgespült, das Ni-NTA Agarose Gemisch mit dem Lysat auf eine leere Säule gegeben und der Durchfluss so weit abgelassen und für spätere Verwendung aufbewahrt, bis nur noch die Ni-NTA Agarose auf der Fritte mit wenig Flüssigkeit in der Säule blieb. An einem an das System angeschlossenen Schreiber konnten eluierte Proteine in den einzelnen Fraktionen beim Durchlaufen des Systems sichtbar gemacht werden. Die Säule wurde an das System angeschlossen und so viel Puffer B zugegeben, bis sich an dem Schreiber ein konstanter Wert eingestellt hatte. 
Anschließend wurde vier mal mit Puffer $C$ und vier mal mit Puffer D gewaschen, bis sich ein konstanter Wert eingestellt hatte. In beiden Proben war ein leichter Proteinpeak bei dem jeweils zweiten Waschschritt mit Puffer C und D erkennbar. Anschließend wurden die His-Tag Fusionsproteine mit Puffer E von der Säule gelöst, wobei mehrere kleine Fraktionen getrennt aufgenommen wurden. Nachdem sich ein konstanter Wert eingestellt hatte wurde zusätzlich stringenter unter saurerem $\mathrm{pH}$ Wert mit Puffer E, pH 3,5 gewaschen, um restliche noch gebundene Proteine von der Säule zu lösen.

Die Säule wurde vom System abgekoppelt, mit 0,2 M Essigsäure+ 30\% Glycerin durchgespült, die Gelmatrix aufgeschüttelt, sämtliche Flüssigkeit ablaufen lassen, mit $30 \%$ Ethanol aufgefüllt, verschlossen und bei $4^{\circ} \mathrm{C}$ aufbewahrt.

\subsubsection{Proteinbestimmung}

Eine Bestimmung der Proteinkonzentration erfolgte im Prinzip nach der Methode von Lowry et al. (1951) mit Hilfe des BCA Protein Assay Kits (Pierce, Rockford, IL, USA) nach den Angaben des Herstellers.

\subsubsection{SDS-Gelelektrophorese}

Um Proteine elektrophoretisch aufzutrennen, wurden diese auf SDSPolyacrylamidgele geladen und im elektrischen Feld indirekt nach ihrer Größe aufgetrennt.

Die zu untersuchenden Proteine wurden mit vierfach konzentriertem SDSProbenpuffer im Verhältnis 1:4 gemischt, $5 \mathrm{~min}$ auf $100{ }^{\circ} \mathrm{C}$ erhitzt und auf SDSPolyacrylamidgele aufgetragen. Parallel wurde ein Gemisch von Markerproteinen bekannten Molekulargewichts aufgetragen.

Die SDS-PAGE wurde nach der Methode von Laemmli (1970) unter denaturierenden Bedingungen in 0,75 mm dicken Vertikalgelen durchgeführt. Für die Herstellung der Gele wurden zunächst die Trenngele mit ca. 12\% Polyacrylamid zum Nachweis von Proteinen unter $100 \mathrm{kDa}$ und 7,5\% Polyacrylamid zum Nachweis von größeren Proteinen in die Gelkammern gegossen. Bis zur vollständigen Polymerisation der Trenngele wurden sie vorsichtig mit Isopropanol überschichtet. Nach dem Entfernen 
des Alkohols durch gründliches Waschen wurde ein 4,4\%iges Sammelgel auf das Trenngel gegossen und der Probenkamm luftblasenfrei eingesetzt.

Nach dem Probenauftrag erfolgte die Gelelektrophorese mit einem diskontinuierlichen Laufpuffer bei 25 mA pro Gel für etwa 90 min bis die Bromphenolblaufront aus dem Gel herauslief.

Trenngel, $7,5 \% \quad$ Trenngel, ca. $12 \%$

750 mM Tris, pH 8,8

$2,5 \mathrm{ml}$

$2,5 \mathrm{ml}$

Acrylamid/ Bisacrylamid 30\% $(30 / 0,8)$

$1,25 \mathrm{ml}$

$1,94 \mathrm{ml}$

SDS $10 \%$

$121 \mu \mathrm{l}$

$121 \mu \mathrm{l}$

$\mathrm{H}_{2} \mathrm{O}$ bidest.

$1,1 \mathrm{ml}$

$0,875 \mathrm{ml}$

APS $10 \%$

$20 \mu \mathrm{l}$

$20 \mu \mathrm{l}$

TEMED

$10 \mu \mathrm{l}$

$10 \mu \mathrm{l}$

\section{Sammelgel, $4,4 \%$}

250 mM Tris, pH 6,8

$1,25 \mathrm{ml}$

Acrylamid/ Bisacrylamid 30\% $(30 / 0,8)$

$250 \mu \mathrm{l}$

SDS $10 \%$

$25 \mu l$

$\mathrm{H}_{2} \mathrm{O}$ bidest.

$1 \mathrm{ml}$

APS 10\%

$10 \mu \mathrm{l}$

TEMED

$10 \mu \mathrm{l}$

Bromphenolblau 1\%

$10 \mu \mathrm{l}$

\section{Laufpuffer}

25 mM Tris, $\mathrm{pH} 8,3$

0,2 M Glycin

$0,1 \%$ SDS

\author{
Zweifach-Probenpuffer \\ $20 \%$ Glycerin \\ $65 \mathrm{mM}$ Dithiothreitol (DTT) \\ $4 \%$ SDS \\ 0,004\% Bromphenolblau \\ 125 mM Tris- $\mathrm{HCl}, \mathrm{pH}$ 6,8
}

\subsection{Coomassie-Färbung}

Um Proteine auf dem SDS-Polyacrylamidgel sichtbar zu machen, wurden die Gele nach Beendigung der Elektrophorese für mindestens $2 \mathrm{~h}$ bei Raumtemperatur in Coomassie-Färbelösung geschwenkt (Weber et al., 1972). Farbrückstände wurden 
anschließend durch Schwenken für $45 \mathrm{~min}$ in einem Entfärbebad herausgewaschen. Danach wurden die Gele in $1 \%$ Glycerin in $\mathrm{H}_{2} \mathrm{O}$ dest. mit ebenfalls in dieser Lösung angefeuchteter Einmachfolie mehrere Tage in einem Rahmen getrocknet.

\author{
Coomassie-Färbelösung \\ $50 \%$ Methanol \\ $10 \%$ Essigsäure \\ $0,1 \%$ Coomassie Brilliant Blue
}

Coomassie-Entfärbelösung

$10 \%$ Methanol

$5 \%$ Essigsäure

\title{
2.2.2.2.5 Western Blot
}

Die durch SDS-PAGE aufgetrennten Proteine wurden durch Semi-Dry-Blotting (Kyhse-Andersen, 1984) elektrophoretisch auf Nitrozellulose-Membranen (Hybond ECL Nitrocellulose Membrane, Amersham Büchler, Braunschweig) übertragen.

Die Transfereinheit war wie folgt aufgebaut:

- Graphitelektrode (Kathode)

- 1 Filterpapier dick

- 1 Whatman Filterpapier dünn

- SDS-PAGE Gel

- Nitrocellulose-Membran

- 1 Whatman Filterpapier dünn

- 1 Filterpapier dick

- Graphitelektrode (Anode)

Alle Bestandteile der Transfereinheit, außer dem Gel, waren in Western-Blot Puffer getränkt und wurden während des Aufbaus feucht gehalten.

Die Proteine wurden mit $0,8 \mathrm{~mA} / \mathrm{cm}^{2}$ Transferfläche für $90 \mathrm{~min}$ auf die NitrozelluloseMembran übertragen. Zur Kontrolle des Transfers wurde die Membran anschließend für 2 min in Ponceau S Lösung inkubiert und anschließend mit destilliertem Wasser entfärbt. Mit dieser Färbung konnte zusätzlich eine gleichmäßige Beladung aller Spuren kontrolliert werden.

Um spezifische Proteine mittels einer Immunfärbung nachzuweisen, wurden zunächst unspezifische Bindungsstellen über Nacht bei $4{ }^{\circ} \mathrm{C}$ in Blockierlösung abgesättigt. Nach kurzem Waschen in Waschlösung wurde die Membran $2 \mathrm{~h}$ mit dem 
Primärantikörper in der angegebenen Konzentration in Inkubationslösung inkubiert. Nach 3x 10 min Waschen in Waschlösung wurde $1 \mathrm{~h}$ mit dem Sekundärantikörper (Peroxidase-konjugiertes Ziege-anti-Kaninchen IgG oder Peroxidase-konjugiertes Ziege-anti-Maus IgG) in Inkubationslösung inkubiert. Anschließend wurde intensiv mit Waschlösung gewaschen (mind. 3x 20 min). Die Membran wurde ca. 2 min in Peroxidase-Färbelösung inkubiert bis ein Signal zu erkennen war und die Färbereaktion durch Waschen mit $\mathrm{H}_{2} \mathrm{O}$ gestoppt.

Western Blot Puffer

$25 \mathrm{mM}$ Tris

$150 \mathrm{mM}$ Glycin

$20 \%$ Methanol

Waschlösung

0,02\% Tween 20

in PBS
Blockierlösung

5\% Magermilchpulver

0,2\% Tween 20

$0,02 \% \mathrm{NaN}_{3}$

in PBS

\section{Inkubationslösung}

$5 \%$ Magermilchpulver

$0,02 \%$ Tween 20 in PBS

\section{Peroxidase-Färbelösung}

1,25 ml 1 M Tris, pH 7,5

$1,25 \mathrm{ml} 10 \% \mathrm{NiCl}_{2}$

$15 \mu \mathrm{l} 30 \% \mathrm{H}_{2} \mathrm{O}_{2}$

Spatelspitze 3,3'-Diaminobenzidin

$22,5 \mathrm{ml} \mathrm{H}_{2} \mathrm{O}$ dest.

\subsubsection{Tierexperimente und Antikörperaufreinigung}

\subsubsection{Immunisierung von Mäusen zur Antikörpergewinnung}

Um Antiseren gegen TgPMA1 zu gewinnen, wurden jeweils 4 Balb/c Mäuse (6- 8 Wochen alt) mit den aufgereinigten His-Tag Fusionsproteinen aus dem C-Terminus bzw. dem Loop von TgPMA1 immunisiert. Je 0,5 mg aufgereinigtes Protein in $2 \mathrm{ml}$ PBS wurden in einem Fläschchen Adjuvans ABM-S (Antibody-Multiplier spezial, Linaris, Bettingen) nach den Angaben des Herstellers gelöst und mit diesem vermengt. Je 0,1 ml der Emulsion wurde intramuskulär in den Beinmuskel und subkutan in den Nacken jeder Maus gespritzt. Zur Nachboosterung nach zwei Wochen wurde ABM-N (Antibody-Multiplier normal, Linaris) verwendet, in dem jeweils $0,5 \mathrm{mg}$ His-Tag Fusionsprotein gelöst worden war. Dieses wurde wie oben 
den Mäusen injiziert. Nach weiteren zwei Wochen erfolgte eine weitere Boosterung mit ABM-N, um nach insgesamt sechs Wochen die Mäuse auszubluten. Nach $3 \mathrm{~h}$ bei Raumtemperatur wurde das inzwischen geronnene Blut $5 \mathrm{~min}$ bei $3000 \mathrm{rpm}$ und $4{ }^{\circ} \mathrm{C}$ abzentrifugiert, das Serum abgenommen und zur Konservierung mit 0,02\% $\mathrm{NaN}_{3}$ versetzt.

\subsubsection{Affinitätschromatographie über CNBr-aktivierte Sepharose B}

Zur Erhöhung der Spezifiät der durch Immunisierung mit dem Loop-His-Tag Fusionsprotein gewonnenen Maus-Antiseren, sollten durch eine Affinitätschromatographie nur die für das Fusionsprotein spezifischen Antikörper angereichert werden.

Als Matrix zur Immobilisierung des Liganden wurde CNBr-aktivierte Sepharose 4B (Pharmacia, Erlangen) ausgewählt. Zur Vorbereitung des Gels wurde $1 \mathrm{~g}$ der gefriergetrockneten Sepharose mit $200 \mathrm{ml} 1 \mathrm{mM} \mathrm{HCl}$ für 15 min gewaschen. 1,2 ml der nun gequollenen Sepharose wurde auf eine leere Säule gegeben, nach dem Absetzen der Säulenmatrix zwei mal mit $5 \mathrm{ml} \mathrm{H}_{2} \mathrm{O}$ bidest. gewaschen und die Säule unten verschlossen.

$1,2 \mathrm{mg}$ des aufgereinigten Loop-His-Tag Fusionsproteins wurden in $1,2 \mathrm{ml}$ Kopplungspuffer gelöst, mit der Säulenmatrix vermischt und die verschlossene Säule zur Kopplung des Peptids an die Sepharose $2 \mathrm{~h}$ bei Raumtemperatur in einem Überkopfschüttler vermischt. Überschüssige Liganden wurden durch Waschen mit 6 Volumina Kopplungspuffer entfernt und die übrigen aktiven Bindestellen der Sepharose in Blockierungspuffer für $2 \mathrm{~h}$ blockiert. Vor der Zugabe des Serums wurde die Säule noch drei mal alternierend mit Waschpuffer I, gefolgt von Waschpuffer II gewaschen. Anschließend wurde die Säule einmal mit PBS gespült, das Kaninchenanti-Peptid Serum 1:1 mit PBS verdünnt und auf die jeweilige Säule gegeben. Der Durchfluss wurde jeweils aufgefangen und insgesamt zwei mal über die Säule laufen lassen um möglichst alle für die Peptide spezifischen Antikörper an diese zu binden. Nach zweimaligem Waschen mit PBS wurden die gebundenen Antikörper mit $15 \mathrm{mM}$ $\mathrm{NaOH}$ eluiert und in Eppendorf-Caps aufgefangen, in denen 0,2 M Tris, pH 7/ 0,5 M $\mathrm{NaCl}$ vorgelegt war. 


\section{Kopplungspuffer}

$0,1 \mathrm{M} \mathrm{NaHCO}_{3}$

$0,5 \mathrm{M} \mathrm{NaCl}$

$\mathrm{pH} 8,3$

\section{Blockierungspuffer}

$0,1 \mathrm{M}$ Tris- $\mathrm{HCl}$

$\mathrm{pH} 8,0$

\section{Waschpuffer I}

0,1 M Azetat-Puffer

$0,5 \mathrm{M} \mathrm{NaCl}$

$\mathrm{pH} 4,0$

\section{Waschpuffer II}

0,1 M Tris- $\mathrm{HCl}$

$0,5 \mathrm{M} \mathrm{NaCl}$

$\mathrm{pH} 8,3$

\subsubsection{Affinitätschromatographie mit dem HydraS Activated Affinity Resin Kit}

Zur Erhöhung der Spezifität der Kaninchen-anti-Peptidantiseren sollten durch eine Affinitätschromatographie nur die für die jeweiligen Peptide spezifischen Antikörper angereichert werden.

Zur Immobilisierung der Liganden wurde der HydraS activated affinity resin kit (ImmunoTec, Marl) ausgewählt. Die HydraS Matrix reagiert dabei während der Kopplungsreaktion mit primären oder sekundären Aminogruppen des Proteins und präsentiert diese über acht-C-Atome lange hydrophile Spacer dem Serum, das über die Säule gegeben wird.

Jeweils ca. $4 \mathrm{mg}$ der Peptide WB1 und WB2 wurden mit $5 \mathrm{ml}$ Coupling Buffer vermengt, mit je $5 \mathrm{ml}$ der aktivierten HydraS Matrix versetzt und bei Raumtemperatur für $36 \mathrm{~h}$ im Überkopfschüttler an die Matrix gebunden. Um restliche freie Bindungsstellen zu blockieren, wurden $7 \mathrm{ml}$ Blocking Buffer zugesetzt und weitere 5 h im Überkopfschüttler inkubiert. Das Gemisch wurde auf die untere Fritte einer verschlossenen leeren Säule pipettiert, nach dem Absetzen der Säulenmatrix die obere Fritte eingesetzt und das $\mathrm{Gel}$ drei mal mit je $30 \mathrm{ml} \mathrm{H}_{2} \mathrm{O}$ bidest. und anschließend mit $25 \mathrm{ml}$ Elution Buffer gewaschen. Die Säulen wurden mit drei mal 30 ml PBS äquilibriert und das mit PBS verdünnte Kaninchen-anti-Peptid-Serum drei mal über die Säule gegeben, an die das jeweilige Peptid gekoppelt war. Nach Waschen mit 5x 15 ml PBS wurden die an die Peptide gebundenen Antikörper mit je $50 \mathrm{ml}$ Elution Buffer von der Säule eluiert und in Fraktionen zu je ca. $5 \mathrm{ml}$ aufgefangen.

Anschließend wurden die Säulen einmal mit PBS/ 0,1\% $\mathrm{NaN}_{3}$ über Nacht bei $4^{\circ} \mathrm{C}$ gespült, und in weiteren $30 \mathrm{ml} \mathrm{PBS} / 0,1 \% \mathrm{NaN}_{3}$ bei $4{ }^{\circ} \mathrm{C}$ aufbewahrt. 


\section{Ergebnisse}

\subsection{Eigenschaften von TgPMA1}

Ein den vollständigen offenen Leserahmen von tgpma1 umfassender 3,1 kb cDNA Klon wurde sequenziert und konzeptionell translatiert.

Abhängig vom prognostizierten Startcodon kodiert der offene Leserahmen für 1151, bzw. 1039 Aminosäuren, was einem errechneten Molekulargewicht von 127, bzw. $116 \mathrm{kDa}$ entspricht. Dies ist etwas mehr als die durchschnittliche Größe von P-Typ Plasmamembran Protonen-ATPasen aus anderen Spezies von ca. 100 kDa. Ein Hydropathie-Plot zeigt das für diese Klasse von Proteinen typische Bild von 10 Transmembrandomänen und vier zytoplasmatischen Domänen mit einem kleinen und einem großen zytoplasmatischen Loop, wie in Abb. 4 dargestellt (Serrano, 1988; Lutsenko \& Kaplan, 1995).

\subsubsection{Homologievergleich mit anderen P-Typ ATPasen}

Ein Homologievergleich (Aminosäure gegen translatierte DNA) liefert größte Ähnlichkeit zu einer P-Typ ATPase der Rotalge Cyanidium caldarium mit einem P-Wert von $\mathrm{e}^{-119}$ und $27,7 \%$ Identität auf Aminosäure-Ebene. Neben Homologen aus Rotalgen und Archaebakterien wie Methanococcus jannaschii $\left(P=\mathrm{e}^{-112}\right)$ zeigen vor allem Homologe aus höheren Pflanzen wie Arabidopsis thaliana $\left(P=e^{-110}\right)$, Lycopersicum esculentum $\left(P=e^{-110}\right)$ oder Prunus persica $\left(P=e^{-109}\right)$ größere Ähnlichkeiten zu TgPMA1 als solche aus Pilzen wie Saccharomyces cerevisiae $\left(P=\mathrm{e}^{-102}\right)$. Als Beispiel für das Ausmaß der Ähnlichkeit hochkonservierter Bereiche wurde der große zytoplasmatische Loop von TgPMA1 mit jeweils einem Vertreter der Rotalgen, Archaebakterien, Parasiten und Pilze verglichen (s. Anhang, Abb. 22). 
A)

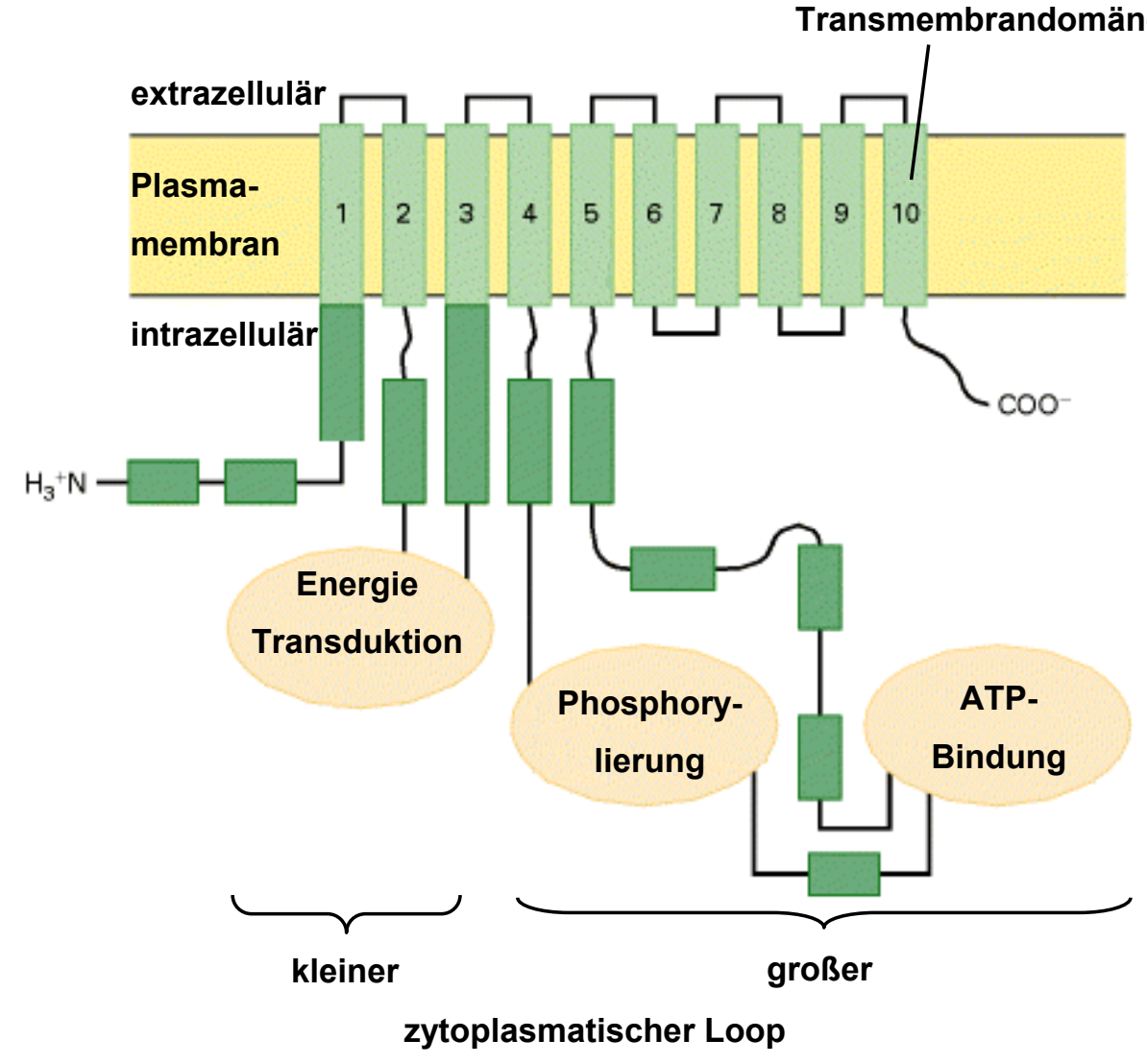

B)

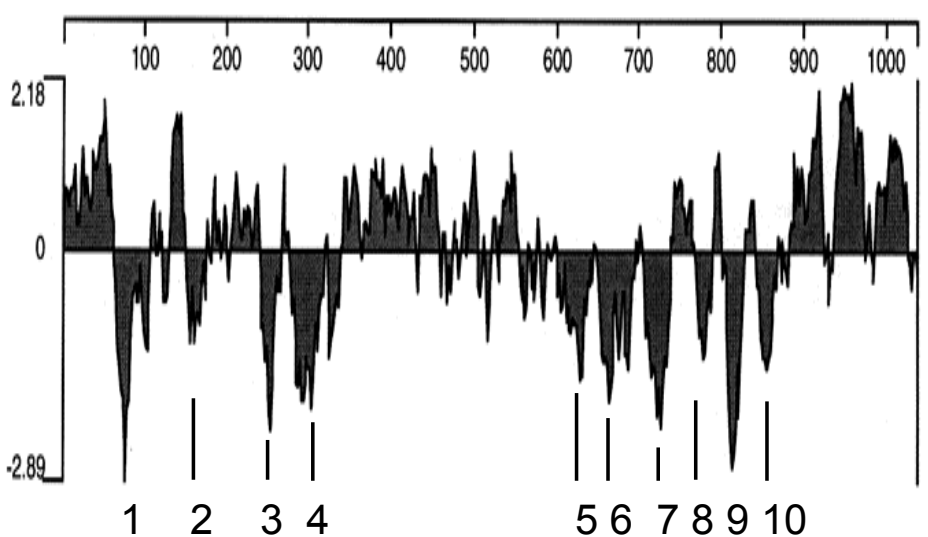

Abb. 4. A) Modell von P-Typ Plasmamembran-ATPasen. Typisch für diese Klasse von Proteinen sind die 8- 10 Transmembrandomänen, der kleine und große zytoplasmatische Loop mit ATP-Bindungsund Phosphorylierungsstelle. Modifiziert aus Lodish et al., 2000. B) Hydropathie-Plot von TgPMA1 mit voraussichtlich 10 Transmembrandomänen. Die in dieser Darstellung negativen Werte weisen auf Transmembrandomänen hin.

\subsubsection{Expressionsprofil von tgpma1}

Um die Stadienspezifität der Expression von tgpma1 experimentell zu bestätigen und festzustellen, wann in der Differenzierung zum Bradyzoiten tgpma1 exprimiert wird, wurde eine semiquantitative RT-PCR an in vitro differenzierten Bradyzoiten zu verschiedenen Zeiten nach Induktion der Differenzierung durchgeführt. 
Tachyzoiten des Stammes Prugniaud/HX wurden auf einem konfluenten Zellrasen HFFs in T25 Zellkulturflaschen 6 Tage lang einem pH-Shift $(\mathrm{pH}=8,2)$ unterzogen, wobei 2, 4 und 6 Tage nach Induktion des pH-Shifts Parasiten geerntet wurden. Als Kontrolle wurden Tachyzoiten zwei Tage nach Infektion von HFFs in DMEM/ 1\% FCS verwendet.

Die Parasiten wurden durch Filtration von den Wirtszellresten getrennt, Gesamt-RNA isoliert und die mRNA in cDNA umgeschrieben.

In einer semiquantitativen RT-PCR wurden die Mengen der so gewonnenen cDNAProben durch Vergleich der Expressionsstärke des konstitutiv exprimierten ß-tubulin Gens angeglichen. Um eine Vergleichbarkeit der Bandenintensitäten zu gewährleisten, wurden jeweils drei Verdünnungen $(1,1 / 3,1 / 10)$ jeder cDNA Probe in der PCR-Reaktion eingesetzt (s. Abb. 5).

Der Erfolg des pH-Shifts konnte durch Analyse der Expression des bradyzoitspezifisch exprimierten Gens bag1 (Bohne et al., 1995) überprüft werden. Die Expression von tgpma1 verhielt sich ähnlich wie die von bag1, indem erst nach vier Tagen pH-Shift Bedingungen ein Transkript nachgewiesen werden konnte. Allerdings war die Expression von tgpma1 sehr viel schwächer als die von bag1, da für den Nachweis eine um fünf Zyklen längere PCR durchgeführt werden musste, um ein Signal zu erhalten.

Neben TgPMA1 besitzt $T$. gondii noch mindestens eine weitere Isoform einer P-Typ $\mathrm{H}^{+}$-ATPase, die durch das EST-Fragment TgEST_1435326 repräsentiert wird. Die Expression von tgpma2 wurde ebenfalls per RT-PCR untersucht. Wie in Abb. $5 \mathrm{zu}$ sehen ist, lässt sich auch bei dieser Isoform eine Hochregulierung im Bradyzoitenstadium feststellen, allerdings ist, im Gegensatz zu tgpma1, auch eine deutliche Expression im Tachyzoitenstadium zu erkennen. 


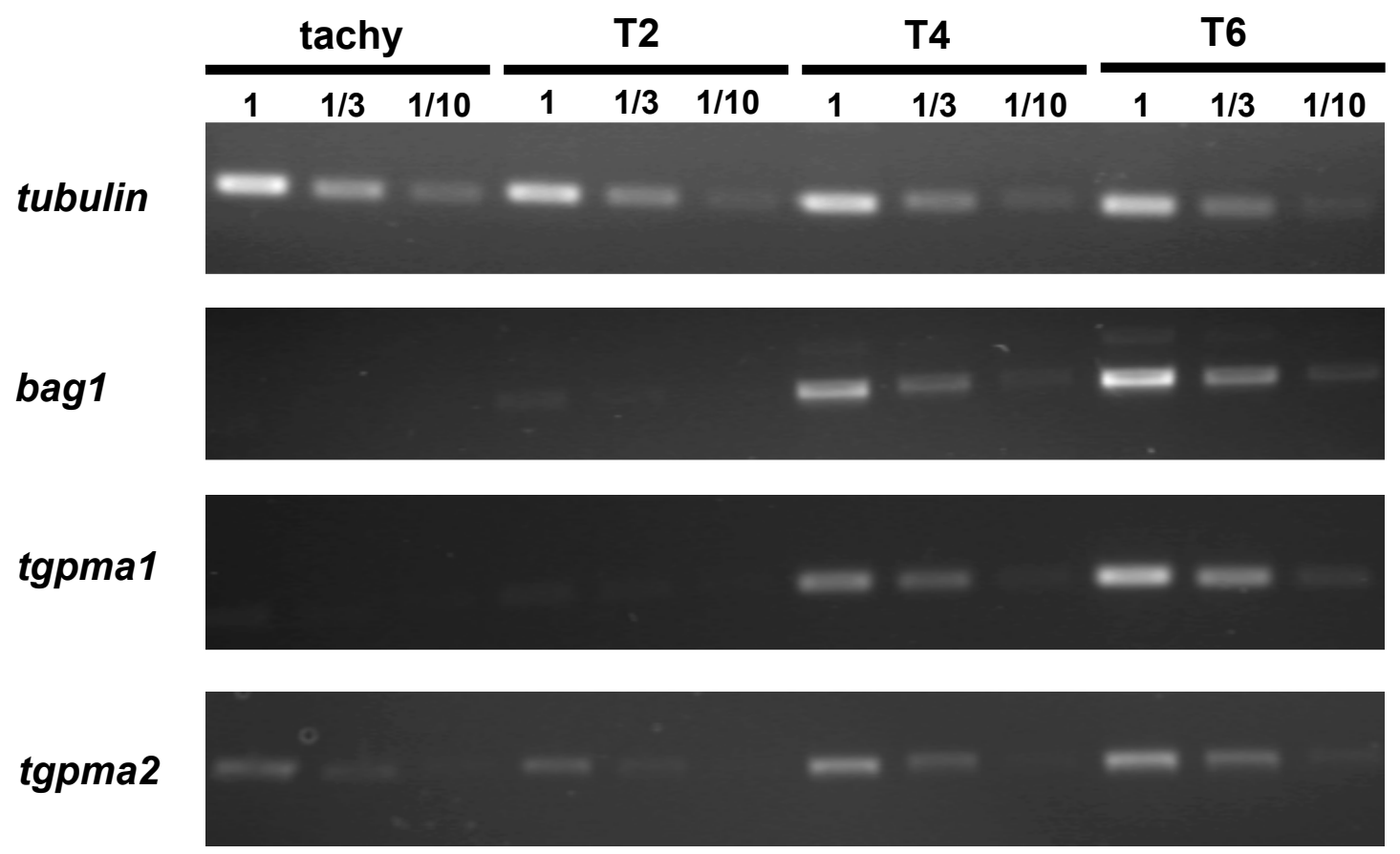

Abb. 5. Semiquantitative RT-PCR Analyse zur Induktion der tgpma1 Expression während der Stadienkonversion.

Prugniaud/HX Tachyzoiten wurden für 2, 4 und 6 Tage (T2-6) einem $\mathrm{pH}-\mathrm{Shift}$ unterzogen. Als Kontrolle wurden nicht-differenzierte Tachyzoiten (Tachy) mitgeführt. In einer semiquantitativen RT-PCR Analyse wurden die Proben bezüglich ihrer Expression der Gene bag1, tgpma1 und tgpma2 untersucht. Als Beladungskontrolle diente das konstitutiv exprimierte $\beta$-tubulin Gen aus Toxoplasma gondii. Um eine Vergleichbarkeit der Proben zu gewährleisten, wurden für jede Probe drei Verdünnungsstufen $(1,1 / 3,1 / 10)$ an CDNA in der PCR eingesetzt.

\subsection{Genomische Organisation von tgpma1}

\subsubsection{Isolierung eines genomischen Klons}

Um Informationen über die Intron-Exon Struktur von tgpma1 zu erhalten und für nachfolgende Experimente ein möglichst großes Stück flankierender DNA aus dem tgpma1 Lokus zu isolieren, wurde eine $\lambda \mathrm{DASH}$ genomische Bibliothek aus dem $T$. gondii Stamm P(LK) (Bohne et al., 1998) nach einem geeigneten Klon durchsucht.

\subsubsection{Generierung einer Sonde}

Eine nicht-radioaktive Sonde wurde durch Digoxigenin-Markierung eines PCR-Fragments erstellt. Ein 1100 nt Fragment aus dem Offenen Leserahmen von tgpma1 wurde mit den Oligonukleotiden 9-2/+ und 9-10/- amplifiziert (für die Lage der 
Primer: s. Anhang, Abb. 21). Die DNA wurde auf einem Agarosegel aufgetrennt und die 1100 nt Bande ausgeschnitten und aufgereinigt.

\subsubsection{Screening einer genomischen T. gondii Cosmid Bibliothek}

Um eine genomische Toxoplasma gondii Bibliothek nach einem Klon zu durchsuchen, der den tgpma1 Lokus enthielt, musste zunächst sichergestellt werden, dass zumindest theoretisch jedes Gen einmal auf den Platten repräsentiert wurde. Bei einer errechneten Genomgröße von $89 \mathrm{Mb}$ für Toxoplasma gondii und durchschnittlich $40 \mathrm{~kb}$ Insert pro Cosmid mussten mindestens 8 Platten mit je ca. 150 Kolonien in der ersten Runde des Screens eingesetzt werden. Die Bakterien der genomischen $T$. gondii Bibliothek wurden auf acht LB/ Tetracyclin-Platten hochgezogen und mittels Kolonie-Blot auf Nitrocellulose-Filter übertragen. Die Filter wurden mit der Digoxigenin-markierten aufgereinigten Sonde hybridisiert. Mit Anti-Digoxigeninalkalische Phosphatase Konjugat wurde die Sonde detektiert und mittels alkalischer Phosphatase Färbung auf der Membran sichtbar gemacht.

Im ersten Durchlauf konnten auf diese Weise fünf positive Klone von zwei unterschiedlichen Platten gepickt werden, die erneut auf einer LB/ Tetracyclin Platte ausgestrichen wurden. Zusammen mit sieben neu ausgestrichenen Platten aus der $T$. gondii Bibliothek wurden in der nächsten Runde des Screens von den ursprünglichen fünf vermeintlich positiven Klonen einer als positiv verifiziert und drei neue gepickt. Von diesen vier blieben nach der dritten Runde des Screens die zwei positiven Klone A1 und B3 übrig, die beide ursprünglich von der selben Platte gestammt hatten.

\subsubsection{Verifizierung der positiven Klone}

Cosmid-DNA wurde aus den beiden Klonen A1 und B3 isoliert und die DNA- Konzentration bestimmt. Um herauszufinden, ob es sich bei A1 und B3 tatsächlich um verschiedene Klone, oder um zwei Isolate des selben Klons handelte, wurde je $1 \mu \mathrm{g}$ Plasmid-DNA von A1 und B3 in einem Restriktionsdoppelverdau mit den Restriktionsenzymen EcoRI und BamHI verdaut, auf einem Agarosegel aufgetrennt und durch einen Kapillarblot auf eine Nylonmembran übertragen. Diese wurde im 
Anschluss mit der gleichen Sonde hybridisiert, die auch schon für das Screening der genomischen Toxoplasma Cosmid Bibliothek verwendet worden war.

Eine bereits bekannte Erkennungsstelle für EcoRI befindet sich im tgpma1 Lokus ca. 300 nt $3^{\prime}$ der Sonde, so dass durch diesen Restriktionsdoppelverdau die Position einer $5^{\prime}$ der Sonde gelegenen BamHI oder EcoRI Schnittstelle bestimmt werden konnte. Nach dem Nachweis der Sonde auf dem Southern Blot mit dem AntiDigoxigenin-alkalische Phosphatase Konjugat und anschließender alkalischer Phosphatase Färbung, wurde in beiden Restriktionsverdauen jeweils eine Bande von $4,5 \mathrm{~kb}$ sichtbar gemacht.

$\mathrm{Da}$ das Bandenmuster der Restriktionsfragmente beider Klone im Agarosegel identisch war und in beiden das gleiche tgpma1-Fragment im Southern Blot nachgewiesen werden konnte, legte dies den Schluss nahe, dass es sich bei A1 und B3 um den selben Cosmid-Klon handelt.

\subsubsection{Subklonierung eines Cosmid-Fragments in pKS}

Da zur Sequenzierung und näheren Charakterisierung des tgpma1 Lokus das Cosmid mit geschätzten $36 \mathrm{~kb}$ Insert zu groß erschien, sollte ein Fragment von ca. 8 $\mathrm{kb}$ in den Vektor pKS subkloniert werden, welches den kompletten offenen Leserahmen von tgpma1 enthielt.

Cosmid DNA des Klons A1 wurde durch Kombination zweier geeigneter Restriktionsenzyme verdaut, auf einem Agarosegel aufgetrennt und auf eine Nylonmembran geblottet. Durch Hybridisierung mit der Digoxigenin-markierten DNA Sonde wurde nach Fragmenten gesucht, die ca. 8 kb umfassten. Von den Kombinationen der Restriktionsenzyme BamHI/ Sacll, BamHI/ Apal, BamHI/ Notl, BamHI/ Sall, BamHI/ Xbal, Notl/ Bglll, Notl/ BspDI, Notl/ EcoRV, Notl/ Hpal, Notl/ Ndel, Notl/ Kpnl, zeigten die vier Kombinationen BamHI/ Apal, BamHI/ Sall, Notl/ EcoRV und Notl/ Kpnl jeweils eine Bande in der gewünschten Größe.

Um ein DNA-Fragment in den Vektor pKS zu klonieren, wurden sowohl Cosmid DNA, als auch DNA des Vektors pKS erneut mit BamHI/Sall und Notl/Kpnl verdaut und die Bande der durch den vorangegangenen Blot bereits bekannten Größe aus dem Gel isoliert, aufgereinigt und in den geschnittenen pKS Vektor ligiert. Nach Transformation in chemisch kompetente E. coli DH5a und Plasmid DNA Minipräparation wurden die so isolierten Cosmid-Subklone erneut durch Southern Blot verifiziert. Durch 
Kombination geeigneter Restriktionsenzyme konnte eine vorläufige Restriktionskarte erstellt werden, die später durch Sequenzierung der kompletten Insert-Region vervollständigt wurde.

\subsubsection{Charakterisierung der genomischen tgpma1 Subklone}

Die auf diese Weise gewonnene Sequenzinformation umschließt den gesamten offenen Leserahmen, einschließlich 1100 nt $5^{\prime}$ des putativen Startcodons und $600 \mathrm{nt}$

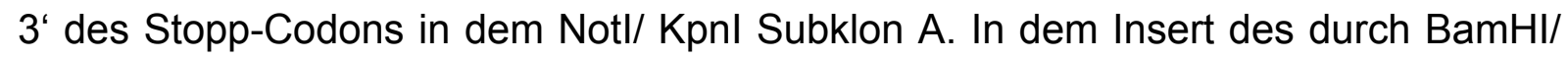
Sall Verdau erhaltenen Subklons F war weniger Sequenz aus dem 5' UTR, dafür aber zusätzliche 2200 nt aus dem 3، UTR enthalten.

Ein Vergleich mit der Sequenz der cDNA offenbarte zwei Introns, die beide die typische GT/AG Sequenz an der Spleiß-Donor und Spleiß-Akzeptor Stelle aufweisen. Wie in Abb. 6 schematisch dargestellt befindet sich das erste, $321 \mathrm{nt}$ große Intron in dem 5‘ untranslatierten Bereich bei nt 1453-1665, nur 156 nt 5` des putativen StartCodons. Ein zweites, 397 nt langes Intron befindet sich bei nt 2376-2769, 496 nt 3' des putativen Start-Codons (s. Anhang, Abb. 23 für die Sequenz).

$\begin{array}{lllllll}0 & 1 & 2 & 3 & 4 & 5 & 6 \mathrm{~kb}\end{array}$

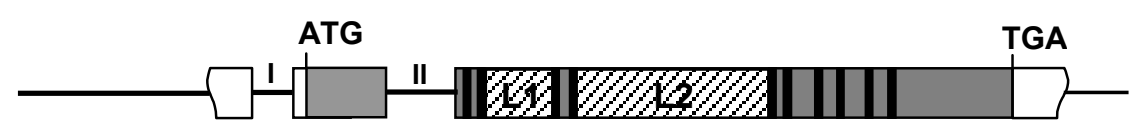

Abb. 6. Schematische Darstellung der genomischen Organisation von tgpma1. Die Lage der kodierenden Region ist durch das putative ATG Start- und TGA-Stopp Codon angegeben. Die Positionen der beiden Introns sind durch ,I' und ,I' angedeutet. Die 10 Transmembrandomänen wurden durch das Programm TMpred (http://www.ch.embnet.org/software/TMPRED_form.html) vorhergesagt und sind durch schwarze Balken dargestellt. L1 und L2 repräsentieren den kleinen und den großen zytoplasmatischen Loop. Nicht-translatierte Bereiche außerhalb der kodierenden Region sind durch dünne Linien gekennzeichnet.

\subsubsection{Klonierung des 5' UTR von tgpma1}

Eine Klonierung der bisher unbekannten DNA-Region, die sich direkt 5 ‘ der bekannten tgpma1-Sequenz befand, sollte mittels einer inversen PCR ermöglicht werden.

Genomische DNA des Stammes RH/HX' wurde aus zwei durchlysierten 175er Zellkulturflaschen isoliert, in $\mathrm{H}_{2} \mathrm{O}$ bidest. gelöst und mit den Restriktionsenzymen Sacl, 
Xhol, EcoRI, Dral und Nhel verdaut. Die Proben wurden anschließend aufgereinigt und in einem großen Volumen mit sich selbst ligiert. Nun wurden sie erneut aufgereinigt und pro Ligationsansatz jeweils zwei PCR Reaktionen mit den Primern 9-20/und 9-21/- durchgeführt. Die Primer wurden so gewählt, dass jeweils 9-20/- oder 921/- in 5 'Richtung aus der bekannten Sequenz heraus amplifizierten und je nach vorherigem Restriktionsverdau ein Primer, der möglichst nahe der Restriktionsschnittstelle innerhalb des tgpma1 Lokus lag, in $3^{\prime}$ Richtung amplifizierte: Sacl: PMA1seq/+; Xhol: PM1-5'2; EcoRI: P-7/+; Dral: PMA1seq/+; Nhel: P-13/+. Da größere PCR-Produkte zu erwarten waren, wurde zusätzlich jede Reaktion mit und ohne Zusatz von TaqExtender durchgeführt, um die Ausbeute zu verbessern. Die PCR-Produkte wurden durch Agarosegelelektrophorese aufgetrennt, einige Banden ausgeschnitten und aus dem Gel aufgereinigt. Die Fragmente wurden in den Vektor pCR2.1 subkloniert und sequenziert.

Durch Generierung neuer Primer und eine weitere Runde inverser PCR mit anschließender Subklonierung und Sequenzierung konnte auf diese Weise die bekannte Sequenz aus dem 5' UTR von tgpma1 auf 2,1 kb erweitert werden.

\subsubsection{Bestimmung der Kopienzahl von tgpma1}

Toxoplasma gondii hat ein haploides Genom, was die Charakterisierung von Genen stark vereinfacht.

Um herauszufinden, ob tgpma1 in nur einer oder in mehreren Kopien im Genom des Parasiten vertreten ist, wurde genomische DNA aus Toxoplasma gondii isoliert und mit den Restriktionsenzymen EcoRl, BamHI, bzw. Hindlll verdaut. Die so geschnittene DNA wurde auf einem Agarosegel aufgetrennt und durch Kapillarblot auf eine Nylonmembran geblottet. Nach Hybridisierung mit einem ${ }^{32} \mathrm{P}$-markierten 1,6 kb tgpma1 cDNA Fragment unter hochstringenten Bedingungen, konnte in jedem Restriktionsverdau nur eine Bande sichtbar gemacht werden (s. Abb. 7). Dies bestätigt, dass es sich bei tgpma1 um ein single-copy Gen handelt. 


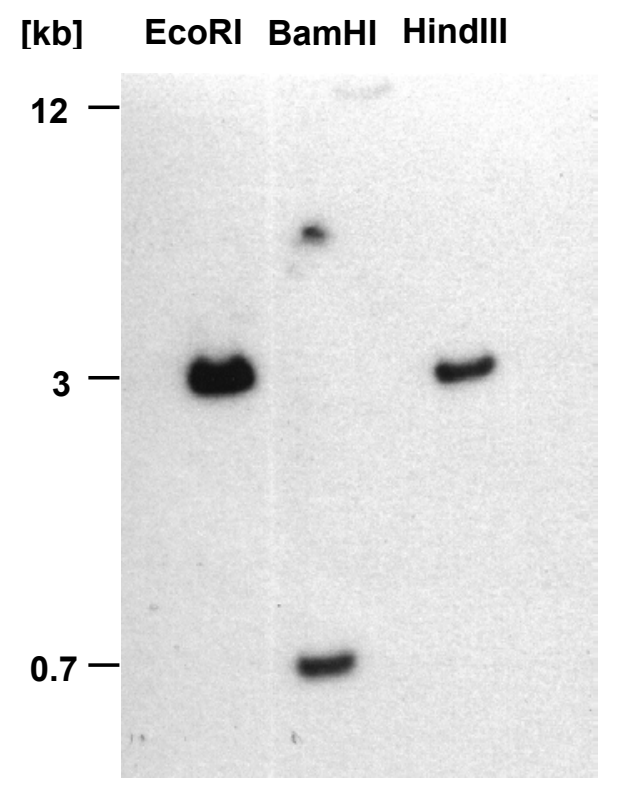

Abb. 7. Southern Blot Analyse an mit Restriktionsenzymen verdauter genomischer Toxoplasma gondii DNA, hybridisiert mit einem ${ }^{32} \mathrm{P}$-markierten 1,6 kb tgpma1 cDNA Fragment. Die Größen der DNA-Fragmente (in kb) sind links angegeben.

\subsection{Lokalisation von TgPMA1 in Bradyzoiten}

Um die Lokalisation von TgPMA1 innerhalb des Parasiten mittels Immunfluoreszenz bestimmen zu können, sollte Antiserum gegen das Protein generiert werden. Zu diesem Zweck musste entweder das komplette Protein, oder ein Teil davon rekombinant exprimiert, aufgereinigt und zusammen mit Adjuvantien für eine Immunisierung verwendet werden.

\subsubsection{Expression rekombinanter TgPMA1-Fragmente in E. coli}

Da TgPMA1 ein sehr großes und mit seinen zehn Transmembrandomänen auch sehr hydrophobes Protein ist, wurden zwei hydrophile Fragmente aus dem zytoplasmatischen Loop und dem C-Terminus des Proteins zur späteren Expression in E. coli ausgewählt, deren Lage innerhalb von TgPMA1 in Abb. 8 schematisch dargestellt ist. 


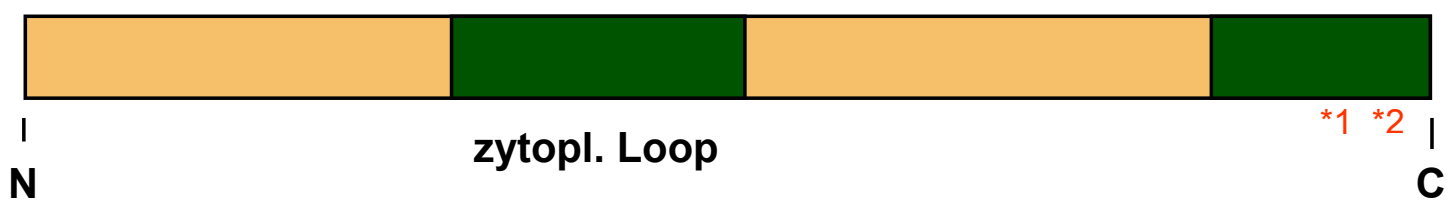

*1 : Position von Peptid WB1: $\mathrm{NH}_{2}$-CKTSTEDEVALPRKDA-COOH

*2 : Position von Peptid WB2: $\mathrm{NH}_{2}$-CAVDQKNREVSRSSGK-COOH

Abb. 8. Schematische Darstellung der Lage des zytoplasmatischen Loop und C-Terminus Fragments innerhalb von TgPMA1, die beide als His-Tag Fusionsproteine in E. coli exprimiert wurden. $\mathrm{N}=\mathrm{N}-$ Terminus, $\mathrm{C}=\mathrm{C}$-Terminus von TgPMA1. Mit , *' sind die Positionen der beiden Peptide WB1 und WB2 gekennzeichnet, die zur Immunisierung von Kaninchen verwendet wurden.

\subsubsection{Klonierung des rekombinanten Loop und C-Terminus Fragments}

Zur Klonierung in den Expressionsvektor pQE30 wurden die zwei Fragmente aus Loop und C-Terminus mittels PCR an einem cDNA-Klon amplifiziert, welcher den kompletten ORF von TgPMA1 enthielt. Die hierfür verwendeten Primer wurden so gewählt, dass sie jeweils am 5'-Ende des Amplifikats eine BamHI und am 3'-Ende eine Kpnl-Schnittstelle an die amplifizierte cDNA anfügten. Das Loop-Fragment (Primer PM1-1008-Bam/+, PM1-1785-Kpn/-) kodiert mit 777 bp für ein 28,7 kDa großes Protein, während das C-Terminus Fragment (Primer PM1-2608-Bam/+, ATPase-3-Kpn/-) mit einer Größe von ca. 500 nt für ein 18,7 kDa großes Protein kodiert. Die PCR-Produkte wurden durch Agarosegelelektrophorese aufgetrennt, die Banden ausgeschnitten und aufgereinigt. Nach Restriktionsdoppelverdau mit den Restriktionsenzymen BamHI und Kpnl wurden die beiden DNA-Fragmente in den Vektor pQE30 ligiert, welcher zuvor ebenfalls mit BamHI/ Kpnl linearisiert worden war. Nach Transformation in kompetente E. coli M15(pREP4) und Selektion auf Ampicillin/ Kanamycin haltigen LB-Agarplatten wurden jeweils acht Klone nach DNAMinipräparation mittels Restriktionsverdau mit BamHI/ Kpnl auf erfolgreiche Insertion des PCR-Fragments getestet.

\subsubsection{Expression der rekombinanten Loop und C-Terminus Proteine}

Zum Nachweis der Induzierbarkeit und Expression der His-Tag Fusionsproteine, wurden jeweils zwei Klone für Loop- (L2, L3) und C-Terminus $(C 4, C 5)$ ausgewählt. 
Vergleichbare Mengen der nicht-induzierten und der IPTG-induzierten E. coli Lysate wurden durch SDS-PAGE aufgetrennt und die Proteine mittels Coomassie-Färbung sichtbar gemacht. Nach Entfärben des Gels konnte eine deutliche Bande der zu erwartenden Größe nur in der jeweils induzierten Probe nachgewiesen werden, was die Induzierbarkeit der His-Tag Fusionsproteine bestätigte (s. Abb. 9).

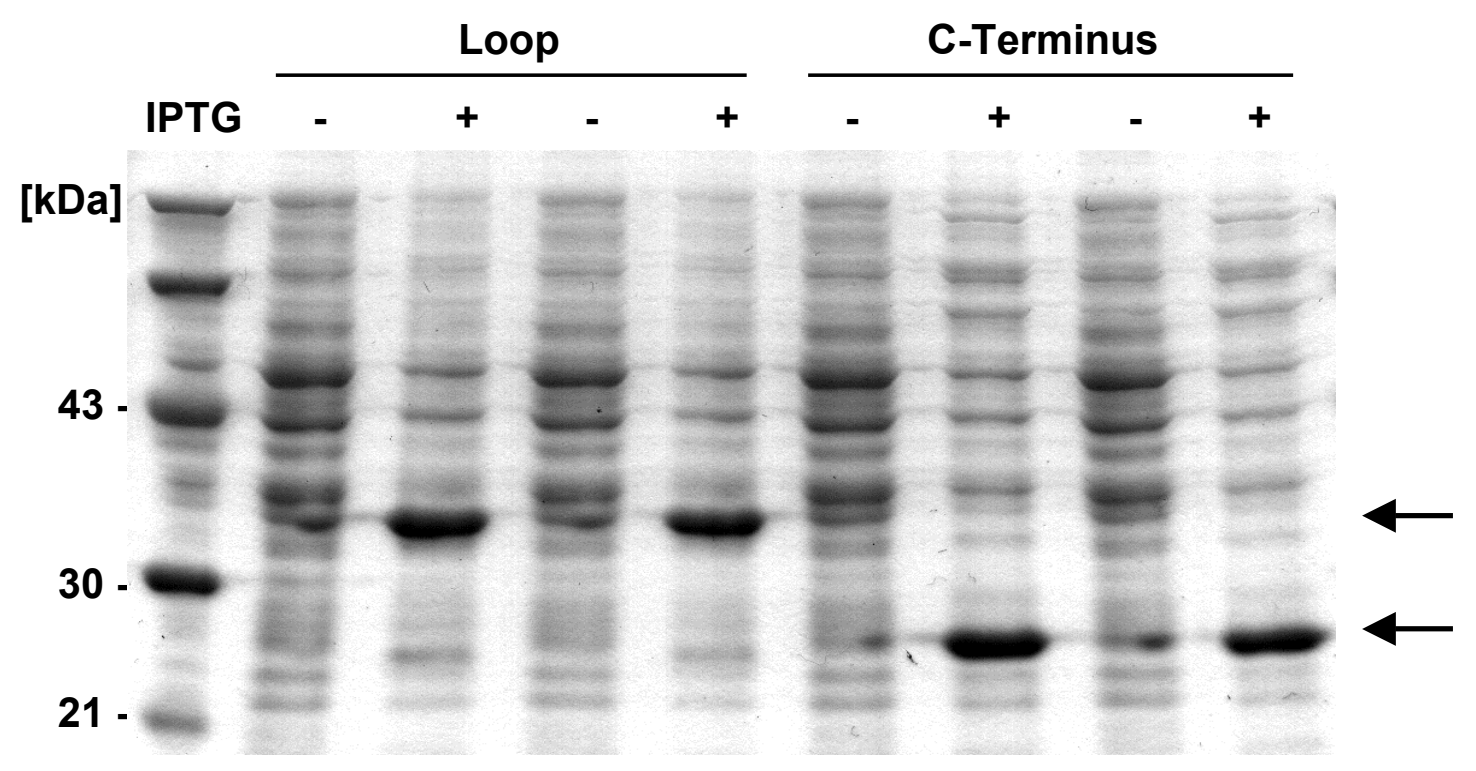

Abb. 9. Expression von TgPMA1 Loop und C-Terminus als His-Tag Fusionsproteine. E. coli Lysate aus induzierten (+) und nicht-induzierten (-) Kulturen wurden durch SDS-PAGE aufgetrennt und mit Coomassie-Blau angefärbt. Die Positionen der induzierten Proteine sind rechts mit einem Pfeil angedeutet. Proteingrößen in kDa sind angegeben.

Um zu zeigen, dass es sich bei den im Coomassie-gefärbten Gel beobachteten Banden auch tatsächlich um die His-Tag Fusionsproteine handelte und um die Expressionsstärke einzelner Klone vergleichen zu können, wurden jeweils vier Klone für Loop und C-Terminus (L2-5, C2-5) induziert. Nach Auftrennung der Lysate durch SDS-PAGE wurden die Proteine auf eine Nitrocellulosemembran übertragen. Diese wurde nach Blockieren in 1\% Magermilchpulver mit monoklonalen Maus-anti-His-Tag Antikörpern (1:2000 in PBS) inkubiert und anschließend mit alkalische PhosphataseZiege-anti-Maus IgG Konjugat (1:5000 in PBS) nachgewiesen. Durch eine alkalische Phosphatase-Färbung wurden die erkannten Proteine auf der Membran sichtbar gemacht.

In den Lysaten aller Klone bis auf C2 war eine deutliche Bande in der erwarteten Höhe zu sehen, wobei die Expressionsstärke in allen positiven Klonen annähernd gleich war. 


\subsubsection{Optimierung der Protein-Aufreinigungsbedingungen}

Da die Bindung von Ni-NTA an den His-Tag des rekombinanten Proteins nicht von der Tertiärstruktur abhängt, können die Proteine entweder unter nativen oder unter denaturierenden Bedingungen aufgereinigt werden. Die Entscheidung, welche Aufreinigungsbedingungen für ein rekombinantes Protein die besten sind, hängt von der Lokalisation innerhalb der Zelle, der Löslichkeit des jeweiligen Proteins, der Lage des His-Tags innerhalb des Proteins und dem späteren Verwendungszweck ab.

Weil für die angedachten Anwendungen der His-Tag Fusionsproteine (Immunisierung und Western Blot) keine biologische Funktionalität und auch nicht unbedingt eine intakte Tertiärstruktur erforderlich waren, wurde die Aufreinigung unter nativen und denaturierenden Bedingungen mit einer kleinen Kultur von L2 und C5 ausgetestet, um dann im größeren Maßstab mit den optimalen Bedingungen arbeiten zu können.

\subsection{Native Proteinaufreinigung}

Jeweils $1 \mathrm{ml}$ einer induzierten Kultur von L2 und C5 wurden für eine Proteinaufreinigung unter nativen Bedingungen verwendet. Vergleichbare Mengen aller Aliquots wurden zusammen mit je $10 \mu \mathrm{l}$ des induzierten und des nicht-induzierten $E$. coli Lysats durch SDS-PAGE aufgetrennt und die Proteine im Anschluss durch Coomassie-Färbung sichtbar gemacht.

Bei L2 war das Fusionsprotein zwar im Lysepuffer (A1) deutlich sichtbar, doch bereits nach dem Lysieren der Zellen, noch vor der Bindung an Ni-NTA Agarose (A2), nicht mehr nachweisbar. Folglich liegt das induzierte Fusionsprotein in E. coli nicht in löslicher Form, sondern vor allem unlöslich in Form von Einschlusskörperchen vor und kann durch native Bedingungen nicht effektiv gewonnen werden.

Das C-Terminale His-Tag Fusionsprotein (C5) war nach Induktion und Lyse der Zellen als deutliche Bande im Gel zu erkennen. Doch auch hier war das Protein noch vor Bindung an die Ni-NTA-Agarose kaum noch nachweisbar und lag damit vor allem in unlöslicher Form vor. 


\subsection{Denaturierende Bedingungen}

Um die Proteinaufreinigung unter denaturierenden Bedingungen auszutesten, wurde ebenfalls jeweils $1 \mathrm{ml}$ einer induzierten Kultur von L2 und C5 verwendet.

Die Aliquots wurden nach der Aufreinigung durch SDS-PAGE aufgetrennt und anschließend mit Comassie-Blau gefärbt. Bei der Aufreinigung beider Proteine war eine deutliche Bande in allen Proben zu erkennen. Das Protein ließ sich also durch die Lysebedingungen in Lösung bringen, aber ein großer Teil konnte nicht an die Ni-NTA Agarose gebunden werden. Bei den Waschschritten ging nur ein relativ geringer Anteil des Proteins verloren, der Rest war stabil an die Matrix gekoppelt und ließ sich unter den vorliegenden Elutionsbedingungen auch in ausreichenden Mengen wieder lösen.

Die gewählten denaturierenden Bedingungen waren also geeignet, größere Mengen des Fusionsproteins aus induzierten E. coli Lysaten aufzureinigen.

\subsubsection{Proteinaufreinigung unter denaturierenden Bedingungen}

Nachdem die geeigneten Aufreinigungsbedingungen ausgetestet worden waren, wurden für einen größeren Ansatz Kulturen von jeweils 1 I für L2 und C5 unter denaturierenden Bedingungen aufgearbeitet.

Aliquots aller bei der Proteinaufreinigung angefallener Fraktionen wurden auf SDS Polyacrylamidgelen aufgetrennt und mit Coomassie angefärbt (s. Abb. 10).

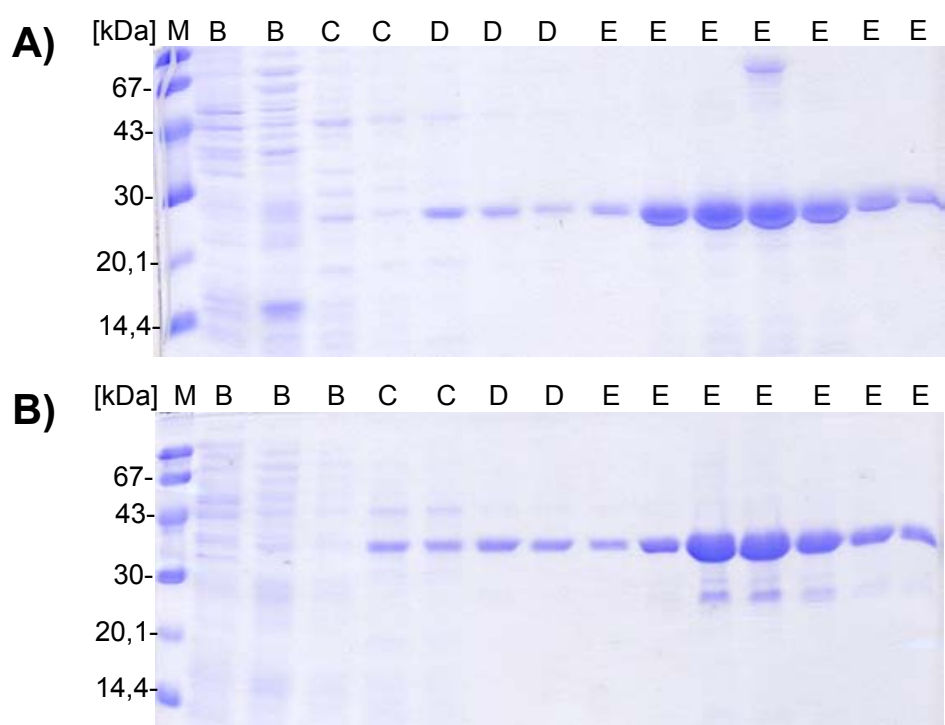

Abb. 10. Proteinaufreinigung der His-Tag Fusionsproteine aus dem C-Terminus (A) und Loop (B) von TgPMA1 unter denaturierenden Bedingungen. Aliquots wurden durch SDS-PAGE aufgetrennt und mit Coomassie-Blau Färbung sichtbar gemacht. Es ist eine deutliche Anreicherung des Proteins in den Elutionsschritten (E1-7) gegenüber den Waschschritten (C, D) zu erkennen. 
Proteinbanden waren in allen Waschfraktionen erkennbar, allerdings wurde deutlich mehr Protein in den einzelnen Elutionsschritten von der Säule gelöst, was in Einklang mit den Daten des Schreibers während der Proteinaufreinigung steht. Es war jeweils eine saubere Bande erkennbar, nur in einer Elutionsfraktion des Proteins aus dem C-Terminus war eine kontaminierende Proteinbande zu sehen. Die besten Elutionsfraktionen wurden zu jeweils zwei Pools zusammengefasst und die Proteinkonzentration bestimmt. Damit ergab sich die in Tabelle 4 dargestellte Ausbeute an aufgereinigtem His-Tag Fusionsprotein.

\begin{tabular}{|c|c|c|c|}
\hline $\begin{array}{l}\text { Proteinausbeute } \\
\text { nach Aufreiniqung }\end{array}$ & $\begin{array}{l}\text { bestehend aus } \\
\text { Fraktionen }\end{array}$ & $\begin{array}{c}\text { Proteinkonzentration } \\
{[\mu \mathrm{g} / \mathrm{ml}]}\end{array}$ & $\begin{array}{c}\text { Gesamtmenge Protein } \\
\text { [mg] }\end{array}$ \\
\hline Loop, Pool I & $\mathrm{E} 3, \mathrm{E} 4, \mathrm{E} 5$ & 580 & 8 \\
\hline Loop, Pool II & E2, E6, E7 & 187 & 3,5 \\
\hline C-Terminus, Pool I & $E 2, E 3, E 5$ & 339 & 3 \\
\hline C-Terminus, Pool II & E6, E7 & 131 & 2,3 \\
\hline
\end{tabular}

Tabelle 4. Konzentration und Gesamtmenge an aufgereinigten His-Tag Fusionsproteinen.

\subsubsection{Gewinnung von Antiserum gegen TgPMA1}

In einem ersten Versuch, Antiserum gegen TgPMA1 zu gewinnen, wurden jeweils vier Balb/c Mäuse mit dialysierten aufgereinigten His-Tag Fusionsproteinen aus dem C-Terminus oder dem Loop von TgPMA1 immunisiert. Den Mäusen wurde das Antigen, gemischt mit Adjuvans, je zur Hälfte subkutan und intramuskulär gespritzt. Nach jeweils zwei Wochen wurde mit Antigen geboostert, anschließend nach insgesamt sechs Wochen den Mäusen Blut entnommen und Serum gewonnen.

Zysten wurden aus chronisch infizierten Mäusen isoliert, durch einen Pepsinverdau die Bradyzoiten aus den Zysten befreit und auf Lochobjektträgern mit 4\% Paraformaldehyd/ PBS fixiert. In einer Immunfluoreszenzfärbung wurden extrazelluläre Bradyzoiten mit den Maus-anti-TgPMA1 Seren (jeweils 1:100 und 1:1000 in PBS) inkubiert und mit Cy3-konjugiertem Esel-anti-Maus IgG (1:1000 in PBS) nachgewiesen. Von den vier Antiseren, die gegen den C-Terminus von TgPMA1 gerichtet waren, konnte bei zweien eine schwache Membranfärbung und bei einem eine relativ starke granuläre Färbung der Bradyzoiten beobachtet werden. Ein Serum zeigte überhaupt keine Reaktion mit den Parasiten. Bei den Loop-Antiseren war in allen Fällen eine deutliche Membranfärbung zu erkennen. 
Um die Spezifität der Antiseren für Bradyzoiten auszutesten wurden Tachyzoiten auf HFFs, die zwei Tage zuvor infiziert worden waren, mit 4\% Paraformaldehyd/ PBS fixiert und permeabilisiert. In einer Immunfluoreszenzfärbung wurden die Maus-antiTgPMA1 Seren 1:100 und 1:1000 in PBS verdünnt auf die Zellen gegeben und mit Cy3-konjugiertem Esel-anti-Maus IgG nachgewiesen. In allen Fällen war eine leichte Membranfärbung der Tachyzoiten zu erkennen, wobei zusätzlich interne Strukturen der Parasiten und der Wirtszellen angefärbt waren.

Da bei allen Antiseren eine Membranfärbung der Tachyzoiten auftrat, aber die LoopAntiseren eine deutlich bessere Membranfärbung an Bradyzoiten lieferten, sollten diese durch eine Affinitätsreinigung gegen das rekombinante Loop His-Tag Fusionsprotein aufgereinigt werden. Hierzu wurden die anti-Loop Antiseren gepoolt und über eine Säule aus CNBr-aktivierter Sepharose B affinitätsgereinigt, an die zuvor das Loop His-Tag Fusionsprotein gekoppelt worden war. Die Eluate wurden anschließend in verschiedenen Verdünnungen (1:100, 1:10, 1:5, 1:2 in PBS) in einer Immunfluoreszenzfärbung an in vitro durch einen pH-Shift induzierten Bradyzoiten ausgetestet. In keinem Fall konnte eine Membranfärbung beobachtet werden, wobei bei der Verdünnung von 1:2 die Wirtszellen stark angefärbt wurden. Da auch in einem Western Blot das Loop His-Tag Fusionsprotein durch die affinitätsgereinigten Loop-Antiseren nicht mehr nachgewiesen werden konnte, mussten neue Antiseren zum Nachweis von TgPMA1 erstellt werden.

Hierfür wurde eine andere Strategie gewählt: Es sollte ein Antiserum aus Kaninchen gewonnen werden, welches nur gegen ein relativ kleines Peptid von TgPMA1 gerichtet war. Um eine spätere Kreuzreaktivität gegen andere P-Typ ATPasen der Wirtszelle und Toxoplasma gondii von Anfang an möglichst gering zu halten, wurden durch intensiven Vergleich der Aminosäuresequenzen von TgPMA1 mit anderen bekannten P-Typ ATPasen, einschließlich TgPMA2, mehrere Peptide von ca. 10 bis 30 Aminosäuren Länge ausgewählt, die in den nicht-konservierten Bereichen des großen zytoplasmatischen Loops, bzw. des C-Terminus von TgPMA1 liegen. Die Sequenz und Lage der beiden Peptide WB1 und WB2 innerhalb von TgPMA1, die schließlich für die Immunisierung verwendet wurden, zeigt Abb. 8. Durch die Firma BioScience (Göttingen) wurden die beiden Peptide ausgewählt, synthetisiert, an KLH (Keyhole Limpet Hemocyanin) gekoppelt und dazu verwendet, zwei Kaninchen zu immunisieren. Vor der Immunisierung wurde zehn Kaninchen Präimmunserum abgenommen, um eine eventuell bereits vorhandene Infektion der Tiere mit Toxoplasma 
gondii auszuschließen, die ansonsten zu starker Kreuzreaktivität der Seren geführt hätte. Hierzu wurden die Seren 1:20 verdünnt im Immunfluoreszenztest auf HFFs getestet, die zwei Tage zuvor mit Tachyzoiten des $\mathrm{RH} / \mathrm{HX}^{-}$-Stammes infiziert worden waren. Als Nachweisantikörper wurde Cy3-konjugiertes Esel-anti-Kaninchen IgG eingesetzt. Es wurden schließlich die zwei Kaninchen ausgewählt, deren Präimmunseren die niedrigste Reaktion mit Toxoplasma gondii Tachyzoiten zeigten und für die Immunisierung gegen jeweils ein Peptid verwendet. Nach 21 Tagen wurde den Tiere zur Erhöhung der Immunantwort erneut gekoppeltes Peptid injiziert. Nach 35 Tagen erfolgte die erste Blutabnahme, 14 Tage später wurde ein letztes mal geboostert, um nach insgesamt 60 Tagen die finale Blutentnahme vorzunehmen.

\subsubsection{Affinitätsreinigung der Peptidantikörper}

Sämtliche Seren wurden im Immunfluoreszenztest wie oben beschrieben gegen mit Tachyzoiten infizierte HFFs ausgetestet. Allerdings zeigten die Seren beider Kaninchen eine hohe unspezifische Hintergrundfärbung, so dass eine Affinitätsreinigung notwendig wurde.

Hierzu wurde eine Affinitätschromatographie mit dem HydraS activated affinity resin kit durchgeführt, wobei die Antiseren über eine Säule aus HydraS Matrix gereinigt wurden, an die zuvor das jeweilige Peptid gekoppelt worden war.

Um den Erfolg der Affinitätsreinigung zu überprüfen, wurden jeweils $5 \mu \mathrm{g}$ der aufgereinigten TgPMA1 Loop und C-Terminus His-Tag Fusionsproteine mit $5 \mu$ l eines $E$. coli Lysats vermischt, durch SDS-PAGE aufgetrennt und auf eine Nitrocellulosemembran geblottet. Der Blot wurde durch eine Ponceau S Färbung der Membran kontrolliert und über Nacht mit $10 \%$ FCS bei $4{ }^{\circ} \mathrm{C}$ blockiert. Die Membran wurde in dünne Streifen geschnitten und die einzelnen Streifen mit den verschiedenen Antikörperfraktionen (1:500 in PBS) inkubiert.

Nach dreimaligem Waschen mit PBS/ 0,5\% Tween 20, Inkubation mit Peroxidasegekoppeltem Ziege-anti-Kaninchen IgG (1:5000 in PBS) und erneutem dreimaligem Waschen mit PBS/ 0,5\% Tween 20 wurde eine Peroxidase-Färbung durchgeführt. Das Ergebnis dieser Färbung ist in Abb. 11 dargestellt. 
A) $[\mathrm{kDa}]$

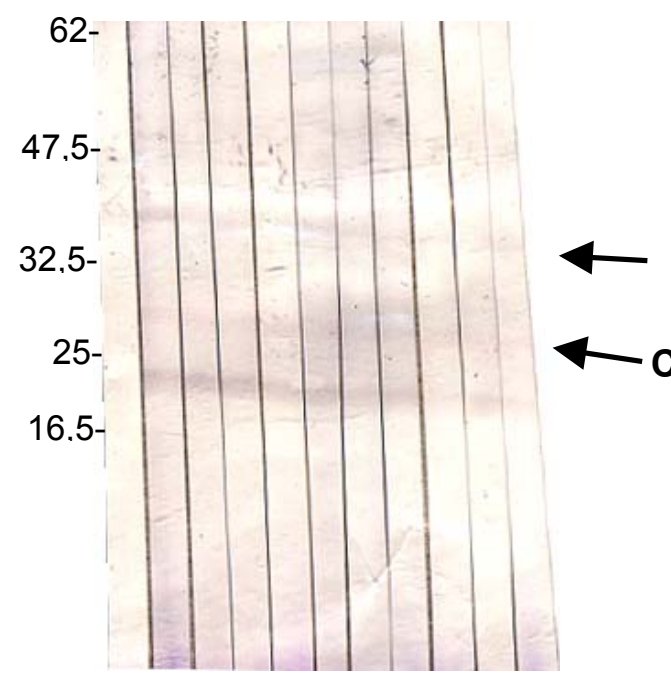

B) $[\mathrm{kDa}]$

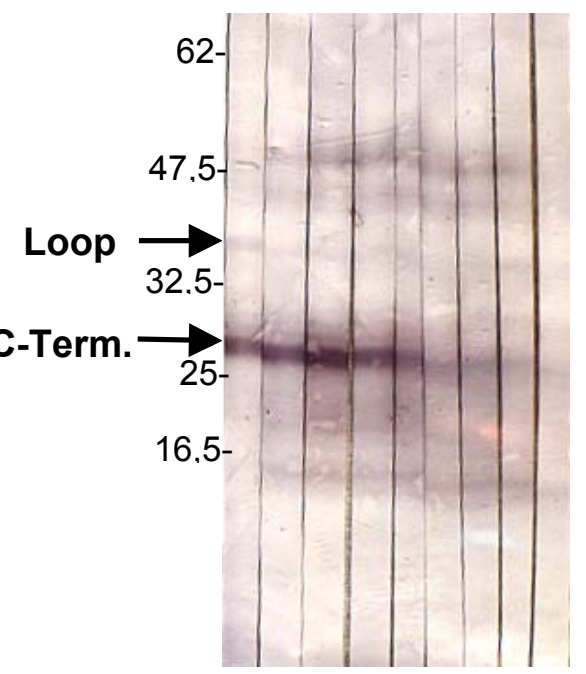

Abb. 11. Spezifität der affinitätsgereinigten Peptidantikörperfraktionen. Nach Elution von der Säule wurden die Antikörperfraktionen 1:500 in PBS verdünnt und gegen rekombinante His-Tag Fusionsproteine im Western Blot ausgetestet. Die Größen der Loop- und C-Terminus His-Tag Fusionsproteine sind mit einem Pfeil gekennzeichnet. A) Anti-WB1 Fraktionen; es ist keine Affinität gegenüber den Fusionsproteinen erkennbar. B) Anti-WB2 Fraktionen; das His-Tag Fusionsprotein aus dem C-Terminus von TgPMA1 wird spezifisch erkannt. Die ersten fünf Fraktionen wurden gepoolt und für spätere Versuche weiterverwendet.

Die Antikörperfraktionen des anti-WB1 Serums zeigten nur eine schwache Reaktion gegen rekombinantes Loop-Protein und wurden daher für weitere Versuche nicht weiter verwendet. Die Fraktion 2- 6 des anti-WB2 Serums reagierten hingegen stark mit dem rekombinanten C-Terminus Protein; sie wurden gepoolt und als antiTgPMA1 Antiserum für Immunfluoreszenzfärbungen eingesetzt.

\subsubsection{Lokalisation von TgPMA1 auf der Oberfläche von Toxoplasma Brady- zoiten}

Um mit den affinitätsgereinigten Antikörpern die Lokalisation von TgPMA1 innerhalb des Parasiten festzustellen, wurden Doppelimmunfluoreszenz-Studien an Tachyzoiten und Bradyzoiten durchgeführt.

Zysten des Stammes ME49 wurden aus den Gehirnen chronisch infizierter NMRI Mäuse isoliert und über einen Percollgradienten aufgereinigt. Durch einen Pepsinverdau wurden Bradyzoiten aus den Zysten befreit und dazu verwendet, einen konfluenten HFF Zellrasen auf Glasplättchen in 24-Napf Schalen in DMEM/1\% FCS/ 1\% Pen-Strep zu infizieren. Drei Stunden nach Infektion wurden die Kulturen mit $4 \%$ Paraformaldehyd/ PBS fixiert und mit PBS/ 0,25\% Triton X-100 permeabilisiert. In 
einem Doppelimmunfluoreszenztest wurden sie mit Kaninchen-anti-TgPMA1 (1:100 in PBS), und dem Bag1 spezifischen monoklonalen Antikörper 7E5 angefärbt. Als Zweitantikörper wurden Cy3-konjugiertes Esel-anti-Kaninchen IgG und DTAFkonjugiertes Esel-anti-Maus IgG eingesetzt.

HFFs auf Glasplättchen, die mit ME49 Tachyzoiten infiziert waren, wurden $36 \mathrm{~h}$ nach Infektion analog fixiert und permeabilisiert. Diese wurden mit Kaninchen-antiTgPMA1 (1:100 in PBS) in Kombination mit 6A8 (1:500 in PBS; Kasper, 1987), einem monoklonalem Antikörper, der für das Hauptoberflächenantigen von Tachyzoiten Sag1 spezifisch ist, gefärbt und mit den gleichen Zweitantikörpern detektiert.

Durch Auswertung an einem Konfokalmikroskop und Überlagerung der Färbungen lässt sich erkennen, dass TgPMA1 ausschließlich auf der Membran von Bradyzoiten lokalisiert ist, interne Strukturen wurden nicht angefärbt (s. Abb. 12). In Tachyzoiten lässt sich kein TgPMA1 nachweisen, was die stadienspezifische Expression bestätigt, die bereits durch RT-PCR auf RNA-Ebene gezeigt werden konnte.

Kontrollexperimente, in denen anstatt Kaninchen-anti-TgPMA1-Antiserum Präimmunserum verwendet wurde, ergaben keine Färbung von Tachyzoiten oder Bradyzoiten.

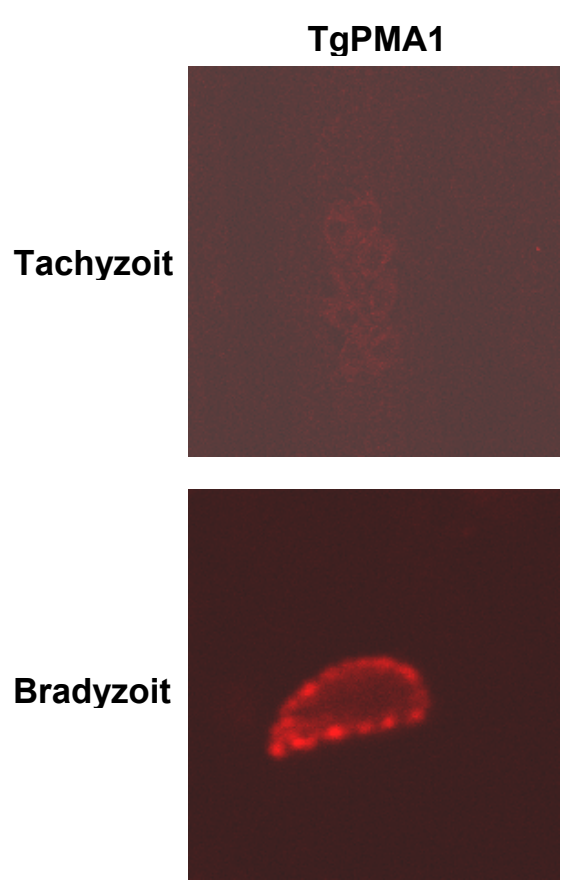

TgPMA1
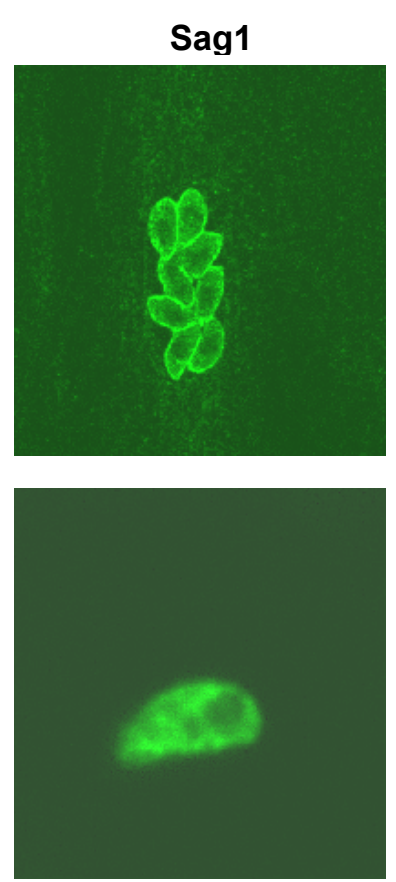

Bag1
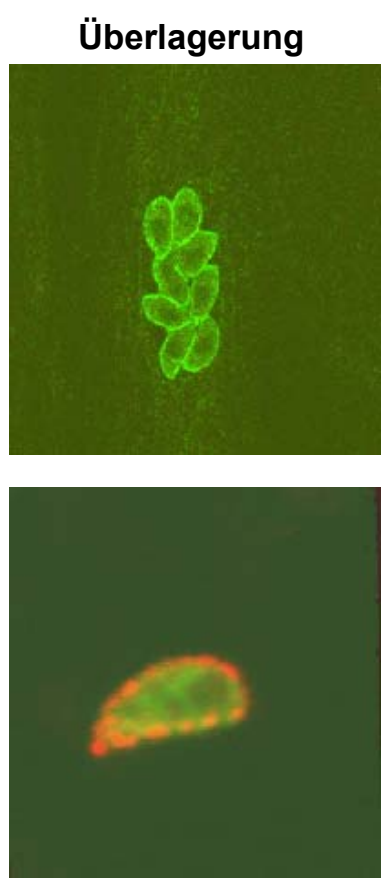

Überlagerung

Abb. 12. Immunfluoreszenzfärbung von Tachyzoiten und aus dem Gehirn von chronisch infizierten Mäusen isolierten Bradyzoiten mit affinitätsgereinigtem Kaninchen-anti-TgPMA1 Antiserum. Die Parasiten wurden nach Infektion von HFFs auf Deckgläschen fixiert und in einer Doppelimmunfluoreszenzfärbung gefärbt. Als Nachweis von Tachyzoiten wurde in der Färbung neben Kaninchen-antiTgPMA1 der monoklonale Antikörper 6A8 verwendet, der das Hauptoberflächenantigen von Tachyzoiten Sag1 erkennt. Bei Bradyzoiten wurde neben Kaninchen-anti-TgPMA1 der monoklonale Antikörper 7E5 verwendet, der gegen das bradyzoitspezifische kleine Hitzeschockprotein Bag1 gerichtet ist. 


\subsection{Disruption des tgpma1 Lokus}

Zur genaueren Untersuchung der Funktion der stadienspezifisch exprimierten P-Typ Plasmamembran ATPase TgPMA1 im Parasiten, sollte die Expression des funktionellen Proteins durch Disruption des offenen Leserahmens unterbunden werden, also eine Gendeletionsmutante generiert werden. In Toxoplasma gondii nutzt man zu diesem Zweck die relativ hohe Rate homologer Rekombination des Parasiten aus, indem man auf einem Plasmid den offenen Leserahmen des Zielgens durch Integration eines Selektionsmarkers unterbricht und dieses sogenannte ,Targeting Construct' in den Parasiten transfiziert (Donald et al., 1994).

Da Toxoplasma gondii ein haploides Genom besitzt und bereits durch Southern Blot gezeigt wurde, dass TgPMA1 ein single-copy Gen ist, musste zu diesem Zweck nur eine einfache Integration des Plasmids an seinen homologen Genlokus im Wildtyp erreicht werden.

\subsubsection{Klonierung des tgpma1, Targeting Construct*}

Um eine Gendeletion im Genom von Toxoplasma gondii einzuführen, muss auf dem Plasmid, mit dem die homologe Rekombination erreicht werden soll, ein möglichst großes Fragment homologer Sequenz 5' und 3' der Deletionsstelle des Zielgens vorhanden sein. An Stelle der deletierten Sequenz wird ein Selektionsmarker eingefügt, so dass nach der Transfektion auf die Integration des Targeting Constructs selektiert werden kann.

Für die Klonierung des Targeting Constructs wurden zwei DNA-Fragmente aus dem genomischen tgpma1 Klon über PCR mit Pfu-DNA-Polymerase jeweils 5' und 3' der Deletionsstelle amplifiziert.

Das 5'-tgpma1 Fragment umfasst mit einer Größe von 2369 nt beide Introns, das Startcodon, einen Bereich von 1117 nt aus dem 5' untranslatierten Bereich und die ersten $854 \mathrm{nt}$ aus dem kodierenden Bereich. Auf diesem Fragment sind der NTerminus des Proteins, die ersten zwei Transmembrandomänen und die Hälfte des kleinen zytoplasmatischen Loops kodiert. Zur Klonierung wurde durch die verwendeten Primer PMAI5'Apa/+ und PMAI5'Cla/- eine Apal Schnittstelle am 5'-Ende des Fragments und eine Erkennungsstelle für Clal am 3'-Ende eingefügt. 
Das 2812 nt große 3'-tgpma1 Fragment, amplifiziert durch die Primer PMAI3'/+ und PMAI3'/-, umfasst $2179 \mathrm{nt}$ aus dem offenen Leserahmen von tgpma1 zuzüglich 633 nt aus dem 3' untranslatierten Bereich. Der auf diesem Fragment kodierte Bereich umfasst alle Domänen des Proteins, die C-terminal des großen zytoplasmatischen Loops liegen, einschließlich diesem.

Beide PCR-Fragmente wurden zunächst in den TOPO pCR2.1 Vektor kloniert, aus dem sie durch Restriktionsdoppelverdau mit BamHI/ Notl (3'tgpma1) und Apal/ Clal (5'tgpma1) isoliert wurden.

Als Ausgangsplasmid für die Klonierung des Targeting Constructs wurde das Plasmid pSK-Tub/CAT/Sag verwendet. Dieses basiert auf pSK Bluescript (Stratagene) und trägt zusätzlich eine CAT-Expressionskassette, die als Selektionsmarker in $T$. gondii verwendet werden kann. Die Expressionskassette besteht aus der kodierenden Sequenz des Chloramphenicoltransferase (CAT) Gens, flankiert von einem 2,9 kb Fragment aus dem 5' UTR des $T$.gondii ß-tubulin Gens und ca. 300 nt aus dem 3“ UTR des sag1 Gens von Toxoplasma gondii.

In dieses Plasmid wurde das 3'tgpma1-Fragment über BamHI/ Notl, sowie das 5‘tgpma1-Fragment über Apal/ Clal Restriktionsschnittstellen eingefügt.

Wie in Abb. 13 schematisch dargestellt, enthält das fertiggestellte Targeting Construct fast den kompletten offenen Leserahmen von tgpma1, einschließlich beider Introns und kurzer flankierender Bereiche aus dem 5' und 3' UTR. Dabei wurde an die Stelle einer 422 nt Deletion der Selektionsmarker Tub/CAT/Sag eingefügt, welcher den offenen Leserahmen unterbricht. Einem möglichen Translationsprodukt des auf diesem Plasmid kodierten TgPMA1 würden somit die Hälfte des kleinen zytoplasmatischen Loops und zwei Transmembrandomänen fehlen, wobei außer der Integration des Selektionsmarkers zusätzlich eine Verschiebung des offenen Leserahmens eingeführt wurde. 


$\begin{array}{llllllllll}0 & 1 & 2 & 3 & 4 & 5 & 6 & 7 & 8 & 9 \mathrm{~kb}\end{array}$
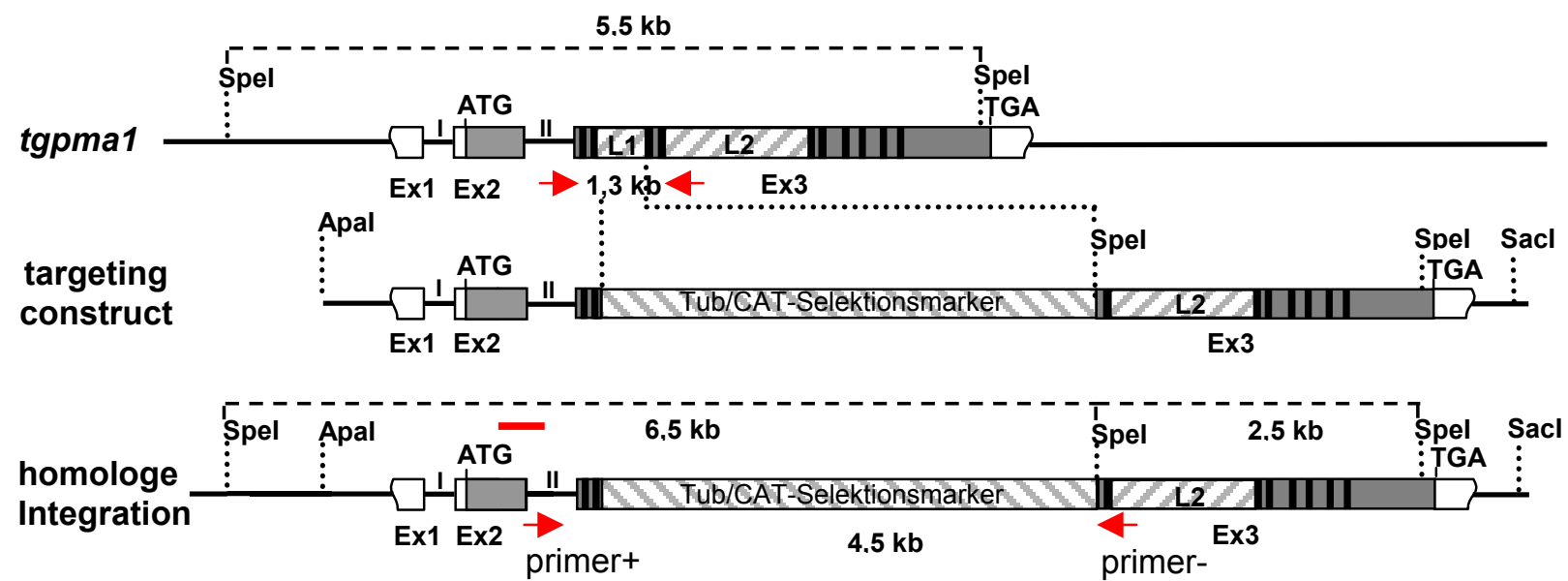

Abb. 13. Schematische Darstellung der Disruption von tgpma1 durch homologe Integration des Targeting Constructs. Introns (I, II), Exons (Ex1-3), und die von innen kodierten Bereiche des Proteins sind wie in Abb. 6 dargestellt. Wichtige Restriktionsschnittstellen für Spel, Apal und Sacl, sowie durch einen Restriktionsverdau zu erwartende DNA-Fragmentgrößen sind angegeben. Die Positionen der Primer Intr/+ und P-12/-, die zur Unterscheidung zwischen homologer und nicht-homologer Integration verwendet wurden, sind durch rote Pfeile angedeutet. Die DNA-Sonde, die zur Hybridisierung der restriktionsverdauten genomischen DNA benutzt wurde, ist als roter Balken dargestellt.

Durch einen doppelten Cross-Over am tgpma1 Lokus wird dieser durch das Targeting Construct ersetzt. Durch die Integration des Selektionsmarkers in den offenen Leserahmen von tgpma1 wird dieser unterbrochen und ein $422 \mathrm{nt}$ Fragment deletiert, so dass keine Expression des funktionellen Proteins mehr stattfinden kann.

\subsubsection{Transfektion des Targeting Constructs und Selektion einer TgPMA1 Gen- deletionsmutante}

Ca. $1 \mathrm{mg}$ an Plasmid-DNA des fertigen Targeting Constructs wurden durch DNAMaxipräparation gewonnen, durch Restriktionsverdau mit Notl linearisiert, anschließend mit Ethanol gefällt und in sterilem Cytomix in einer Konzentration von 1 $\mu \mathrm{g} / \mu \mathrm{l}$ aufgenommen.

Tachyzoiten des Stammes Prugniaud/HX (D. Soldati) wurden in $2 \mathrm{~mm}$ Elektroporationsküvetten mit $50 \mu \mathrm{g}$ linearisiertem Targeting Construct $(1 \mu \mathrm{g} / \mu \mathrm{l}$ in Cytomix) vermischt und in einem BTX ElectroCell Manipulator transfiziert. Anschließend wurden die Parasiten auf T25 Zellkulturflaschen gegeben, die mit einem konfluenten HFF Zellrasen beschichtet waren und in DMEM/ 1\% FCS/ 1\% Pen-Strep/ $20 \mu \mathrm{M}$ Chloramphenicol selektiert.

Als Selektionskontrolle wurde eine Flasche mit nicht-transfizierten Prugniaud/ $\mathrm{HX}^{-}$ infiziert und mitgeführt. Nach drei bis vier Passagen auf HFFs setzte die Selektionswirkung des Chloramphenicols ein und etwa $80 \%$ aller Parasiten wurden abgetötet, wobei keine Parasiten der Negativkontrolle überlebten. Die übrigen chloramphenicol- 
resistenten Parasiten wurden noch zwei mal unter $20 \mu \mathrm{M}$ Chloramphenicol passagiert und anschließend auf HFF-beschichteten Mikrotiter-Flachbodenplatten durch differentielle Verdünnungsreihen kloniert.

Die Klone wurden auf 12-Napf Zellkulturschalen, die zuvor mit einem konfluenten Zellrasen HFFs beschichtet worden waren, überführt und diese so lange inkubiert, bis erste Plaques im Zellrasen zu erkennen waren. Die Parasiten wurden daraufhin zusammen mit den Wirtszellen abgeschabt, durch Kanülen gepresst und die eine Hälfte weiter passagiert, während aus der anderen Hälfte der Parasiten genomische DNA durch Aceton-Fällung gewonnen wurde.

Die isolierte genomische DNA der Klone wurde durch PCR auf Integration des Targeting Constructs überprüft. Es wurden jeweils zwei PCR Reaktionen pro Klon durchgeführt. Mit der Primerkombination Intr/+, P11/- (für die Lage der Primer: s. Anhang, Abb. 21) wurde auf Vorhandensein des wildtypischen tgpma1 Lokus getestet. Während der Primer P11/- 837 nt $3^{\prime}$ der Deletionsstelle im Targeting Construct bindet, befindet sich die Bindungsstelle für Intr/+ 423 nt $5^{\prime}$ der Deletionsstelle, innerhalb des zweiten Introns von tgpma1. Durch Lokalisation der Primerbindungsstelle innerhalb des Introns konnte gleichzeitig eine potentielle Kontamination mit tgpma1 cDNA vermieden werden. Auf diese Weise ergibt sich sowohl bei nicht-transfizierten Parasiten, als auch bei solchen, die das Targeting Construct durch nicht-homologe Integration an einer anderen Stelle ihres Genoms integriert haben, ein PCR-Produkt von $1683 \mathrm{nt}$, wohingegen bei homologer Integration ein PCR-Produkt von etwa 4,8 kb zu erwarten ist. Da allerdings ein PCR-Produkt von 4,8 kb mit genomischer DNA, die durch Aceton-Fällung gewonnen wurde, kaum zu erreichen ist, wurde mit einer zweiten PCR-Reaktion auf Vorhandensein des Targeting Constructs in den Klonen getestet. Hierfür wurde wieder der Primer P11/verwendet, allerdings diesmal in Kombination mit Tub/CAT4/+, einem Primer, der innerhalb der kodierenden Sequenz des CAT-Selektionsmarkers bindet. Eine PCRReaktion mit dieser Primerkombination sollte bei allen Parasiten, die das Targeting Construct in ihrem Genom integriert haben, die gewünschte Bande von ca. $1700 \mathrm{nt}$ liefern. Da eine Selektion mit Chloramphenicol bei Toxoplasma gondii immer einige Parasiten überleben, ohne eigentlich resistent zu sein, war dieser zweite Schritt notwendig, um die doch recht hohe Anzahl an Klonen herauszufiltern, die kein Targeting Construct integriert hatten. Als Kontrolle für die PCR-Reaktionen wurde jeweils gDNA 
von nicht-transfizierten Prugniaud/HX' als Wildtyp-Kontrolle und isoliertes Targeting Construct als Positivkontrolle für die Gendeletionsmutante mitgeführt.

Nachdem auf diese Weise einige hundert Klone gescreent worden waren, konnte der Klon IH5 gefunden werden, der zwar das Targeting Construct im Genom integriert hatte, aber kein Produkt nach PCR-Reaktion mit den flankierenden Primern Intr/+, P11/- lieferte.

\subsubsection{Nachweis der homologen Integration in der TgPMA1 Gendeletions- mutante}

Um zu beweisen, dass es sich bei der Mutante IH5 tatsächlich um eine funktionelle TgPMA1 Deletionsmutante handelte, und um nachzuweisen, dass sich das Targeting Construct nur einmal in das Genom integriert hatte, und zwar durch homologe Rekombination, wurden drei Nachweisverfahren angewandt.

Erstens wurde mit Restriktionsenzymen verdaute genomische DNA von Wildtyp und Mutante im Southern Blot auf veränderte Fragmentgröße untersucht. Zweitens wurde eine PCR-Reaktion mit Primern durchgeführt, die die Integrationsstelle flankieren und ebenfalls mittels Southern Blot die Identität der Banden verifiziert. Ferner wurde in einer Immunfluoreszenzfärbung an in vitro differenzierten Bradyzoiten direkt das Fehlen der TgPMA1 Expression nachgewiesen.

\subsubsection{Southern Blot mit genomischer DNA}

Zum Nachweis einer homologen Rekombination am tgpma1 Lokus in der IH5 Mutante wurden $4 \mu \mathrm{g}$ genomische DNA des Klons und des Prugniaud/HX' Wildtypstammes mit dem Restriktionsenzym Spel über Nacht verdaut. Spel schneidet im Wildtyp einmal innerhalb der kodierenden Region von tgpma1, etwa auf Höhe des Stopp-Codons. Eine weitere Schnittstelle befindet sich etwa 5,5 kb 5' davon, außerhalb der kodierenden Region. Auf dem Targeting Construct ist eine zusätzliche SpelSchnittstelle, gleich 3“ des Selektionsmarkers. Durch homologe Integration des Targeting Constructs in das Chromosom an der Stelle des tgpma1 Lokus wird auf diese Weise eine zusätzliche Spel-Schnittstelle in den tgpma1 Lokus eingeführt, was 
eine Vergrößerung des Spel-Restriktionsproduktes durch den Selektionsmarker auf ca. $6,5 \mathrm{~kb}$ zur Folge hat.

Die Spel-verdaute genomische DNA wurde auf einem 0,7 prozentigen Agarosegel elektrophoretisch aufgetrennt und auf eine Nylonmembran geblottet. Zur Hybridisierung wurde ein $250 \mathrm{nt}{ }^{32} \mathrm{P}$-markiertes Sacl/ EcoRI Restriktionsfragment des genomischen TgPMA1 Klons verwendet. Dieses liegt zwischen dem Startcodon und dem 3'-Ende des zweiten Introns, also noch 5' der Integrationsstelle des Selektionsmarkers auf dem Targeting Construct.

Nach Auswertung eines exponierten Screens an einem Phospho-Imager war deutlich jeweils eine Bande in der erwarteten Höhe bei Wildtyp und IH5 zu erkennen, was auf eine Integration des Targeting Constructs durch homologe Rekombination bei der Mutante schließen lässt (s. Abb. 14 A).

\subsubsection{PCR mit flankierenden Primern}

An isolierter genomischer DNA von Prugniaud/HX- Wildtyp und Mutante $\mathrm{IH} 5$ wurde eine PCR-Reaktion mit den Primern Intr/+ und 9-3/- durchgeführt. Diese Primer flankieren den Bereich des tgpma1 Leserahmens, der im Targeting Construct deletiert und in den der Selektionsmarker integriert wurde. In einer PCR Reaktion sollte im Wildtyp durch diese Primer ein Amplifikat von 1262 nt erzeugt werden, wogegen bei einer homologen Integration des Targeting Constructs eine Bande von ca. 4,8 kb auf dem Agarosegel zu erwarten ist. Eine PCR-Reaktion mit nachfolgender Agarosegelelektrophorese ergab die erwarteten Bandengrößen bei Wildtyp und Mutante. Um sicherzustellen, dass es sich bei den beobachteten PCR-Produkten wirklich um die gewünschten Amplifikate aus dem tgpma1 Lokus handelte, wurde ihre Spezifität durch Hybridisierung mit einer tgpma1-Sonde überprüft.

Hierfür wurden annähernd gleiche Mengen der Amplifikate auf einem Agarosegel aufgetrennt und auf eine Nylonmembran geblottet. Als Sonde wurde ein Digoxigeninmarkiertes PCR-Fragment verwendet, welches mit den Primern Intr/+ und P-12/- an genomischer Prugniaud/HX DNA amplifiziert worden war. Der Primer P-12/- bindet ca. 60 nt 5 der Deletionsstelle auf dem Targeting Construct, so dass durch dieses PCR-Fragment die geblotteten Amplifikate von sowohl Wildtyp als auch Gendeletionsmutante erkannt werden sollten. 
A)

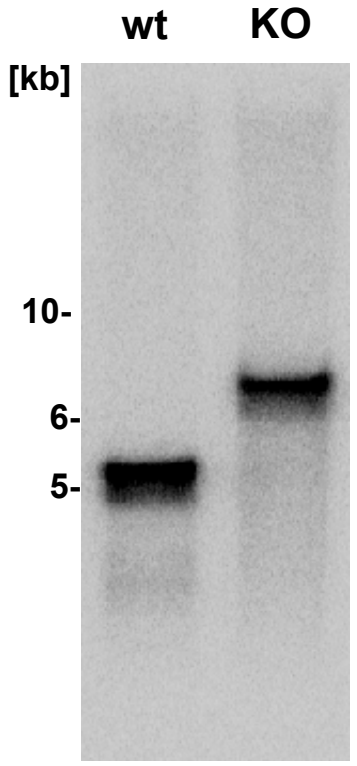

C)

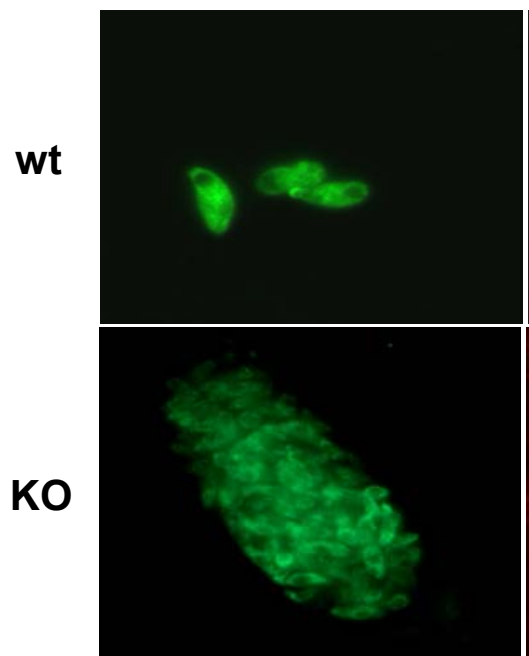

B)

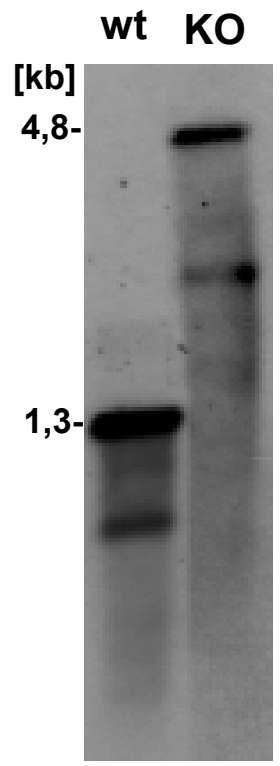

TgPMA1

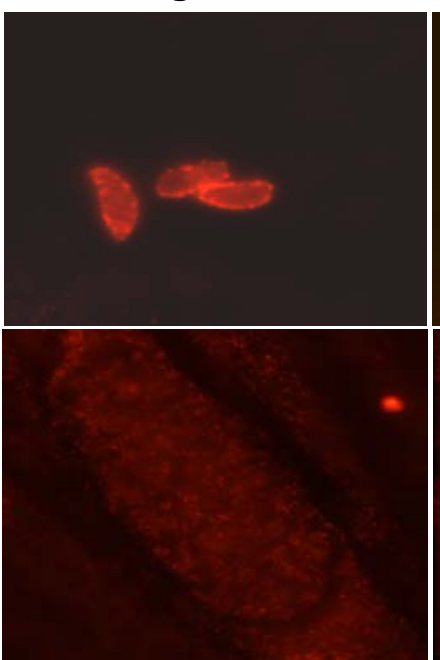

Überlagerung

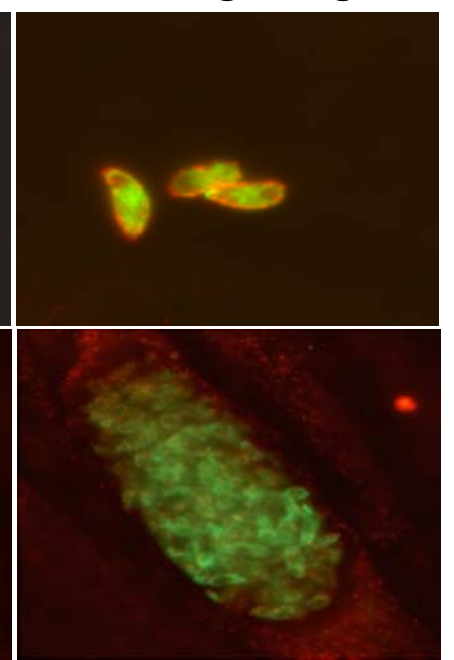

Abb. 14. Nachweis der funktionellen Disruption von tgpma1 in der Gendeletionsmutante. A) Mit Spel verdaute genomische DNA von Wildtyp (wt) und Mutante (KO) wurde auf eine Nylonmembran übertragen und mit einem radioaktiv markierten 250 nt Restriktionsfragment aus dem offenen Leserahmen von tgpma1 hybridisiert. B) Eine PCR-Reaktion mit Primern, die die Integrationsstelle des Selektionsmarkers flankieren, wurde an genomischer DNA von Wildtyp und Gendeletionsmutante durchgeführt. Nach Agarosegelelektrophorese wurde die DNA auf eine Nylonmembran übertragen und mit einem Digoxigenin-markierten PCR-Fragment hybridisiert. C) In vitro differenzierte Bradyzoiten wurden mit ihren Wirtszellen auf Deckgläschen fixiert und in einer Doppelimmunfluoreszenzfärbung mit Kaninchen-anti-TgPMA1 und dem Bag1-spezifischen 7E5 gefärbt.

Die Sonde wurde mit anti-Digoxigenin-alkalische Phosphatase Konjugat erkannt und mittels CSPD Chemiluminiszenz-Färbung auf einem Röntgenfilm detektiert, wodurch die Spezifität der PCR-Produkte bestätigt werden konnte (s. Abb. 14 B). 


\subsubsection{Doppelimmunfluoreszenzfärbung an Bradyzoiten}

Für den direkten Nachweis einer fehlenden Expression von TgPMA1 in der IH5Mutante wurden Tachyzoiten von IH5 und des Prugniaud/HX Wildtypstammes auf HFFs gegeben, die konfluent auf Glasplättchen in 24-Napf-Zellkulturschalen wuchsen. Stadienkonversion der Parasiten wurde durch einen $\mathrm{pH}$-Shift von sechs Tagen induziert. Anschließend wurden die Zellen mit 4\% Paraformaldehyd/ PBS fixiert, mit $0,25 \%$ Triton X100 in PBS permeabilisiert und in einem Doppelimmunfluoreszenztest auf die gleichzeitige Expression von Bag1 und TgPMA1 untersucht. Der Bag1-spezifische monoklonale Antikörper 7E5 (1:500 in PBS) wurde zusammen mit affinitätsgereinigtem Kaninchen-anti-TgPMA1 (1:100 in PBS) auf den Zellen inkubiert. Zur Detektion der Antikörper wurden Cy2-konjugiertes Esel-anti-Maus IgG (1:500 in PBS) und Cy3-konjugiertes Esel-anti-Kaninchen IgG (1:1000 in PBS) verwendet. Die Fluoreszenz der Proben wurde an einem konfokalen Mikroskop analysiert.

Wie in Abb. $14 \mathrm{C}$ zu erkennen ist, konnte keine Expression von TgPMA1 in den Bradyzoiten der IH5 Mutante festgestellt werden, wogegen durch die vorhandene Expression von Bag1 der Erfolg der induzierten Stadienkonversion verifiziert wurde. In den Prugniaud/HX' Parasiten konnte dagegen eine Co-Expression von TgPMA1 und Bag1 in den selben Parasiten gezeigt werden.

\subsection{Charakterisierung der tgpma1 Gendeletionsmutante in vitro}

\subsubsection{Wachstumsgeschwindigkeit von Tachyzoiten}

Obwohl tgpma1 ein bradyzoitspezifisch exprimiertes Gen ist, sollte zunächst festgestellt werden, ob die tgpma1 Gendeletionsmutante im Tachyzoitenstadium durch die Disruption des tgpma1 Leserahmens in ihrer Vitalität beeinträchtigt wurden.

Ein konfluenter Zellrasen HFFs wurde auf Glasplättchen in 24-Napf-Zellkulturschalen mit Tachyzoiten von Prugniaud/HX und tgpma1 Deletionsmutante infiziert und in DMEM/ 1\% FCS/ 1\% Pen-Strep im Zellkulturinkubator für 30 h, bzw. 45 h inkubiert. Anschließend wurden die Zellen mit Methanol fixiert und in einer Immunfluoreszenzfärbung mit polyklonalem Kaninchen-anti-Toxoplasma Antiserum (1:2000 in PBS), nachgewiesen durch Cy3-markiertes Esel-anti-Kaninchen IgG (1:1000 in PBS), 
angefärbt. Unter dem Fluoreszenzmikroskop wurde die Anzahl an Parasiten pro Vakuole aus jeweils drei mal 100 Vakuolen die mindestens zwei Parasiten enthielten, für Wildtyp und Mutante bestimmt. Die Mittelwerte der prozentualen Verteilung sind in Abb. 15 A+B jeweils für Wildtyp und Mutante von Vakuolen mit 2, 4, 8, 16 und $\geq 32$ Parasiten angegeben.

Mit der durchschnittlichen Anzahl an Parasiten in einer bestimmten Zeit ergibt sich ein Maß für die Wachstumsgeschwindigkeit und damit die Vitalität der Parasiten. Diese ist, wie zu erwarten, bei Wildtyp und Gendeletionsmutante im Tachyzoitenstadium ohne signifikanten Unterschied (s. Tabelle 5).

\begin{tabular}{|ccc|}
\hline Inkubationszeit als Tachyzoiten & $30 \mathrm{~h}$ & $45 \mathrm{~h}$ \\
Prugniaud/HX' & $5,53 \pm 0,79$ & $16,24 \pm 2,48$ \\
tgpma1 Gendeletion & $4,59 \pm 0,93$ & $15,90 \pm 0,68$ \\
\hline
\end{tabular}

Tabelle 5. Durchschnittliche Anzahl an Parasiten pro Vakuole nach Inkubation als Tachyzoiten für 30, bzw. $45 \mathrm{~h}$.

\subsubsection{Wachstumsgeschwindigkeit während Stadienkonversion von Tachyzoiten zu Bradyzoiten}

Da tgpma1 ein bradyzoitspezifisch exprimiertes Gen ist, könnte sich die Disruption von tgpma1 auf das Wachstum im Bradyzoitenstadium auswirken. Um dies zu untersuchen, wurden Tachyzoiten des Prugniaud/HX- Stammes und der Gendeletionsmutante dazu verwendet, einen konfluenten Zellrasen HFFs auf Deckgläschen in DMEM/ 1\% FCS/ 1\% Pen-Strep zu infizieren. Nach $4 \mathrm{~h}$ wurde das Medium gegen $\mathrm{pH}$-Shift Medium ( $\mathrm{pH} 8,2)$ ausgetauscht und die Zellen in einem Zellkulturinkubator bei $37{ }^{\circ} \mathrm{C}$ ohne $\mathrm{CO}_{2}$-Zufuhr inkubiert. Nach $20 \mathrm{~h}$, bzw. $41 \mathrm{~h}$ Inkubation in pH-Shift Medium wurden die Zellen mit Methanol fixiert und wie zuvor die Tachyzoiten in einer Immunfluoreszenzfärbung mit polyklonalem Kaninchen-anti-Toxoplasma Antiserum (1:2000 in PBS) und anschließend mit Cy3-markiertem Esel-anti-Kaninchen IgG (1:1000 in PBS) angefärbt. Wieder wurde bei je drei mal 100 Vakuolen die Anzahl mit $2,4,8,16$, oder $\geq 32$ Parasiten am Fluoreszenzmikroskop ausgezählt, jeweils die Mittelwerte gebildet und die prozentuale Verteilung der Vakuolengröße für Wildtyp und Mutante in einem Säulendiagramm in Abb. $15 \mathrm{C}+\mathrm{D}$ dargestellt. Die durchschnittliche Anzahl an Parasiten pro Vakuole wurde berechnet (s. Tabelle 6). 
Auch während Bedingungen, die eine Stadienkonversion induzierten, war die Replikationsrate bei Wildtyp und Gendeletionsmutante ohne signifikante Unterschiede.

\begin{tabular}{|ccc|}
\hline Inkubationszeit während pH-Shift & $20 \mathrm{~h}$ & $41 \mathrm{~h}$ \\
Prugniaud/HX- & $4,22 \pm 0,70$ & $16,33 \pm 2,91$ \\
tgpma1 Gendeletion & $3,52 \pm 0,62$ & $16,17 \pm 0,70$ \\
\hline
\end{tabular}

Tabelle 6. Durchschnittliche Anzahl an Parasiten pro Vakuole während Induktion der Stadienkonversion durch $\mathrm{pH}$-Shift Bedingungen.

A)

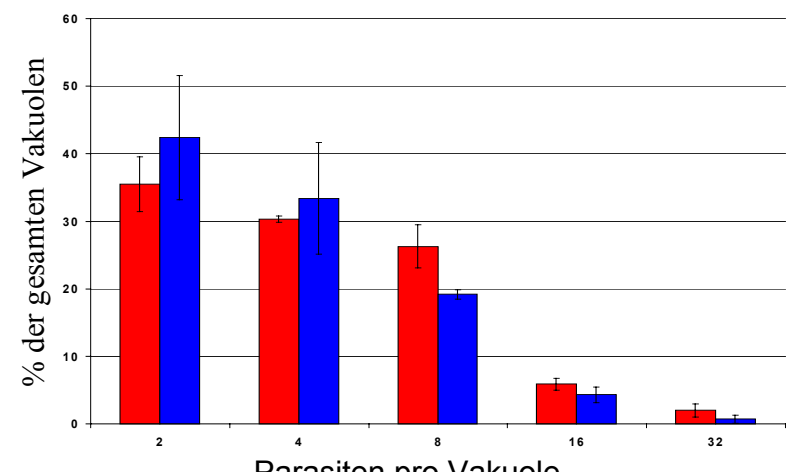

Parasiten pro Vakuole

C)

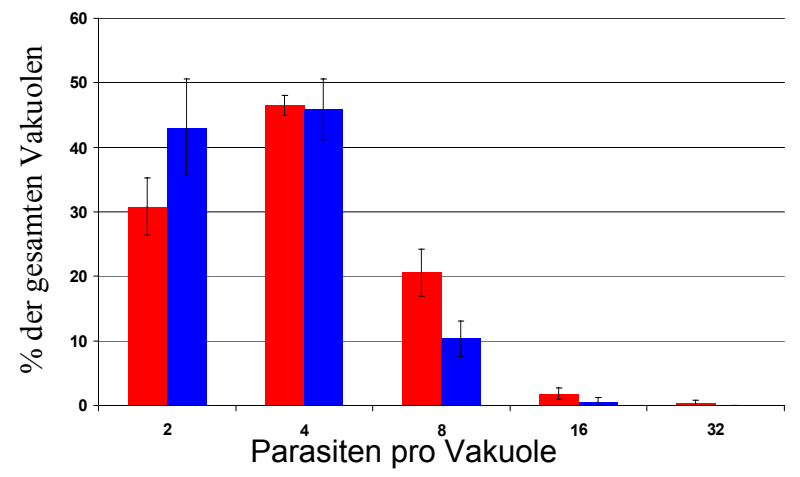

E)

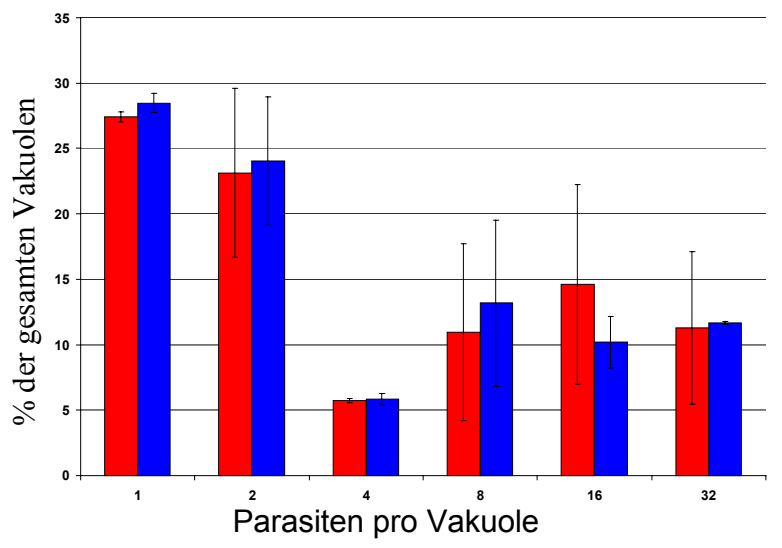

B)

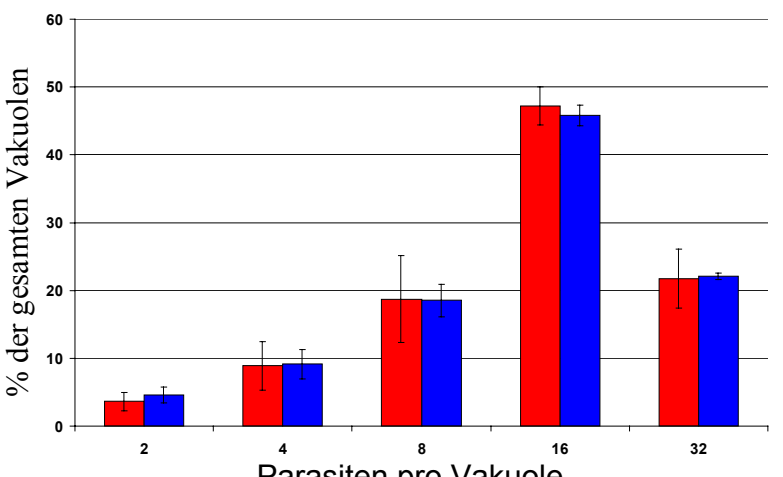

D)

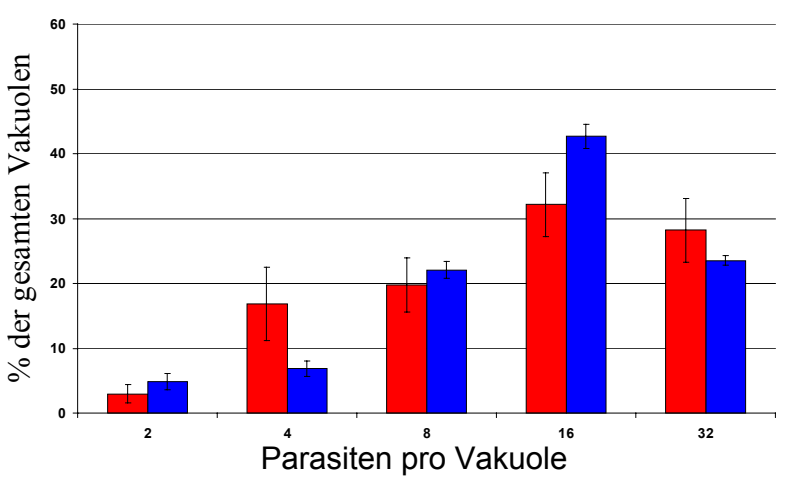

Abb. 15. Wachstumsgeschwindigkeit von Tachyzoiten nach A) $30 \mathrm{~h}$ und B) $45 \mathrm{~h}$. Tachyzoiten des Prugniaud/HX' Stammes (rot) und der tgpma1 Gendeletionsmutante (blau) wurden zusammen mit HFFs auf Glasplättchen inkubiert und nach 30, bzw. 45 h fixiert. Um das Wachstum unter Differenzierungsbedingungen zu untersuchen, wurden Tachyzoiten nach Infektion ihrer Wirtszellen unter $\mathrm{pH}-$ Shift Bedingungen gehalten und nach $\mathbf{C}$ ) $20 \mathrm{~h}$, bzw. D) $41 \mathrm{~h}$ fixiert.

E) Wachstumsgeschwindigkeit von Bradyzoiten während der Umwandlung zu Tachyzoiten. Aus chronisch infizierten Mäusen

wurden Zysten isoliert, die Parasiten durch Pepsinverdau aus diesen befreit und ein Zellrasen HFFs auf Deckgläschen mit diesen für $48 \mathrm{~h}$ infiziert.

Die Anzahl an Parasiten pro Vakuole wurde für drei mal 100 Vakuolen ausgezählt und jeweils der Mittelwert gebildet. Die Standardabweichung ist als Balken dargestellt. 


\subsubsection{Wachstumsgeschwindigkeit während Stadienkonversion von Bradyzoiten zu Tachyzoiten}

Zur Bestimmung der Wachstumsgeschwindigkeit von Bradyzoiten während der Stadienkonversion zu Tachyzoiten wurden Mäuse i. p. mit 10- 20 Zysten Prugniaud/HX oder tgpma1 Deletionsmutante infiziert und vier Wochen nach Infektion die Gehirne dieser Mäuse präpariert. Die Gehirne wurden homogenisiert und Zysten über Percollgradienten isoliert. Durch einen Pepsinverdau wurden die Bradyzoiten aus den Zysten befreit und dazu verwendet, einen konfluenten Zellrasen HFFs auf Deckgläschen in 24-Napf-Zellkulturschalen zu infizieren. Nach $48 \mathrm{~h}$ wurden die Zellen mit Methanol fixiert und mit polyklonalem Kaninchen-anti-Toxoplasma Antiserum (1:2000 in PBS) in einer Immunfluoreszenzfärbung inkubiert. Durch DTAFkonjugiertes Esel-anti-Kaninchen IgG (1:500 in PBS) wurden die Parasiten angefärbt und mit einem Immunfluoreszenzmikroskop die Verteilung der Parasitenanzahl pro Vakuole wie zuvor bestimmt (s. Abb. 15 E). Eine Berechnung der durchschnittlichen Anzahl der Parasiten pro Vakuole ergab beim Wildtyp mit 8,06 $\pm 3,76$ und bei der Mutante mit 7,69 $\pm 0,98$ auch hier keinen signifikanten Unterschied.

\subsubsection{Induktion der Stadienkonversion}

Zur weiteren Charakterisierung der Gendeletionsmutante sollte die Fähigkeit zur Bradyzoitendifferenzierung geprüft werden. Hierfür wurde die Expression verschiedener stadienspezifischer Gene während der ersten Tage der Stadienkonversion für Prugniaud/HX- und Mutante verglichen.

\subsubsection{Stadienkonversion durch pH-Shift}

Ein konfluenter Zellrasen HFFs auf Deckgläschen wurde mit Tachyzoiten des Prugniaud/ $/ \mathrm{HX}^{-}$Stammes und der Gendeletionsmutante infiziert und ein $\mathrm{pH}-\mathrm{Shift}(\mathrm{pH}$ 8,2) von vier, bzw. sechs Tagen durchgeführt. Zur Untersuchung der Expression verschiedener stadienspezifischer Antigene wurden die Zellen, je nach verwendetem Antikörper (s. Tabelle 7), entweder mit 4\% Paraformaldehyd/ PBS und anschließend 
mit $0,25 \%$ Triton X100/ PBS fixiert und permeabilisiert oder ohne zusätzliche Permeabilisierung nur mit Methanol fixiert. In einer Doppelimmunfluoreszenzfärbung wurden die fixierten Zellen mit verschiedenen monoklonalen Antikörpern (s. Tabelle 7; 1:500 in PBS) und polyklonalem Kaninchen-anti-Toxoplasma Antiserum (1:2000 in PBS) inkubiert und anschließend mit Cy2-, bzw. Cy3- markiertem Sekundärantikörper angefärbt. An einem Fluoreszenzmikroskop wurden für jeden zu untersuchenden Marker drei mal 50 Vakuolen ausgezählt und der prozentuale Anteil der für den jeweiligen Marker positiven Vakuolen bestimmt. Die Mittelwerte der Expression eines Markers nach 4, bzw. 6 Tagen pH-Shift Bedingungen sind für Prugniaud/HX- und tgpma1 Deletionsmutante jeweils im Vergleich in Abbildung 16 graphisch dargestellt. Unabhängig vom verwendeten Bradyzoitenmarker konnte in allen Fällen eine deutlich reduzierte Expression in der Deletionsmutante im Vergleich zum parentalen Stamm festgestellt werden.

\begin{tabular}{|c|c|c|c|c|}
\hline $\begin{array}{l}\text { Bezeichnung } \\
\text { des AK }\end{array}$ & $\begin{array}{l}\text { erkanntes } \\
\text { Protein }\end{array}$ & $\begin{array}{l}\text { Fixierungs- } \\
\text { bedingung }\end{array}$ & $\begin{array}{l}\text { Herkunft aus } \\
\text { Spezies }\end{array}$ & Literaturangabe \\
\hline 7E5 & Bag1 & Pfa & Maus & Bohne et al., 1993 \\
\hline $4 \mathrm{~F} 8$ & $?$ & Methanol & Maus & Bohne et al., 1993 \\
\hline T8 4A12 & $\begin{array}{c}\text { Pb36 } \\
\text { (= BSR4) }\end{array}$ & Methanol & Maus & $\begin{array}{l}\text { Tomavo et al., } 1991 \\
\text { Knoll \& Boothroyd, } 1998 \text { a }\end{array}$ \\
\hline T8 3B1 & $\begin{array}{c}\text { Pb18 } \\
(=\text { Sag4 })\end{array}$ & Methanol & Maus & $\begin{array}{l}\text { Tomavo et al., } 1991 \\
\text { Ödberg-Ferragut et al., } 1996\end{array}$ \\
\hline T8 2C2 & Pb34 & Methanol & Maus & Tomavo et al., 1991 \\
\hline $\mathrm{T} 84 \mathrm{G} 10$ & $\mathrm{~Pb} 21$ & Methanol & Maus & Tomavo et al., 1991 \\
\hline DC11 & $?$ & Methanol & Ratte & Gross et al., 1995 \\
\hline DB Lektin & CST1 & $\mathrm{Pfa}$ & $\begin{array}{l}\text { Dolichos } \\
\text { biflorus }\end{array}$ & $\begin{array}{l}\text { Boothroyd et al., } 1997 \\
\text { Zhang et al., } 2001\end{array}$ \\
\hline
\end{tabular}

Tabelle 7. Bezeichnung, Herkunft und Spezifität der verwendeten Antikörper 

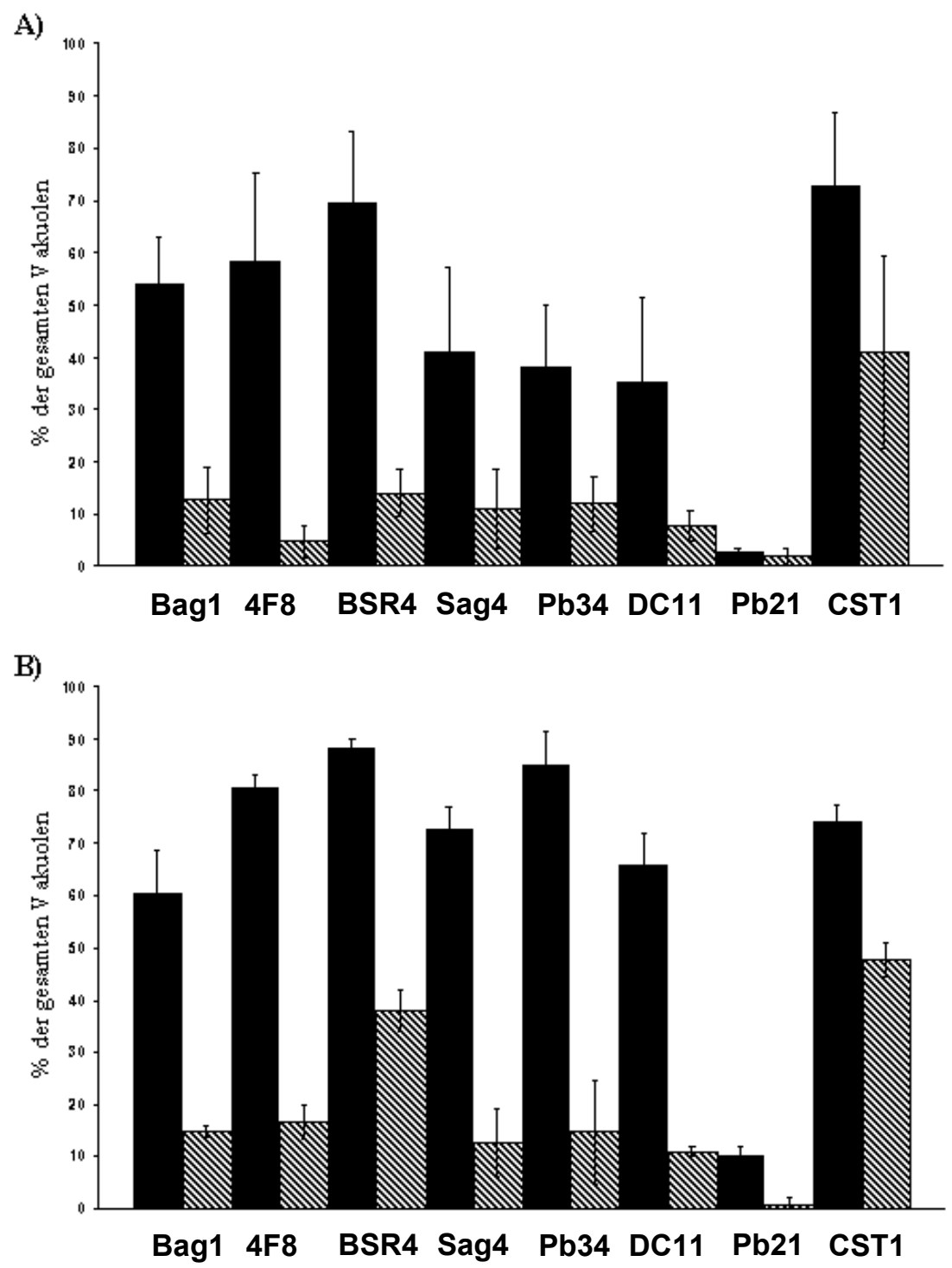

Abb. 16. Stadienkonversion durch pH-Shift. Ein konfluenter Zellrasen HFFs auf Deckgläschen wurde mit Tachyzoiten des Prugniaud/HX Stammes und der tgpma1 Gendeletionsmutante infiziert und diese anschließend für A) vier, bzw. B) sechs Tage unter $\mathrm{pH}$-Shift Bedingungen gehalten. Die Zellen wurden fixiert und in einer Doppelimmunfluoreszenzfärbung mit polyklonalem Kaninchen-antiToxoplasma Antiserum in Kombination mit verschiedenen monoklonalen Antikörpern gefärbt, die jeweils ein bradyzoitspezifisch exprimiertes Antigen erkannten. Der Prozentsatz der für den jeweiligen Marker positiven Vakuolen wurde ausgezählt und jeweils der Mittelwert aus drei mal 50 Vakuolen gebildet. Die Werte für Prugniaud/HX sind als schwarze Säulen dargestellt, jene für die Deletionsmutante sind schraffiert, Standardabweichungen sind angegeben. Die Namen der jeweils nachgewiesenen Proteine oder der verwendeten Antikörper sind unter dem Diagramm aufgeführt.

\subsubsection{Stadienkonversion durch andere Shift-Methoden}

Da ein deutlicher Unterschied in der Expression sämtlicher untersuchter stadienspezifisch exprimierter Proteine zwischen der Gendeletionsmutante und dem Wildtyp zu erkennen war, stellte sich die Frage, ob es sich um ein generelles 
Phänomen handelte, oder ob dies nur auf die Methode zurückzuführen war, mit der die Stadienkonversion induziert worden war.

Um dies zu beantworten, wurden alternative Methoden ausgetestet, von denen bekannt war, dass sie auch zu einer Stadienkonversion führen können.

\subsection{Stadienkonversion durch extrazelluläre Inkubation}

Tachyzoiten von Wildtyp und Deletionsmutante wurden zusammen mit ihren Wirtszellen aus einer T25 Zellkulturflasche abgeschabt und durch mehrere Passagen durch Kanülen von diesen befreit. In einer leeren T25 Zellkulturflasche wurden die Parasiten $12 \mathrm{~h}$ bei $37{ }^{\circ} \mathrm{C}$ in einem Zellkulturinkubator unter $\mathrm{CO}_{2}$-Begasung inkubiert. Die Zellen wurden pelletiert, das Medium gegen frisches DMEM/ 1\% FCS/ 1\% PenStrep ausgetauscht und auf HFFs verteilt, die konfluent auf Glasplättchen in 24-NapfZellkulturschalen wuchsen. Nach zwei Tagen wurden die Zellen mit Methanol fixiert und in einer Doppelimmunfluoreszenzfärbung mit den bradyzoitspezifischen monoklonalen Antikörpern 4F8, bzw. T8 4A12 (je 1:500 in PBS) und polyklonalem Kaninchen-anti-Toxoplasma Antiserum (1:2000 in PBS) inkubiert. Durch Cy3konjugiertes Esel-anti-Maus IgG (1:1000 in PBS) und DTAF-markiertes Esel-antiKaninchen IgG (1:500 in PBS) wurden die Antikörper detektiert. Mit Hilfe eines Fluoreszenzmikroskops wurden drei mal 50 Vakuolen, die mindestens vier Parasiten enthielten, ausgezählt und die prozentuale Häufigkeit an Vakuolen bestimmt, die für 4F8, bzw. T8 4A12 (BSR4) positiv waren.

Während im Wildtyp eine deutliche Expression der untersuchten Marker zu erkennen war, konnte fast keine Expression der untersuchten bradyzoitspezifischen Proteine in der Mutante festgestellt werden (s. Abb. 17 A).

Eine Wiederholung des Versuchs mit extrazellulärer Inkubation in pH-Shift Medium (pH 8,2), anstatt DMEM/ 1\% FCS/ 1\% Pen-Strep und in einem Zellkulturinkubator ohne $\mathrm{CO}_{2}$-Begasung, lieferte ein ähnliches Ergebnis. 

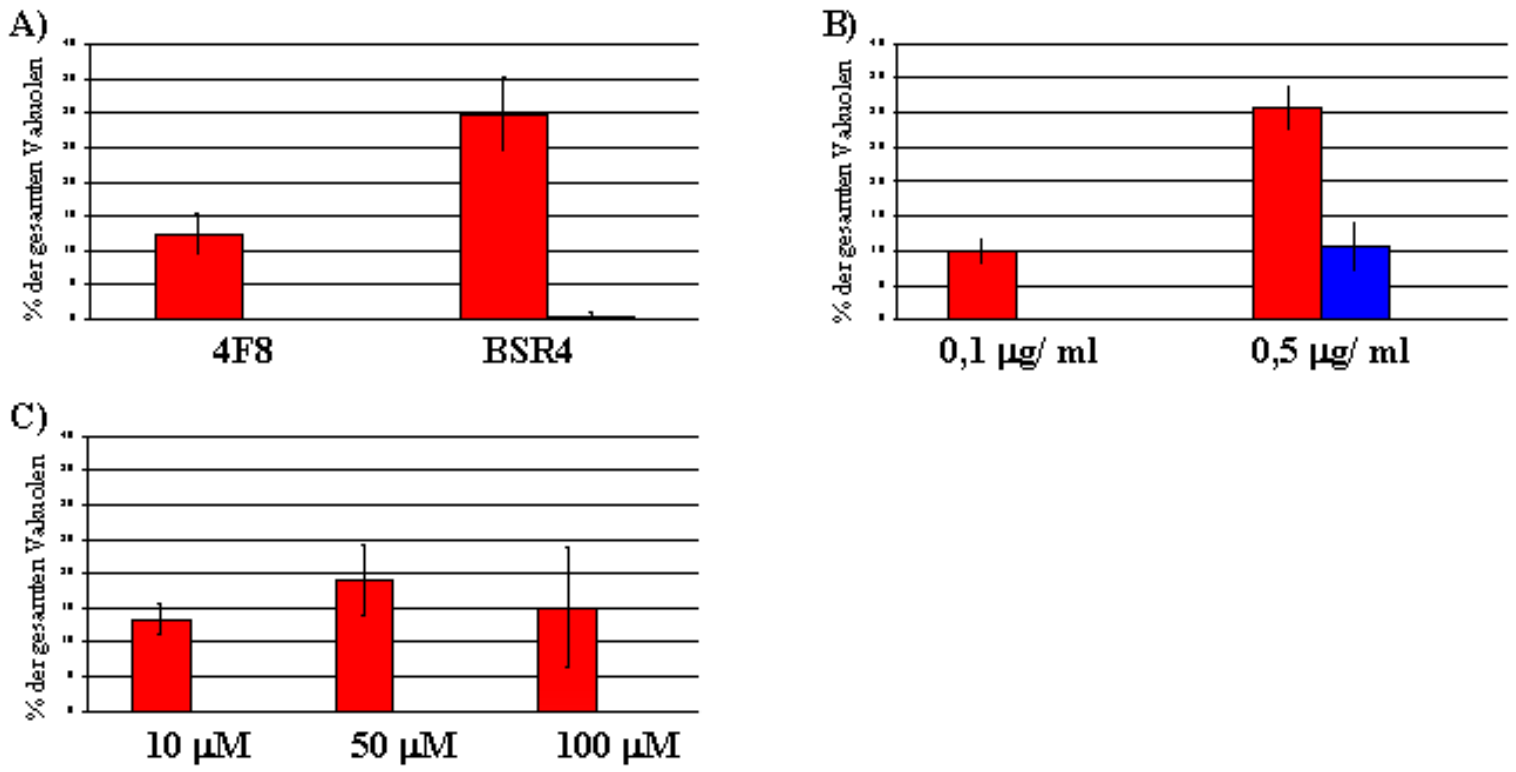

\begin{abstract}
Abb. 17. Alternative Differenzierungsmethoden. Dargestellt sind jeweils die Mittelwerte von drei mal 50 ausgezählten Vakuolen mit Standardabweichung. Es wurden Tachyzoiten des Prugniaud/ $\mathrm{HX}^{-}$ Stammes (rote Balken) und der tgpma1 Deletionsmutante (blaue Balken) verwendet. A) extrazelluläre Inkubation. Tachyzoiten wurden von ihren Wirtszellen befreit und $12 \mathrm{~h}$ extrazellulär bei $37^{\circ} \mathrm{C}$ inkubiert. Mit den Parasiten wurde ein konfluenter Zellrasen HFFs auf Deckgläschen infiziert und zwei Tage nach Infektion fixiert. In einer Doppelimmunfluoreszenzfärbung wurde der Prozentsatz an 4F8, bzw. T8 4A12 (=BSR4) positiven Vakuolen bestimmt.

B) Stadienkonversion durch Oligomycin. Aus ihren Wirtszellen befreite Tachyzoiten wurden zusammen mit $0,1 \mu \mathrm{g} / \mathrm{ml}$ und $0,5 \mu \mathrm{g} / \mathrm{ml}$ Oligomycin im umgebenden Medium für vier Tage auf HFFs inkubiert und anschließend fixiert. In einem Doppelimmunfluoreszenztest wurde die Anzahl der 4F8 positiven Vakuolen bestimmt. C) Stadienkonversion durch eine externe NO-Quelle. Tachyzoiten wurden zusammen mit $10 \mu \mathrm{M}, 50 \mu \mathrm{M}$ und $100 \mu \mathrm{M}$ SNP für vier Tage auf HFFs inkubiert, anschließend fixiert und in einem Doppelimmunfluoreszenztest die Anzahl an 4F8 positiven Vakuolen bestimmt.
\end{abstract}

\title{
3.5.4.2.2 Stadienkonversion durch Oligomycin
}

Oligomycin ist ein Inhibitor der mitochondrialen Atmungskette. Es führt bei Exposition Toxoplasma gondii Tachyzoiten gegenüber zur Induktion der Bradyzoitbildung (Bohne et al., 1994) und bietet damit eine weitere Möglichkeit, Tachyzoiten zur Stadienkonversion anzuregen.

Tachyzoiten des Wildtyps und der Gendeletionsmutante wurden mitsamt ihrer Wirtszellen aus einer T25 Zellkulturflasche abgeschabt und mit mehrfachen Passagen durch Kanülen von diesen befreit. Durch Zentrifugation wurde das Medium gegen frisches DMEM/ 1\% FCS/ 1\% Pen-Strep ausgetauscht und jeweils Oligomycin in einer Endkonzentration von $0,1 \mu \mathrm{g} / \mathrm{ml}, 0,5 \mu \mathrm{g} / \mathrm{ml}$, bzw. $1 \mu \mathrm{g} / \mathrm{ml}$ zugegeben. Ein konfluenter Zellrasen HFFs, die zuvor auf Glasplättchen in 24-Napf-Zellkulturschalen ausgesät worden waren, wurde mit den Tachyzoiten in Medium unterschiedlicher Oligomycinkonzentration infiziert und in einem Zellkulturinkubator bei $37{ }^{\circ} \mathrm{C}$ mit $\mathrm{CO}_{2}$ - 
Zufuhr vier Tage lang inkubiert. Anschließend wurden die Zellen mit Methanol fixiert und einer Doppelimmunfluoreszenzfärbung unterzogen. Die verwendeten Antikörper waren hierbei der bradyzoitspezifische monoklonale Antikörper 4F8 (1:500 in PBS), nachgewiesen durch Cy3-konjugiertes Esel-anti-Maus IgG und polyklonales Kaninchen-anti-Toxoplasma Antiserum (1:2000 in PBS), angefärbt durch DTAF-konjugiertes Esel-anti-Kaninchen IgG (1:500 in PBS). An einem Fluoreszenzmikroskop wurde durch Auszählen von je drei mal 50 Vakuolen der prozentuale Anteil an 4F8-positiven bestimmt (s. Abb. 17 B).

Bei einer Oligomycinkonzentration von $0,5 \mu \mathrm{g} / \mathrm{ml}$ waren die Vakuolen deutlich kleiner als bei $0,1 \mu \mathrm{g} / \mathrm{ml}$ und bei $1 \mu \mathrm{g} / \mathrm{ml}$ waren keine Vakuolen mehr sichtbar, was die Wirksamkeit von Oligomycin als mitochondrialer Inhibitor bestätigt.

\subsection{Stadienkonversion durch eine externe NO-Quelle}

Eine weitere Möglichkeit, Stadienkonversion zu induzieren, ist eine Erhöhung der Konzentration von NO im externen Medium. NO wird normalerweise von aktivierten Makrophagen ausgeschüttet und reagiert mit Eisen-Schwefel-Zentren in Proteinen, wodurch letztendlich Proteine der mitochondrialen Atmungskette inhibiert werden. Es konnte gezeigt werden, dass Natriumnitroprussiat (SNP) als externe NO-Quelle im Medium einen ähnlichen Effekt auf Tachyzoiten hat, wie Interferon- $\gamma$ aktivierte Makrophagen, nämlich eine Induktion der Stadienkonversion zu bewirken (Bohne et al., 1994).

Tachyzoiten wurden wie oben beschrieben von ihren Wirtszellen befreit und dazu verwendet, einen konfluenten Zellrasen HFFs auf Glasplättchen zu infizieren. In das DMEM/ 1\% FCS/ 1\% Pen-Strep Medium der Zellen wurde zusätzlich SNP in den Konzentrationen $10 \mu \mathrm{M}, 50 \mu \mathrm{M}$ und $100 \mu \mathrm{M}$ zugesetzt und vier Tage in einem Zellkulturinkubator bei $37{ }^{\circ} \mathrm{C}$ unter $\mathrm{CO}_{2}$-Begasung inkubiert. Das Medium wurde jeden Tag erneuert und am vierten Tag die Zellen mit Methanol fixiert. In einer Doppelimmunfluoreszenzfärbung wurden die Parasiten mit dem monoklonalen Antikörper 4F8 (1:500 in PBS) und polyklonalem Kaninchen-anti-Toxoplasma Antiserum (1:2000 in PBS), jeweils detektiert durch Cy3-konjugiertes Esel-anti-Maus IgG (1:1000 in PBS) und DTAF-konjugiertes Esel-anti-Kaninchen IgG (1:500 in PBS), 
angefärbt. Unter einem Fluoreszenzmikroskop wurden wie zuvor drei mal 50 Vakuolen ausgezählt und der Anteil an 4F8-positiven bestimmt (s. Abb. 17 C).

Auch hier zeigte sich, wie bereits zuvor bei der extrazellulären Inkubation und bei Zugabe von Oligomycin zum Medium, dass zwar Tachyzoiten des Wildtyps zur Stadienkonversion angeregt werden konnten, bei der tgpma1 Mutante aber fast keine Expression bradyzoitspezifischer Proteine induziert wurde.

\subsubsection{Semiquantitative RT-PCR an in vitro differenzierten Bradyzoiten}

Eine Untersuchung der Stadienkonversion durch Immunfluoreszenztests war limitiert durch die geringe Anzahl an verfügbaren Antikörpern gegen stadienspezifisch exprimierte Proteine. Eine umfassendere Untersuchung der Regulation von Genen für die keine Antikörper existierten, war also nicht weiter auf Proteinebene möglich, jedoch auf RNA-Ebene durch semiquantitative RT-PCR durchzuführen.

Da alle untersuchten Methoden zur Induktion der Stadienkonversion ein ähnliches Ergebnis lieferten, aber der pH-Shift sich als die effektivste und zuverlässigste Methode erwiesen hatte, wurde zur Gewinnung von in vitro differenzierten Bradyzoiten für die RT-PCR Analyse ein pH-Shift durchgeführt.

Jeweils vier T25 Zellkulturfläschchen die mit einem konfluenten Zellrasen HFFs beschichtet waren, wurden mit Tachyzoiten von Prugniaud/HX und tgpma1 Gendeletionsmutante infiziert. Stadienkonversion der Parasiten wurde durch einen $\mathrm{pH}$-Shift $(\mathrm{pH} \mathrm{8,2)}$ von sechs Tagen induziert. Als Kontrolle wurden Tachyzoiten des Prugniaud/HX- Ausgangsstammes und der Mutante mitgeführt, die zwei Tage lang auf HFFs in DMEM/ $1 \% \mathrm{FCS} / 1 \%$ Pen-Strep bei $37{ }^{\circ} \mathrm{C}$ in einem Zellkulturinkubator mit $\mathrm{CO}_{2}$-Zufuhr gehalten wurden.

Die Parasiten wurden samt Wirtszellen von den Fläschchen abgeschabt, mehrmals durch Kanülen gepresst und durch Filtration (Porengröße $3 \mu \mathrm{m}$ ) von den Zellresten befreit. Gesamt-RNA wurde aus den Parasiten isoliert, mit DNase behandelt und in cDNA umgeschrieben.

In einer semiquantitativen RT-PCR Analyse wurde zunächst die Konzentration der Proben mit Hilfe des konstitutiv exprimierten ß-tubulin Gens angeglichen. Da die Tubulin-Primer Tub2/+ und Tub/2- so gewählt worden waren, dass sie ein Intron im ß-tubulin Lokus umspannten, konnten die Proben auf diese Weise nochmals auf das Vorhandensein von restlicher genomischer DNA überprüft werden. 
Um die Bandenintensitäten besser vergleichen zu können und zu gewährleisten, dass sich die PCR-Reaktion noch nicht im Sättigungsbereich befand, wurden von den Proben jeweils drei Verdünnungsstufen von 1, 1/3 und 1/10 in der PCR eingesetzt und nebeneinander auf dem Gel aufgetragen.

Nach dem Abgleich der Proben in Bezug auf die ß-tubulin Expression, wurde durch semiquantitative RT-PCR die Expression einer Reihe von Genen untersucht von denen bekannt war, dass sie im Bradyzoitenstadium hochreguliert werden (Singh et al., 2002; http://paradb.cis.upenn.edu/toxo1/index.html) (s. Tabelle 8 und 9).

Das Ergebnis der RT-PCR Analyse ist in Abb. 18 zusammengefasst. Die in der Literatur beschriebene Hochregulierung im Bradyzoitenstadium konnte allerdings nicht für alle Gene bestätigt werden.

\begin{tabular}{|ccl|}
\hline Toxoplasma Gen & kodiertes Protein & \multicolumn{1}{c|}{ Literaturangabe } \\
B-tubulin & B-Tubulin & Nagel \& Boothroyd, 1988 \\
tgpma1 & P-Typ Plasmamembran ATPase 1 & Holpert et al., 2001 \\
BAG1 & Hitzeschock Protein HSP30 & Bohne et al., 1995 \\
ENO1 & Enolase & Manger et al., 1998 \\
LDH2 & Lactat Dehydrogenase & Yang\& Parmley, 1997 \\
Sag4 & Surface antigen Sag4 & Ödberg-Ferragut et al., 1996 \\
SRS9 & Sag1-related protein SRS9 & Cleary et al., 2002 \\
tgpis1 & Phosphatidylinositol Synthase 1 & Yahiaoui et al., 1999 \\
Mag1 & Matrix associated antigen 1 & Parmley et al., 1994 \\
Sag1 & Surface antigen 1 & Kasper et al., 1983 \\
Sag2D & Surface antigen 2 related Sag2D & Lekutis et al., 2000 \\
\hline
\end{tabular}

Tabelle 8. In der RT-PCR untersuchte stadienspezifisch exprimierte Gene

\begin{tabular}{|c|c|c|}
\hline EST & Homologes Gen (Abkürzung) & aus Spezies \\
\hline ctoxoqual_4101 & - & 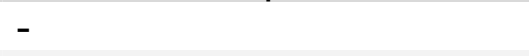 \\
\hline ctoxoqual_4436 & $\begin{array}{l}\text { Desoxyribosephosphat Aldolase } \\
\text { (DRPA) }\end{array}$ & Plasmodium spec. \\
\hline ctoxoqual_3969 & - & - \\
\hline ctoxoqual_-4080 & $\begin{array}{l}\text { Methionin Aminopeptidase Typ II } \\
\text { (MetAP2) }\end{array}$ & Plasmodium spec. \\
\hline ctoxoqual_2388 & $\begin{array}{c}\text { Translations Initiations Faktor elf-5A } \\
\text { (TIF) }\end{array}$ & Plasmodium yoellii yoellii \\
\hline ctoxoqual_1284 & $\begin{array}{l}\text { Oligoendopeptidase F } \\
\text { (Oligopep) }\end{array}$ & $\begin{array}{l}\text { Sinorhizobium melioti, } \\
\text { Agrobacterium tumefaciens }\end{array}$ \\
\hline
\end{tabular}

Tabelle 9. Untersuchte ESTs, Bezeichnung und mögliche Homologe. 


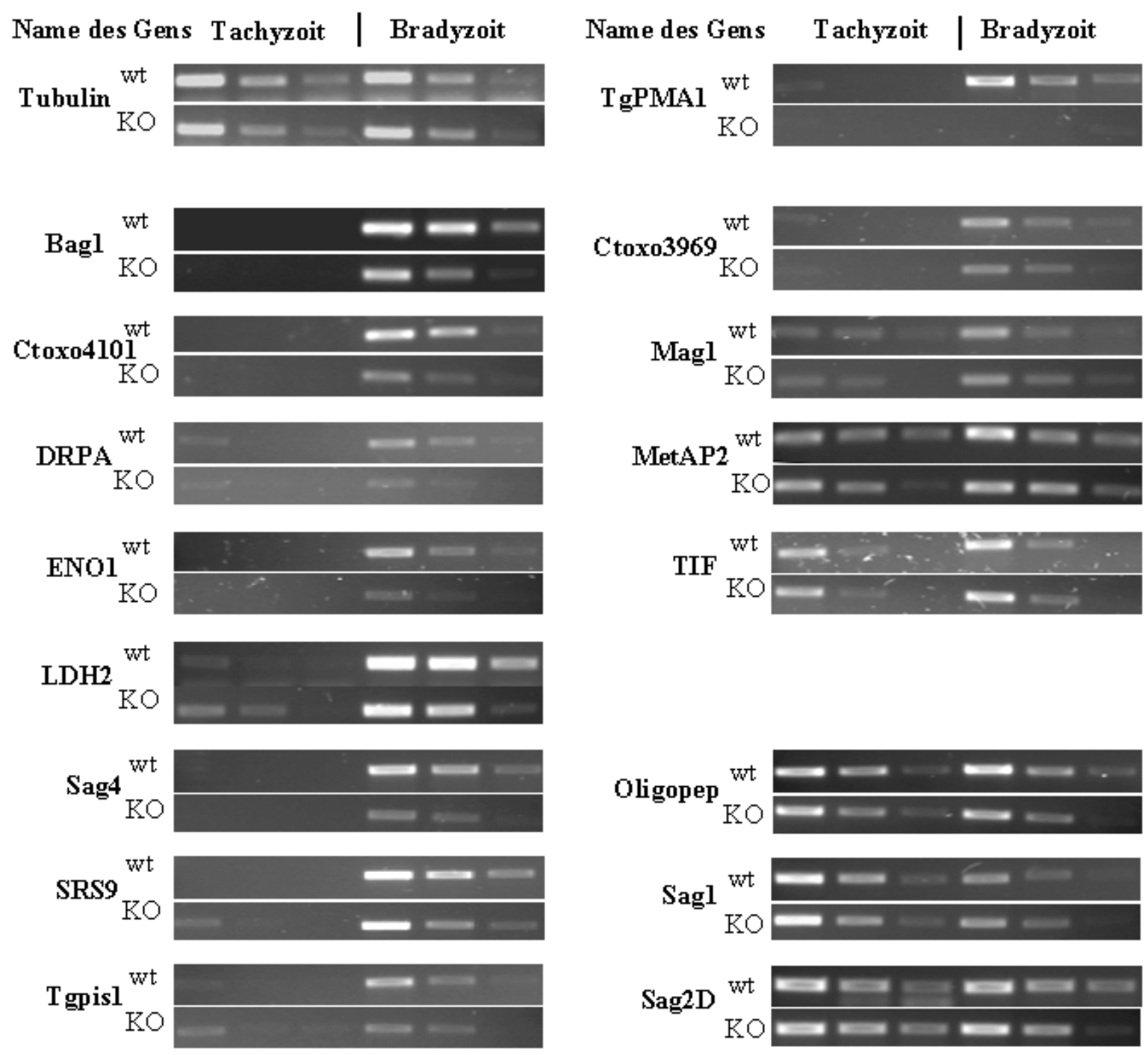

Abb. 18. Semiquantitative RT-PCR an in vitro differenzierten Bradyzoiten. Tachyzoiten des Prugniaud/HX Stammes (wt) und der tgpma1 Gendeletionsmutante (KO) wurden für sechs Tage unter $\mathrm{pH}$-Shift Bedingungen gehalten, bevor RNA aus ihnen isoliert wurde. Nach der cDNA Synthese wurden die Proben in einer semiquantitativen RT-PCR Analyse auf gleiche Bandenintensitäten des konstitutiv exprimierten $\beta$-tubulin Gens eingestellt. Die Expression verschiedener stadienspezifischer Gene in Tachyzoiten und Bradyzoiten wurde untersucht. Um eine Vergleichbarkeit der Proben zu gewährleisten, wurden für jede Probe drei Verdünnungsstufen $(1,1 / 3,1 / 10)$ an cDNA in der PCR eingesetzt. Gene, deren Expression in Wildtyp Bradyzoiten stärker hochreguliert wurde als in der Mutante, sind links im Bild dargestellt. Gene, deren Expression in Wildtyp und KO Bradyzoiten ähnlich stark hochreguliert wurden, sind in der rechten Spalte oben dargestellt. Gene, für die eine bradyzoitspezifische Expression nicht bestätigt werden konnte, sind in der rechten Spalte unten dargestellt. Untersuchte Gene sind: tgpma1; bag1; Ctox04101 (=Ctoxoqual_4101); DRPA (=Ctoxoqual_4436); ENO1, LDH2, Sag4, SRS9, Tgpis1, Ctoxo3969 (=Ctoxoqual_3969); Mag1; MetAP2 (=Ctoxoqual_4080); TIF (=Ctoxoqual_2388); Oligopep (=Ctoxoqual_1284); Sag1; Sag2D

\subsubsection{Real-Time RT-PCR an in vitro Bradyzoiten}

Da durch semiquantitative RT-PCR nur Vergleiche in der Hoch- oder Runterregulation der Expression einzelner Gene zwischen Wildtyp und Deletionsmutante getroffen werden konnten, aber kein Vergleich über die Expressionsstärke der Gene 
untereinander möglich war, wurde die Expression einzelner Gene mittels Real-Time RT-PCR quantitativ untersucht.

RNA wurde wie beschrieben aus Parasiten gewonnen, die vier Tage unter pH-Shift Bedingungen $(\mathrm{pH}$ 8,2) gehalten worden waren. Nach DNase Behandlung zur Vermeidung von kontaminierender genomischer DNA in den Proben wurde die RNA in cDNA umgeschrieben. Diese wurde in einem Lightcycler einer quantitativen RTPCR unterzogen, um die Expression folgender Gene zu untersuchen: bag1, Lactatdehydrogenase $L D H 2$, tgpma2, einem Homologen zu VEE-repeat Proteinen aus $P$. falciparum (= ctoxoqual_4131), einem Homologen zu 14-3-3 Proteinen (Koyama et al., 2001), myosinC, und der V-Typ Protonen ATPase tgvp1 (Drozdowicz et al., 2003). Es wurde jeweils die Expression des zu untersuchenden Gens und $\beta$ tubulin in Tachyzoiten und Bradyzoiten aus Wildtyp und Mutante gemessen, um die eingesetzten cDNA Mengen abgleichen zu können. Bezüglich der Expression von $\beta$ tubulin normiert, wurden die Induktionsfaktoren (If) als Maß für die Expression in Bradyzoiten berechnet und zum Vergleich von Wildtyp und Gendeletionsmutante auf einer logarithmischen Skala dargestellt (s. Abb. 19). Der Quotient der Induktionsfaktoren $\mathrm{If}_{\mathrm{wt}} / \mathrm{If}_{\mathrm{KO}}$ wurde für jedes Gen berechnet. Er besagt, wie viel stärker ein Gen im Wildtyp im Vergleich mit der Mutante durch den pH-Stress induziert wurde. 


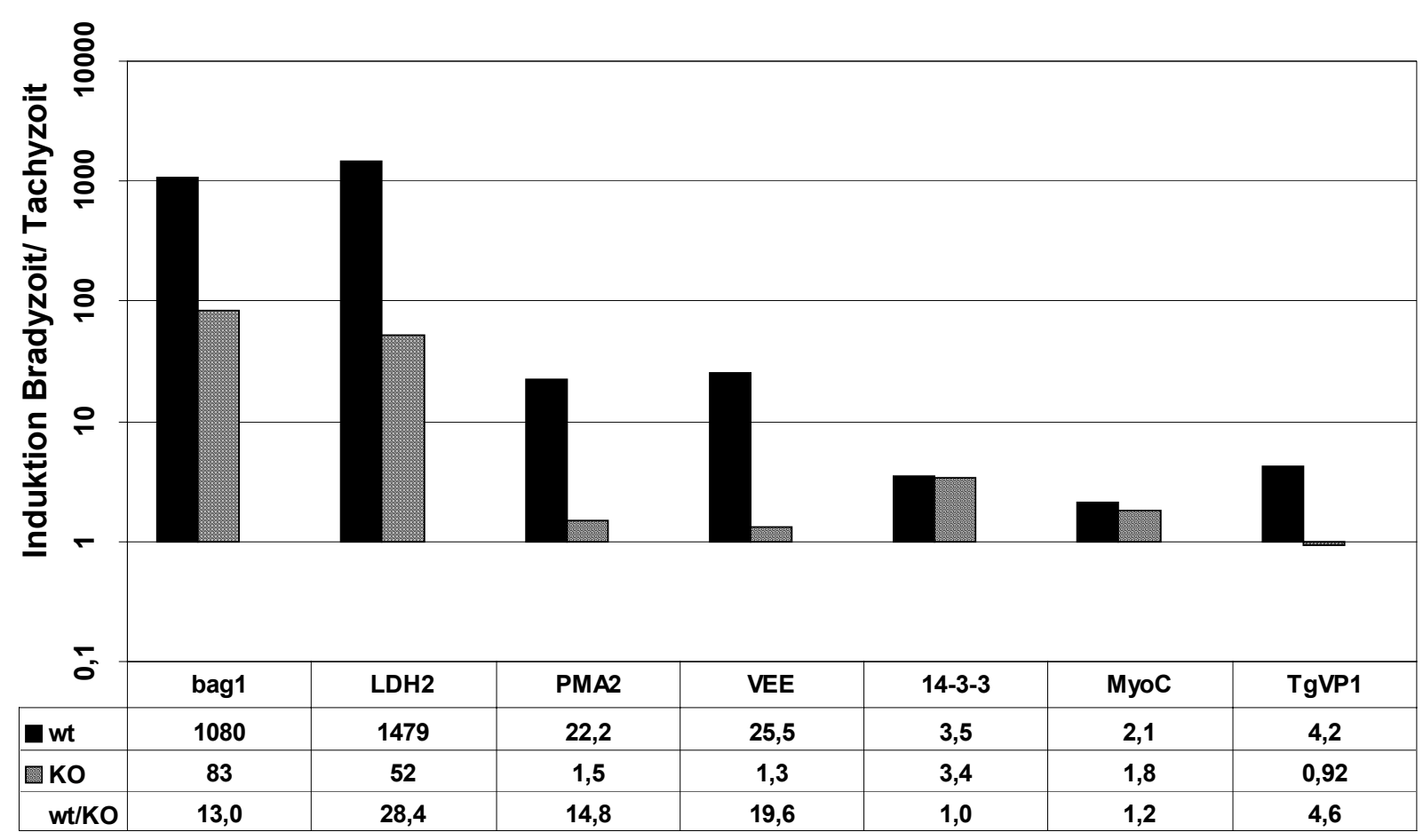

Abb. 19. Real-Time RT-PCR Analyse einiger ausgewählter Gene. In vitro durch pH-Stress differenzierte Bradyzoiten aus Wildtyp (wt, schwarze Balken) und tgpma1 Deletionsmutante (KO, schraffiert) wurden im Lightcycler auf die Expression von bag1, LDH2, TgPMA2, VEE (=ctoxoqual_4131), 14-3-3 (=ctoxoqual_3690), MyoC (=ctoxoqual_3175) und TgVP1 untersucht. Die Werte wurden über die $\beta$-Tubulin Expression abgeglichen, mit Proben aus nicht-differenzierten Tachyzoiten verglichen und die Differenz der abgeglichenen Expression Bradyzoit/ Tachyzoit als Maß für die Induktion der Stadienkonversion angegeben. Die absoluten Induktionswerte der Expression von wt und KO sind in der Tabelle unterhalb der Grafik zu sehen, zusammen mit dem Quotienten aus den Werten der Induktion wt/ Induktion KO.

\subsection{Charakterisierung der tgpma1 Gendeletionsmutante in vivo}

Während in vitro nur die ersten Schritte der Differenzierung vom Tachyzoiten zum Bradyzoiten untersucht werden können, ist das Mausmodell immer noch unerlässlich, um ausdifferenzierte Bradyzoiten zu studieren. Folgende Fragen sollten für die tgpma1 Gendeletionsmutante geklärt werden:

a) können in der Maus noch Zysten gebildet werden?

b) sind diese noch infektiös?

c) können sie eine Magenpassage überstehen?

\subsubsection{Infektion von Mäusen mit Tachyzoiten}

Tachyzoiten des Prugniaud/HX Stammes und der tgpma1 Deletionsmutante wurden aus T25 Zellkulturflaschen zusammen mit den HFFs abgeschabt und durch mehrfache Passagen durch Kanülen aus diesen befreit. 
Je drei NMRI Mäuse wurden mit 500, 5000 und 50000 Tachyzoiten i. p. infiziert. Nach 4 Wochen wurden die Gehirne der Mäuse präpariert, durch Schütteln mit Glaskugeln homogenisiert und in jeweils $3 \mathrm{ml}$ RPMl aufgenommen. Das umgebende Zellgewebe wurde durch mehrfache Passagen durch Kanülen zerstört und vorhandene Zysten freigesetzt. Lichtmikroskopisch wurde die Anzahl der Zysten pro Gehirn in drei Aliquots zu je $10 \mu \mathrm{l}$ ausgezählt, der Mittelwert gebildet und auf die Gesamtmenge hochgerechnet.

$\mathrm{Zu}$ einem späteren Zeitpunkt wurden weitere vier NMRI Mäuse mit je 5000 Tachyzoiten aus Wildtyp und Mutante infiziert und wie oben beschrieben nach vier Wochen Zysten aus den Gehirnen isoliert und ausgezählt. Die Anzahl der gefundenen Zysten pro Maus aus beiden Präparationen ist in Abb. 20 A dargestellt. An dieser Stelle sollte erwähnt werden, dass aus einer Maus, die zuvor mit 500 Tachyzoiten der tgpma1 Mutante infiziert worden war, rechnerisch 32000 Zysten isoliert wurden. Da diese hohe Anzahl im Kontext der anderen errechneten Werte aus dem Rahmen fiel, wurde dies als Einzelfall gewertet und nicht in der Grafik aufgenommen. Je eine Maus, die mit 5000 Tachyzoiten der Deletionsmutante, bzw. 50000 Tachyzoiten des Wildtyps infiziert worden war verstarb, bevor Zysten präpariert wurden.

Durch Infektion mit Tachyzoiten der Gendeletionsmutante ließen sich in allen Fällen Zysten aus dem Gehirn chronisch infizierter Mäuse isolieren. Dies beweist, dass diese Tachyzoiten in vivo noch eine vollständige Differenzierung zum Bradyzoitenstadium mit Zystenbildung durchlaufen können.

\subsection{2 i.p. Infektion von Mäusen mit Zysten}

Die aus der Infektion mit Tachyzoiten gewonnenen Zysten wurden dazu verwendet, wiederum Mäuse i. p. mit jeweils 10- 20 Zysten zu infizieren. Vier Wochen nach Infektion wurden die Gehirne der Mäuse präpariert, Zysten von dem umgebenden Gewebe durch Homogenisieren mit Glaskugeln und mehrfacher Passage durch Kanülen befreit und in $3 \mathrm{ml}$ RPMI Medium pro Gehirn aufgenommen. Unter einem Lichtmikroskop wurden Aliquots zu je $10 \mu \mathrm{l}$ ausgezählt und rechnerisch die Anzahl an Zysten pro Gehirn bestimmt. 
10- 20 der präparierten Zysten wurden mitsamt des Gehirn-Homogenats in $200 \mu \mathrm{l}$ RPMI wiederum i. p. in NMRI und CBA/Ca Mäuse injiziert und aus diesen Mäusen nach vier Wochen erneut Zysten isoliert.

Auf diese Weise konnten Daten über die Zystenzahl von 8 mit Prugniaud/ $/ \mathrm{HX}^{-}$ infizierten NMRI, bzw. 9 CBA/Ca Mäusen und 9 mit tgpma1 Gendeletionsparasiten infizierten NMRI, bzw. $10 \mathrm{CBA} / \mathrm{Ca}$ Mäusen gewonnen werden. Aus jeder Gruppe wurde der Median berechnet und die Werte grafisch dargestellt (s. Abb. 20 B).

Auch hier konnte kein Unterschied in der Zystenzahl zwischen dem Wildtyp und der Mutante festgestellt werden. Die Tatsache, dass Zysten der Deletionsmutante in vivo noch voll infektiös sind, weist darauf hin, dass die Parasiten noch einen kompletten Differenzierungszyklus durchlaufen können: Die injizierten Bradyzoiten müssen sich zur Infektion von Zellen in Tachyzoiten umwandeln, welche sich wiederum in Bradyzoiten zurückdifferenzieren müssen, die schließlich im Gehirn in Form von Zysten nachgewiesen wurden.

\subsubsection{Orale Infektion mit Zysten}

Bradyzoiten gelten im Gegensatz zu Tachyzoiten als magensäureresistent. Sie können allerdings nicht nur längere Zeit den Enzymen des Magensafts widerstehen (Jacobs et al., 1960), sondern auch saurem Milieu allgemein (Pettersen, 1979), was bei Tachyzoiten unter den gleichen Bedingungen innerhalb kurzer Zeit zum Verlust der Infektiosität führt.

Für P-Typ Plasmamembran Protonen ATPasen aus Pflanzen konnte gezeigt werden, dass ihre transgene Expression in Hefemutanten und in Arabidopsis thaliana das Wachstum auf sauren pH-Werten ermöglicht (Luo et al., 1999, Young et al., 1998). Auch Wurzelzellen aus Zea mays können sich durch eine verstärkte Expression von P-Typ Plasmamembran Protonen ATPasen an saure pH-Werte anpassen (Yan et al., 1998).

Da bisher noch keine Erklärung für den Unterschied in der pH-Resistenz zwischen Tachyzoiten und Bradyzoiten von $T$. gondii gefunden werden konnte, sollte getestet werden, ob dies mit der bradyzoitspezifischen Expression von TgPMA1 zusammenhängt und Bradyzoiten der tgpma1 Deletionsmutante noch immer den sauren $\mathrm{pH}$ Wert einer Magenpassage überstehen können. 
Aus dem Gehirn chronisch infizierter NMRI Mäuse wurden Zysten des Prugniaud/HXStammes und der tgpma1 Gendeletionsmutante durch Homogenisieren und anschließende wiederholte Passagen durch Kanülen aus dem Gewebe isoliert, in 3 $\mathrm{ml}$ RPMI aufgenommen und ausgezählt. 10- 20 Zysten wurden in $100 \mu \mathrm{l} \mathrm{RPMI}$ Medium aufgenommen und mittels einer Magensonde, die zuvor in Pflanzenöl getaucht worden war, oral jeweils 5 NMRI Mäusen appliziert.

Vier Wochen nach Infektion wurden die Gehirne der Mäuse isoliert. Das Hirngewebe wurde homogenisiert, in $2 \mathrm{ml}$ RPMl aufgenommen und Zysten durch mehrere Passagen durch Kanülen von sie umschließendem Gewebe befreit. Unter einem Lichtmikroskop wurden pro Gehirn zwei Aliquots von jeweils $10 \mu \mathrm{l}$ ausgezählt, die Gesamtzahl an Zysten pro Gehirn rechnerisch bestimmt und der Median jeder Gruppe gebildet. Die gefundenen Werte sind in Abb. $20 \mathrm{C}$ dargestellt. Die Werte einer mit der Mutante infizierten Maus wurde nicht in der Grafik aufgenommen, da bei dieser mit errechneten 90000 Zysten deutlich mehr als bei den restlichen Mäusen gefunden wurden. Diese Maus war ein paar Tage vor Präparation bereits durch ihre kleine Gestalt und motorische Störungen aufgefallen.

Auch nach oraler Infektion konnte kein Unterschied zwischen Wildtyp und Mutante in der Anzahl der Zysten festgestellt werden. Dies deutet darauf hin, dass TgPMA1 zumindest nicht alleine für die beobachtete Säureresistenz von Bradyzoiten verantwortlich ist

Die aus den Gehirnen isolierten Zysten des Wildtyps und der Mutante wurden über einen Percollgradienten aufgereinigt und Bradyzoiten durch Pepsinverdau freigesetzt. Aus den so gewonnenen Parasiten wurde genomische DNA gewonnen und diese in einer PCR-Reaktion analog der in Kapitel 3.4.3.2. zum Nachweis der Gendeletionsmutante als Template eingesetzt. Die Größe der PCR-Produkte entsprach den in Abb. $14 \mathrm{~B}$, was die Identität der Mutante verifizierte. 
A)

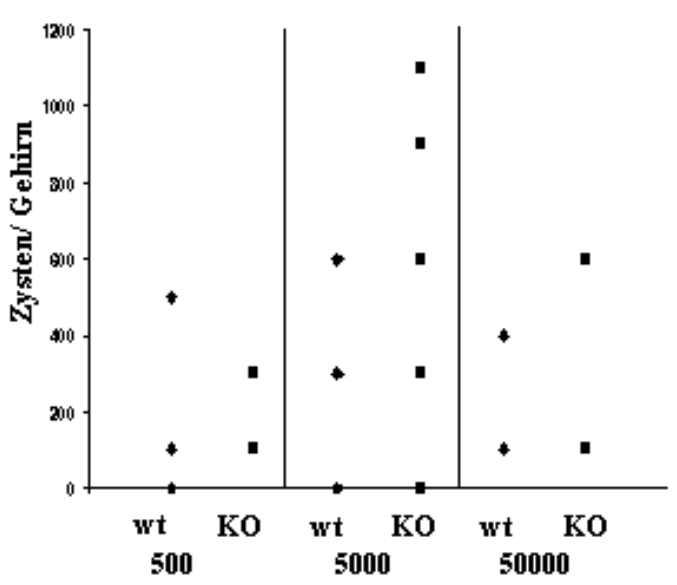

C)

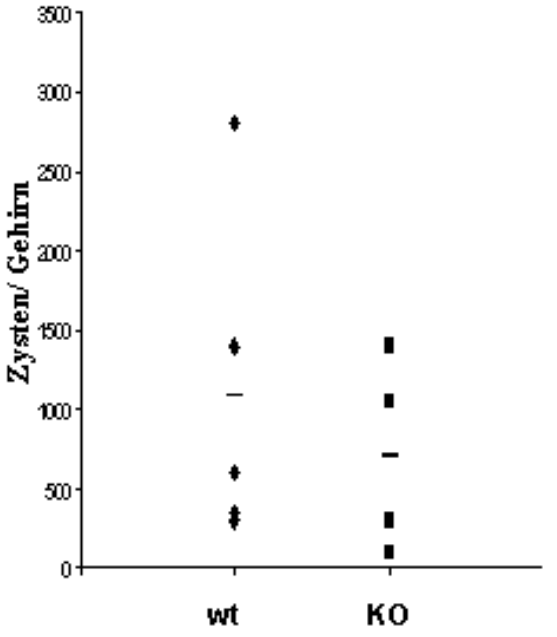

B)

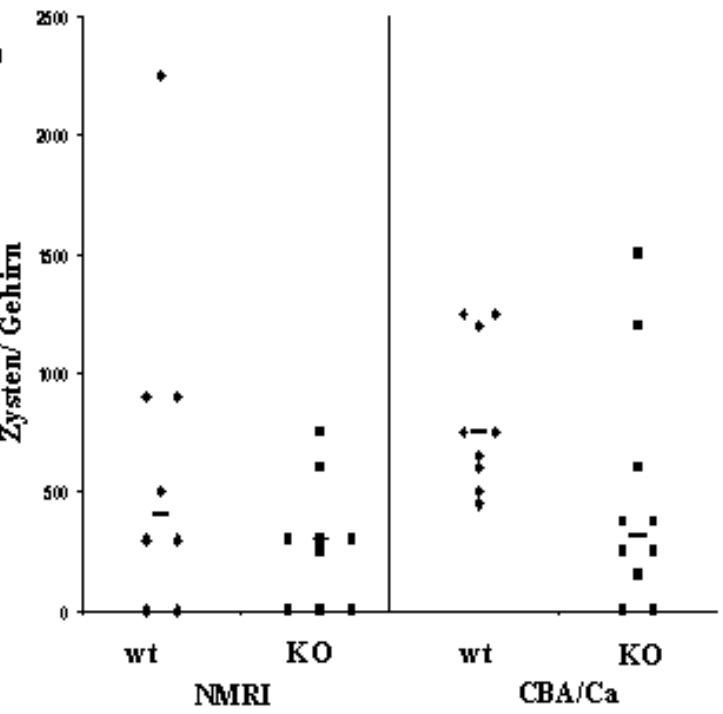

Abb. 20. Anzahl an Zysten im Gehirn von Mäusen, die chronisch mit den parentalen Prugniaud/HX(wt) und Parasiten der tgpma1 Gendeletionsmutante (KO) infiziert waren. 28 Tage nach Infektion wurden die Gehirne in $3 \mathrm{ml} \mathrm{PBS/Gehirn} \mathrm{homogenisiert} \mathrm{und} \mathrm{die} \mathrm{Zystenanzahl} \mathrm{aus} \mathrm{je} \mathrm{drei} \mathrm{Aliquots} \mathrm{von}$ $10 \mu \mathrm{l}$ bestimmt. (A) NMRI Mäuse wurden i.p. mit 500, 5000 und 50000 Tachyzoiten infiziert. (B) NMRI und CBA/Ca Mäuse wurden i.p. mit Hirnhomogenat infiziert, in dem sich 10- 20 Zysten befanden.

(C) NMRI Mäuse wurden mit 10-20 Zysten oral durch eine Magensonde infiziert. Der Median jeder Gruppe ist angegeben (-). 


\section{Diskussion}

Aktive lonentransportprozesse finden in jeder lebenden Zelle statt und haben die Aufgabe, bestimmte lonenkonzentrationen innerhalb des Zytosols oder der Organellen unabhängig von äußeren Bedingungen aufrecht zu erhalten. Durch ATP getriebene lonenpumpen lassen sich dabei in drei Klassen unterteilen: F-, V- und PTyp ATPasen.

F- und V- Typ lonenpumpen sind sich strukturell ähnlich und unterscheiden sich hierbei stark von P-Typ ATPasen. Alle bekannten F- und V-Typ Pumpen transportieren ausschließlich Protonen. Sie bestehen aus großen Komplexen, die aus über neun Untereinheiten zusammengesetzt sind. V-Typ ATPasen halten den $\mathrm{pH}$-Wert saurer Kompartimente wie der Vakuolen in Pflanzen, oder Lysosomen und anderer Vesikel in tierischen Zellen aufrecht, indem sie Protonen entgegen dem Konzentrationsgradienten in die Organellen transportieren. F-Typ ATPasen finden sich in bakteriellen Plasmamembranen, Chloroplasten und Mitochondrien. Im Gegensatz zu Pumpen vom V-Typ arbeiten sie normalerweise, indem sie Protonen mit dem Konzentrationsgefälle transportieren und dabei ATP produzieren.

P-Typ ATPasen bestehen aus einer katalytischen Untereinheit von ca. $100 \mathrm{kDa}$, die ATP Hydrolyse und lonentransport durchführen kann. Bei einigen spezialisierten tierischen P-Typ ATPasen wird noch eine zweite Glykoprotein Untereinheit von ca. $35 \mathrm{kDa}$ zur korrekten Faltung und Katalyse benötigt (McDonough et al., 1990). Ein Charakteristikum von P-Typ ATPasen ist die Bildung eines phosphorylierten Intermediats an einem hochkonservierten Aspartat durch Übertragung eines Phosphatrests des ATP während des Reaktionszyklus, was auch zu dem Namen ,PTyp' geführt hat. Dieses Aspartat befindet sich innerhalb des streng konservierten Motivs DKTGT, welches in allen P-Typ ATPasen zu finden ist. Eine weitere Gemeinsamkeit aller P-Typ ATPasen ist, dass sie durch geringe Konzentrationen an Orthovanadat gehemmt werden können (Pedersen \& Carafoli, 1987).

Diese Klasse von Transportproteinen lässt sich aufgrund von Sequenzvergleichen in fünf Subtypen (I-V) unterteilen, die mit der lonenspezifität der einzelnen Mitglieder korrelieren (Axelsen \& Palmgren, 1998; s. Tabelle 10). 


\begin{tabular}{|cc|l|}
\hline Subtyp & & lonenspezifität \\
\hline Typ I & A & $\mathrm{K}^{+}$ \\
& B & Schwermetalle \\
\hline Typ II & A & $\mathrm{Ca}^{2+}$ \\
& B & $\mathrm{Ca}^{2+}$ \\
& C & $\mathrm{H}^{+} / \mathrm{K}^{+} ; \mathrm{Na}^{+} / \mathrm{K}^{+}$ \\
& D & unbekannt \\
\hline Typ III & A & $\mathrm{H}^{+}$ \\
& B & $\mathrm{Mg}^{2+}$ \\
\hline Typ IV & & Phospholipide \\
\hline Typ V & & unbekannt \\
\hline
\end{tabular}

Tabelle 10. Korrelation der Ionenspezifität mit der Zugehörigkeit zu phylogenetisch verwandten Subtypen innerhalb der P-Typ ATPasen.

Strukturell sind sich alle P-Typ ATPasen ähnlich. Sie bestehen gewöhnlich aus acht bis 10 Transmembrandomänen, wobei sich der N- und C-Terminus auf der Seite des Zytosols befinden. Innerhalb von zwei zytoplasmatischen Domänen, dem kleinen und großen zytoplasmatischen Loop, befinden sich alle hochkonservierten Bereiche, die für diese Klasse von Transportproteinen charakteristisch sind. P-Typ ATPasen stellen eine sehr große Klasse von Transportproteinen dar, die untereinander eine recht unterschiedliche Aminosäuresequenz aufweisen, wobei lediglich 18 Aminosäuren zwischen allen heute bekannten Vertretern identisch sind (Lutsenko \& Kaplan, 1995; Morsomme et al., 2000). Allerdings lassen sich zwischen Angehörigen der gleichen Subtypen recht große Übereinstimmungen in der Sequenz feststellen. Durch Vergleich der Röntgenkristallstruktur der $\mathrm{Ca}^{2+}$-ATPase aus dem sarkoplasmatischen Reticulum (Zhang et al., 1998) und der Neurospora crassa H H$^{+}$-ATPase (Auer et al., 1998) konnte gezeigt werden, dass trotz erheblicher Unterschiede in der Aminosäuresequenz eine fast identische Transmembrantopologie zwischen diesen beiden Proteinen besteht. Signifikante strukturelle Unterschiede wurden allerdings in den zytoplasmatischen Domänen gefunden, was auf eine Rolle in der lonenspezifität schließen lässt (Kühlbrandt et al., 1998). Der genaue Mechanismus der lonenspezifität ist zwar noch immer unbekannt, es wird aber angenommen, dass die lonenbindung an einer gut konservierten Bindungsstelle innerhalb einer Transmembrandomäne stattfindet (Clarke et al., 1989). 


\section{1 lonenspezifität von TgPMA1}

Die lonenspezifität von P-Typ ATPasen ist nicht unmittelbar aus der Sequenz ersichtlich. Allerdings weisen P-Typ ATPasen gleicher lonenspezifität untereinander wesentlich größere Ähnlichkeiten auf, als mit Angehörigen der anderen Subtypen.

Ein Datenbankvergleich mit der kompletten Aminosäuresequenz von TgPMA1 liefert als Proteine mit der größten Ähnlichkeit mit P-Werten von $\mathrm{e}^{-119}$ und $\mathrm{e}^{-112}$ die P-Typ Protonen ATPasen aus der Rotalge Cyanidium caldarium und dem Archaebakterium Methanococcus jannaschii mit jeweils $27,7 \%$ und $27,4 \%$ Identität auf Aminosäureebene. Da N- und C-Terminus von P-Typ ATPasen in ihrer Sequenz besonders stark divergieren, lässt sich die Ähnlichkeit durch Beschränkung des Vergleichs auf die Sequenzen zwischen den Transmembransegmenten TM2 und TM9 auf 36,2\%, bzw. 38,3\% erhöhen, wie es bereits für Aspergillus nidulans pmaA vorgeschlagen wurde (Reoyo et al., 1998). Ein Vergleich von TgPMA1 mit sämtlichen P-Typ ATPasen anderer lonenspezifität als für $\mathrm{H}^{+}$des Saccharomyces cerevisiae Genoms, erbrachte signifikant geringere Aminosäureidentitäten von $18 \%$ bis $22 \%$. Von 118 Aminosäuren aus P-Typ ATPasen von Pilzen und Pflanzen, die in keiner PTyp ATPase anderer lonenspezifität vorkommen und daher mit $\mathrm{H}^{+}$-Spezifität in Verbindung gebracht wurden (Wach et al., 1992), kommen über $50 \%$ an den entsprechenden Stellen auch in TgPMA1 vor.

Zusammengenommen deuten diese Daten sehr stark auf eine Rolle von TgPMA1 als Protonenpumpe hin, auch wenn andere lonenspezifitäten nicht völlig ausgeschlossen werden können.

\subsection{Analyse der genetischen Organisation von tgpma1}

Für eine erfolgreiche Expression von TgPMA1 kommen zwei mögliche Startcodons in Betracht. Während bei einer Translation ab ATG $_{1880}$ (die Nummerierung der Nukleotide bezieht sich auf die Sequenz im Anhang, Abb. 23) ein Protein mit einem errechneten Molekulargewicht von $127 \mathrm{kDa}$ kodiert wird, würde ab $\mathrm{ATG}_{2216}$ ein Protein von $116 \mathrm{kDa}$ entstehen. Die durchschnittliche Größe von P-Typ Protonen ATPasen anderer Spezies liegt bei $100 \mathrm{kDa}$, also in jedem Fall darunter. Da N- und C-Terminus der P-Typ ATPasen nur sehr schwach konserviert sind, ist es alleine mit 
Homologievergleichen schwierig zu entscheiden, welches Startcodon das wahrscheinlich verwendete ist.

Bei Eukaryonten findet meistens die Translationsinitiation am ersten AUG-Triplett nach dem 5'-Ende statt. Nach dem ,Scanning-Modell' bindet dabei die $40 \mathrm{~S}$ Untereinheit der Ribosomen an die 5'-Cap Struktur der mRNA und ,scannt' in 3'Richtung nach dem ersten AUG-Codon, welches innerhalb eines bestimmten Nukleotidkontexts steht. Dies führt dann zum Translationsstart, welcher positiv durch die Consensus-Sequenz um das Startcodon beeinflusst wird (Kozak, 1987; Lutcke, 1987). Für Toxoplasma gondii konnte eine Consensus-Sequenz ermittelt werden, die leicht von der für höhere Eukaryonten geltenden Kozak-Sequenz abweicht (Seeber, 1997).

Die zwei möglichen Startcodons von tgpma1 liegen 336 nt voneinander entfernt. Betrachtet man die Consensus-Sequenz und vergleicht diese mit dem Kontext der beiden potentiellen Startcodons (s. Tabelle 11), so zeigt sich ein entscheidender Unterschied in der Position -3 bezogen auf das ATG. Da gerade ein Purin an dieser Position eine wichtige Rolle bei der Translationsinitiation am ersten Startcodon spielt, und dieses nur bei dem weiter 5'-gelegenen ATG $_{1880}$ zu finden ist, spricht dies für ATG $_{1880}$ als tatsächlichen Startpunkt der Translation (Kozak, 1989; Pain, 1996).

\begin{tabular}{|lc|}
\hline Startcodon & Kontext \\
\hline Toxoplasma Consensus-Sequenz & gNCAAaATGg \\
ATG $_{1880}$ & TGAAGTATGG \\
ATG $_{2216}$ & CGAGTGATGG \\
\hline
\end{tabular}

Tabelle 11. Vergleich der unmittelbaren Nukleotidumgebung der potentiellen Translations-Startcodons mit der für Toxoplasma ermittelten Consensus-Sequenz.

Die zweite Aminosäure eines Proteins scheint bei der Proteinexpression in Toxoplasma eine entscheidende Rolle zu spielen. In $32 \%$ von 86 untersuchten Proteinen aus T. gondii kommt ein Alanin an zweiter Position vor, mit großem Abstand gefolgt von Arginin mit einem Vorkommen in 9\% der Proteine (Matrajt et al., 2002b). Auch dieser Befund spricht für $\mathrm{ATG}_{1880}$ als das tatsächlich verwendetes Startcodon, da in diesem Fall ein Alanin an zweiter Position im Protein steht. Da es sich bei $\mathrm{ATG}_{1880}$ um das erste Startcodon auf der mRNA handelt und unter Berücksichtigung oben erwähnter Hinweise, soll es im Folgenden als das tatsächlich verwendete Startcodon angesehen werden. 
Bei der Betrachtung der genomischen Organisation von tgpma1 fallen die beiden Introns auf, bei denen sich eines unmittelbar 5' und das andere etwas 3' des Startcodons befindet. Zwei oder mehr Introns sind in T. gondii nichts ungewöhnliches und unterbrechen die Leserahmen etlicher Toxoplasma Gene. Aber ein Intron im 5'untranslatierten Bereich ist ungewöhnlich und wurde in $T$. gondii bisher nur für MAG1 beschrieben, das für ein $65 \mathrm{kDa}$ Antigen kodiert, welches in der Matrix und Wand von Zysten vorkommt (Parmley et al., 1994). Hier konnte zwar keine Funktion des Introns nachgewiesen werden, es wurde ihm aber eine regulatorische Rolle zugeschrieben, da es wahrscheinlich das erste AUG Codon der mRNA von weiter 5' gelegenen Erkennungssequenzen der Translationsinitiation trennt.

Eine mögliche Polyadenylierungssequenz befindet sich zwischen den Nukleotiden 6427-6436, wie im Anhang, Abb. 23 angegeben (Webgene HCpola; http://www.itba.mi.cnr.it/webgene/).

Promotoren in $T$. gondii sind nicht besonders gut untersucht. Zwar sind einige stadienspezifische 5'-UTRs beschrieben, die teilweise durch Deletionsstudien auf wichtige Elemente reduziert werden konnten, doch sind kaum konservierte Elemente bekannt (Bohne et al., 1997; Nakaar et al., 1998). Konventionelle cis-wirkende eukaryontische Promotorelemente wie TATA-Box oder SP1 Motiv konnten bisher in keiner 5'-UTR von T. gondii gefunden werden. Analysen von 5'-UTR Sequenzen einiger Gene führten allerdings zur Identifizierung der hochkonservierten Heptanukleotidsequenz T/AGAGACG in den Promotor-Bereichen von GRA1, GRA2, GRA5, GRA6, TUB1, SAG1 und MIC2 (Ajioka et al., 2001). Dieses Motiv kommt auch in dem 27 bp Element vor, das in sechs Wiederholungen in tandem im 5'-UTR von SAG1 den Startpunkt der Transkriptionsinitiation festlegt (Soldati \& Boorthroyd, 1995). Die Anzahl und Position dieser Heptanukleotidmotive ist in den untersuchten Genen sehr variabel, ebenso ihre Orientierung, die direkt oder invertiert sein kann. Promotor-Expressionsstudien mit CAT als Reporterprotein ergaben, dass eine Deletion des Heptanukleotidmotivs, das dem Startcodon am nächsten ist, den größten Effekt auf die CAT Aktivität zeigt (Soldati \& Boothroyd, 1995; Mercier et al., 1996). Dies deutet auf eine Funktion ähnlich der SP1 Elemente bei der Festlegung des Startpunktes der Transkriptionsinitiation in der Abwesenheit von TATA Boxen hin. Interessanterweise lassen sich auch in der 5'UTR von tgpma1 einige dieser Heptanukleotidmotive wiederfinden (s. Anhang, Abb. 23). 
Obwohl mehrere Versuche, den tatsächlichen Anfang der mRNA von tgpma1 per 5'RACE zu bestimmen fehlschlugen, konnte dieser durch versetzte 5'-Primer in einer RT-PCR auf ca. 120 Nukleotide eingegrenzt werden. Die Sequenz GCAGTCC, die an Position 1061-1067 innerhalb dieser Sequenz liegt, passt dabei genau zu der Konsensussequenz PyPyA(+1)N(T/A)PyPy, die für den Transkriptionsstartpunkt "Inr" einer großen Gruppe von Genen vorgeschlagen wurde, denen TATA Boxen fehlen. Dabei ist A+1 der Transkriptionsstart. Für die $T$. gondii NTPase NTP3 konnte gezeigt werden, dass eine Mutation der „Inr"-ähnlichen Sequenz die Expression eines Reportergens fast vollständig inhibiert (Nakaar et al., 1998).

\subsection{Aufgaben von P-Typ Protonen ATPasen}

In den meisten höheren Eukaryonten, deren externer pH-Wert neutral ist, werden metabolisch generierte Protonen gegen $\mathrm{Na}^{+}$durch einen $\mathrm{Na}^{+} / \mathrm{H}^{+}$-Antiporter ausgetauscht. Dies wird durch einen $\mathrm{Na}^{+}$-Gradienten ermöglicht, der durch eine $\mathrm{Na}^{+} / \mathrm{K}^{+}$-ATPase aufgebaut wird. Wenn aber der externe $\mathrm{pH}$-Wert niedriger ist als der innere, ist ein $\mathrm{Na}^{+} / \mathrm{K}^{+}$-Austausch energetisch unvorteilhaft. Deshalb verwenden Zellen, die einen alkalischeren inneren $\mathrm{pH}-\mathrm{Wert}\left(\mathrm{pH}_{\mathrm{i}}\right)$ haben als ihre Umgebung, meist ATP-getriebene Protonen Pumpen. Das Ausschleusen von Protonen ist elektrogen und wird gewöhnlich durch einen oder mehrere Anionen- oder Kationenkanäle unterstützt, die dazu dienen, das Membranpotential aufrecht zu erhalten und dabei die Effizienz der Pumpe noch verstärken (Vanderheyden et al., 2000).

In Pilzen, Pflanzen und Protozoen konnten P-Typ Protonen ATPasen etliche Funktionen nachgewiesen werden, wobei in Protozoen noch nicht sehr viel über die Aufgaben dieser Klasse von Transportmolekülen bekannt ist.

\subsubsection{P-Typ Protonen ATPasen in Pilzen}

In Saccharomyces cerevisiae existieren zwei Isoformen einer P-Typ Protonen ATPase, wobei eine (PMA1) essentiell für das Wachstum der Hefen ist (Serrano et al., 1986). Das Protein ist das Hauptoberflächenprotein von S. cerevisiae und macht ca. $9 \%$ bis $20 \%$ des Gesamtproteinanteils der Plasmamembran aus (Perlin et al., 
1989; Chang \& Fink, 1995). Dabei ist die Menge des Proteins direkt proportional zur Wachstumsgeschwindigkeit der Hefen. Neben der Menge an Protein kann auch die Aktivität des Enzyms durch äußere Einflüsse wie pH-Änderungen, Glucosekonzentration oder Hitzeschock um das zwei- bis dreifache reguliert werden (Eraso \& Gancedo, 1987). Das Enzym baut einen Protonengradienten über der Plasmamembran auf, der für eine Nährstoffaufnahme durch Symport von Protonen essentiell ist. Ferner wird dem Protein eine strukturelle Rolle in der Plasmamembran zugesprochen und es wird mit der Aufrechterhaltung des intrazellulären $\mathrm{pH}$ Wertes in Verbindung gebracht. In einer Reihe wichtiger pathogener Pilze, wie Candida albicans, Aspergillus fumigatus und Cryptococcus neoformans wurde die Plasmamembran Protonen ATPase durch ihre essentiellen Aufgaben als neuer Angriffspunkt für Arzneimittel postuliert (Monk et al., 1995; Soteropoulos et al., 2000; Burghoorn et al., 2002). Das Fehlen von P-Typ Protonen ATPasen in den Zellen höherer Tiere und die recht großen Unterschiede in der Sequenz zu Transportern anderer lonenspezifitäten machen sie dafür geeignet. Bereits in der Medizin verwendete P-Typ ATPase-Hemmer wie Digoxin, Omeprazol, Oubain oder Staurosporin zeigen, dass trotz ihrer großen Verbreitung selektiv einzelne Typen von ATPasen gehemmt werden können (Perlin, 1998).

\subsubsection{Pflanzen: viele Isoformen an P-Typ Protonen ATPasen}

In allen bisher untersuchten Pflanzen wurde jeweils eine große Anzahl Isoformen von P-Typ Protonen ATPasen gefunden. Durch das Arabidopsis Genom Projekt (Arabidopsis Genome Initiative, 2000) weiß man mittlerweile, dass es 12 Arabidopsis Gene für P-Typ H ${ }^{+}$ATPasen gibt, von denen eines wahrscheinlich ein Pseudogen ist. Im Genom von Nicotiana plumbaginifolia wurden bisher neun entsprechende Gene gefunden (Boutry et al., 1989; Oufattole et al., 2000), was die Meinung bestätigt, dass es in jeder Pflanze eine große Familie an $\mathrm{H}^{+}$-ATPasen gibt. Plasmamembran $\mathrm{H}^{+}$-ATPasen sind in der Pflanze sehr verbreitet- sie wurden bisher in fast jedem untersuchten Zelltyp gefunden. Allerdings haben manche Zelltypen wesentlich höhere Konzentrationen dieser Proteine, als andere. Im Allgemeinen sind die Zelltypen mit hohem Vorkommen an $\mathrm{H}^{+}$-ATPasen auf besonders aktiven Transport spezialisiert und akkumulieren lösliche Stoffe aus ihrer Umgebung (Palmgren, 2001). So sind $\mathrm{H}^{+}$-ATPasen essentiell für die Beladung von Sucrose und möglicherweise 
anderer photosynthetischer Assimilate ins Phloem (Zhao et al., 2000). Eine Regulierung der Stomataöffnung kann, ebenso wie die Nährstoffaufnahme der Wurzeln und die Beladung des Xylems wahrscheinlich ebenfalls auf die Wirkung von $\mathrm{H}^{+}$-ATPasen zurückgeführt werden (Assmann et al., 1985; Parets-Soler et al., 1990). Neben ihrer Hauptaufgabe, der Aktivierung des sekundären Metabolittransports, kommen Plasmamembran $\mathrm{H}^{+}$-ATPasen aber noch eine Reihe anderer Funktionen zu. Durch einen Protonengradienten kann zum Beispiel eine Salztoleranz der Pflanze induziert werden, wobei ein $\mathrm{Na}^{+} / \mathrm{H}^{+}$-Antiport ermöglicht wird. So erklärt sich auch die Akkumulierung von $\mathrm{H}^{+}$-ATPase mRNA in den Wurzeln und Blättern während Salzstress. Die Aufrechterhaltung des $\mathrm{pH}_{\mathrm{i}}$ konnte in Pflanzen noch nicht auf eine alleinige Wirkung der Plasmamembran $\mathrm{H}^{+}$-ATPasen zurückgeführt werden, aber es scheint gesichert, dass sie zumindest darin involviert sind (Morsomme \& Boutry, 2000). Ebenso konnten $\mathrm{H}^{+}$-ATPasen für das Längenwachstum und die zelluläre Expansion verantwortlich gemacht werden (Palmgren, 2001; Rayle \& Cleland, 1992). Selbst so spezialisierte Aufgaben, wie die Ansäuerung des Verdauungssaftes fleischfressender Pflanzen, oder der Metabolitaustausch von Leguminosen mit symbiontischen Bakteroiden können auf P-Typ $\mathrm{H}^{+}$-ATPasen zurückgeführt werden (An et al., 2001; Fedorova et al., 1999).

Bei der Vielzahl an Aufgaben, die $\mathrm{H}^{+}$-ATPasen in Pflanzen zu erfüllen haben, verwundert die große Anzahl an Isoformen nicht, die differentiell in den verschiedenen Zelltypen exprimiert werden. Eine biochemische Charakterisierung einzelner Enzyme wurde zunächst durch die gleichzeitige Expression mehrerer Isoformen in einer Zelle erschwert. Mittlerweile ist aber eine heterologe Expression von P-Typ $\mathrm{H}^{+}$-ATPasen in Hefemutanten möglich, in denen die beiden endogenen $\mathrm{H}^{+}$-ATPasen entweder deletiert wurden, oder durch einen induzierbaren Promotor ausgeschaltet werden können (Villalba et al., 1992). Es konnte gezeigt werden, dass P-Typ $\mathrm{H}^{+}$-ATPasen aus Pflanzen und anderen Spezies in diesem heterologen Expressionssystem die essentielle Rolle der Hefe PMA1 komplementieren können (Palmgren \& Christensen, 1993). Dabei funktioniert eine erfolgreiche Komplementation nicht mit allen $\mathrm{H}^{+}$ATPasen, was womöglich in erster Linie auf eine autoinhibitorische Domäne am CTerminus von pflanzlichen $\mathrm{H}^{+}$-ATPasen zurückzuführen ist, wodurch das Protein in Hefe zwar synthetisiert, aber nicht zur Plasmamembran transportiert wird (Dambly \& Boutry, 2000; Maudoux et al., 2000). Durch die erfolgreiche Expression mehrerer Isoformen in Hefe wurde der Nachweis ermöglicht, dass diese unterschiedliche 
enzymatische Aktivitäten aufweisen und den Hefemutanten verschiedene pH-Sensitivitäten verleihen (Palmgren et al., 1994; Luo et al., 1999). Mutationen dieser heterolog exprimierten Proteine können die Aktivität der Enzyme noch verstärken und damit Hefen das Wachstum auf niedrigeren pH-Werten erlauben (Morsomme et al., 1996).

\subsubsection{P-Typ Protonen ATPasen in Protozoen}

\subsubsection{Funktion von P-Typ $\mathrm{H}^{+}$-ATPasen in Flagellaten}

In Protozoen konnten auch P-Typ $\mathrm{H}^{+}$-ATPasen nachgewiesen werden, deren Funktion in einigen Fällen auch aufgeklärt werden konnte. In ihrem Entwicklungszyklus wandeln sich Leishmania Parasiten von den Promastigoten zu Amastigoten um. Während Promastigoten flagelliert sind und im pH neutralen Darm des Vektors des Parasiten, der Sandfliege, leben, finden sich die obligat intrazellulären unbeweglichen Amastigoten im sauren Milieu von Phagolysosomen in Makrophagen von Säugetieren. Die erfolgreiche Anpassung und das Überleben des Parasiten in diesen stark unterschiedlichen Umgebungen hängt von seiner Fähigkeit ab, Nährstoffe aus seiner Umgebung aufzunehmen und das intrazelluläre Milieu konstant zu halten. Die beiden Lebensstadien zeigen verschiedene Abhängigkeiten des Metabolismus: während Promastigoten wesentlich mehr L-Prolin aufnehmen als Amastigoten und dies als Hauptenergiequelle nutzen, decken Amastigoten ihren Energiebedarf eher durch Fettsäuren (Krassner \& Flory, 1972; Hart \& Coombs, 1982). Mit Inhibitionsstudien konnte gezeigt werden, dass die aktive Aufnahme von L-Prolin und Glucose in Leishmania donovani Promastigoten und Amastigoten abhängig von einem $\mathrm{pH}$ Gradienten und dem Membranpotential ist, die beide von einer Protonen ATPase aufgebaut werden. Ob diese ATPase vom P- oder V-Typ ist, wurde nicht untersucht (Glaser \& Mukkada, 1992; Glaser et al., 1992). Eine Vanadat-sensitive P-Typ ATPase, die eine Aktivität im Transport von Protonen zeigte, konnte auf der Oberfläche von Leishmania donovani Promastigoten nachgewiesen werden (Zilberstein \& Dwyer, 1988; Liveanu et al., 1991; Anderson et al., 1994). Zwei Gene, die beide für P-Typ $\mathrm{H}^{+}$-ATPasen kodieren, werden in Leishmania donovani differentiell exprimiert. Die beiden Gene, $L D H 1 A$ und $\angle D H 1 B$, liegen in tandem etwa $2 \mathrm{~kb}$ voneinander entfernt und unterscheiden sich nur durch 34 Nukleotide. Während $L D H 1 A$ in beiden 
Lebensstadien gleich stark exprimiert wird, zeigt $L D H 1 B$ eine wesentlich stärkere Expression in Amastigoten (Meade et al., 1987; 1989). Beide Gene sind in den verschiedenen Leishmania Spezies hochkonserviert (Meade et al., 1991). In Leishmania major Promastigoten wurde neben der $\mathrm{H}^{+}$-ATPase auch eine Rolle von $\mathrm{Cl}^{-}$-Kanälen bei der Aufrechterhaltung des $\mathrm{pH}_{\mathrm{i}}$ und Membranpotentials festgestellt (Vieira et al., 1995). Dies steht in guter Übereinstimmung mit dem Befund, dass eine P-Typ $\mathrm{H}^{+}$ATPase in Leishmania mexicana amazonensis Amastigoten für die Aufrechterhaltung des intrazellulären $\mathrm{pH}$ Wertes und Membranpotentials verantwortlich ist, während Promastigoten ihren $\mathrm{pH}_{\mathrm{i}}$ nur sehr schlecht regulieren können (Marchesini \& Docampo, 2002).

Zusammenfassend deutet alles auf unterschiedliche Regulierungsvorgänge des $\mathrm{pH}_{\mathrm{i}}$ und der Nährstoffaufnahme in den beiden Lebensstadien von Leishmania spp. hin, die von verschiedenen P-Typ $\mathrm{H}^{+}$-ATPase Isoformen abhängig sind.

Ähnlich sieht es bei den verwandten Trypanosomen aus. Trypanosoma brucei, der Erreger der Schlafkrankheit, lebt in Vertebraten extrazellulär im Blut. Die Blutformen des Erregers sind dabei einem konstanten äußeren pH-Wert ausgesetzt. Werden die Parasiten von blutsaugenden Tsetsefliegen aufgenommen, wandeln sie sich im Mitteldarm des Insekts in die prozyklische Form um. Hier sind sie einem sauren äußeren pH-Wert ausgesetzt. Die unterschiedlichen äußeren Bedingungen machen sich auch in verschiedenen metabolischen Adaptionen des Parasiten bemerkbar. Die Blutformen des Erregers finden im Blut konstante Konzentrationen von Glucose vor. Die Energiegewinnung erfolgt dabei ausschließlich über Glykolyse. Eine Glucoseaufnahme erfolgt über einen Glucosetransporter in der Plasmamembran durch einen diffusionsabhängigen Vorgang, unabhängig von $\mathrm{Na}^{+}$-, oder $\mathrm{H}^{+}$-Gradienten (Seyfang \& Duszenko, 1991). Durch Glykolyse wird Glucose zu Pyruvat abgebaut, welches über einen Pyruvattransporter diffusionsabhängig wieder ins Blut abgegeben wird (Wiemer et al., 1992; Barnard et al., 1993). Bei der Differenzierung in die prozyklische Form ändern sich die äußeren Verhältnisse und der Parasit passt sich den neuen Lebensbedingungen entsprechend an. Durch Herunterregulierung der Pyruvat Kinase wird nun 100-fach weniger Pyruvat abgegeben, als in der Blutstromform (Barnard \& Pedersen, 1994). Die Hauptsubstrate des Metabolismus der prozyklischen Form sind Aminosäuren und Glucose, die durch einen aktiven Transportprozess, abhängig von einem Protonengradienten aufgenommen werden 
können, wobei Glykolyse und oxidative Phosphorylierung stattfinden (Zilberstein, 1993). Auch die Regulierung des $\mathrm{pH}_{\mathrm{i}}$ spiegelt die externen Bedingungen wieder und findet in den beiden Lebensstadien über verschiedene Mechanismen statt. Während die prozyklische Form ihren $\mathrm{pH}_{\mathrm{i}}$ auch bei größeren äußeren Schwankungen konstant halten kann und vor allem eine $\mathrm{H}^{+}$-ATPase für diesen Zweck verwendet, kann die Blutstromform ihren $\mathrm{pH}-$ Wert nur sehr schlecht schwankenden externen $\mathrm{pH}$-Werten anpassen. Für die Regulierung wird hierbei zwar zu einem geringen Anteil auch eine $\mathrm{H}^{+}$-ATPase gebraucht, doch die Hauptaufgabe erledigt in diesem Lebensstadium ein Pyruvat/ $\mathrm{H}^{+}$-Symporter (Fraser-L'Hostis et al., 1997; Vanderheyden et al., 2000). Neben der Protonenpumpe exprimieren beide Lebensstadien noch eine $\mathrm{Na}^{+}$-Pumpe, die neben dieser für die Generierung des Membranpotentials verantwortlich gemacht wird. Dabei kommt in der prozyklischen Form auch für diese Aufgabe vor allem die $\mathrm{H}^{+}$-ATPase auf, während in der Blutstromform eine $\mathrm{Na}^{+}$-Pumpe die Hauptaufgabe übernimmt (Van Der Heyden \& Docampo, 2002a). Neben der P-Typ Protonen ATPase übernimmt auch eine V-Typ Protonen Pyrophosphatase (V-H(+)-PPase) die Rolle der $\mathrm{pH}_{\mathrm{i}}$-Regulation. Mutanten mit geringerer Expression der $\mathrm{V}-\mathrm{H}(+)-\mathrm{PPase}$ VP1 in entweder der prozyklischen oder der Blutstromform haben Defekte bei der Aufrechterhaltung ihres intrazellulären $\mathrm{pH}$ Wertes, verbunden mit einer reduzierten Wachstumsrate (Lemercier et al., 2002).

Wiederum ähnlich sind die Verhältnisse in Trypanosoma cruzi, dem Erreger der Chagas-Krankheit. Während in allen Lebensstadien, Trypomastigoten, Epimastigoten und Amastigoten, eine $\mathrm{H}^{+}$-ATPase eine große Rolle bei der Aufrechterhaltung des Membranpotentials spielt, wird diese nur in Trypomastigoten durch eine $\mathrm{Na}^{+}-\mathrm{Pumpe}$ unterstützt (Van Der Heyden \& Docampo, 2002b). Zwei P-Typ Protonen ATPasen, deren Gene TcHA1 und TcHA2 analog denen in Leishmania strukturiert und zu $80 \%$ mit diesen identisch sind, wurden im Genom von T. cruzi entdeckt (Meade et al., 2000). Diese werden differentiell in den verschiedenen Lebensstadien des Parasiten exprimiert, TcHA2 vor allem in Trypomastigoten und TcHA1 in erster Linie in Epimastigoten. Beide Proteine stellen funktionelle Plasmamembran $\mathrm{H}^{+}$-ATPasen dar, was durch erfolgreiche Komplementierung von Hefemutanten bewiesen werden konnte (Luo et al., 2002).

Amastigoten und Trypomastigoten regulieren beide ihren $\mathrm{pH}_{\mathrm{i}}$ über Plasmamembran Protonen ATPasen, die von $\mathrm{K}^{+}$- und $\mathrm{Cl}^{-}$-Kanälen unterstützt werden (Van Der Heyden \& Docampo, 2000). Die Wirkungsweise der Protonen ATPase, die den $\mathrm{pH}_{\mathrm{i}}$ 
reguliert, scheint sich aber bei Amastigoten und Trypomastigoten zu unterscheiden. Während in beiden Lebensstadien eine V-Typ $\mathrm{H}^{+}$-ATPase auf der Oberfläche und in intrazellulären Kompartimenten des Parasiten nachgewiesen werden konnte, deren Funktion den pH-Wert beeinflusst, schleust diese nur in Amastigoten Protonen aus dem Parasiten heraus (Benchimol et al., 1998). Es wurde postuliert, dass V-Typ $\mathrm{H}^{+}$ATPasen in der reduzierenden Umgebung des Zytoplasmas wahrscheinlich aktiv, dagegen aber in der putativ oxidierenden Umgebung vieler Plasmamembranen inaktiv sind (Harvey \& Wieczorek, 1997). Intrazelluläre Parasiten, die im Kontakt mit dem Zytosol ihrer Wirtszelle stehen, sollten sich dabei wie intrazelluläre Organelle verhalten, so dass V-Typ $\mathrm{H}^{+}$-ATPasen in ihrer Plasmamembran aller Wahrscheinlichkeit nach aktiv sind (Moreno et al., 1998). Dies könnte auch die oben beschriebene stadienspezifische Protonenausschleusung durch V-Typ Protonen ATPasen bei (intrazellulären) T. cruzi Amastigoten und (extrazellulären) Epimastigoten erklären.

Zusammenfassend lässt sich sagen, dass P-Typ Protonen ATPasen ein breites Spektrum an Aufgaben zuteil wird, wobei ihre Hauptaufgabe in allen untersuchten Spezies in der Generierung und Aufrechterhaltung eines Protonengradienten liegt, der für sekundären Metabolittransport und Membranpotential wichtig ist. Allerdings können Aufgaben wie die Aufrechterhaltung des $\mathrm{pH}_{\mathrm{i}}$ auch durch $\mathrm{V}$-Typ $\mathrm{H}^{+}$-PPasen oder $\mathrm{H}^{+}$-ATPasen übernommen werden und werden oft nicht alleine von P-Typ $\mathrm{H}^{+}$ATPasen erfüllt.

\subsubsection{Transportvorgänge in Plasmodium}

Da T. gondii oft als Modellorganismus für Plasmodium bezeichnet wird, stellt sich die Frage, ob P-Typ ATPasen in Plasmodium ähnlich vertreten sind, wie in Toxoplasma und vielleicht ähnliche Aufgaben übernehmen. Nach der Komplettierung des Genomprojektes für Plasmodium falciparum und Plasmodium yoelii yoelii (Gardner et al., 2002; Carlton et al., 2002) kann über eine Datenbankabfrage das komplette Genom beider Spezies nach P-Typ ATPasen durchsucht werden. In beiden Plasmodium Spezies lassen sich mindestens zehn unterschiedliche P-Typ ATPasen

finden. Darunter befinden sich die bereits untersuchten PfATPasen 1-6 aus Plasmodium falciparum (Krishna et al., 1993; Trottein \& Cowman, 1995; Rozmajzl et al., 2001), als auch bisher noch unbekannte Proteine. Durch Homologien zu 
bekannten ATPasen lassen sich diese in Schwermetall-transportierende ATPasen (Subtyp I), $\mathrm{Ca}^{2+}$-ATPasen (Subtyp II), Phospholipid-transportierende ATPasen (Subtyp IV) und P-Typ ATPasen des Subtyps V mit bisher unbekannter Spezifität einteilen. Auffällig ist hierbei, dass im Genom von $P$. falciparum und $P$. yoelii yoelii keine Typ III P-Typ ATPasen kodiert sind. Um eine mögliche Erklärung dieses Unterschiedes zu T. gondii zu finden, muss kurz etwas über lonentransport in Plasmodium falciparum und die bereits charakterisierten P-Typ ATPasen aufgeführt werden.

Durch den Stich infizierter Anopheles Mücken kommen die Sporozoiten ins Blut des Menschen, von wo aus die Parasiten sich zunächst in der Leber weiterentwickeln und danach wieder in die Blutbahn zurückkehren, um Erythrozyten zu befallen und sich in innen innerhalb einer parasitophoren Vakuole zu vermehren und weiterzuentwickeln. Infizierte Erythrozyten werden dabei vom Parasiten extensiv modifiziert, es wird ein tubovesikuläres Netzwerk aufgebaut, das die parasitophore Vakuole mit der Peripherie des Erythrozyten verbindet. Es wird angenommen, dass durch dieses Netzwerk Nährstoffe wie Nukleoside und Aminosäuren effizient in den Parasiten gelangen können (Lauer et al., 1997). Der Metabolismus der Lebensstadien innerhalb der Erythrozyten hängt stark von Energiegewinnung durch Glykolyse ab, die zu der Produktion von Lactat führt (Sherman, 1979). Lactat und durch ATP-Hydrolyse generierte Protonen werden durch einen Lactat/ $\mathrm{H}^{+}$-Symporter in der Plasmamembran aus dem Parasiten entfernt, und dadurch sowohl der $\mathrm{pH}_{\mathrm{i}}$ reguliert, als auch die Glykolyse effizient gehalten (Elliot et al., 2001). Der Hauptteil der Protonen wird durch diesen Lactat-Symport aus der Zelle transportiert (Ginsburg, 2002), aber daneben konnten noch drei weitere Protonen-Pumpen in der Plasmamembran des Parasiten nachgewiesen werden: eine V-Typ $\mathrm{H}^{+}$-ATPase und zwei V-Typ $\mathrm{H}^{+}$-PPasen (Saliba \& Kirk, 1999; McIntosh et al., 2001). Durch Inhibitorstudien konnte gezeigt werden, dass die $\mathrm{V}$-Typ $\mathrm{H}^{+}$-ATPase für die Aufrechterhaltung des $\mathrm{pH}_{\mathrm{i}}$ des Parasiten und eine Ansäuerung des Zytoplasmas des Erythrozyten verantwortlich ist, also einen Protonengradienten über der Plasmamembran des Parasiten aufrecht erhält (Saliba \& Kirk, 1999; Hayashi et al., 2000). Der Protonengradient wird in Plasmodium wie in anderen Organismen dazu gebraucht, um Nährstoffe in die Zelle zu transportieren, wie im Falle von Pantothenat gezeigt werden konnte (Saliba \& Kirk, 2001). Beide Typen von V-Typ Protonen Pumpen konnten auch in der Membran der Verdauungsvakuole des Parasiten nachgewiesen werden, wo sie ähnlich den sauren Tonoplasten von Pflanzen für eine Ansäuerung des Innenraums dieses Organells 
sorgen (Saliba et al., 2003). V-Typ Protonen ATPasen werden auch in zunehmendem Maße in den Plasmamembranen tierischer Zellen gefunden, wo sie wichtige spezialisierte Aufgaben übernehmen (Finbow \& Harris, 1997).

Die P-Typ ATPasen aus Plasmodium unterscheiden sich von P-Typ ATPasen aus anderen Spezies, indem sie nur sehr geringe Ähnlichkeiten in ihrer Sequenz aufweisen und teilweise extrem hydrophile Insertionen enthalten. Diese sogenannten „malarial inserts" wurden auch in anderen Proteinen aus Plasmodium gefunden und scheinen keinen Einfluss auf die Struktur und enzymatische Aktivität der Proteine zu auszuüben (Krishna et al., 2001).

Warum Plasmodium keine P-Typ Protonen ATPase, sondern V-Typ Protonen ATPase und PPase in der Plasmamembran besitzt, kann hier nicht beantwortet werden. Es ist aber interessant, dass auch durch die angelaufenen Genomprojekte anderer Apicomplexa, wie Babesia bovis, Eimeria tenella und Cryptosporidium parvum bisher noch keine P-Typ Protonen ATPasen gefunden werden konnten.

\subsubsection{Transportprozesse in Toxoplasma gondii}

Über Transportprozesse in $T$. gondii ist recht wenig bekannt und die meisten Untersuchungen haben sich bislang auf das Tachyzoitenstadium beschränkt.

Nach Infektion mit Tachyzoiten kann ein Absinken der $\mathrm{Na}^{+}-$Konzentration im Wirtszellzytoplasma beobachtet werden, während gleichzeitig die Konzentrationen an $\mathrm{K}^{+}$und $\mathrm{Cl}^{-}$steigen (Bouchot et al., 1999). Da die parasitophore Vakuole wie ein Molekularsieb funktioniert und kleinere Substanzen als $1300 \mathrm{kDa}$, einschließlich lonen, ungehindert zwischen Wirtszelle und parasitophorer Vakuole diffundieren können (Schwab et al., 1994), wirken sich lonentransportvorgänge des Parasiten innerhalb der Vakuole direkt auf das Membranpotential der Wirtszelle aus. So findet nach Infektion mit $T$. gondii eine Hyperpolarisation der Wirtszellplasmamembran statt (Bouchot et al., 2001).

Was Protonen ATPasen betrifft, wurde bereits eine V-Typ $\mathrm{H}^{+}$-ATPase in $T$. gondii identifiziert (Moreno et al., 1998). Das Enzym befindet sich auf der Plasmamembran und in zytoplasmatischen Vesikeln innerhalb von Tachyzoiten. Eine Inhibitionsstudie zeigte, dass die V-Typ $\mathrm{H}^{+}$-ATPase für die Aufrechterhaltung des $\mathrm{pH}_{\mathrm{i}}$ und Membranpotentials wichtig ist. Über eine Expression und Funktion in Bradyzoiten ist nichts bekannt. 
Die T. gondii P-Typ $\mathrm{Ca}^{2+}$-ATPase TgA1 wurde kloniert und charakterisiert (Luo et al., 2001). Das Gen wird sowohl in Tachyzoiten, als auch in Bradyzoiten exprimiert. TgA1 läßt sich auch auf der Plasmamembran, aber vor allem in zytoplasmatischen Vakuolen von Tachyzoiten und Bradyzoiten nachweisen. Diese Vakuolen konnten als Acidocalcisomen identifiziert werden, einem sauren Organell, das zuvor in Trypanosomen beschrieben worden war. Acidocalcisomen stellen einen intrazellulären Speicher von $\mathrm{Ca}^{2+}, \mathrm{Mg}^{2+}$, Zink und Polyphosphaten dar, was an isolierten Acidocalcisomen von $T$. gondii bestätigt werden konnte (Rodrigues et al., 2002). Für dieses Organell typisch sind die Transportproteine, die in der Membran gefunden werden können. Unter anderem lassen sich dort typischerweise neben einer $\mathrm{V}$-Typ $\mathrm{H}^{+}$-ATPase, einer $\mathrm{Ca}^{2+}$-ATPase, und einem $\mathrm{Na}^{+} / \mathrm{K}^{+}$-Austauscher auch $\mathrm{V}$ Typ $\mathrm{H}^{+}$-PPasen finden. Letztere wurde auch in Toxoplasma zunächst biochemisch identifiziert und charakterisiert, später durch Klonierung und Expression in Hefe bestätigt (Rodrigues et al., 2000; Drozdowicz et al., 2003). Die V-Typ H+-PPase TgVP1 spaltet Pyrophosphat und pumpt $\mathrm{K}^{+}$-abhängig Protonen in die Acidocalcisomen, wodurch sich dieses Organell erheblich ansäuert. Die Verteilung von TgVP1 in der Zelle ist dynamisch und ändert sich bei der Invasion einer Wirtszelle. Während das Protein normalerweise hauptsächlich apikal punktiert innerhalb des Parasiten nachzuweisen ist, verändert sich diese Verteilung während einer Wirtszellinvasion derart, dass sich eine gürtelähnliche Struktur um den Parasiten ausbildet, die im Laufe der Invasion posterior wandert. Inhibitoren des Enzyms blockieren allerdings nicht die Invasion, sondern die Replikation intrazellulärer Parasiten. Es wurde eine wichtige Rolle von TgVP1 bei der Bereitstellung eines $\mathrm{Ca}^{2+}$-Speichers postuliert, der für die Motilität des Parasiten und während der Invasion benötigt wird (Drozdowicz et al., 2003). Ob das Protein auch auf der Plasmamembran lokalisiert ist, ist umstritten (Luo et al., 2001; Drozdowicz et al., 2002). Wieder beschränkten sich alle durchgeführten Studien auf das Tachyzoitenstadium, so dass eine Rolle von TgVP1 in Bradyzoiten völlig ungeklärt bleibt.

Fasst man alle bisher aufgeführten Daten über P-Typ und V-Typ $\mathrm{H}^{+}$-ATPasen und PPasen in Protozoen zusammen, scheint es eher so, als wäre die bradyzoitspezifische Expression von TgPMA1 eine Anpassung an die besonderen Lebensbedingungen in den Zysten während dieses Lebensstadiums. Ob eine Expression einer weiteren P-Typ $\mathrm{H}^{+}$-ATPase (wie TgPMA2) auf der Oberfläche von T. gondii 
Tachyzoiten stattfindet, muss noch gezeigt werden. Innerhalb der Apicomplexa scheint also nicht Plasmodium durch das Fehlen einer P-Typ $\mathrm{H}^{+}$-ATPase, sondern Toxoplasma durch die Anwesenheit eines solchen lonentransporters herauszustechen.

Ihren phylogenetischen Ursprung haben viele Gene der Apicomplexa in einer Grünoder Rotalge, die durch sekundäre Endosymbiose aufgenommen wurde und deren Überbleibsel im heutigen Apicoplasten des Parasiten zu finden sind. Deshalb verwundert es auch nicht weiter, dass sehr viele Proteine aus $T$. gondii oder anderen Apicomplexa große Ähnlichkeiten zu Grün- oder Rotalgen aufweisen (Roos et al., 1999). Wie auch bei anderen extrachromosomalen Genomen fand in Apicoplasten im Laufe der Evolution ein Gentransfer vom Plastid in den Nukleus statt, so dass viele Gene im Nukleus kodiert werden, ihr phylogenetischer Ursprung aber im Vorläufer des Apicoplasten liegt. Dies erklärt auch die große Ähnlichkeit von tgpma1 zu Homologen aus Rotalgen und Archaebakterien. Wie oben erwähnt, konnte im Gegensatz zu den übrigen Angehörigen der Apicomplexa bisher nur in Toxoplasma eine P-Typ $\mathrm{H}^{+}$-ATPase gefunden werden. Phylogenetisch betrachtet ist daher davon auszugehen, dass das Gen im Laufe der Evolution in den übrigen Vertretern der Apicomplexa verloren ging und nur in T. gondii erhalten blieb.

\subsection{Charakterisierung der tgpma1 Gendeletionsmutante}

Die erfolgreiche Disruption von tgpma1 in Tachyzoiten von $T$. gondii beweist, dass das Gen für dieses Lebensstadium nicht essentiell ist, wie durch die bradyzoitspezifische Expression auch zu vermuten war. In Pilzen wie Saccharomyces cerevisiae und wahrscheinlich in Aspergillus fumigatus, Aspergillus nidulans und Cryptococcus neoformans stellt die P-Typ Protonen ATPase ein essentielles Gen dar (Serrano et al., 1986; Burghoorn et al., 2002; Reoyo et al., 1998; Soteropoulos et al., 2000). Allerdings lässt sich die zweite Isoform PMA2 in Saccharomyces ohne einen erkennbaren Phänotyp ausschalten, ist also mit Sicherheit auch nicht essentiell (Supply et al., 1993).

Parasiten der tgpma1 Gendeletionsmutante sind in der Lage, sowohl in vitro, als auch in vivo infektiöse Zysten zu bilden. Möglicherweise kann ein anderes Enzym, eine $\mathrm{V}$-Typ $\mathrm{H}^{+}$-ATPase oder die zweite Isoform TgPMA2 das Fehlen von TgPMA1 
komplementieren, oder TgPMA1 wird für die Bildung von Zysten nicht benötigt. In der Wachstumsrate von Tachyzoiten und von sich differenzierenden Parasiten zeigte sich ebenfalls kein Unterschied zwischen wildtypischen und tgpma1- Parasiten, was wiederum zeigt, dass TgPMA1, im Unterschied zu Saccharomyces PMA1, die Wachstumsrate nicht beeinflusst. Im Falle der Hefe PMA1 konnte gezeigt werden, dass die Proteinmenge direkt proportional zur Wachstumsrate ansteigt und auf diese einen direkten Einfluss ausübt (Rao et al., 1993).

Obwohl in vivo kein Unterschied in der Zystenmenge zwischen einer Infektion von Mäusen mit Wildtyp und tgpma1- Parasiten festgestellt werden konnte, war bei der Induktion einer Stadienkonversion in vitro ein deutlicher Unterschied im Expressionsmuster aller per Immunfluoreszenz untersuchten bradyzoitspezifischen Proteine sichtbar. Dieser beobachtete Phänotyp der Gendeletionsmutante rührt von einer unterschiedlichen Effizienz in der Stadienkonversion zwischen den Wildtyp und tgpma1- Parasiten her. Wie eingangs bereits erwähnt, wird bei Stadienkonversionsversuchen in der Zellkultur eine Art von Stress auf die Parasiten appliziert, der immer auch für die Wirtszellen toxisch ist. So lassen sich derartige Versuche nur über die Dauer von ein paar Tagen durchführen und die so induzierten Bradyzoiten unterscheiden sich noch erheblich von solchen, die aus chronisch infizierten Mäusen isoliert werden können. Während der Stadienkonversion in vivo treten auch zunächst Zwischenformen auf, also Parasiten, die sowohl tachyzoit-, als auch bradyzoitspezifische Proteine exprimieren (Ferguson \& Hutchison, 1987). Die durch in vitro Induktion erzeugten Bradyzoiten ähneln diesen insofern, dass bestimmte ,späte' Bradyzoitenmarker wie Pb21 entweder gar nicht, oder nur selten zu beobachten sind und auch oft eine Co-Expression von Tachyzoiten- und Bradyzoitenmarkern auftritt. In der Zellkultur lassen sich also nur die ersten Schritte der Stadienkonversion zum Bradyzoiten induzieren, während spätere Schritte nur in vivo auftreten.

Während der Stadienkonversion in vitro zeigte sich ein deutlicher Unterschied zwischen den tgpma1 Parasiten und dem Ausgangsstamm. Bei Parasiten der Mutante ließ sich zwar eine Stadienkonversion induzieren, die Differenzierungsrate war aber für die meisten untersuchten Bradyzoitenmarker in der Immunfluoreszenz um den Faktor vier bis sechs niedriger, als im Wildtyp. Dies könnte dadurch erklärt werden, dass die Induktion der Stadienkonversion, also der Reiz, der die Differenzierung auslöst, in tgpma1- Parasiten stärker sein muss. Die Reizschwelle scheint in den Mutanten höher zu liegen, so dass ein stärkerer, oder länger 
wirkender Reiz nötig ist, um in den Parasiten eine Stadienkonversion auszulösen. Im Einklang mit dieser Hypothese steht auch das Ergebnis der verschiedenen, an der Gendeletionsmutante ausgetesteten Methoden zur Induktion der Stadienkonversion. Während ein pH-Shift sich als zuverlässigste Methode herausstellte und bei $60-90 \%$ der Parasiten des Wildtyps eine Expression der meisten Bradyzoitenmarker induzierte, konnten durch extrazelluläre Inkubation oder Behandlung mit Oligomycin und SNP nur in 20-30\% der wildtypischen Parasiten eine Stadienkonversion induziert werden. Der Reiz, den diese Shift-Methoden auf die Parasiten ausübten, war also entsprechend niedriger, als eine Änderung des äußeren pH-Wertes. In der Gendeletionsmutante konnten diese schwächeren Reize dementsprechend auch nur bei $1-5 \%$ der Parasiten eine Stadienkonversion auslösen, deutlich weniger, als durch einen $\mathrm{pH}-\mathrm{Shift}$ induziert wurden. Doch obwohl die Differenzierungsrate der Mutante deutlich niedriger war, konnten bei den in vivo Infektionsversuchen keine Unterschiede in der Zystenzahl im Gehirn chronisch infizierter Mäuse festgestellt werden. Dies deutet darauf hin, dass sich ausdifferenzierte Bradyzoiten zwischen Deletionsmutante und Wildtyp nicht weiter unterscheiden. Die Stadienkonversion wird oft als ein Mechanismus beschrieben, der es dem Parasiten ermöglicht, der während der akuten Phase der Infektion entstehenden Immunantwort des Wirtes zu entkommen. Ob die durch die Immunantwort bedingte Differenzierungsrate der tgpma1- Parasiten sich von der des Ausgangsstammes unterscheidet, geht aus den durchgeführten Experimenten nicht hervor. Gesichert ist aber, dass sich die Mutanten auch in vivo differenzieren können und die Differenzierungsrate ausreichend ist, ähnliche Zystenzahlen wie der Ausgangsstamm im Gehirn von Mäusen zu erzeugen. Demnach muss TgPMA1 eine Rolle während der frühen Phase der Stadienkonversion spielen, die im späteren Verlauf der Differenzierung nicht mehr nötig ist.

Eine genauere Untersuchung des in vitro beobachteten Phänotyps wurde durch RTPCR ermöglicht. Da sämtliche durch Antikörper nachgewiesenen Bradyzoitenproteine eine ähnliche verringerte Differenzierungsrate in der Gendeletionsmutante zeigten war es von Interesse, die Expression weiterer bradyzoitspezifisch regulierter Gene zu untersuchen. Hierdurch sollte festgestellt werden, ob einige stadienspezifische Gene nicht vom Fehlen der TgPMA1 Expression beeinflusst wurden, oder ob tatsächlich alle bradyzoitspezifischen Gene betroffen waren. Die Auswahl der zu untersuchenden Gene richtete sich dabei nach zwei kurz zuvor veröffentlichten 
Arbeiten mit $T$. gondii Differenzierungsmutanten, die durch Microarrays mit den jeweiligen Wildtypen verglichen worden waren (Matrajt et al., 2002a; Singh et al., 2002). Die durch chemische oder Insertionsmutagenese erzeugten Mutanten waren dabei in beiden Fällen auf Defekte in der Bradyzoitendifferenzierung selektiert worden und zeigten einen vergleichbaren Phänotyp mit der tgpma1 Gendeletionsmutante: eine verringerte Stadienkonversionsrate in vitro. Allerdings konnten Matrajt et al. eine erhöhte Wachstumsrate ihrer Differenzierungsmutanten unter Stadienkonversionsbedingungen (Pyrimidinmangel und pH-Shift) feststellen, die die tgpma1 Deletionsmutante nicht aufwies. Singh et al. konnten für ihre Differenzierungsmutanten eine verringerte Zystenbildung in Mäusen nachweisen. Das Transkriptionsprofil der Differenzierungsmutanten wies starke Ähnlichkeiten, aber auch einige Unterschiede zu der tgpma1 Gendeletionsmutante auf (s. Abb. 18).

Die Expression der Gene des kleinen Hitzeschockproteins Bag1, der Lactatdehydrogenase LDH2, der Enolase ENO1 und des Oberflächenproteins SAG4 war in allen Mutanten reduziert. Ferner war das Gen des bradyzoitspezifischen Oberflächenproteins SRS9 (Cleary et al., 2002) und ein Gen mit Homologie zu dem $P$. falciparum VEE Repeat Protein oder der Desoxyribosephosphat Aldolase DRPA in den Differenzierungsmutanten von Singh et al. ebenfalls weniger stark hochreguliert. Eine bradyzoitspezifische Expression von SAG2D (Lekutis et al., 2000) und eines Gens mit Homologie zu Oligoendopeptidasen (Cleary et al., 2002), konnte unter den hier gewählten Bedingungen zur Induktion der Stadienkonversion nicht bestätigt werden.

Bei den durchgeführten RT-PCR Studien wurden einige Gene zwar während der Stadienkonversion heraufreguliert, aber von der fehlenden tgpma1 Expression nicht beeinflusst, darunter Gene mit Homologie zu Methionin Aminopeptidase 2 (MetAP2), dem Tranlationsinitiationsfaktor elF-5A aus Plasmodium, oder einem $T$. gondii Homologen zu 14-3-3 Proteinen. Dieses ist zwar kaum stadienspezifisch reguliert, wie durch Real-Time RT-PCR gezeigt werden konnte (s. Abb. 19), die Expression dieses Gens in der Gendeletionsmutante war aber von besonderem Interesse. 14-33 Proteine erfüllen in der Zelle eine große Anzahl an Funktionen, unter anderem konnte innen auch eine Rolle bei der Aktivierung pflanzlicher P-Typ $\mathrm{H}^{+}$-ATPasen nachgewiesen werden. Dabei muss zunächst die vorletzte Aminosäure, ein in pflanzlichen $\mathrm{H}^{+}$-ATPasen hochkonserviertes Threonin, phosphoryliert werden. 14-3-3 Proteine binden anschließend an dieses phosphorylierte Threonin und bewirken, 
dass der C-Terminus, der in pflanzlichen $\mathrm{H}^{+}$-ATPasen eine autoinhibitorische Domäne darstellt, eine Konformationsänderung durchläuft und dadurch die ATPase aktiviert wird (Portillo, 2000). Diese Aktivierung durch Phosphorylierung findet auch bei heterologer Expression der pflanzlichen ATPasen in Hefe statt (Maudoux et al., 2000). Endogene Hefe P-Typ $\mathrm{H}^{+}$-ATPasen werden zwar auch phosphoryliert, aber nicht von 14-3-3 Proteinen gebunden und müssen daher durch einen anderen Mechanismus aktiviert werden (Goossens et al., 2000).

Ein weiteres interessantes Ergebnis der RT-PCR Studien war, dass TgPMA2 in der tgpma1 Gendeletionsmutante ebenfalls weniger stark induziert wird, als im Wildtyp. Eine Möglichkeit bei der Disruption eines Gens ist, dass ein anderes Protein die Funktion des betroffenen Proteins übernehmen kann und dadurch die fehlende Expression zumindest partiell komplementiert. Dies scheint im Falle von TgPMA2 aber nicht zu geschehen, zumindest nicht durch verstärkte Transkription des Gens.

\subsection{Transportprozesse in Bradyzoiten und mögliche Funktion von TgPMA1}

Über aktive Transportprozesse in Bradyzoiten kann man nur spekulieren. Da sich Metabolismus und Zusammensetzung der Oberflächenmoleküle erheblich von Tachyzoiten unterscheiden, lassen sich die Ergebnisse der Transporterstudien aus Tachyzoiten auch nicht einfach auf Bradyzoiten übertragen. Wie bei Leishmanien und Trypanosomen findet man auch bei Toxoplasma eine Umstellung des Metabolismus in den verschiedenen Lebensstadien. Da ein veränderter Metabolismus unterschiedliche intrazelluläre Verhältnisse hervorruft ist es sehr wahrscheinlich, dass auch $T$. gondii Tachyzoiten und Bradyzoiten dies durch verschiedene lonentransportvorgänge regulieren, wie es bei anderen Protozoen bereits nachgewiesen werden konnte. Die stadienspezifische Expression von TgPMA1 auf der Oberfläche von Bradyzoiten deutet darauf hin, dass sich die beiden Lebensstadien von $T$. gondii in solchen Prozessen wie Nährstoffaufnahme und/ oder Kontrolle des $\mathrm{pH}_{\mathrm{i}}$, sowie des Membranpotentials unterscheiden könnten. TgPMA1 scheint dabei eine wichtige Rolle während der frühen Phase der Stadienkonversion zu spielen. Eine mögliche Funktion wäre dabei eine Änderung des zytoplasmatischen $\mathrm{pH}$ Wertes als ein Signal, das die Differenzierung vorantreibt. In zahlreichen Organismen 
konnten veränderte intrazelluläre $\mathrm{pH}$-Werte mit Differenzierungsvorgängen in Verbindung gebracht werden. Durch zytosolische pH-Änderungen können solche Prozesse wie Glykolyse, Protein- und DNA Synthese, Motilität und Aktivierung von dormanten Lebensstadien reguliert werden (Busa \& Nuccitelli, 1984). In der Amöbe Dictyostelium discoideum bewirkt hyperosmotischer Stress eine Stressantwort in Form einer Ansäuerung des Zytosols und der externen Umgebung, wobei letzteres auf die Ausschleusung von Protonen aus der Zelle zurückgeführt werden kann (Oyama \& Kubota, 1997; Pintsch et al., 2001). Eine Rolle von zytoplasmatischen pHÄnderungen bei Differenzierungsvorgängen in Fibroblasten konnte durch heterologe Expression der Hefe P-Typ Protonen ATPase PMA1 nachgewiesen werden (Perona \& Serrano, 1988). Die transgenen Fibroblasten exprimierten PMA1 zumindest teilweise auf ihrer Oberfläche, zeigten einen transformierten Phänotyp in vitro und konnten eine Tumorbildung in Nacktmäusen induzieren. PMA1 verhielt sich dabei wie ein Onkogen in den tierischen Zellen, was auf die Aktivität der ATPase zurückgeführt werden konnte. Die transformierten Zellen zeigten einen erhöhten intrazellulären $\mathrm{pH}-$ Wert, was auch in anderen Tumorzellen festgestellt wurde, die zusätzlich einen aktivierten $\mathrm{Na}^{+} / \mathrm{H}^{+}$-Tauscher aufwiesen (Ober \& Pardee, 1987). Dagegen können Fibroblasten, die einen Defekt im $\mathrm{Na}^{+} / \mathrm{H}^{+}$-Austauscher haben, ihren zytoplasmatischen $\mathrm{pH}-$ Wert als Antwort auf Wachstumsfaktoren nicht mehr erhöhen, um die DNA-Synthese zu reinitialisieren (Pouyssegur et al., 1985). Ein erhöhter $\mathrm{pH}_{\mathrm{i}}$ aktiviert in tierischen Zellen Glykolyse, Protein- und DNA Synthese und Mikrotubulusbildung (Epel \& Dube, 1987).

Im Gegensatz zu Tachyzoiten sind Bradyzoiten ausschließlich auf Glykolyse angewiesen. Da eine Alkalisierung des intrazellulären pH-Wertes in tierischen Zellen unter anderem die Glykolyse aktivieren kann, bietet sich folgendes Arbeitsmodell für die Wirkungsweise von TgPMA1 während der frühen Phase der Bradyzoitenbildung an:

Eine Expression von TgPMA1 führt zu erhöhtem Ausstoß von Protonen aus dem Parasiten. Dies bewirkt eine Alkalisierung des intrazellulären $\mathrm{pH}$-Wertes, der wiederum ein Signal für die Umstellung des Parasiten auf das Bradyzoitenstadium darstellt. Glykolyse wird dabei zum alleinigen Weg der Energiegewinnung und der Parasit durchläuft die vollständige Stadienkonversion zum Bradyzoiten. Eine mögliche Erklärung dafür, dass TgPMA1 nur während der frühen Stadien der Differenzierung und nicht mehr später eine Rolle spielt, könnte darin begründet sein, 
dass zytosolische pH-Änderungen als "synergistischer Messenger" agieren (Busa \& Nuccitelli, 1984), also immer in Verbindung mit anderen Botenstoffen, die etwas zeitverzögert durchaus alleine eine Differenzierung bewirken könnten.

Um dieses Modell zu bekräftigen, müsste der $\mathrm{pH}_{\mathrm{i}}$ von Wildtyp und Gendeletionsmutante gemessen werden. Dieser sollte sich im Bradyzoitenstadium unterscheiden, zu erwarten wäre ein niedrigerer $\mathrm{pH}_{\mathrm{i}}$ in der Mutante zumindest während der frühen Phasen der Differenzierung. Ebenfalls interessant wäre eine Untersuchung der Regulationsmechanismen, die den $\mathrm{pH}_{\mathrm{i}}$ in Tachyzoiten und Bradyzoiten aufrecht erhalten. Wie oben bereits erwähnt unterscheiden sich diese, ebenso wie die Mechanismen der Nährstoffaufnahme, zwischen den Lebensstadien anderer Protozoen teilweise erheblich. Der Reiz, der eine Stadienkonversion der Gendeletionsmutante auslöst, muss anscheinend stärker sein, als im Wildtyp. Da zu erwarten ist, dass mehrere verschiedene Botenstoffe an der Induktion der Stadienkonversion beteiligt sein müssen, könnte eine stärkere Anreicherung dieser Botenstoffe in der Gendeletionsmutante zu deren Identifizierung führen. Somit könnten die Schlüsselgene, die für die Differenzierung des Parasiten verantwortlich sind, entdeckt und neue Ansatzpunkte für eine Therapie gegen die chronische Phase der Infektion gewonnen werden. 


\section{Zusammenfassung}

Die Differenzierung zu Bradyzoiten ist eine wichtige Vorraussetzung für die Persistenz von Toxoplasma gondii in seinen Wirten. Während dieser Stadienkonversion beginnt der Parasit eine Reihe neuer, bradyzoitspezifischer Gene zu exprimieren, während die Expression vieler tachyzoitspezifischer Gene herunterreguliert wird. Die Schlüsselgene des Parasiten, die diese Differenzierung auslösen, sind bisher nicht bekannt.

Im Rahmen dieser Arbeit wurde eine bradyzoitspezifische P-Typ Protonen-ATPase (TgPMA1) identifiziert und funktionell charakterisiert. In Pflanzen, Pilzen und einigen Protozoen generiert dieser Proteintyp einen Protonengradienten, der für die Nährstoffaufnahme durch sekundäre Transporter essentiell ist. Ferner konnten diese Transportproteine mit der Regulation des intrazellulären $\mathrm{pH}$ Wertes $\left(\mathrm{pH}_{\mathrm{i}}\right)$ in Verbindung gebracht werden. Über Transportprozesse im Bradyzoitenstadium von $T$. gondii ist bisher so gut wie nichts bekannt. $\mathrm{Da}$ Änderungen des $\mathrm{pH}_{\mathrm{i}}$ in vielen Zelltypen Differenzierungsvorgänge auslösen können, war es von Interesse zu erfahren, ob TgPMA1 eine Aufgabe bei der Stadienkonversion des Parasiten übernimmt.

TgPMA1 hat eine errechnete Größe von $127 \mathrm{kDa}$ und besitzt die für P-Typ ATPasen typischen 10 Transmembrandomänen, sowie alle in dieser Klasse von Transportproteinen hochkonservierten Bereiche. Auf Aminosäureebene zeigen sich größte Ähnlichkeiten zu P-Typ H $\mathrm{H}^{+}$-ATPasen aus der Rotalge Cyanidium caldarium und dem Archaebakterium Methanococcus jannaschii. Der Leserahmen des single-copy Gens wird durch zwei etwa 350 nt große Introns unterbrochen, wobei eines direkt 5' und das andere 3' des putativen Startcodons liegt. Mit Hilfe eines Antiserums, das gegen ein Peptid aus dem C-Terminus generiert wurde, konnte in einem Immunfluoreszenztest gezeigt werden, dass TgPMA1 ausschließlich auf der Membran von Bradyzoiten lokalisiert ist.

Zur weiteren Charakterisierung wurde durch Disruption des Leserahmens von tgpma1 eine Gendeletionsmutante in $T$. gondii hergestellt. Diese wies unabhängig 
vom Parasitenstadium keine veränderte Teilungsrate auf. Eine Differenzierung zu Bradyzoiten konnte in vitro zwar noch immer erfolgreich induziert werden, die Parasiten wiesen jedoch eine im Vergleich zum Wildtyp signifikant reduzierte Expressionsrate einiger bradyzoitspezifischer Gene auf. Obwohl die in vitro untersuchte frühe Differenzierung zu Bradyzoiten in der Gendeletionsmutante weniger effizient zu sein scheint, ist die generelle Fähigkeit zur Zystenbildung in vivo nicht beeinflusst.

Von besonderem Interesse war auch, ob TgPMA1 als Protonentransporter für die Säureresistenz von Bradyzoiten verantwortlich ist und somit das Überleben einer Magenpassage vermittelt. Dies scheint allerdings nicht der Fall zu sein, da nach oraler Infektion von Mäusen mit Zysten der Gendeletionsmutante auch weiterhin eine erfolgreiche Infektion etabliert werden kann.

Das Fehlen von TgPMA1 führt demnach zwar in der Frühphase der Differenzierung zu einer Veränderung des Transkriptionsprofils, wichtige physiologische Merkmale wie Persistenz und Infektiosität bleiben hiervon jedoch unbeeinflusst. Eine mögliche Erklärung hierfür ist, dass eine durch TgPMA1 verursachte Änderung des $\mathrm{pH}_{\mathrm{i}}$ als Differenzierungssignal in der Gendeletionsmutante fehlt. Da pH-Änderungen immer als synergistische Signale auftreten, kann dieses Fehlen jedoch wahrscheinlich durch andere Differenzierungssignale kompensiert werden. Die Deletionsmutante scheint einen stärkeren Reiz zur Induktion der Differenzierung zu benötigen, sich danach aber nicht weiter von wildtypischen Bradyzoiten zu unterscheiden. Zukünftige Versuche müssen demnach den $\mathrm{pH}_{\mathrm{i}}$ von Wildtyp und Gendeletionsmutante messen und miteinander vergleichen. Ferner muss geklärt werden, ob sich Tachyzoiten und Bradyzoiten ähnlich der Lebensstadien anderer Protozoen hinsichtlich ihrer Nährstoffaufnahme und Regulation des $\mathrm{pH}_{\mathrm{i}}$ unterscheiden. Die Deletionsmutante könnte ein guter Ansatzpunkt sein, die für die Stadienkonversion des Parasiten nötigen Schlüsselgene zu identifizieren und somit helfen, neue Medikamente gegen das Zystenstadium des Parasiten zu entwickeln. 


\section{Summary}

Toxoplasma gondii is an obligate intracellular parasite that causes persistent infections in a broad range of warm-blooded vertebrates, including humans. A stage differentiation from tachyzoites to bradyzoites is a prerequisite for the persistence of the parasite in its hosts, as it is a mechanism for evasion of the host's immune response. During this differentiation event, a set of genes is down-regulated, while a new set of genes is switched on. The key genes responsible for this stage conversion have yet to be identified.

In this work, we studied the expression and function of the bradyzoite-specific P-type proton ATPase TgPMA1. In plants, fungi and some protozoa, this class of transport proteins generates a proton gradient across the plasma membrane that is essential for nutrient uptake by secondary transporters. Furthermore, they have been correlated to the regulation of intracellular $\mathrm{pH}$. Almost nothing is known about transport processes in bradyzoites. As changes in intracellular $\mathrm{pH}$ can initiate differentiation processes in several different cells, it was of interest to determine the role of TgPMA1 for stage differentiation of Toxoplasma gondii.

TgPMA1 has an estimated molecular weight of $127 \mathrm{kDa}$ and possesses all of the ten transmembrane segments and highly conserved sequence motifs characteristic for P-type ATPases. Highest amino acid homology can be seen with P-type proton ATPases of the red alga Cyanidium caldarium and the archaebacterium Methanococcus jannaschii. The open reading frame of this single-copy gene is interrupted by two introns approximately $350 \mathrm{nt}$ in size, one of which is positioned immediately upstream and the other one downstream of the putative start codon. To localize the expression of the protein in the parasite, rabbit antiserum was raised against a small peptide of the C-terminus of TgPMA1. In an immunofluorescence assay, the protein could be visualized exclusively on the outer membrane of bradyzoites.

To further characterize the gene, a T. gondii gene 'knock out' mutant was generated by disruption of the tgpma1 open reading frame. To do this, a plasmid carrying the 
genomic locus of tgpma1 in which the open reading frame had been interrupted by deletion of a small fragment and insertion of a selectable marker was transfected into tachyzoites of the cyst-forming $T$. gondii strain Prugniaud/ $\mathrm{HX}$. After cloning the parasites, one $T$. gondii clone could be isolated that carried a single copy of the targeting construct in its genome that had been integrated by homologous recombination. The identity of the gene knock out mutant was characterized and the lacking expression of TgPMA1 in bradyzoites was confirmed in an immunofluorescence assay.

The knock out mutant did not show an altered growth rate as tachyzoites, during conversion to bradyzoites or during the spontaneous re-differentiation from bradyzoites to tachyzoites. A differentiation to bradyzoites could still be induced successfully in vitro, but the mutant parasites exhibited a markedly reduced expression of some bradyzoite-specific genes, when compared to the wild type strain. This difference in expression could be quantified to approximately the factor 10.

Although the early events of differentiation to bradyzoites that were studied in vitro occur less efficiently in the knock out mutant, the ability to generate tissue cysts in vivo is not effected. When parasites of the knock out mutant were used to infect mice i. p., similar amounts of cysts could be found in the brains of these mice as were generated by the wild type. Of special interest was whether TgPMA1 as a proton transporter was responsible for the observed acid resistance of bradyzoites, thereby allowing survival of a stomach passage. This does not seem to be the case, though, as parasites remain viable and able to establish a successful infection cycle after oral infection of mice with cysts of the knock out strain.

Thus, lack of TgPMA1 expression leads to a difference in the transcription profile during the early phase of differentiation, but important physiological characteristics like persistance and infectivity remain unaltered. A possible explanation could be that TgPMA1 causes a change in intracellular $\mathrm{pH}$ during stage conversion of the parasite, a signal that is missing in the knock out mutant. As changes in intracellular $\mathrm{pH}$ always act as synergistic messengers, this could be complemented by other differentiation signals. As these would have to be stronger than in the wildtype, this 
would explain the phenotype of the knock out mutant with its decrease in differentiation rate during the early phase of stage conversion. The gene deletion mutant seems to need a stronger signal for the induction of differentiation but does not differ from wildtype parasites in later stage of differentiation. Future studies have to measure and compare the intracellular $\mathrm{pH}$ of wildtype and knock out mutant. Furthermore, it has to be tested whether tachyzoites and bradyzoites differ in their means of nutrient acquisition and regulation of intracellular $\mathrm{pH}$, as has been found for the alternative life stages of other protozoans. The gene knock out mutant could be a good start for identifying the key genes needed for stage conversion of $T$. gondii and could thus help to develop new drugs against the cyst stage of the parasite. 


\section{$\underline{7 \text { Literatur }}$}

Achbarou, A., Mercereau-Puijalon, O., Sadak, A. (1991). Differential targeting of dense granule proteins in the parasitophorous vacuole of Toxoplasma gondii. Parasitology 103, 321-329.

Ajioka, J. W., Boothroyd, J. C., Brunk, B. P., Hehl, A., Hillier, L., Manger, I. D., Marra, M., Overton, G. C., Roos, D. S., Wan, K.-L., Waterston, R., Sibley, L. D. (1998). Gene discovery by EST sequencing in Toxoplasma gondii reveals sequences restricted to the Apicomplexa. Genome Res. 8, 18-28.

Ajioka, J. W., Fitzpatrick, J. M., Reitter, C. P. (2001). Toxoplasma gondii genomics: shedding light on pathogenesis and chemotherapy. Exp. Rev. Mol. Med. 6, 1-19.

Ambroise-Thomas, P., Pelloux, H. (1993). Toxoplasmosis- congenital and in immunocompromised patients: a parallel. Parasitol. Today 9, 61-63.

An, C.-I., Fukusaki, E.-I., Kobayashi, A. (2001). Plasma-membrane $\mathrm{H}^{+}$-ATPases are expressed in pitchers of the carnivorous plant Nepenthes alata Blanco. Planta $212,547-555$.

Anderson, S. A., Jiang, S., Mukkada, A. J. (1994). The beta-aspartyl phosphate intermediate in a Leishmania donovani promastigote plasma membrane P-type ATPase. Biochim. Biophys. Acta 1195, 81-88.

Arabidopsis Genome Initiative (2000). Analysis of the genome sequence of the flowering plant Arabidopsis thaliana. Nature 408, 796-815

Asai, T., Miura, S., Sibley, L. D., Okabayashi, H., Takeuchi, T. (1995). Biochemical and molecular characterization of nucleoside triphosphate hydrolase isozymes from the parasitic protozoan Toxoplasma gondii. J. Biol. Chem. 270, 11391-11397.

Assmann, S. M., Simoncini, L., Schroeder, J. I. (1985). Blue light activates electrogenic ion pumping in guard cell protoplasts of Vicia faba. Nature 318, 285287.

Auer, M., Scarborough, G. A., Kühlbrandt, W. (1998). Three-dimensional map of the plasma membrane H+-ATPase in the open conformation. Nature 392, 840-843

Axelsen, K. B., Palmgren, M. G. (1998). Evolution of Substrate Specificities in the P-Type ATPase Superfamily. J. Mol. Evol. 46, 84-101.

Barnard, J. P., Reynafarje, B., Pedersen, P. L. (1993). Glucose catabolism in African trypanosomes. Evidence that the terminal step is catalyzed by a pyruvate 
transporter capable of facilitating uptake of toxic analogs. J. Biol. Chem. 268, 36543661.

Barnard, J. P., Pedersen, P. L. (1994). Alteration of pyruvate metabolism in African trypanosomes during differentiation from bloodstream into insect forms. Arch. Biochem. Biophys. 313, 77-82.

Benchimol, M., De Souza, W., Vanderheyden, N., Zhong, L., Lu, H. G., Moreno, S. N., Docampo, R. (1998). Functional expression of a vacuolar-type H+-ATPase in the plasma membrane and intracellular vacuoles of Trypanosoma cruzi. Biochem. J. 332, 695-702.

Bermudes, D., Peck, K. R., Afifi, M. A., Beckers, C. J., Joiner, K. A. (1994). Tandemly repeated genes encode nucleoside triphosphate hydrolase isoforms secreted into the parasitophorous vacuole of Toxoplasma gondii. J. Biol. Chem. 269, 29252-29260.

Black, M. W., Boothroyd, J. C. (1998). Development of a stable episomal shuttle vector for Toxoplasma gondii. J. Biol. Chem. 273, 3972-3979.

Black, M., Seeber, F., Soldati, D., Kim, K., Boothroyd, J. C. (1995). Restriction enzyme-mediated integration elevates transformation frequency and enables cotransfection of Toxoplasma gondii. Mol. Biochem. Parasitoly 74, 55-63.

Bohne, W., Heesemann, J., Gross, U. (1993). Induction of bradyzoite-specific Toxoplasma gondii antigens in gamma interferon-treated mouse macrophages. Infect. Immun. 61, 1141-1145.

Bohne W, Heesemann J, Gross U. (1994). Reduced replication of Toxoplasma gondii is necessary for induction of bradyzoite-specific antigens: a possible role for nitric oxide in triggering stage conversion. Infect. Immun. 62, 1761-1767.

Bohne, W., Gross, U., Ferguson, D. J. P., Heesemann, J. (1995). Cloning and characterization of a bradyzoite-specifically expressed gene (hsp30/bag1) of Toxoplasma gondii, related to genes encoding small heat-shock proteins of plants. Mol. Microbiol. 16, 1221-1230.

Bohne, W., Parmley, S. F., Yang, S., Gross, U. (1996). Bradyzoite-specific genes. Curr. Top. Microbiol. Immun. 219, 81-91.

Bohne, W., Roos, D. S. (1997). Stage-specific expression of a selectable marker in Toxoplasma gondii permits selective inhibition of either tachyzoites or bradyzoites. Mol. Biochem. Parasitol. 88, 115-126. 
Bohne, W., Wirsing, A., Gross, U. (1997). Bradyzoite-specific gene expression in Toxoplasma gondii requires minimal genomic elements. Mol. Biochem. Parasitol. 85, 89-98.

Bohne, W., Hunter, C. A., White, M. W., Ferguson, D. J. P., Gross, U., Roos, D. S. (1998). Targeted disruption of the bradyzoite-specific gene Bag1 does not prevent tissue cyst formation in Toxoplasma gondii. Mol. Biochem. Parasitol. 92, 291-301.

Bohne, W., Holpert, M., Gross, U. (1999). Stage Differentiation of the Protozoan Parasite Toxoplasma Gondii. Immunobiology 201, 248-254.

Boothroyd, J. C., Black, M., Bonnefoy, S., Hehl, A., Knoll, L. J., Manger, I. D., Ortega-Barria, E., Tomavo, S. (1997). Genetic and biochemical analysis of development in Toxoplasma gondii. Philos. Trans. R. Soc. London Scr. B 352, 1347-1354.

Boothroyd, J. C., Hehl, A., Knoll, L. J., Manger, I. D. (1998). The surface of Toxoplasma: more and less. Int. J. Parasitol. 28, 3-9.

Bouchot, A., Zierold, K., Bonhomme, A., Kilian, L., Belloni, A., Balossier, G., Pinon, J. M., Bonhomme, P. (1999). Tachyzoite calcium changes during cell invasion by Toxoplasma gondii. Parasitol. Res. 85, 809-818.

Bouchot, A., Millot, J. M., Charpentier, S., Bonhomme, A., Villena, I., Aubert, D., Pinon, J. M. (2001). Membrane potential changes after infection of monocytes by Toxoplasma gondii. Int. J. Parasitol. 31, 1114-1120.

Boutry, M., Michelet, B., Goffeau, A. (1989). Molecular cloning of a family of plant genes encoding a protein homologous to plasma membrane $\mathrm{H}^{+}$-translocating ATPases. Biochem. Res. Commun. 162, 567-574.

Brecht, S., Erdhart, H., Soete, M., Soldati, D. (1999). Genome engineering of Toxoplasma gondii using the site-specific recombinase Cre. Gene 234, 239-247.

Burghoorn, H. P., Soteropoulos, P., Paderu, P., Kashiwazaki, R., Perlin, D. S. (2002). Molecular Evaluation of the Plasma Membrane Proton Pump from Aspergillus fumigatus. Antimicrob. Agents Chemother. 46, 615-624.

Busa, W. B., Nuccitelli, R. (1984). Metabolic regulation via intracellular pH. Am. J. Physiol. 246, R409-438.

Carlton, J. M., Angiuoli, S. V., Suh, B. B., Kooij, T. W., Pertea, M., Silva, J. C., Ermolaeva, M. D., Allen, J. E., Selengut, J. D., Koo, H. L., Peterson, J. D., Pop, M., Kosack, D. S., Shumway, M. F., Bidwell, S. L., Shallom, S. J., van Aken, S. E., Riedmuller, S. B., Feldblyum, T. V., Cho, J. K., Quackenbush, J., Sedegah, 
M., Shoaibi, A., Cummings, L. M., Florens, L., Yates, J. R., Raine, J. D., Sinden, R. E., Harris, M. A., Cunningham, D. A., Preiser, P. R., Bergman, L. W., Vaidya, A. B., van Lin, L. H., Janse, C. J., Waters, A. P., Smith, H. O., White, O. R., Salzberg, S. L., Venter, J. C., Fraser, C. M., Hoffman, S. L., Gardner, M. J., Carucci, D. J. (2002). Genome sequence and comparative analysis of the model rodent malaria parasite Plasmodium yoelii yoelii. Nature 419, 512-519.

Carruthers, V. B., Sibley, L. D. (1999). Mobilization of intracellular calcium stimulates microneme discharge in Toxoplasma gondii. Mol. Microbiol. 31, 421-428.

Chang, A., Fink, G. R. (1995). Targeting of the yeast plasma membrane [H+]ATPase: a novel gene AST1 prevents mislocalization of mutant ATPase to the vacuole. J. Cell. Biol. 128, 39-49.

Clarke, D. M., Loo, T. W., Inesi, G., MacLennan, D. H. (1989). Location of high affinity $\mathrm{Ca2+-binding} \mathrm{sites} \mathrm{within} \mathrm{the} \mathrm{predicted} \mathrm{transmembrane} \mathrm{domain} \mathrm{of} \mathrm{the}$ sarcoplasmic reticulum Ca2+-ATPase. Nature 339, 476-478.

Cleary, M. D., Singh, U., Blader, I. J., Brewer, J.L., Boothroyd, J.C. (2002). Toxoplasma gondii asexual development: identification of developmentally regulated genes and distinct patterns of gene expression. Eukaryot. Cell. 1, 329340.

Cornelissen, A.W., Overdulve, J.P., Hoenderboom, J.M. (1981). Separation of Isospora (Toxoplasma) gondii cysts and cystozoites from mouse brain tissue by continuous density-gradient centrifugation. Parasitology 83, 103-108.

Dambly, S., Boutry, M. (2000). The two major plant plasma membrane $\mathrm{H}^{+}$-ATPases display different regulatory properties. J. Biol. Chem. 276, 7017-7022.

Dando, C., Schroeder, E. R., Hunsaker, L. A., Deck, L. M., Royer, R. E., Zhou, X., Parmley, D. F., Vander Jagt, D. L. (2001). The kinetic properties and sensitivities to inhibitors of lactate dehydrogenases (LDH1 and LDH2) from Toxoplasma gondii: comparisons with pLDH from Plasmodium falciparum. Mol. Biochem. Parasitol. 118, 23-32.

Dardé, M. L., Bouteille, B., Pestre-Alexander, M. (1992). Isoenzyme analysis of 35 Toxoplasma gondii isolates: biological and epidemiological implications. J. Parasitol. 78, 786-794.

Dendouga, N., Callebaut, I., Tomavo, S. (2002). A novel DNA repair enzyme containing RNA recognition, G-patch and specific splicing factor 45-like motifs in the protozoan parasite Toxoplasma gondii. 
Denton, H., Roberts, C. W., Alexander, J., Thong, K.-W., Coombs, G. H. (1996). Enzymes of energy metabolism in the bradyzoites and tachyzoites of Toxoplasma gondii. FEMS Microbiol. Lett. 137, 103-108.

Dobrowolski, J. M., Sibley, L. D. (1996). Toxoplasma invasion of mammalian cells is powered by the actin cytoskeleton of the parasite. Cell 84, 933-939.

Donald, R. G. K., Roos, D. S. (1993). Stable molecular tranformation of Toxoplasma gondii: a selectable dihydrofolate reductase-thymidylate synthase marker based on drug-resistance mutations in malaria. Proc. Natl. Acad. Sci. USA 90, 11703-11707.

Donald, R. G. K., Roos, D. S. (1994). Homologous recombination and gene replacement at the dihydrofolate reductase-thymidylate synthase locus in Toxoplasma gondii. . Mol. Biochem. Parasitol. 63, 243-253.

Donald, R. G. K., Roos, D. S. (1995). Insertional mutagenesis and marker rescue in a protozoan parasite: Cloning of the uracil phosphoribosyl transferase locus from Toxoplasma gondii. Proc. Natl. Acad. Sci. USA 92, 5749-53.

Donald, R. G. K., Carter, D., Ullman, B., Roos, D. S. (1996). Insertional tagging, cloning and expression of the Toxoplasma gondii hypoxanthine-xanthine-guanine phosphoribosyltransferase gene. J. Biol. Chem. 271, 14010-14019.

Donald, R. G. K., Roos, D. S. (1998). Gene knock-outs and allelic replacements in Toxoplasma gondii: HXGPRT as a selectable marker for hit-and-run mutagenesis. Mol. Biochem. Parasitol. 91, 295-305.

Drozdowicz, Y.M., Shaw, M., Nishi, M., Striepen, B., Liwinski, H.A., Roos, D.S., Rea, P.A. (2003). Isolation and characterization of TgVP1, a type I vacuolar $\mathrm{H+-}$ translocating pyrophosphatase from Toxoplasma gondii. THE DYNAMICS OF ITS SUBCELLULAR LOCALIZATION AND THE CELLULAR EFFECTS OF A DIPHOSPHONATE INHIBITOR. J. Biol. Chem. 10, 1075-1085.

Dubey, J. P., Peattie, C. P. (1988). Toxoplasmosis of animal and man. CRC Press, Boca Raton, USA.

Dubey, J. P. (1997). Bradyzoite-induced murine toxoplasmosis: stage conversion, pathogenesis, and tissue cyst formation in mice fed bradyzoites of different strains of Toxoplasma gondii. J. Euk. Microbiol. 44, 592-602.

Dubey, J. P., Lindsay, D. S., Speer, C. A. (1998). Structures of Toxoplasma gondii tachyzoites, bradyzoites, and sporozoites and biology and development of tissue cysts. Clin. Microbiol. Rev. 11, 267-299. 
Dubremetz, J. F., Garcia-Réguet, N., Conseil, V., Fourmaux, M. N. (1998). Apical organelles and host-cell invasion by Apicomplexa. Int. J. Parasitol. 28, 1007-1013.

Dzierszinski, F., Popescu, O., Toursel, C., Slomianny, C., Yahiaoui, B., Tomavo, S. (1999). The Protozoan Parasite Toxoplasma gondii Expresses Two Plant-like Glycolytic Enzymes. J. Biol. Chem. 35, 24888-24895.

Dzierszinski, F., Mortuaire, M., Dendouga, N., Popescu, O., Tomavo, S. (2001). Differential Expression of Two Plant-like Enolases with Distinct Enzymatic and Antigenic Properties during Stage Conversion of the Protozoan Parasite Toxoplasma gondii. J. Mol. Biol. 309, 1017-1027.

Elliott, J. L., Saliba, K. J., Kirk, K. (2001). Transport of lactate and pyruvate in the intraerythrocytic malaria parasite, Plasmodium falciparum. Biochem J. 355, 733739.

Epel, D., Dube, F. (1987). in: Control of Animal Cell Proliferation Vol 2 (eds Boynton, A. L. \& Leffert, H. L.) Academic Press New York, 363-393.

Eraso, P., Gancedo, C. (1987). Activation of yeast plasma membrane ATPase by acid $\mathrm{pH}$ during growth. FEBS Lett. 224, 187-192.

Fedorova, E., Thomson, R., Whitehead, L. F., Maudoux, O., Udvardi, M. K., Day, D. A. (1999). Localization of $\mathrm{H}^{+}$-ATPases in soybean root nodules. Planta 209, 2532.

Ferguson, D. J. P., Hutchison, W. M. (1987). An ultrastructural study of the early development and tissue cyst formation of Toxoplasma gondii in the brains of mice. Parasitol. Res. 73, 483-491.

Ferguson, D. J. P., Hutchison, W. M. (1989). Tissue cyst rupture in mice chronically infected with T. gondii. Parasitol. Res. 75, 599-603.

Ferguson, D. J. P., Cesbron-Delauw, M. F., Dubremetz, J. F., Sibley, L. D., Joiner, K. A., Wright, S. (1999). The Expression and Distribution of Dense Granule Proteins in the Enteric (Coccidian) Forms of Toxoplasma gondii in the Small Intestine of the Cat. Exp. Parasitol. 91, 203-211.

Ferguson, D. J. P., Parmley, S. E., Tomavo, S. (2002). Evidence for nuclear localisation of two stage-specific isoenzymes of enolase in Toxoplasma gondii correlates with acive parasite replication. Int. J. Parasitol. 32, 1399-1410.

Fichera, M. E., Roos, D. S. (1997). A plastid organelle as a drug target in apicomplexan parasites. Nature 390, 407-9. 
Finbow, M. E., Harrison, M. A. (1997). The vacuolar $\mathrm{H}^{+}$-ATPase: a universal proton pump of eukaryotes. Biochem. J. 324, 697-712.

Fourmaux, M. N., Achbarou, A., Mercereau-Puijalon, O., Biderre, C., Briche, I., Loyens, A., Odberg-Ferragut, C., Camus, D., Dubremetz, J. F. (1996). The MIC1 microneme protein of Toxoplasma gondii contains a duplicated receptor-like domain and binds to host cell surface. Mol. Biochem. Parasitol. 83, 201-210.

Fox, B. A., Belperron, A. A., Bzik, D. J. (1999). Stable transformation of Toxoplasma gondii based on a pyrimethamine resistant trifunctional dihydrofolate reductase- cytosine deaminase- thymidylate synthase gene that confers sensitivity to 5-fluorocytosine. Mol. Biochem. Parasitol. 98, 93-103.

Fraser-L'Hostis, C., Defrise-Quertain, F., Coral, D., Deshusses, J. (1997). Regulation of the intracellular $\mathrm{pH}$ in the protozoan parasite Trypanosoma brucei brucei. Biol. Chem. 378, 1039-1046.

Frenkel, J. K., Dubey, J. P., Miller, N. L. (1970). Toxoplasma gondii in cats: fecal stages identified as coccidian oocysts. Science 167, 893- 896.

Frenkel, J. K. \& Escajadillo, A. (1987). Cyst rupture as a pathogenic mechanism of toxoplasmic encephalitis. Am. J. Trop. Hyg. 36, 517-522.

Frenkel, J. K. (1988). Pathophysiology of toxoplasmosis. Parasitol. Today 4, 273278.

Freyre, A., Dobey, J. P., Smith, D. D., Frenkel, J. K. (1989). Oocyst-induced Toxoplasma gondii infection in cats. J. Parasitol. 75, 750-755.

Gardner, M. J., Hall, N., Fung, E., White, O., Berriman, M., Hyman, R. W., Carlton, J. M., Pain, A., Nelson, K. E., Bowman, S., Paulsen, I. T., James, K., Eisen, J. A., Rutherford, K., Salzberg, S. L., Craig, A., Kyes, S., Chan, M. S., Nene, V., Shallom, S. J., Suh, B., Peterson, J., Angiuoli, S., Pertea, M., Allen, J., Selengut, J., Haft, D., Mather, M. W., Vaidya, A. B., Martin, D. M., Fairlamb, A. H., Fraunholz, M. J., Roos, D. S., Ralph, S. A., McFadden, G. I., Cummings, L. M., Subramanian, G. M., Mungall, C., Venter, J. C., Carucci, D. J., Hoffman, S. L., Newbold, C., Davis, R. W., Fraser, C. M., Barrell, B. (2002). Genome sequence of the human malaria parasite Plasmodium falciparum. Nature 419, 498511.

Ginsburg, H. (2002). Abundant proton pumping in Plasmodium falciparum, but why?. TRENDS Parasitol. 18, 483-486. 
Glaser, T. A., Mukkada, A. J. (1992). Proline transport in Leishmania donovani amastigotes: dependence on $\mathrm{pH}$ gradients and membrane potential. Mol. Biochem. Parasitol. 51, 1-8.

Glaser, T. A., Utz, G. L., Mukkada, A. J. (1992). The plasma membrane electrical gradient (membrane potential) in Leishmania donovani promastigotes and amastigotes. Mol. Biochem. Parasitol. 51, 9-16.

Gleeson, M. T. (2000). The plastid in Apicomplexa: what use is it?. Int. J. Parasitol. 30, 1053-1070.

Goossens, A., De La Fuente, N., Forment, J., Serrano, R., Portillo, F. (2000). Regulation of Yeast $\mathrm{H}^{+}$-ATPase by Protein Kinases Belonging to a Family Dedicated to Activation of Plasma Membrane Transporters. Mol. Cell. Biol. 20, 7654-7661.

Grigg, M. E., Bonnefoy, S., Hehl, A. B., Suzuki, Y., Boothroyd, J. C. (2001). Success and virulence in Toxoplasma as the result of sexual recombination between two distinct ancestries. Science 294, 161-165.

Grimwood, J., Smith, J. E. (1996). Toxoplasma gondii: the role of parasite surface and secreted proteins in host cell invasion. Int. J. Parasitol. 26, 169-173.

Groß, U. (1994). Toxoplasmose. Immunologische und molekulare Parasitologie. M. Röllinghoff, M. Rommel. Jena, Gustav Fischer Verlag, 83-103.

Gross, U., Bohne, W. (1994). Toxoplasma gondii: Strain- and Host Cell-Dependent Induction of Stage Differentiation. J. Euk. Microbiol. 41, 10S-11S.

Gross, U., Bohne, W., Lüder, C. G. K., Lugert, R., Seeber, F., Dittrich, C., Pohl, F., Ferguson, D. J. P. (1996). Regulation of developmental differentiation in the protozoan parasite Toxoplasma gondii. J. Euk. Microbiol. 43, 114S-116S.

Hart, D. T., Coombs, G. H. (1982). Leishmania mexicana: energy metabolism of amastigotes and promastigotes. Exp. Parasitol. 54, 397-409.

Harvey, W. R., Wieczorek, H. (1997). Animal plasma membrane energization by chemiosmotic H+ V-ATPases. J. Exp. Biol. 200, 203-216.

Hayashi, M., Yamada, H., Mitamura, T., Horii, T., Yamamoto, A., Moriyama, Y. (2000). Vacuolar $\mathrm{H}(+)$-ATPase localized in plasma membranes of malaria parasite cells, Plasmodium falciparum, is involved in regional acidification of parasitized erythrocytes. J. Biol. Chem. 275, 34353-34358. 
Hehl, A., Manger, I. D., Boothroyd, J. C. (1997a). Genetic analysis in Toxoplasma: Gene discovery with expressed sequence tags and rapid mapping of natural polymorphisms. Meth. Enz. 13, 89-102.

Hehl, A., Krieger, T., Boothroyd, J. C. (1997b). Identification and charaterization of SRS1, a Toxoplasma gondii surface antigen upstream and related to SAG1. Mol. Biochem. Parasitol. 89, 271-282.

Higuchi, R., Dollinger, G., Walsh, P. S., Griffith, R. (1992). Simultaneous amplification and detection of specific DNA sequences. Biotechnology (N Y) 10, 413-417.

Holpert, M., Luder, C. G., Gross, U., Bohne, W. (2001). Bradyzoite-specific expression of a P-type ATPase in Toxoplasma gondii. Mol. Biochem. Parasitol. 112, 293- 296.

Howe, D., Sibley, L. D. (1995). Toxoplasma gondii comprises three clonal lineages: correlation of parasite genotype with human disease. J. Infect. Dis. 172, 1561-1566.

http://www.ch.embnet.org/software/TMPRED_form.html

\section{http://paradb.cis.upenn.edu/toxo1/index.html}

Hu, K., Roos, D. S., Murray, J. M. (2002). A novel polymer of tubulin forms the conoid of Toxoplasma gondii. J. Cell Biol. 156, 1039-1050.

Jacobs, L., Remington, J. S., Melton, M. L. (1957). The resistance of the encysted form of Toxoplasma gondii. J. Parasitol. 46, 11-21.

Joiner, K. A., Fuhrman, S. A., Miettinen, H. M., Kasper, L. H., Mellman, I. (1990). Toxoplasma gondii: Fusion incompetence of parasitophorous vacuoles in Fc receptor-transfected fibroblasts. Science 249, 641-646.

Joiner, K. A., Dubremetz, J. F. (1993). Toxoplasma gondii: a protozoan for the nineties. Infect. Immun. 61, 1169-1172.

Kasper, L. H., Crabb, J. H., Pfefferkorn, E. R. (1983). Purification of a major membrane protein of Toxoplasma gondii by immunoabsorption with a monoclonal antibody. Immunol. 130, 2407-2412.

Kasper, L. H., Bradley, M. S., Pfefferkorn, E. R. (1984). Identification of stagespecific sporozoite antigens of Toxoplasma gondii by monoclonal antibodies. J. Immun. 132, 443-449.

Kasper, L. H. (1987). Isolation and characterization of a monoclonal anti-P30 antibody resistant mutant of Toxoplasma gondii. Parasite Immunol. 9, 433-445. 
Kasper, L. H. (1989). Identification of stage-specific antigens of Toxoplasma gondii. Infect. Immun. 57, 668-672.

Kim, K., Soldati, D., Boothroyd, J. C. (1993). Gene Replacement in Toxoplasma gondii with Chloramphenicol Acetyltransferase as Selectable Marker. Science 262, 911-914.

Kim, K., Boothroyd, J. C. (1995). Toxoplasma gondii: Stable Complementation of sag1 (p30) Mutants Using SAG1 Transfection and Fluorescence-Activated Cell Sorting. Exp. Parasitol. 80, 46-53.

Kirkman, L. A., Weiss, L. M., Kim, K. (2001). Cyclic Nucleotide Signaling in Toxoplasma gondii Bradyzoite Differentiation. Infect. Immun. 69, 148-153.

Knoll, L. J., Boothroyd, J. C. (1998a). Isolation of developmentally regulated genes from Toxoplasma gondii by a gene trap with the positive and negative selectable marker hypoxanthine-xanthine-guanine phosphoribosyltransferase. Mol. Cell. Biol. $18,807-814$.

Knoll, L., J., Boothroyd, J. C. (1998b). Molecular biology's lessons about Toxoplasma development: stage-specific homologs. Parasitol. Today 14, 490-493.

Kohler, S., Delwiche, C. F., Denny, P. W., Tilney, L. G., Webster, P., Wilson, R. J., Palmer, J. D., Roos, D. S. (1997). A plastid of probable green algal origin in Apicomplexan parasites. Science 275, 1485-1489.

Koyama, T., Ohsawa, T., Shimada, S., Omata, Y., Xuan, X., Inoue, N., Maeda, R., Mikami, T., Saito, A. (2001). A 14-3-3 protein homologue is expressed in feline enteroepithelial-stages of Toxoplasma gondii. Vet. Parasitol. 96, 65-75.

Krassner, S. M., Flory, B. (1972). Proline metabolism in Leishmania donovani promastigotes. J. Protozool. 19, 682-685.

Krishna, S., Cowan, G., Meade, J. C., Wells, R. A., Stringer, J. R., Robson, K. J. (1993). A Family of Cation ATPase-like Molecules from Plasmodium falciparum. J. Cell Biol. 120, 385-398.

Krishna, S., Webb, R., Woodrow, C. (2001). Transport proteins of Plasmodium falciparum: defining the limits of metabolism. Int. J. Parasitol. 31, 1331-1342.

Kühlbrandt, W., Auer, M., Scarborough, G. A. (1998). Structure of the P-type ATPases. Curr. Opin. Struct. Biol. 8, 510-516.

Kyhse-Andersen (1984). Electroblotting of multiple gels: a simple apparatus without buffer tank for rapid transfer of proteins from polyacrylamide to nitrocellulose. J. Biochem. Biophys. Methods 10, 203-209. 
Laemmli, U. K. (1970). Cleavage of structural proteins during the assembly of the head of bacteriophage T4. Nature 227, 680-685.

Lauer, S. A., Rathod, P. K., Ghori, N., Haldar, K. (1997). A Membrane Network for Nutrient Import in Red Cells Infected with the Malaria Parasite. Science 276, 11221125.

Lekutis, C., Ferguson, D.J., Boothroyd, J.C. (2000). Toxoplasma gondii: identification of a developmentally regulated family of genes related to SAG2. Exp. Parasitol. 96, 89-96.

Lemercier, G., Dutoya, S., Luo, S., Ruiz, F. A., Rodrigues, C. O., Baltz, T., Docampo, R., Bakalara, N. (2002). A vacuolar-type H+-pyrophosphatase governs maintenance of functional acidocalcisomes and growth of the insect and mammalian forms of Trypanosoma brucei. J. Biol. Chem. 277, 37369-37376.

Lindquist, S., Craig, E. A. (1988). The heat-shock proteins. Ann. Rev. Genet. 22, 631-677.

Lindsay, D. S., Dubey, J. P., Blagburn, B. L., Toivio-Kinnucan, M. (1991). Examination of tissue cyst formation by Toxoplasma gondii in cell cultures using bradyzoites, tachyzoites, and sporozoites. J. Parasitol. 77, 126-132.

Liveanu, V., Webster, P., Zilberstein, D. (1991). Localization of the plasma membrane and mitochondrial $\mathrm{H}+$.ATPases in Leishmania donovani promastigotes. Europ. J. Cell Biol. 54, 95-101.

Lodish, H., Berk, A., Zipursky, S. L., Matsudaira, P., Baltimore, D., Darnell, J. E. (2000). Molecular Cell Biology. 4th ed. New York: W H Freeman \& Co.

Lourenco, E. V., Pereira, S. R., Faca, V. M., Coelho-Castelo, A. A., Mineo, J. R., Roque-Barreira, M. C., Greene, L. J., Panunto-Castelo, A. (2001). Toxoplasma gondii micronemal protein MIC1 is a lactose-binding lectin. Glycobiology 11, 541-7.

Lowry, O., Rosebrough, N., Farr, A., Randall, R. (1951). Protein measurement with the Folin phenol reagent. J. Biol. Chem 193, 265-275.

Luft, B. J., Remington, J. S. (1992). Toxoplasmic Encephatitis in AIDS. Clinical Infectious Diseases 15, 211-222.

Luft, B. J., Hafner, R., Korzun, A. H., Leport, C., Antoniskis, D. (1993). Toxoplasmic encephalitis in patiens with the acquired immunodeficiency. N. Engl. J. Med. 329, 995-1000.

Lunde, M. N., Jacobs, L. (1983). Antigenic differences between endozoites and cystozoites of Toxoplasma gondii. J. Parasitol. 69, 806-808. 
Luo, H., Morsomme, P., Boutry, M. (1999). The two major types of plant plasma membrane H+-ATPases show different enzymatic properties and confer differential $\mathrm{pH}$ sensitivity of yeast growth. Plant Physiol 119, 627-634.

Luo, S., Vieira, M., Graves, J., Zhong, L., Moreno, S. N. J. (2001). A plasma membrane-type $\mathrm{Ca}^{2+}$-ATPase co-localizes with a vacuolar $\mathrm{H}^{+}$-pyrophosphatase to acidocalcisomes of Toxoplasma gondii. EMBO J. 20, 55-64.

Luo, S., Scott, D. A., Docampo, R. (2002). Trypanosoma cruzi H+-ATPase 1 (TcHA1) and 2 (TcHA2) genes complement yeast mutants defective in $\mathrm{H}+$ pumps and encode plasma membrane P-type H+-ATPases with different enzymatic properties. J Biol Chem. 277, 44497-44506.

Lutsenko, S., Kaplan, J. H. (1995). Organization of P-Type ATPases: Significance of Structural Diversity. Biochem. 34, 15607-15613.

Manger, I. D., Hehl, A. B., Boothroyd, J. C. (1998a). The surface of Toxoplasma tachyzoites is dominated by a family of glycosylphosphatidylinositol-anchored antigens related to SAG1. Infect. Immun. 66, 2237-2244.

Manger, I. D., Hehl, A., Parmley, S., Sibley, L. D., Marra, M., Hillier, L., Waterson, R., Boothroyd, J. C. (1998b). Expressed sequence tag analysis of the bradyzoite stage of Toxoplasma gondii: identification of developmentally regulated genes. Infect. Immun. 66, 1632-1637.

Marchesini, N., Docampo, R. (2002). A plasma membrane P-type $\mathrm{H}^{+}$-ATPase regulates intracellular $\mathrm{pH}$ in Leishmania mexicana amazonensis. Mol. Biochem. Parasitol. 119, 225-236.

Matrajt, M., Donald, R. G., Singh, U., Roos, D. S. (2002a). Identification and characterization of differentiation mutants in the protozoan parasite Toxoplasma gondii. Mol. Microbiol. 44, 735-747.

Matrajt, M., Nishi, M., Fraunholz, M. J., Peter, O., Roos, D. S. (2002b). Aminoterminal control of transgenic protein expression levels in Toxoplasma gondii. Mol. Biochem. Parasitol. 120, 285-289.

Maudoux, O., Batoko, H., Oecking, C., Gevaert, K., Vandekerckove, J., Boutry, M., Morsomme, P. (2000). A Plant Plasma Membrane $\mathrm{H}^{+}$-ATPase Expressed in Yeast Is Activated by Phosphorylation at Its Penultimate Residue and Binding of 143-3 Regulatory Proteins in the Absence of Fusicoccin. J. Biol. Chem. 275, 1776217770. 
McDonough, A. A., Geering, K., Farley, R. A. (1990). The sodium pump needs its subunit. FASEB J. 4, 1598-1605.

McIntosh, M. T., Drozdowicz, Y. M., Laroiya, K., Rea, P. A., Vaidya, A. B. (2001). Two classes of plant-like vacuolar-type $\mathrm{H}(+)$-pyrophosphatases in malaria parasites. Mol Biochem Parasitol. 114, 183-195.

Meade, J. C., Shaw, J., Lemaster, S., Gallagher, G., Stringer, J. R. (1987). Structure and expression of a tandem gene pair in Leishmania donovani that encodes a protein structurally homologous to eucaryotic cation-transporting ATPases. Mol. Cell. Biol. 7, 3937-3946.

Meade, J. C., Hudson, K. M., Stringer, S. L., Stringer, J. R. (1989). A tandem pair of Leishmania donovani cation transporting ATPase genes encode isoforms that are differentially expressed. Mol. Biochem. Parasitol. 33, 81-91.

Meade, J. C., Coombs, G. H., Mottram, J. C., Steele, P. E., Stringer, J. R. (1991). Conservation of cation-transporting ATPase genes in Leishmania. Mol Biochem Parasitol. 45, 29-38.

Meade, J. C., Li, C., Stiles, J. K., Moate, M. E., Penny, J. I., Krishna, S., Finley, R. W. (2000). The Trypanosoma cruzi genome contains ion motive ATPase genes which closely resemble Leishmania proton pumps. Parasitol. Int. 49, 309-320.

Mercier, C., Hende, S. L.-V., Garber, G. E., Lecordier, L., Capron, A., CesbronDelauw, M.-F. (1996). Common cis-acting elements critical for the expression of several genes of Toxoplasma gondii. Mol. Microbiol. 21, 421-428.

Mercier, C., Dubremetz, J. F., Rauscher, B., Lecordier, L., Sibley, L. D., CesbronDelauw, M. F. (2002). Biogenesis of Nanotubular Network in Toxoplasma Parasitophorous Vacuole Induced by Parasite Proteins. Mol. Biol. Cell 13, 23972409.

Messina, M., Niesman, I., Mercier, C., Sibley, L.D. (1995). Stable DNA transformation of Toxoplasma gondii using phleomycin selection. Gene 165, 213217.

Michel, R., Schupp, K., Raether, W., Bierther, F. W. (1980). Formation of a close junction during invasion of erythrocytes by Toxoplasma gondii in vitro. Int. J. Parasitol. 10, 309-313.

Mineo, J. R., McLeod, R., Mack, D., Smith, J., Khan, I. A., Ely, K. H., Kasper, L. H. (1993). Antibodies to Toxoplasma gondii major surface protein (SAG-1, P30) inhibit 
infection of host cells and are produced in murine intestine after peroral infection. J. Immunol. 150, 3951-3964.

Monk, B. C., Mason, A. B., Abramochkin, G., Haber, J. E., Seto-Young, D., Perlin, D. S. (1995). The yeast plasma membrane proton pumping ATPase is a viable antifungal target. I. Effects of the cysteine-modifying reagent omeprazole. Biochim. Biophys. Acta 1239, 81-90.

Mordue, D.G., Desai, N., Dustin, M., Sibley, L.D. (1999). Invasion by Toxoplasma gondii establishes a moving junction that selectively excludes host cell plasma membrane proteins on the basis of their membrane anchoring. J. Exp. Med. 190, 1783-1792

Moreno, S. N. J., Zhong, L., Lu, H.-G., de Souza, W., Benchimol, M. (1998). Vacuolar-type $\mathrm{H}+$-ATPase regulates cytoplasmic $\mathrm{pH}$ in Toxoplasma gondii tachyzoites. Biochem. J. 330, 853-860.

Morsomme, P., Boutry, M. (2000). The plant plasma membrane $\mathrm{H}^{+}$ATPase: structure, function and regulation. Biochim. Biophys. Acta 1465, 1-16.

Morsomme, P., de Kerchove d'Exaerde, A., De Meester, S., Thines, D., Goffeau, A:, Boutry, M. (1996)., Single point mutations in various domains of a plant plasma membrane $\mathrm{H}^{+}$-ATPase expressed in Saccharomyces cerevisiae increase $\mathrm{H}^{+}$pumping and permit yeast growth at low pH. EMBO J. 15, 5513-5526.

Nagel, S. D., Boothroyd, J. C. (1988). The alpha- and beta-tubulins of Toxoplasma gondii are encoded by single copy genes containing multiple introns. Mol. Biochem. Parasitol. 29, 261-273.

Nakaar, V., Bermudes, D., Peck, K. R., Joiner, K. A. (1998). Upstream elements required for the expression of nucleoside triphosphate hydrolase genes of Toxoplasma gondii. Mol. Biochem. Parasitol. 92, 229-239.

Nakaar, V., Samuel, B. U., Ngo, E. O., Joiner, K. A. (1999). Targeted reduction of nucleotide triphosphate hydrolase by antisense RNA inhibits Toxoplasma gondii proliferation. J. Biol. Chem. 274, 5083-5087.

Nakaar, V., Ngo, E. O., Joiner, K. A. (2000). Selection based on the expression of antisense hypoxanthine-xanthine-guanine-phosphoribosyltransferase RNA in Toxoplasma gondii. Mol. Biochem. Parasitol. 110, 43-51.

Nasmyth, K. (1996). Viewpoint: putting the cell cycle in order. Science 274, 16431645. 
Nicolle, C., Manceaux, L. (1909). Sur un protozoaire nouveau du gondi. C. R. Hebd. Séances Acad. Sci. 148, 369-372.

Ober, S. S., Pardee, A. B. (1987). Intracellular pH is increased after transformation of Chinese hamster embryo fibroblasts. Proc. Natl. Acad. Sci. USA 84, 2766-2770.

Odaert, H., Soete, M., Fortier, B., Camus, D., Dubremetz, J. F. (1996). Stage conversion of Toxoplasma gondii in mouse brain during infection and immunodepression. Parasitol. Res. 82, 28-31.

Ödberg-Ferragut, C., Soete, M., Engels, A., Samyn, B., Loyens, A., Van Beeumen, J., Camus, D., Dubremetz, J.-F. (1996). Molecular cloning of the Toxoplasma gondii sag4 gene encoding an $18 \mathrm{kDa}$ specific surface protein. Mol. Biochem. Parasitol. 82, 237-244.

Ortega-Barria, E., Boothoyd, J. C. (1999). A Toxoplasma lectin-like activity specific for sulfated polysaccharides is involved in host cell infection. J. Biol. Chem. 274, 1267-1276.

Omata, Y., Igarashi, M., Ramos, M. I., Nakabayashi, T. (1989). Toxoplasma gondii: antigenic differences between endozoites and cystozoites defined by monoclonal antibodies. Parasitol. Res. 75, 189-193.

Oufattole, M., Arango, M., Boutry, M. (2000). Identification and expression of three new Nicotiana plumbaginifolia genes which encode isoforms of a plasmamembrane $\mathrm{H}^{+}$-ATPase, and one of which is induced by mechanical stress. Planta $10,715-722$.

Oyama, M., Kubota, K. (1997). $\mathrm{H}^{+}$secretion induced by hypertonic stress in the cellular slime mold Dictyostelium discoideum. J. Biochem. 122, 64-70.

Palmgren M. G., Christensen, G. (1993). Complementation in situ of the yeast plasma membrane $\mathrm{H}+$-ATPase gene pma1 by an $\mathrm{H}^{+}$-ATPase gene from a heterolgous species. FEBS 317, 216-222.

Palmgren, M. G. (1994). Why isoforms of the plant plasma membrane H+ATPase?. Symp. Soc. Exp. Biol. 48, 23-31.

Palmgren, M. G. (2001). Plant Plasma Membrane $\mathrm{H}^{+}-\mathrm{ATPases}$ : Powerhouses for Nutrient Uptake. Annu. Rev. Plant Mol. Biol. 52, 817-845.

Parets-Soler, A., Pardo, J. M., Serrano, R. (1990). Immunocytolocalization of plasma membrane $\mathrm{H}^{+}$-ATPase. Plant Physiol. 93, 1654-1658.

Parmley, S. F., Yang, S., Harth, G., Sibley, L. D., Sucharczuk, A., Remington, J. S. (1994). Molecular characterization of a 65-kilodalton Toxoplasma gondii antigen 
expressed abundantly in the matrix of tissue cysts. Mol. Biochem. Parasitol. 66, 283-296.

Parmley, S. F., Weiss, L. M., Yang, S. (1995). Cloning of a bradyzoite-specific gene of Toxoplasma gondii encoding a cytoplasmic antigen. Mol. Biochem. Parasitol. 73, 253-257.

Pavesio, C. E. N., Chiappino, M. L., Setzer, P. Y., Nichols, B. A. (1992). Toxoplasma gondii: differentiation and death of bradyzoites. Parasitol. Res. 78, 1-9.

Pedersen, P. L., Carafoli, E. (1987). Ion motive ATPases. I. Ubiquity, properties and significance to cell function. Trends Biochem. Sci. 12, 146-150.

Perlin, D. S., Harris, S. L., Seto-Young, D., Haber, J. E. (1989). Defective H(+)ATPase of hygromycin B-resistant pma1 mutants from Saccharomyces cerevisiae. J. Biol. Chem. 264, 21857-21864.

Perlin, D. S. (1998). Ion pumps as targets for therapeutic intervention: Old and new paradigms. Elect. J. Biotech. 1, 55-64.

Perona, R., Serrano, R. (1988). Increased $\mathrm{pH}$ and tumorigenicity of fibroblasts expressing a yeast pump. Nature $334,438-440$.

Pettersen, E. K. (1979). Destruction of Toxoplasma gondii by HC1 solution. Acta. Pathol. Microbiol. Scand. [B] 87, 217-220.

Pfefferkorn, E. R., Eckel, M., Rebhun, S. (1986). Interferon-gamma suppresses the growth of Toxoplasma gondii in human fibroblasts through starvation for tryptophan. Mol. Biochem. Parasitol. 20, 215-224.

Pfefferkorn, E. R., Borotz, S.E. (1994). Toxoplasma gondii: characterization of a mutant resistant to 6-thioxanthine. Exp. Parasitol. 79, 374-82.

Pintsch, T., Satre, M., Klein, G., Martin, J.-B., Schuster, S. C. (2001). Cytosolic acidification as a signal mediating hyperosmotic stress responses in Dictyostelium discoideum. BMC Cell Biol. 2(1):9.

Portillo. F. (2000). Regulation of plasma membrane $\mathrm{H}^{+}$-ATPase in fungi and plants. Biochim. Biophys. Acta 1469, 31-42.

Pouyssegur, J., Franchi, A., L'Allemain, G., Paris, S. (1985). Cytoplasmic pH, a key determinant of growth factor-induced DNA synthesis in quiescent fibroblasts. FEBS Lett. 190, 115-119.

Rao, R., Drummond-Barbosa, D., Slayman, C. W. (1993). Transcriptional regulation by glucose of the yeast PMA1 gene encoding the plasma membrane $\mathrm{H}(+)$-ATPase. Yeast 9, 1075-1084. 
Rayle, D. L., Cleland, R. E. (1992). The Acid Growth Theory of auxin-induced cell elongation is alive and well. Plant Physiol. 99, 1271-1274.

Remington, J. S., Desmonts, G. (1990). Toxoplasmosis. In: Remington, J. S. and J. O. Klein (eds.): Infectious diseases of the fetus and newborn infant. W. B. Saunders, Philadelphia, pp. 89-195.

Reoyo, E., Espeso, E. A., Penalva, M. A., Suárez, T. (1998). The Essential Aspergillus nidulans Gene pmaA Encodes an Homologue of Fungal Plasma Membrane $\mathrm{H}^{+}$-ATPases. Fung. Genet. Biol. 23, 288-299.

Roberts, F., Roberts, C. W., Johnson, J. J., Kyle, D. E., Krell, T., Coggins, J. R., Coombs, G.H., Milhous, W. K., Tzipori, S., Ferguson, D. J., Chakrabarti, D., McLeod, R. (1998). Evidence for the shikimate pathway in apicomplexan parasites. Nature 393, 801-805.

Rodrigues, C. O., Scott, D. A., Bailey, B. N., De Souza, W., Benchimol, M., Moreno, B., Urbina, J. A., Oldfield, E., Moreno, S. N. (2000). Vacuolar proton pyrophosphatase activity and pyrophosphate (PPi) in Toxoplasma gondii as possible chemotherapeutic targets. Biochem. J. 349, 737-745.

Rodrigues, C. O., Ruiz, F. A., Rohloff, P., Scott, D. A., Moreno, S. N. (2002). Characterization of isolated acidocalcisomes from Toxoplasma gondii tachyzoites reveals a novel pool of hydrolyzable polyphosphate. J. Biol. Chem. 277, 4865048656.

Roos, D. S., Donald, R. G. K., Morrissette, N. S., Moulton, A. L. C. (1994). Molecular tools for genetic dissection of the protozoan parasite Toxoplasma gondii. Methods Cell. Biol. 45, 27-63.

Roos, D. S., Sullivan, W. J., Striepen, B., Bohne, W., Donald, R. G. K. (1997). Tagging genes and trapping promoters in Toxoplasma gondii by instertional mutagenesis. Methods Enzym. 13, 112-122.

Roos, D. S., Crawford, M. J., Donald, R. G., Kissinger, J. C., Klimczak, L. J., Striepen, B. (1999). Origin, targeting, and function of the apicomplexan plastid. Curr. Opin. Microbiol. 2, 426-432.

Rozmajzl, P. J., Kimura, M., Woodrow, C. J., Krishna, S., Meade, J. C. (2001). Characterization of P-type ATPase 3 in Plasmodium falciparum. Mol. Biochem. Parasitol. 116, 117-126.

Saffer, L. D., Schwartman, J. D. (1991). A soluble phospholipase of Toxoplasma gondii associated with host cell penetration. J. Protozool. 38, 454-460. 
Saffer, L. D., Mercereau-Puijalon, O., Dubremetz, J. F., Schwartzman, J. D. (1992). Localization of a Toxoplasma gondii rhoptry protein by immunoelectron microscopy during and after host cell penetration. J. Protozool. 39, 526-30.

Saliba KJ, Kirk K. (1999). pH regulation in the intracellular malaria parasite, Plasmodium falciparum. $\mathrm{H}(+)$ extrusion via a v-type $\mathrm{h}(+)$-atpase. J. Biol. Chem. 274, 33213-33219.

Saliba, K. J., Kirk, K. (2001). H+-coupled pantothenate transport in the intracellular malaria parasite. J. Biol. Chem. 276, 18115-18121.

Saliba, K. J., Allen, R. J., Zissis, S., Bray, P. G., Ward, S. A., Kirk, K. (2003). Acidification of the malaria parasite's digestive vacuole by a $\mathrm{H}+-\mathrm{ATP}$ ase and a $\mathrm{H}+-$ pyrophosphatase. J. Biol. Chem. 278, 5605-5612.

Sambrook, J., Fritsch, E. F., Maniatis, T. (1989). Molecular Cloning. Cold Spring Harbor Laboratory Press, 1.40.

Sasono, P. M. D., Smith, J. E. (1998). Toxoplasma gondii: an ultrastructural study of host-cell invasion by the bradyzoite stage. Parasitol. Res. 84, 640-645.

Schwab, J. C., Beckers, C. J., Joiner, K. A. (1998). The parasitophorous vacuole membrane surrounding intracellular Toxoplasma gondii functions as a molecular sieve. Proc. Natl. Acad. Sci. USA 91, 509-513

Schwartzman, J. D., Pfefferkorn, E. R. (1982). Toxoplasma gondii: Purine synthesis and salvage in mutant host cells and parasites. Exp. Parasitol. 53, 77-86.

Seeber, F., Boothroyd, J. C. (1996). Escherichia coli beta-galactosidase as an in vitro and in vivo reporter enzyme and stable transfection marker in the intracellular protozoan parasite Toxoplasma gondii. Gene 169, 39-45.

Seeber, F. (1997). Consensus sequence of translational initiation sites from Toxoplasma gondii genes. Parasitol. Res. 83, 309-311.

Séron, K., Dzierszinski, F., Tomavo, S. (2000). Molecular cloning, functional complementation in Saccharomyces cerevisiae and enzymatic properties of phosphatidylinositol synthase from the protozoan parasite Toxoplasma gondii. Eur. J. Biochem. 267, 6571-6579.

Serrano, R., Kielland-Brandt, M. C., Fink, G. R. (1986). Yeast plasma membrane ATPase is essential for growth and has homology with $\left(\mathrm{Na}^{+}+\mathrm{K}^{+}\right), \mathrm{K}^{+}-$and $\mathrm{Ca}^{2+}-$ ATPases. Nature 319, 689-693.

Serrano, R. (1988). Structure and function of proton translocating ATPase in plasma membranes of plants and fungi. Biochim. Biophys. Acta 947, 1-28. 
Seyfang, A., Duszenko, M. (1991). Specificity of glucose transport in Trypanosoma brucei. Effective inhibition by phloretin and cytochalasin B. Eur. J. Biochem. 202, 191-196.

Sherman, I. W. (1979). Biochemistry of Plasmodium (malarial parasites). Microbiol. Rev. 43, 453-493.

Sibley, L. D., Weidner, E., Krahenbuhl, J. L. (1985). Phagosome acidification blocked by intracellular Toxoplasma gondii. Nature 315, 416-419.

Sibley, L. D., Boothroyd, J. C. (1992). Virulent strains of Toxoplasma gondii comprise a single clonal lineage. Nature 359, 82-85.

Sibley, L. D., Messina, M., Niesman, I. R. (1994). Stable DNA transformation in the obligate intracellular parasite Toxoplasma gondii by complementation of tryptophan auxotrophy. Proc. Natl. Acad. Sci. USA 91, 5508-5512.

Sibley, L. D., Howe, D. K. (1996). Genetic basis of pathogenicity in Toxoplasmosis. Curr. Top. Microbiol. Immun. 219, 3-15.

Silva, N. M., Gazzinelli, R. T., Silva, D. A., Ferro, E. A., Kasper, L. H., Mineo, J. R. (1998). Expression of Toxoplasma gondii-specific heat shock protein 70 during in vivo conversion of bradyzoites to tachyzoites. Infect. Immun. 66, 3959-3963.

Sinai, A. P., Webster, P., Joiner, K. A. (1997). Association of host cell endoplasmic reticulum and mitochondria with the Toxoplasma gondii parasitophorous vacuole membrane: a high affinity interaction. J. Cell. Sci. 110, 2117-2128.

Sinai, A. P., Joiner, K. A. (2001). The Toxoplasma gondii protein ROP2 mediates host organelle association with the parasitophorous vacuole membrane. J. Cell. Biol. 154, 95-108.

Singh ,U., Brewer, J. L., Boothroyd, J.C. (2002). Genetic analysis of tachyzoite to bradyzoite differentiation mutants in Toxoplasma gondii reveals a hierarchy of gene induction. Mol. Microbiol. 44, 721-733.

Smith, J. E. (1995). A Ubiquitous Intracellular Parasite: The Cellular Biology of Toxoplasma Gondii. Int. J. Parasitol. 25, 1301-1309.

Soete, M., Fortier, B., Camus, D., Dubremetz, J. F. (1993). Toxoplasma gondii: Kinetics of bradyzoite-tachyzoite interconversion in vitro. Exp. Parasitol. 76, 1-6.

Soete, M., Camus, D., Dubremetz, J. F. (1994). Experimental induction of bradyzoite - specific antigen expression and cyst formation by the RH strain of Toxoplasma gondii in vitro. Exp. Parasitol. 78, 361-370. 
Soldati, D., Boothroyd, J. C. (1993). Transient Transfection and Expression in the obligate intracellular parasite Toxoplasma gondii. Science 260, 349-352.

Soldati, D., Boothroyd, J. C. (1995). A selector of transcription initiation in the protozoan parasite Toxoplasma gondii. Mol. Cell. Biol. 15, 87-93.

Soldati, D., Kim, K., Kampmeier, J., Dubremetz, J.-F., Boothroyd, J. C. (1995). Complementation of a Toxoplasma gondii ROP1 knock-out mutant using phleomycin selection. Mol. Biochem. Parasitol. 74, 87-97.

Soteropoulos, P., Vaz, T., Santangelo, R., Paderu, P., Huang, D. Y., Tamás, M. J., Perlin, D. S. (2000). Molecular Characterization of the Plasma Membrane $\mathrm{H}^{+}$ATPase, an Antifungal Target in Cryptococcus neoformans. Antimicrob. Agents Chemother. 44, 2349-2355.

Spano, F., Ricci, I., Di Cristina, M., Possenti, A., Tinti, M., Dendouga, N., Tomavo, S., Crisanti, A. (2002). The SAG5 locus of Toxoplasma gondii encodes three novel proteins belonging to the SAG1 family of surface antigens. Int. J. Parasitol. 32, 121-131.

Speer, C. A., Tilley, M., Temple, M. E., Blixt, J. A., Dubey, J. P., White, M. W. (1995). Sporozoites of Toxoplasma gondii lack dense-granule protein GRA3 and form a unique parasitophorous vacuole. Mol Biochem Parasitol. 75, 75-86.

Striepen, B., He, C. Y., Matrajt, M., Soldati, D., Roos, D. S. (1998). Expression, selection, and organellar targeting of the green fluorescent protein in Toxoplasma gondii. Mol. Biochem. Parasitol. 92, 325-338.

Striepen, B., White, M. W., Li, C., Guerini, M. N., Malik, S. B., Logsdon Jr., J. M., Liu, C., Abrahamsen, M. S. (2002). Genetic complementation in apicomplexan parasites. Proc. Natl. Acad. Sci. USA 99, 6304-6309.

Subauste, C. S., Remington, J. S. (1991). Role of gamma interferon in Toxoplasma gondii infection. Eur. J. Clin. Microbiol. Infect. Dis. 10, 58-76.

Supply, P., Wach, A., Goffeau, A. (1993). Enzymatic properties of the PMA2 plasma membrane-bound $\mathrm{H}(+)$-ATPase of Saccharomyces cerevisiae. J. Biol. Chem. 268, 19753-19759.

Suss-Toby, E., Zimmerberg, J., Ward, G. E. (1996). Toxoplasma invasion: The parasitophorous vacuole is formed from host cell plasma membrane and pinches off via a fission pore. Proc. Natl. Acad. Sci. USA 93, 8413-8418.

Tenter, A. M., Heckeroth, A. R., Weiss, L. M. (2000). Toxoplasma gondii: from animals to humans. Int. J. Parasitol. 30, 1217-1258. 
Tomavo, S., Fortier, B., Soete, M., Ansel, C., Camus, D., Dubremetz, J. F. (1991). Characterization of bradyzoite-specific antigens of Toxoplasma gondii. Infect. Immun. 59, 3750-3753.

Tomavo, S., Boothroyd, J.C. (1995). Interconnection between organellar functions, development and drug resistance in the protozoan parasite, Toxoplasma gondii. Int. J. Parasitol. 25, 1293-1299.

Tomavo, S. (2001). The differential expression of multiple isoenzyme forms during stage conversion of Toxoplasma gondii: an adaptive developmental strategy. Int. J. Parasitol. 31, 1023-1031.

Torpier, G., Charif, H., Darcy, F., Liu, J., Darde, M.-L., Capron, A. (1993). Toxoplasma gondii: differential location of antigens secreted from encysted bradyzoites. Exp. Parasitol. 77, 13-22.

Toursel, C., Dzierszinski, F., Bernigaud, A., Mortuaire, M., Tomavo, S. (2000). Molecular cloning, organellar targeting and developmental expression of mitochondrial chaperone HSP60 in Toxoplasma gondii. Mol. Biochem. Parasitol. 111, 319-332.

Trottein, F., Cowman, A. F. (1995). Molecular cloning and sequence of two novel Ptype adenosinetriphosphatases from Plasmodium falciparum. Eur. J. Biochem. 227, 214-225.

Van Der Heyden, N., Docampo, R. (2000). Intracellular pH in mammalian stages of Trypanosoma cruzi is $\mathrm{K}+-$ dependent and regulated by $\mathrm{H}+-\mathrm{ATPases}$. Mol. Biochem. Parasitol. 105, 237-251.

Van Der Heyden, N., Wong, J., Docampo, R. (2000). A pyruvate-proton symport and an $\mathrm{H}+-$ ATPase regulate the intracellular $\mathrm{pH}$ of Trypanosoma brucei at different stages of its life cycle. Biochem. J. 346, 53-62.

Van der Heyden, N., Docampo, R. (2002a). Significant differences between procyclic and bloodstream forms of Trypanosoma brucei in the maintenance of their plasma membrane potential. J. Eukaryot. Microbiol. 49, 407-413.

Van Der Heyden, N., Docampo, R. (2002b). Proton and sodium pumps regulate the plasma membrane potential of different stages of Trypanosoma cruzi. Mol Biochem Parasitol. 120, 127-139.

Villalba, J. M., Palmgren, M. G., Berberian, G. E., Ferguson, C., Serrano, R. (1992). Functional expression of plant plasma membrane $\mathrm{H}+$-ATPase in yeast endoplasmic reticulum. J. Biol. Chem. 267, 12341-12349. 
Wach, A., Schlesser, A., Goffeau, A. (1992). An Alignment of 17 Deduced Protein Sequences from Plant, Fungi, and Ciliate $\mathrm{H}^{+}$-ATPase Genes. J. Bioenerg. Biomembr. 24, 309-317.

Waller, R. F., Keeling, P. J., Donald, R. G. K., Striepen, B., Handman, E., LangUnnasch, N., Cowman, A. F., Besra, G. S., Roos, D. S. (1998). Nuclear-encoded proteins target to the plastid in Toxoplasma gondii and Plasmodium falciparum. Proc. Natl. Acad. Sci. USA 95, 12352-12357.

Wan, K.-L., Blackwell, J. M., Ajioka, J. W. (1996). Toxoplasma gondii expressed sequence tags: insight into tachyzoite gene expression. Mol. Biochem. Parasitol. 75, 179-186.

Wan, K.-L., Carruthers, V. B., Sibley, L. D., Ajioka, J. W. (1997). Molecular characterization of an expressed sequence tag locus of Toxoplasma gondii encoding the micronemal protein MIC2. Mol. Biochem. Parasitol. 84, 203-214.

Weber, K., Pringle, J. R., Osborn, M. (1972). Measurement of molecular weights by electrophoresis on SDS-acrylamide gel. Methods Enzymol. 26, 3-27

Weiss, L. M., Laplace, D., Tanowitz, H. B., Wittner, M. (1992). Identification of Toxoplasma gondii bradyzoite-specific monoclonal antibodies. J. Infect. Dis. 166, 213-215.

Weiss, L. M., Laplace, D., Takvorian, P. M., Tanowitz, H. B., Cali, A., Wittner, M. (1995). A cell culture system for study of the development of Toxoplasma gondii bradyzoites. J. Eukaryot. Microbiol. 42, 150-157.

Weiss, L. M., Ma, Y. F., Takvorian, P. M., Tanowitz, H. B., Wittner, M. (1998). Badyzoite development in Toxoplasma gondii and the hsp70 stress response. Infect. Immun. 66, 3295-3302.

Weiss, L. M., Kim, K. (2000). The development and biology of bradyzoites of Toxoplasma gondii. Front. Biosci. 5, 391-405.

Wiemer, E. A., Ter Kuile, B. H., Michels, P. A., Opperdoes, F. R. (1992). Pyruvate transport across the plasma membrane of the bloodstream form of Trypanosoma brucei is mediated by a facilitated diffusion carrier. Biochem. Biophys. Res. Commun. 184, 1028-1034.

Yahiaoui, B., Dzierszinski, F., Bernigaud, A., Slomianny, C., Camus, D., Tomavo, S. (1999). Isolation and characterization of a subtractive library enriched for developmentally regulated transcripts expressed during encystation of Toxoplasma gondii. Mol. Biochem. Parasitol. 99, 223-235. 
Yan, F., Feuerle, R., Schaffer, S., Fortmeier, H., Schubert, S. (1998). Adaptation of active proton pumping and plasmalemma ATPase activity of corn roots to low root medium pH. Plant Physiol. 117, 311-319.

Yang, S., Parmley, S. F. (1995). A bradyzoite stage-specifically expressed gene of Toxoplasma gondii encodes a polypeptide homologous to lactate dehydrogenase. Mol. Biochem. Parasitol. 73, 291-294.

Yang, S., Parmley, S. F. (1997). Toxoplasma gondii expresses two distinct lactate dehydrogenase homologous genes during its life cycle in intermediate hosts. Gene 184, 1-12.

Young, J. C., DeWitt, N. D., Sussman, M. R. (1998). A transgene encoding a plasma membrane $\mathrm{H}+-\mathrm{ATPase}$ that confers acid resistance in Arabidopsis thaliana seedlings. Genetics 149, 501-507.

Zhang, P., Toyoshima, C., Yonekura, K., Green, N. M., Stokes, D. L. (1998). Structure of the calcium pump from sarcoplasmic reticulum at $8 \AA$ resolution. Nature 392, 835-839.

Zhang, Y. W., Kim, K., Ma, Y. F., Wittner, M., Tanowitz, H. B., Weiss, L. M. (1999). Disruption of the Toxoplasma gondii bradyzoite-specific gene BAG1 decreases in vivo cyst formation. Mol. Micobiol. 31, 691-701.

Zhang, Y. W., Halonen, S. K., Ma, Y. F., Wittner, M., Weiss, L. M. (2001). Initial Characterization of CST1, a Toxoplasma gondii Cyst Wall Glycoprotein. Infect. Immun. 69, 501-507.

Zhao, R., Dielen, V., Kinet, J. M., Boutry, M. (2000). Cosuppression of a plasma membrane $\mathrm{H}^{+}$ATPase isoform impairs sucrose translocation, stomatal opening, plant growth, and male fertility. Plant Cell 12, 535-546.

Zilberstein, D. (1993). Transport of nutrients and ions across membranes of trypanosomatid parasites. Adv Parasitol. 32, 261-291.

Zilberstein, D., Dwyer, D. M. (1998). Identification of a surface membrane protontranslocating ATPase in promastigotes of the parasitic protozoan Leishmania donovani. Biochem. J. 256, 13-21. 


\section{Anhang}

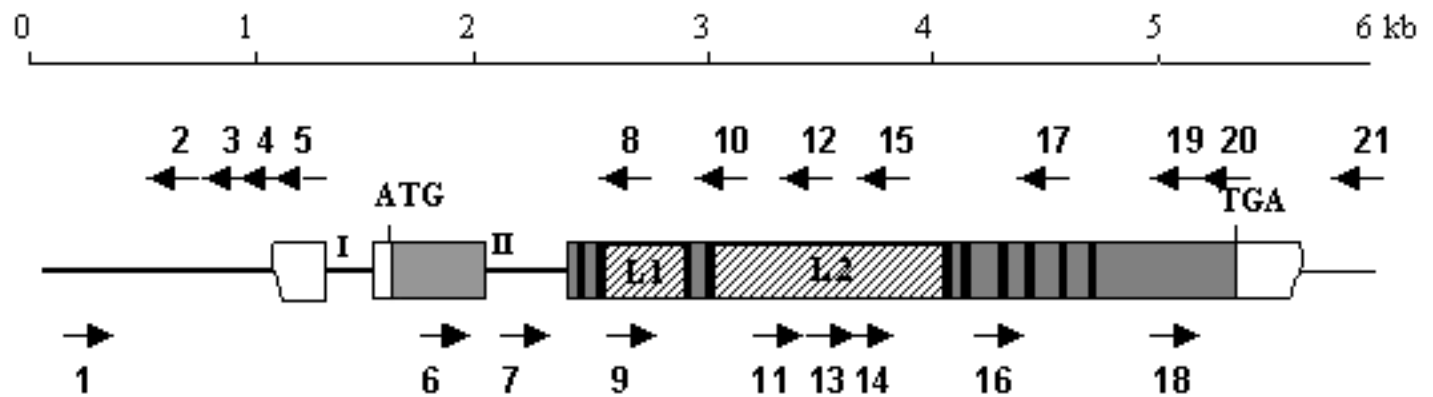
1: PMAI5'Apa/+
2: 9-21/-
3: PM1-5-2
4: $\mathrm{PMA} 1$ seq/+
5: 9-20/-
6: $\mathrm{P}-7 /+$
7: PM1-1008-Bam/+
8: 9-P12/-
9: $\mathrm{P}-13 /+$
10: PMAI5'Cla/-
11: PMAI3'/+

$12: 9-3 /-$

13: $9-2 /+$

14: PM1-1008-Bam/+

15: $\mathrm{P}-11 /-$

16: $9-15 /+$

17: PM1-1785-Kpn/-

18: PM1-2608-Bam/+

19: 9-P10/-

20: ATPase-3-Kpn/-

21: PMAI3'/-

Abb. 21. Schematische Darstellung der Primerbindungsstellen. Primer sind durch Pfeile dargestellt, die die Bindung in 5'-3' (Pfeil nach rechts), oder $3^{\prime}-5^{\prime}$ Richtung (Pfeil nach links) angeben. Für eine genauere Beschreibung der schematischen Darstellung des genomischen tgpma1-Lokus: s. Abb. 6. 


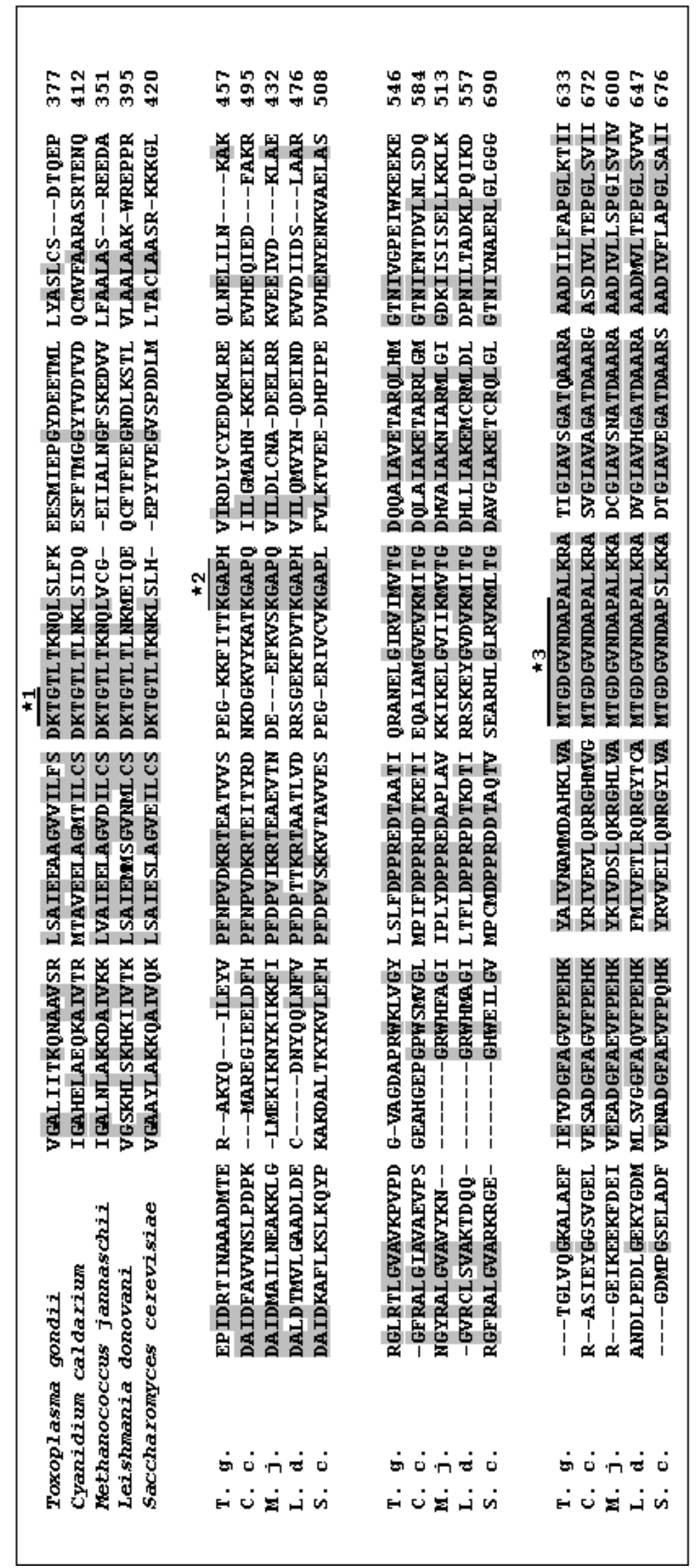

Abb. 22. Homologie-Vergleich von TgPMA1 mit PM- $\left(\mathrm{H}^{+}\right)-A T P a s e n$ anderer Spezies. Vergleich des großen cytoplasmatischen Loops von TgPMA1 mit homologen Genen aus Saccharomyces cerevisiae (accession \# g6321430), Cyanidium caldarium (accession \# 7436369), Leishmania donovani (accession \# 4585231) und Methanococcus jannaschii (accession \# g2127956). Überlagerungen wurden mit dem Programm ClustalW durchgeführt. Aminosäuren, die in mindestens vier Spezies identisch sind, wurden schattiert. P-typ ATPase-spezifische Motive wie die Phosphorylierungsstelle $\left({ }^{*} 1\right)$, die FITC-Bindungsstelle $\left({ }^{*} 2\right)$ und die ATP-Bindungsstelle $\left({ }^{*} 3\right)$ sind gekennzeichnet. 
1 TTCTCAGCCA ATGAGGACAC GACCGTTACG CAACTCGGCG GACACGTACT TCTGCAACTG 61 CACGgATGTA CAAATATGTT GCGATCCACG ACTCTATAGC TCAAATAgAA CATGCAgACA 121 CAgTGgCATA CCTCGATGAA TATCATACTA GTTTTGAGAT GTAAACCCAA TTCTTTGgCG 181 CTGCCGTACG ACACATCCCT ACCGGAGTGT TGAATCAGTA TAAGCGTGCT CGGCATCAGT 241 ATACACAGGC AACTTTGATT GgTGCAGCTT TAgCGTGTGC CGAATTTCCA CATTCATCAC 301 CCCGCGACGC ACTAGCATGC GCGTGGCCCA GCGTGGTGAA CCTGTTCTTA ATGTTTTCGC 361 CGATTCATCG CCCAATCGTT TCGACGAAGC AGCGGAACAG CTAAGCCGTG CTGATGCTCA 421 GgCGTCGTTT TAGTTCTTTC CTGTGGTTTG TCTTACTGCA TTATACTCTA AATGGTGTCA 481 GCGCCTGTCC CCTGCCGGCT GAGGTCCCCT AATAGGTGAC CTTCGAGTGC TCACTTTTAT 541 CCACGCGGTA GATTTCTTGG TAAAAGCACA GGCCTGGATC TTTTCCCCGG CGCAAGAATG 601 TGTGCGAAAG CAACATGgGt GgCACAGCTA TAGGAAGACC TTGTGACGCT GATCTTCTCA 661 ATCCCACGTC ACGAAAATAA CTTAAGGTAT CAATTAGCAC CTTTCCATAT CCGCTTGTCC 721 GCCACTTTTA TTGCTACCGA GGCCAACATT GATGAATTCG TAGATCCTGS ATCACTGCGC 781 GTTAAGGCGC CCGTGAACTT GgCACATAAA CGgATCCGAA GTGTTGCTGA CGCTATTTGA 841 ATTGTAGAAC GTAAATACAT CAACATTCCA CGCACACCAA CGAGCGATTT GCGTGGACCA 901 TTCACACCTC CGCATGCTCC CCAATTCAGA GAATGACTTC AATGCAAAGG AGCTGTTGCC 961 ACGCGTTCCT TCTACTGGTC CGACAACCAG CTGACCCTGT GCCTGTCTTG GCGCATTTCA 1021 AACGCCATGC TTACAGGCCA GCGAGGTAGA CGCGTCTCTG CAGTCCCGTG CGCCGGGAAC 1081 GTTTGCAGAC AGTGCGTGCG CGGGCGTGGC AATCAAGGAT GTCCACGGGT TTCCTGTGAT 1141 GGACTCGTGC ATGCTGCCTG TATGACAGTC GGCTTCGTTG TTGATAAGgG AAgCGTGAAG

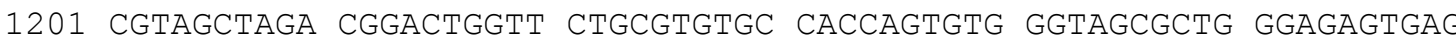
1261 TTTCTGATAA GCTGCACGgT AgAtACTGGC TCGAGTGTCT ATAAAGCGTC TTACCTGAAC 1321 TGTGGCACCA AgACCGCAGg CCGgAAACAA TGATGTGCGA CTCATGCCTT TTCATCTTCT 1381 ACGTCCGAAA CGTGTTTGA CCGCGATTCT ACCTTGATAA TCAGGACAgA tATGCCAGAA 1441 TTACTGCCAC AgGTAAgAtA ACAgATGTAT ACTGGCTGCG TCAATACTCC CGGCAATTGT

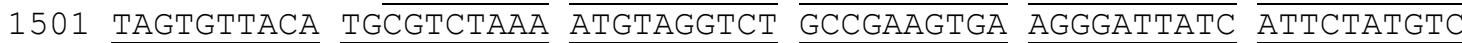
$1561 \overline{\text { TTGCATGGAT }} \overline{\text { TTCAAAAACT }} \overline{\text { TGCCCCTCCA }} \overline{\text { CTAGGTTGCA }} \overline{\text { ACTGCGGTGA }} \overline{\text { TTGCGGTTCG }}$ $1621 \overline{\text { TCCACTTAAT }} \overline{\text { TCTTATCCGC }} \overline{\text { CCTTGTGGGT }} \frac{\text { TGATGTGGTT }}{\text { TCCAGGCCGG }} \overline{\text { CTGGCTGATC }}$

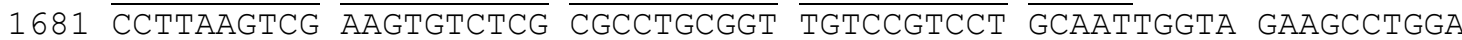
1741 ATtAgGgTtg ACCGTGAgAC TATCTTCCGA ATGTCGGCAC CTGCTTTGAA TACCGAGGCC 1801 GCCGACGCAA GAGTGCAGTA AATGTATAAG ACAGGTGCAA TCCTTGCGCT GCCTTACAGC 1861 TTCTGTGCTG CTGAAgTATg GCAACCGTCT CCAGTGAGAA GgGgGCACTT CTCCCCAAGA 1921 AAGCCAGCGG CCAGCTGCCG TCGTCCATCA CTGGGCGTCC TCGTTTTAAA AACACCACAC 1981 TGCAGCGGGA TGGAGCGCCT AACGCCGGAA CGCCGACCGA GCATTCATAT CAAAAACTCA 2041 CAACAGCAGG AGgCTCCATT GAATTGCATT CGgGTGCGAg TGTAAAgTCT GTAACAgGTA 2101 CTGGTCAAAA TGTGGTAGAT GGAACAGCTG GATTAACCTC TGGCGTGCAG CGgGTGCTTA 2161 GCAACGAGAA AgCAAGTGAA GGAgCTCACT CAAGCGAACG AgGCGCACGA GTGATGgACG 2221 AAGCGAGCAG AAGGGCAGCA GAACTCGAAG CAGCAGCAGA CAAGTTGGAG CAAACAGAGA 2281 CGGTAACCGT AAACTACGAC ACACGAGGCC TGACGTCGGA CCAAGTTGCG GACCTCAGAA 2341 AgAAATATGG CTGGAATGAA GTGAAGCCCC ACCAGGTACG TAGCTTGGTC GAGAGCGTGT 2401 AACCCATAAA GGGTTTTCTG ACCGTGCAGA GCACTGGGCT GCAGCGGAAG AATTCGTGAT 2461 AATGAGTTTA $\overline{\text { GGTATCTCGA }} \frac{\text { CTAAGACGCT }}{\text { CTGTATTGTT }} \frac{\text { ATCAAGCATG }}{\text { TGGCCTACAC }}$ $2521 \overline{\text { GCGTGTTCTC TAACATTCTA }}$ TAGGTGACGT $\overline{\text { GGCGAAACTC }} \overline{\text { GTCCCACTGC }} \overline{\text { GTCTCTACTC }}$ $2581 \overline{\text { AGCACAAAAC }} \overline{\text { TTCCCTGTTC }} \overline{\text { AAAATGTCGA }} \overline{\text { TGACGACCTA }} \overline{\text { AACATGCTAA }} \overline{\text { TTAAAAAAAA }}$ $2641 \overline{\text { TCCGGTTCAA }} \overline{\text { CTGTGGTGTG }} \overline{\text { TTGCCGATCT }} \overline{\text { TTTGTTATAT }} \overline{\text { ATGTGTACAC }} \overline{\text { ATGAACCACA }}$ $2701 \overline{\text { CCGCGTGCCA }} \overline{\text { CGACGAGCAG }} \frac{\text { TTGCCGCTAT }}{\text { TTCCAAAGTC }} \overline{\text { GTTTTTACAT }} \overline{\text { GTGACTGTAT }}$ 2761 CCGTGTGAGC $\overline{\text { AgGTGCCTGA }} \overline{\text { ATGGTTCAAA }} \overline{\text { GTGTTGAAGA }} \overline{\text { AATACCTCTC }} \overline{\text { CCTTGTGCCC }}$ 2821 ATGTTGTTGA TCGTCGCGGC TCTTTTCTCA GTCTGCGTGG TGGAGGACAA CATGCGCGAC 2881 TGGTTTTCTT TCGCTCTTCT TCTCTTTCTG AACAACTCAA TGGTCTGGGC CGATTATATT 2941 GgGCAgCGgt CCGCACATAA CGCCATtGCA GCTGTTGAgA AgTTGgGCGC CCCGgTGTGT 3001 CAgGtgAAgA GAGATGgACA GTGgCAgAAT CGACAgGTGC GCGATCTCGT GCCAGgAgAC 3061 GTTGTTCATC TTAAGGCGgG CGTGATCATG CCAGCTGACG GAGTGTTTGT GACCAAAGgG 3121 ACGACCATCA CTGTTGACGA ATCTGCTCTG ACAGGAGAAT CTGTGCCTAT CCGAAAGCGT 3181 CCGGGGGCGC CACTTCTCTC GGgGTCCGTG GTAGACAGGG GCGAGGGGGA AATGCTTGTA 3241 ACTAAGACAG GCAACGACTC TTTCTATGGC AAAACGTTGT CGTTGCTAGC GCGCGCTGAg 3301 CGACAAGGCT ACCTTGAAAC CGTTCTGCAT AGGACGTCGC TGTTCATCAC CTTCGTCGCC 3361 AgCTGCTGTG CCGCGTTCCT CTTCTTCTGG CAGTCCTTTA ATTCCGATTG GAAATTGATt 3421 ATCCCTGAAA GGCGTTATCT GATTGCGCTG AAGCACGCAT TCATCTTGAT CGCATCTGTC 3481 GCGCCGGCAG CTATGCCTGT AgtTACGACG ACGgTTTTGT CAgTTGgAgC TCtgAtCATt

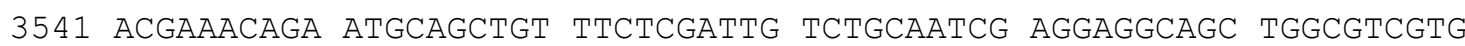
3601 ATTCTATTTA GTGACAAGAC GgGGACTTTG ACGAAAAACC AGCTTTCCCT TTTCAAAgAG 3661 GAGTCCATGA TAGAGCCCGG CTACGACGAG GAAACTATGC TTCTCTACGC AAGCCTCTGC 3721 AgTGATACGC AGGAGCCAGA ACCTATAGAC CGAACAATCA ATGCGGCTGC CGATATGACA 
3781 GAGCGAGCAA AGTATCAAAT TCTTGAGTAT GTACCTTTCA ACCCTGTGGA CAAGAgAACT

3841 GAGGCGACTG TAGTAAGCCC TGAAGGGAAG AAGTTCATTA CTACAAAGGg TGCTCCCCAC

3901 GTTATCAGGG ACCTCGTCTG CTACGAAGAC CAGAAACTGC GTGAGCAGCT GAACGAACTC

3961 ATTTTGAAtA AAgCAAAgCG GGGGCTGAgG ACTCTTGGAG TTGCAGTGAA ACCCGTCCCC

4021 GATGGTGTGG CTGGTGACGC GCCGCGCTGG AAGCTTGTCG GGTACTTATC GCTGTTCGAC

4081 CCTCCTCGTG AAGACACTGC CGCAACTATC CAgAgGGCAA ACGAATTGgg tATTCGTGTA

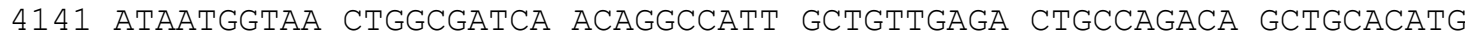

4201 GgCACAAACA tCGTCGgCCC AgAAAtAtgg AAAgAAgAgA AggAgACtgg CCTGgtACAA

4261 GGGAAAGCTC TTGCCGAATT TATTGAAACT GTTGATGGAT TCGCTGGCGT TTTCCCAGAA

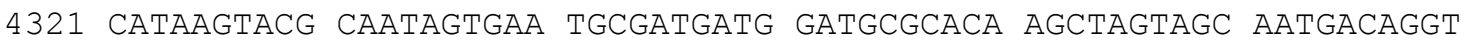

4381 GATGGAgTGA ACGATGCTCC AgCATTGAAA CGAGCGACTA TTGgtATCGC GgTtAgCGgC

4441 GCAACTCAAG CAGCGAGgGC AgCAgCAGAC ATCATTCTgT TTGCACCTGg CCTGAAGACA

4501 ATCATCACTG TCATGTCTCT GTCGAGACAA ATCTTCAAAC GCGTTGAATC CTACATTATT

4561 TTCCGCATAT ACACTAGCTT GATCATTTTG GGCATGTGGT GGGGATGTAT AGTAATTTTG

4621 CGGTATCAGT TTCCATCCTG GACTTTGGTT CTCATGTCAA TGATTAATGA CTTTGTCTTG

4681 ATGAGTTGCT CTCGCGATCG AGTTGCGAGT TCCACCTCAC CCATGATCTG GTCAATGCTG

4741 AGGGTAATTT GCCTCTCCAC TTGGCTTGGT TTTCTAGCGA CAGTCTCTAT TCTGCTCTAC

4801 GTTGTATTCG CAgATCCGTC ACACTGTGTC AACTGgTGgC CCCGATGgGg ATtACCAAAg

4861 TTCACTCCTG ATTGGCCTCT CCCGGTTTCT GAACACTTCA TGAGCTACCA AACAAATGCT

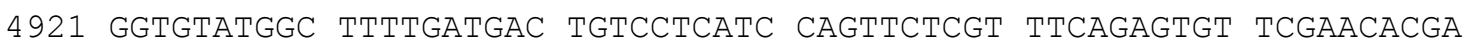

4981 GGCCTATTTT GTAGgTACAA CGAGAATAAC CAGTTCCCGG CCCTCGTTAT CATTATTCCC

5041 CAAATTTGTG CTGTGGTGGT GACAATATTC CTTTCAATtT ACTGGAAGAT CGCATGGAGG

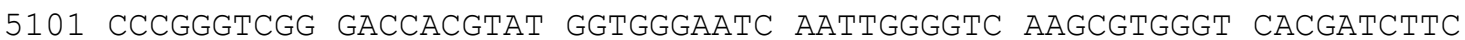

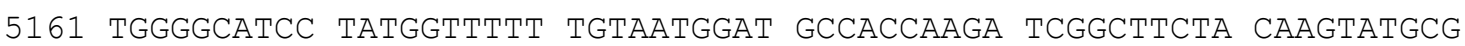

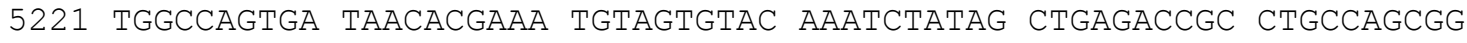

5281 GAgAtCGAgA ACAACAACGT CGCGTCGAAA GTAATGCAGA ATACGgTgCA tTTtCTGGAG

5341 GAgCGCGAgC GTAATGTGgA AAAgCtTGAA GAgAAAgTGg AAgACGCTTT tCTTGCTGCA

5401 GTAACGGATG CCGGTGAGCT TGTCAAGAAT GACCATGGGA AAAGTCACAT TGACAGAAAG

5461 GAGCACAAAG TATCGCCTGA GCCAGGGAAA ACAAGCACCG AGGACGAAGT CTCGCTGCCG

5521 AgGAAGGACG CGAATTCCTT CGTTGTTTCA ATCACTAGTG AAgAgGgAgC GTGCCGgACC

5581 GgCTTCGACG ATGCCGATGC TGGCACTGCG AAACACCGA TCGCCGTGGA CCAGAAAAAT

5641 AgGgAAgTGt CGCGCTCATC CGGGAAAACC AgTATCCCGC TGCACCCGgA tGTCGgAAAA

5701 GGATGCGCGG TTCCTTCGAT CACGCGTTGA TGGGGTAATG TTGTGCTCGT TTCGATACTC

5761 GTTGTTTTTG CAGATGTGTA CATGCGgGCG ATAGACGAAA GTGATTCCTC TTTTCCTTTG

5821 CTCACCAGGT GGGCACCGGC CGCTATGCGg GGgTGTCTCC CCCGTGGAAT CCAGAGCAGA

5881 CCATGCTGTG GTCACCCTAG CTAGAAATGC CAAGAATACG CAGAGTGTCG GCGTTGAACC

5941 AACCCGGCAC ACTATTTGCT GGTCTGTCCG TGTGCCATGG CTGCTACCCG AGGCAGTAGC

6001 TGCTGCTTTC CGCAGTGTGT CCGTAACGTA GCCCGTAGCT CATTCGCGGT TACTGTGCGG

6061 CTTGGGCATA TACTACGGCT TTACTTGATA GCACGAGTGC TATGCGAACA TGAAACTGGC

6121 ATCACTCAGC CCGTTTTCAG GTTGGCACTC CTTTAATGAG AACCCGTTTC ACCTTCTGAT

6181 GAAGACTACC AGCCCCGCGA TCGTGAGCGG AAATGGCTTT GTAGATATTG CCCGTGACAG

6241 CCGGCAAGTA ATTTGCAgGA GTTTTCGTAC CACATAGAAC CACGTTTCTg GTGTTCAgCA

6301 CCATGTCTGT CAGACAAACG AATGCGCAAC TGCTCTCTTG TTTCACAAGg CACAATGCGG

6361 TACCCGTTTG ACGGCCGCCT TGAAATTCAT CGATTTCCTC GCTACGTGGA AAGTGTAGTT

6421 TGAGAATCTA TACACGCCGA CGAGCTGACA CGATCTCCAC AGGATACAGC AGCACCCGGA

6481 CAGCAACCGG GTCGTCTACT TTCTCTTCGC CGCCCAGTTG CTTTGGAATC TACCTATCGT 6541 GCCCTGTAGT tTTCTGACAT TTCGCTGTTC CATATTTTGT GAGATATCGC TTACTGTTTC

\begin{abstract}
Abb. 23. Sequenz von tgpma1 mit flankierenden 5' und 3' Sequenzen. Im Text erwähnte Sequenzmotive sind wie folgt markiert: (rot): Sequenzen mit Ähnlichkeit zu dem Heptanukleotidmotiv T/AGAGACG aus dem 5' UTR von T. gondii Genen und mögliche Polyadenylierungssequenz TCTATACACG im 3' UTR; (rot, fett): mögliche ,Inr' Sequenz, putativer Startpunkt der Transkription. Die Sequenzen der beiden Introns sind unterstrichen. Die beiden putativen ATG-Startcodons und das Stoppcodon TGA sind hervorgehoben.
\end{abstract}




\section{Kongressbeiträge}

Holpert, M., Wirsing, A., Bohne, W., Groß, U. Identifizierung einer Plasmamembran ATPase in Toxoplasma gondii. 4. Minisymposium „Mikrobielle Pathogenität", 18.- 20. Juni 1999, Burg Rothenfels.

Holpert, M., Bohne, W. Stadienspezifische Expression von Plasmamembran- $\left(\mathrm{H}^{+}\right)-$ ATPasen in Toxoplasma gondii. IV. Statusworkshop „Eukaryontische Krankheitserreger", 28-29. Januar 2000, Marburg.

Holpert, M., Groß, U., Bohne, W. Stadienspezifische Expression von Plasmamembran- $\left(\mathrm{H}^{+}\right)$-ATPasen in Toxoplasma gondii

. 19. Tagung der Deutschen Gesellschaft für Parasitologie e.V., 28. März- 1. April 2000, Stuttgart-Hohenheim.

Holpert, M., Groß, U., Bohne, W. Characterization of stage-specific plasmamembrane $\left(\mathrm{H}^{+}\right)$-ATPases in Toxoplasma gondii. 12th Japanese-German Symposium on Protozoan Diseases, 23- 27. September 2000, Bonn

Holpert, M., Pusch, S., Groß, U., Bohne, W. Targeted disruption of a bradyzoitespecific P-type plasma membrane ATPase in Toxoplasma gondii

. Joint Annual Meeting of the German and Dutch Societies of Parasitology, 20-23. März 2002, Lübeck-Travemünde.

Holpert, M., Pusch, S., Groß, U., Bohne, W. Targeted disruption of a bradyzoitespecific P-type plasma membrane ATPase in Toxoplasma gondii. Gordon Conference on Biology Of Host-Parasite Interactions, 16-21 Juni 2002, Newport, Rhode Island, USA

Holpert, M., Pusch, S., Bohne, W. Charakterisierung einer P-Typ Plasma-Membran ATPase in Toxoplasma gondii. Statusworkshop "Eukaryontische Krankheitserreger", 8-9. Februar 2002, Hannover

Holpert, M., Groß, U., Bohne, W. Targeted disruption of a bradyzoite-specific P-type plasma membrane ATPase in Toxoplasma gondii.

, 54. Jahrestagung der Deutschen Gesellschaft für Hygiene und Mikrobiologie, 6.-10. Oktober 2002, Heidelberg. 


\section{Publikationen}

Kowalski, J. C., Belfort, M., Stapleton, M. A., Holpert, M., Dansereau, J. T., Pietrokovski, S., Baxter, S. M., Derbyshire, V. (1999). Configuration of the catalytic GIY-YIG domain of intron endonuclease I-Tevl: coincidence of computational and molecular findings. Nucleic Acids Res. 27, 2115-2125.

Bohne, W., Holpert, M., Gross, U. (1999). Stage differentiation of the protozoan parasite Toxoplasma gondii. Immunobiology 201, 248-54. Review.

Holpert M., Lüder, C. G., Gross, U., Bohne, W. (2001). Bradyzoite-specific expression of a P-type ATPase in Toxoplasma gondii. Mol. Biochem. Parasitol. 112, 293-296. 


\section{Lebenslauf}

Mathias Holpert

Geburtsdatum: $\quad 16.03 .1974$

Geburtsort: Wasserlos/ Alzenau

Familienstand: ledig

Nationalität: deutsch

Schule:

1980- 1984 Grundschule Mömbris

1984- 1993 Hanns-Seidel-Gymnasium Hösbach

Studium:

1993- 1998 Biologie (Diplom) an der Julius-Maximilians- Universität Würzburg

Oktober 1995: Diplom-Vorprüfung

September 1996- Mai 1997: Stipendium für Austausch-Studium in ,Biomedical Sciences' an der State University at Albany/ School of Public Health, Albany, NY, USA

Mai 1997- August 1997: angestellt zur Vollendung der Diplomarbeit bei Prof. Dr. M. Belfort, Wadsworth Center, Albany, NY, USA

September 1998: Diplomprüfung in Würzburg, Abgabe Diplomarbeit bei Prof. Dr. M. Belfort, David Axelrod Institute, School Of Public Health, Albany, NY, USA, über das Thema: "Characterization of the linker region of I-Tevl, the $t d$ intron-encoded endonuclease of phage T4".

ab Oktober 1998: Beginn der Doktorarbeit bei Prof. Dr. U. Groß, Institut für Hygiene und Mikrobiologie, Julius-Maximilians-Universität Würzburg, über das Thema: „Charakterisierung der bradyzoitspezifisch exprimierten P-Typ Plasmamembran ATPase TgPMA1 in Toxoplasma gondii“.

seit August 2000: Umzug der Arbeitsgruppe, Weiterführung der Doktorarbeit bei Prof. Dr. U. Groß, Institut für Medizinische Mikrobiologie, Georg-August-Universität Göttingen über das gleiche Thema. 